PRISCILLA SOUZA ALVES

SÍNTESE E AVALIAÇÃO BIOLÓGICA DE NOVOS AGENTES ANTIINFLAMATÓRIOS PLANEJADOS A PARTIR DO ÁCIDO ANACÁRDICO 


\author{
UNIVERSIDADE DE BRASÍLIA \\ FACULDADE DE CIÊNCIAS DA SAÚDE \\ PROGRAMA DE PÓS-GRADUAÇÃO EM CIÊNCIAS DA SAÚDE
}

PRISCILLA SOUZA ALVES

SÍNTESE E AVALIAÇÃO BIOLÓGICA DE NOVOS AGENTES ANTIINFLAMATÓRIOS PLANEJADOS A PARTIR DO ÁCIDO ANACÁRDICO

Dissertação apresentada como requisito parcial para a obtenção do Título de Mestre em Ciências da Saúde pelo Programa de Pós-Graduação em Ciências da Saúde da Universidade de Brasília.

ORIENTADOR: LUIZ ANTONIO SOARES ROMEIRO

BRASÍLIA 


\title{
SÍNTESE E AVALIAÇÃO BIOLÓGICA DE NOVOS AGENTES ANTI- INFLAMATÓRIOS PLANEJADOS A PARTIR DO ÁCIDO ANACÁRDICO
}

\begin{abstract}
Dissertação apresentada como requisito parcial para a obtenção do Título de Mestre em Ciências da Saúde pelo Programa de Pós-Graduação em Ciências da Saúde da Universidade de Brasília.
\end{abstract}

Aprovado em 24 de Fevereiro de 2015

Banca Examinadora

Prof. Dr. Luiz Antonio Soares Romeiro Universidade de Brasília - UnB

Profa. Dra. Kelly Grace Magalhães Universidade de Brasília - UnB

Prof. Dr. Ângelo Henrique de Lira Machado Universidade de Brasília - UnB

Profa. Dra. Angélica Amorim Amato Universidade de Brasília - UnB 
Esta dissertação é dedicada aos meus maiores incentivadores: aos meus pais, Luis e Tânia, aos meus irmãos Sarah, Pedro e Patrícia e ao meu namorado Jeovah. 


\section{AGRADECIMENTOS}

Agradeço primeiramente a Deus, por me conduzir até aqui, por fazer acontecer a Sua vontade em minha vida. Aos meus pais Luis Antonio e Tânia e irmãos Sarah, Pedro e Patrícia por me incentivarem em todos os momentos e serem responsáveis pela pessoa que hoje me tornei. A Jeovah pelo imensurável amor, apoio e estímulo.

Ao Prof. Luiz Romeiro pela dedicação para com seus orientandos, pelas oportunidades a nós concedidas e por sempre me inspirar a seguir o caminho de pesquisa no âmbito da Química Medicinal. Aos amigos de bancada Aline, Andressa, Fellipe, Giselle e Thaís por tornarem a caminhada mais agradável e por toda ajuda oferecida na realização desse trabalho.

À Prof. Silvia Alcanfor e Margareth Amaral responsáveis pela Central Analítica da Universidade Católica de Brasília (UCB) pela realização dos espectros no Infravermelho (IV) e pesagem das amostras. Ao Prof. Edilberto Silveira e Dr. Patrícia Nascimento do Centro Nordestino de Aplicação e Uso de Ressonância Magnética Nuclear (CENAUREMN) da Universidade Federal do Ceará pela concessão dos espectros de $\mathrm{RMN}{ }^{1} \mathrm{H}$ e $\mathrm{RMN}{ }^{13} \mathrm{C}$.

A Abdellah Allali-Hassani e Prof. Masoud Vedadi do Structural Genomics Consortium (SGC) e à Prof. Dra. Carolyn Cummins e Lilia Magomedova do Nuclear Hormone Receptors in Human Health and Disease da Universidade de Toronto pela realização dos ensaios biológicos.

À Coordenação de Aperfeiçoamento de Pessoas de Nível Superior (Capes) pela concessão de bolsa de estudos e ao CNPq pelo apoio financeiro.

À banca examinadora por aceitar o convite, e desde já pelas críticas e contribuições no enriquecimento do trabalho. 


\section{RESUMO}

ALVES, Priscilla Souza. Síntese e Avaliação Biológica de Novos Agentes Antiinflamatórios Planejados a Partir do Ácido Anacárdico. Dissertação (Mestrado em Ciências da Saúde) - Faculdade de Saúde. Universidade de Brasília, Brasília, 2015.

A doença de Crohn (DC) é uma doença inflamatória intestinal, cujo processo inflamatório transmural e segmentar pode acometer qualquer parte do trato gastrointestinal. Embora a etiologia da DC ainda não tenha sido completamente estabelecida, a maioria dos estudos converge para a associação de vários fatores, dentre os quais destacam-se a desregulação do sistema imune. Neste contexto, este trabalho descreve o planejamento, a síntese e a avaliação biológica de novos compostos inibidores da atividade de p300 e agonistas PPAR- $\alpha$ e PPAR-y como potencial estratégia multialvo para $\circ$ tratamento da $D C$, assim como para 0 tratamento de outras patologias inflamatórias. A partir do ácido anacárdico, um lipídeo fenólico do liquido da casca da castanha de caju com atividade antiinflamatória, foram sintetizados 30 derivados-alvo em rendimentos que variaram de $35 \%$ a $98 \%$. A avaliação da atividade biológica in vitro dos compostos-alvo frente à enzima p300 revelou que os derivados ácidos LDT11 (16), LDT13 (17) e LDT30 (20) foram capazes de inibir mais de $50 \%$ da atividade enzimática na concentração de 50 $\mu \mathrm{M}$, apresentando $\mathrm{IC}_{50}$ de 3,0 $\mu \mathrm{M}$ (16 e 17) e 10,0 $\mu \mathrm{M}$ (20). Os estudos preliminares do perfil frente a PPAR- $\alpha$ e PPAR-y foram finalizados para a primeira série. Os valores de $\mathrm{EC}_{50}$ variaram de $1,5 \mu \mathrm{M}$ a 32,0 $\mu \mathrm{M}$ para PPAR-a. e 12,4 $\mu \mathrm{M}, 12,1 \mu \mathrm{M}$, respectivamente. Considerando PPAR-y, os derivados LDT11 (16) e LDT13 (17) mostraram-se equipotentes com $\mathrm{EC}_{50}$ em torno de 12,0 $\mu \mathrm{M}$. As análises SAR evidenciaram o íon carboxilato e aceptor de ligação de hidrogênio como grupos farmacofórico e moduladores reconhecimento molecular e ativação de ambos PPAR- $\alpha$ e PPAR-y, bem como inibição de p300. O planejamento de novos derivados, a otimização dos rendimentos das reações, bem como a avaliação de todas as séries frente à inibição NF-KB in vitro e posteriormente em modelos de colite in vivo constituem as perspectivas deste trabalho.

Palavras chave: Doença de Crohn; p300; PPAR; LCC; Ácido Anacárdico 


\begin{abstract}
ALVES, Priscilla Souza. Synthesis and Biological Evaluation of New Antiinflammatory Compounds Designed from Anacardic Acid. Dissertação (Mestrado em Ciências da Saúde) - Faculdade de Saúde. Universidade de Brasília, Brasília, 2015.

Crohn's disease is an inflammatory bowel disease, whose transmural and segmental inflammatory process can affect any part of gastrointestinal tract. Although aetiology is unknown, most studies converge to an interplay of many factors, including a deregulated immune system. In this context, this work describes the design, synthesis and biological evaluation of new p300 inhibitors also PPAR- $\alpha$ and PPAR-Y agonists as a multi-target strategy for the treatment of Crohn's disease and also of others inflammatory pathologies. From anacardic acid, an anti-inflammatory phenolic lipid of the cashew nutshell liquid, were synthesized 30 derivatives in yields ranging from $35 \%$ to $98 \%$. The in vitro evaluation of p300 inhibition profile showed that the acids derivatives LDT11 (16), LDT13 (17) and LDT30 (20) were able to inhibit over than $50 \%$ of enzymatic activity at the concentration of $50 \mu \mathrm{M}$, with $\mathrm{IC}_{50}$ of $3.0 \mu \mathrm{M}(16$ and 17) and $10.0 \mu \mathrm{M}$ (20). Preliminary studies about the PPAR activation profile were concluded to the first serie, with $E_{50}$ ranging from 1.5-32.0 $\mu \mathrm{M}$ to PPAR- $\alpha$. Considering PPAR-y, LDT11 (16) and LDT13 (17) also showed potent EC $\mathrm{C}_{50}$ arround 12.0 $\mu \mathrm{M}$. SAR studies exhibited carboxylate ion and hydrogen bond acceptor as pharmacophoric groups and molecular recognition modulators for PPAR- $\alpha / P P A R-\gamma$ activation and p300 inhibition. This work's perspectives include new derivatives design, reaction yields optimization and the evaluation of NF-KB inhibition in vitro and posteriorly in vivo colitis models.
\end{abstract}

Key words: Crohn's disease; p300; PPAR; LCC; Anacardic Acid 


\section{LISTA DE FIGURAS}

Figura 1: Classificação de Montreal 20

Figura 2: Sistema imunológico na doença de Crohn 26

Figura 3: Vias de sinalização do NF-kB 29

Figura 4: Modulação da expressão gênica por PPAR- $\beta / \delta$

Figura 5: Modulação da expressão gênica por PPAR- $\alpha$ e PPAR-y 33

Figura 6: Inibidores HAT relatados na literatura: naturais - 35 garcinol, curcumina e ácido anacárdico - e sintético Lys-CoA, análogo do substrato da HAT Acetil-CoA

Figura 7: Principais fármacos utilizados para o tratamento da 36 doença de Crohn

Figura 8: Principais componentes do líquido da casca da 39 castanha de caju

Figura 9: Prováveis mecanismos de ação do ácido anacárdico e 40 seus derivados na inibição de HAT

Figura 10: Principais sítios de reação do ácido anacárdico 41

Figura 11: Planejamento racional de novos derivados anti- 45 inflamatórios

Figura 12: Numeração e legendas empregadas no assinalamento de sinais em $\mathrm{RMN}{ }^{1} \mathrm{H}$ e $\mathrm{RMN}{ }^{13} \mathrm{C}$

Figura 13: Derivados-alvo sintetizados a partir do ácido anacárdico 84

Figura 14: Atividade inibitória frente à enzima $p 300$ dos compostos 102 da série da série acetóxi, hidróxi e metoxiácidos ou metil ésteres

Figura 15: Derivados LDT10 (46), LDT12 (47) e LDT27 (48) 103

Figura 16: Sítio ativo da p300 com Acetil-CoA 104

Figura 17: Ancoragem de LDT13 (17) no LBD de PPAR-a 106

Figura 18: Ancoragem de LDT11 (16) no LBD de PPAR-y 107 


\section{LISTA DE TABELAS}

Tabela 1: Principais diferenças entre doença de Crohn e colite ulcerativa

Tabela 2: Principais deslocamentos químicos de $\mathrm{RMN}{ }^{1} \mathrm{H}$ e $\mathrm{RMN}$ 90 ${ }^{13} \mathrm{C}$ e no infravermelho (IV) para a caracterização da série dos derivados 2-acetóxi, hidróxi e metóxiácidos ou metil ésteres

Tabela 3: Principais deslocamentos químicos de $\mathrm{RMN}{ }^{1} \mathrm{H}$ e $\mathrm{RMN}$ ${ }^{13} \mathrm{C}$ para a caracterização das 2'-metóxiamidas

${ }^{13} \mathrm{C}$ para a caracterização das 2'-hidroxiamidas

Tabela 5: Principais deslocamentos químicos de $\mathrm{RMN}{ }^{1} \mathrm{H}$ e RMN ${ }^{13} \mathrm{C}$ para a caracterização das 2'-acetóxiamidas

Tabela 6: Principais deslocamentos químicos de RMN ${ }^{1} \mathrm{H}$ e RMN 96 ${ }^{13} \mathrm{C}$ para a caracterização dos 2'-metoxiésteres

Tabela 7: Principais deslocamentos químicos de $\mathrm{RMN}{ }^{1} \mathrm{H}$ e $\mathrm{RMN}$ ${ }^{13} \mathrm{C}$ para a caracterização dos 2'-hidroxiésteres.

Tabela 8: Principais deslocamentos químicos de $\mathrm{RMN}{ }^{1} \mathrm{H}$ e $\mathrm{RMN}$ 98 ${ }^{13} \mathrm{C}$ para a caracterização dos 2'-acetoxiésteres

Tabela 9: Características químicas, rendimentos e ponto de 100 fusão da série acetóxi, hidróxi e metoxiácidos ou metil ésteres

Tabela 10: Características químicas, rendimentos e ponto de 100 fusão dos derivados da série dos derivados amídicos

Tabela 11: Características químicas, rendimentos e ponto de 101 fusão dos derivados da série dos derivados ésteres

Tabela 12: Valores de $I_{50}$ para os derivados 16-21

Tabela 13: Valores de $\mathrm{EC}_{50}$ para os derivados 16-21 


\section{LISTA DE ESQUEMAS}

Esquema 1: Planejamento sintético dos derivados 2-acetóxi, hidróxi e metoxiácidos ou metil ésteres

Esquema 2: Planejamento sintético dos derivados 2'-acetóxi, 48 hidróxi e metóxiamidas e ésteres 


\section{LISTA DE ABREVIATURAS E SIGLAS}

5-ASA: Ácido 5-aminossalicílico

AINE: Anti-inflamatório não esteroidal

ALH: $\quad$ Aceptor de ligação de hidrogênio

BAFF: $\quad$ Fator ativador de células $B$

CARD15: Proteína 15 do domínio de recrutamento da caspase

CBP: $\quad$ CRB-binding protein

CCD: $\quad$ Cromatografia em camada delgada

CEI: Célula epitelial intestinal

COX: Ciclo-oxigenase

C-terminal: Carbóxi terminal

DBD: $\quad$ Domínio de ligação ao DNA

DC: $\quad$ Doença de Crohn

DCM: Diclorometano

DII: Doenças inflamatórias intestinais

DMEM: Dulbecco's modified Eagle's medium

DMF: Dimetilformamida

DMSO: Dimetilsufóxido

DNA: Ácido desoxirribonucleico

$E_{50}$ : $\quad$ Concentração da droga requerida para adquirir $50 \%$ do efeito máximo

FM: $\quad$ Fórmula molecular

HAT: $\quad$ Histona acetiltransferase

HDAC: $\quad$ Histona desacetilase

$\mathrm{IC}_{50}$ : Concentração requerida para adquirir $50 \%$ do efeito inibitório máximo

IFN-y: Interferon gama

IKK: $\quad$ Complexo da kinase IKB

IL: Interleucina

IV: Infravermelho

IKB: $\quad$ Inhibitor of nuclear factor $K B$

LBD: Domínio de ligação ao ligante

LCC: $\quad$ Líquido da casca da castanha de caju

LPS: $\quad$ Lipopolissacarídeo 
LTR: $\quad$ Linfotoxina B

MAP: $\quad$ Mycobacterium avium paratuberculosis

MDP: $\quad$ Muramildipeptídeo

MM: $\quad$ Massa molar

MO: $\quad$ Micro-ondas

NEMO: Modificador essencial do NF-KB

NES: $\quad$ Sequências nucleares de exportação

NF-kB: Fator de transcrição nuclear kappa B

NIK: $\quad$ NF-KB inducing kinase

NLR: $\quad$ Receptores do tipo NOD

NLS: $\quad$ sequência de localização nuclear

NOD-2: Domínio de oligomerização nucleotídea 2

$\mathrm{N}$-terminal: Amino terminal

PCC: $\quad$ Piridínio Cloro Cromato

PF: $\quad$ Ponto de fusão

PPAR: Receptor ativado por proliferador peroxissômico

PPRE: $\quad$ Elementos responsivos ao PPAR

PRR: $\quad$ Receptor de reconhecimento de padrão

PSA: Área de superfície polar

Rf: $\quad$ Fator de retenção

RHD: Domínio de homologia Rel

RMN ${ }^{13} \mathrm{C}$ : Ressonância magnética nuclear de carbono 13

RMN ${ }^{1} \mathrm{H}$ : Ressonância magnética nuclear de hidrogênio

RXR: $\quad$ Receptor $X$ retinóico

SAR: $\quad$ Relação estrutura-atividade

Ser: $\quad$ Serina

TAD: Domínio de ativação transcricional

TEA: Trietilamina

TGl: $\quad$ Trato gastrointestinal

Th: $\quad$ Célula T helper

THF: $\quad$ Tetraidrofurano

TLR: Receptor do tipo toll like

TMS: $\quad$ Tetrametilsilano

TNF- $\alpha$ : Fator de necrose tumoral alfa 
UC: $\quad$ Colite ulcerativa

VCAM-1: $\quad$ Vascular cell adhesion protein 1 
1 INTRODUÇÃO

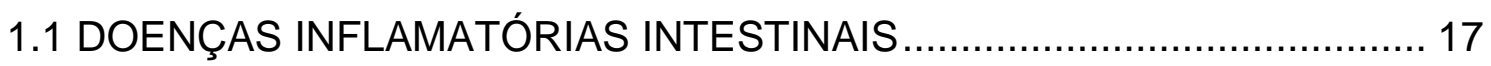

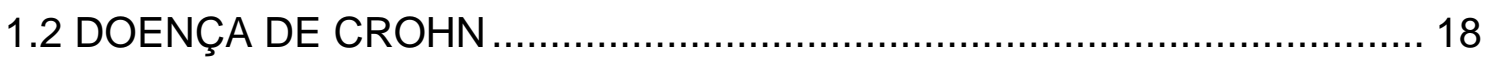

1.3 ASPECTOS CLÍNICOS DA DOENÇA DE CROHN................................. 19

1.4 ETIOPATOGÊNESE DA DOENÇA DE CROHN ........................................ 21

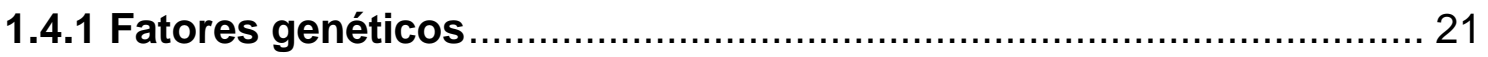

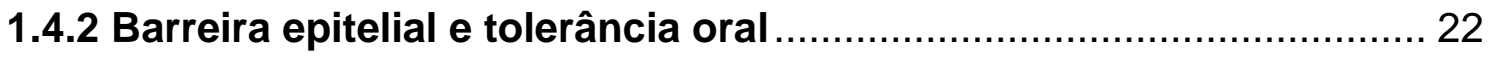

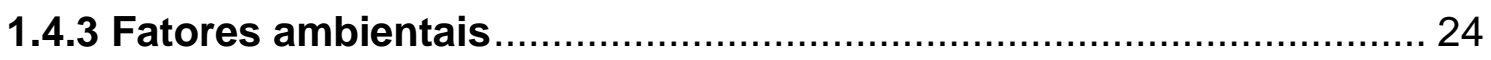

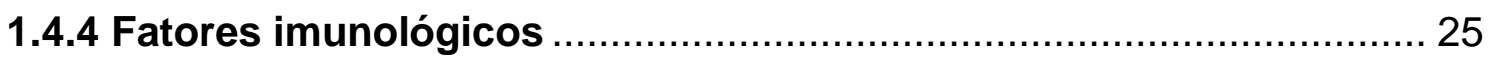

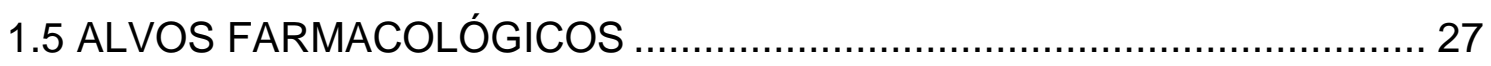

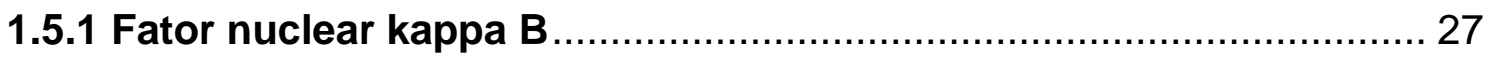

1.5.2 Receptores ativados por proliferadores peroxissomais .................. 30

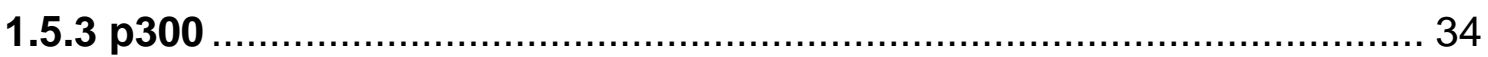

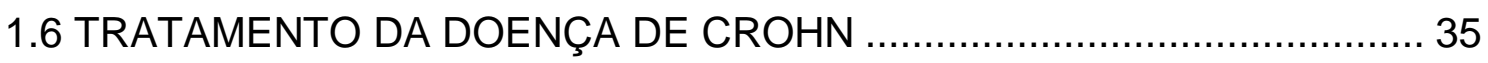

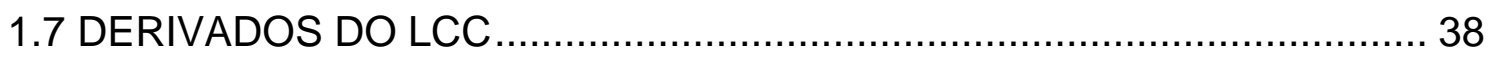

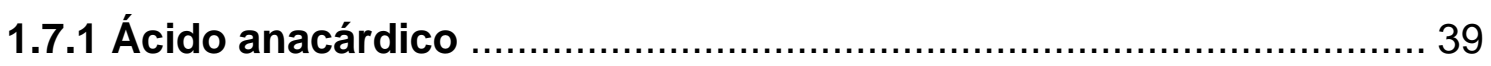

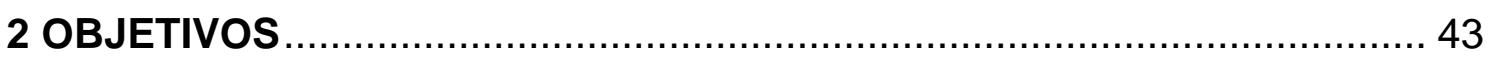

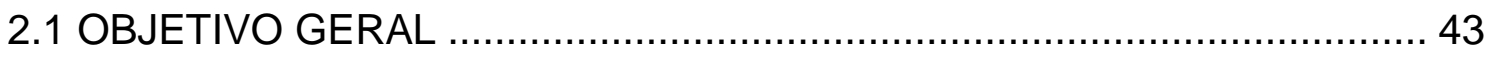

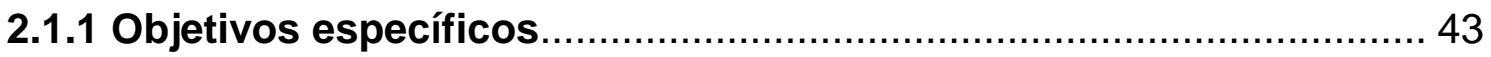

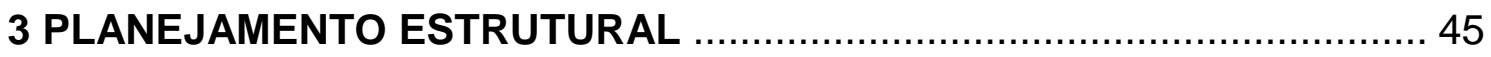

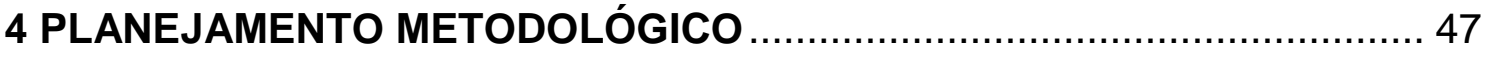

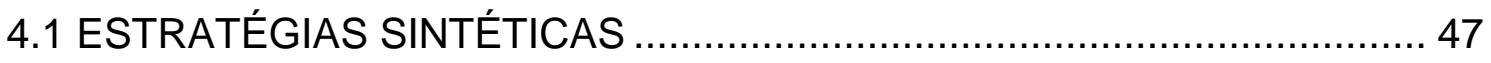

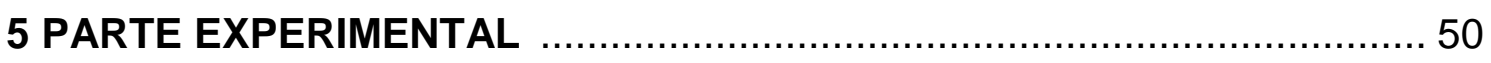

5.1 GENERALIDADES, MATERIAIS E MÉTODOS …................................. 50

5.2 METODOLOGIA SINTÉTICA E CARACTERIZAÇÃO DOS COMPOSTOS 52

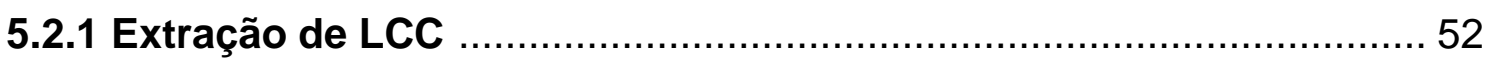

5.2.2 Obtenção de Ácidos Anacárdicos a Partir do LCC Natural .............. 52

5.2.3 Obtenção do Derivado Ácido 2-Hidróxi-6-pentadecilbenzóico (LDT11,

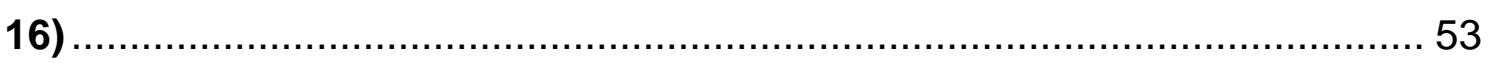

5.2.4 Obtenção do Derivado Ácido 2-Acetóxi-6-pentadecilbenzóico (LDT13, 17) 
5.2.5 Obtenção do Derivado 2-Metóxi-6-pentadecilbezoato de metila (LDT28, 18)

5.2.6 Obtenção do Derivado 2-Hidróxi-6-pentadecilbenzoato de metila (LDT29, 19) 56

5.2.7 Obtenção do Derivado Ácido 2-Metóxi-6-pentadecilbenzóico (LDT30, 20)

5.2.8 Obtenção do Derivado 2-(Acetóxi)-6-pentadecilbenzoato de metila (LDT208, 21)

5.2.9 Obtenção dos Derivados Amidas e Ésteres: 2'-Metoxissubstituídos 60

5.2.10 Obtenção dos Derivados Amidas e Éster LDT659: 2'-

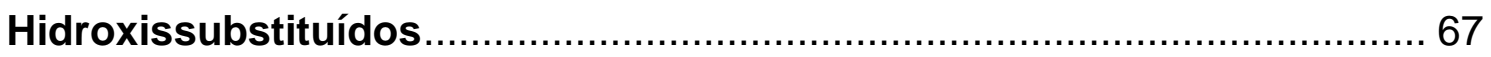

5.2.11 Obtenção dos Derivados 2'-Metoxiésteres via Brometos de Aralquila 71

5.2.12 Obtenção dos Derivados 2'-hidróxiésteres LDT661 (35), LDT663 (36) e LDT665 (37)

5.2.13 Obtenção dos Derivados Amidas e Ésteres: 2'-

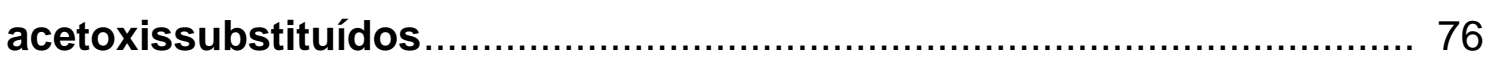

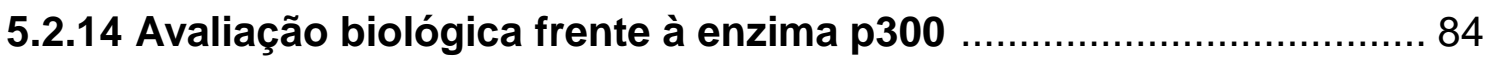

5.2.15 Avaliação biológica frente a PPAR- $\alpha$ e PPAR-y............................. 84

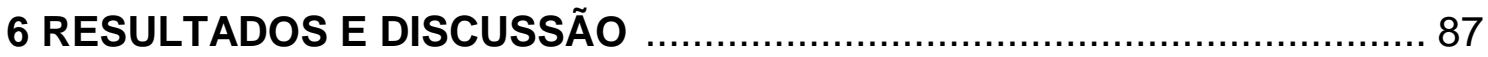

6.1 SÍNTESE E CARACTERIZAÇÃO DOS COMPOSTOS ………................. 87

6.1.1 Série dos Derivados 2-Acetóxi, hidróxi e metoxiácidos ou metil ésteres

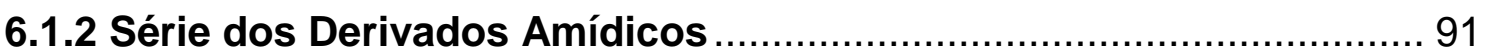

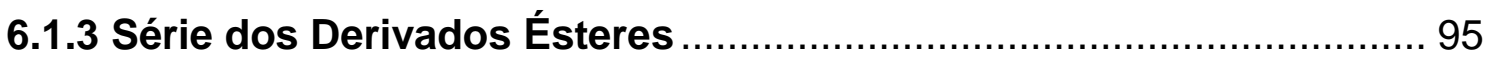

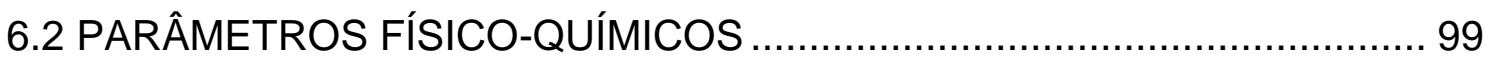

6.3 AVALIAÇÃO BIOLÓGICA E RELAÇÕES ESTRUTURA-ATIVIDADE ..... 103

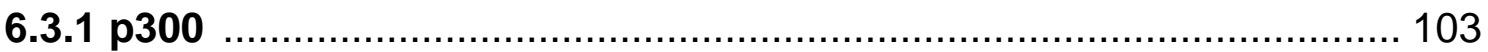

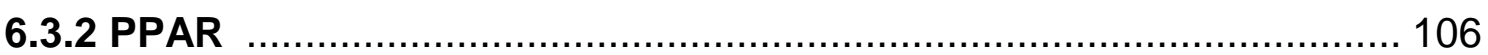

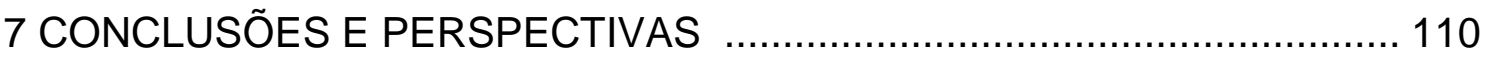

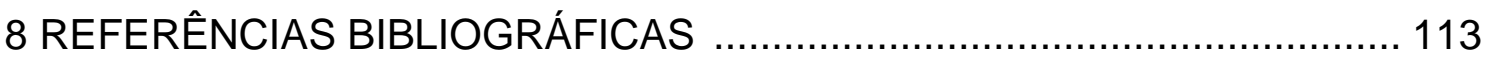

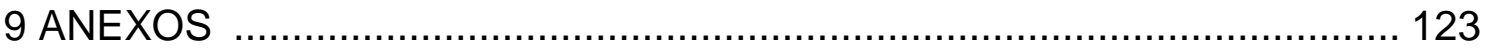




\section{INTRODUÇÃO}

As Doenças Inflamatórias Intestinais (DII) correspondem a um grupo de condições clínicas que envolvem inflamação idiopática e crônica do intestino. Entre as DII, destacam-se a Doença de Crohn (DC) e a Colite Ulcerativa (UC), as quais se diferem pelos segmentos do trato gastrointestinal (TGl) acometidos, pelas características inflamatórias e pelas consequentes complicações [1, 2, 3].

As DII representam um problema de saúde grave devido às suas complicações clínicas de alta severidade, recidivas frequentes e ocorrência de forma crescente em todo mundo, principalmente em jovens [4]. A incidência das DII, particularmente da $D C$, cresceu aproximadamente 10 vezes no século passado nos Estados Unidos e Europa [1]. A predominância antes relatada de colite ulcerativa tem diminuído, enquanto que a DC tem se tornado mais prevalente [2]. No Brasil, estudos realizados têm demonstrado uma tendência de aumento do número de diagnósticos de DC entre 1998 e 2008 [5].

O tratamento farmacológico existente para DC não modifica o curso da doença, direcionando-se apenas ao controle dos sintomas por meio de terapias antiinflamatórias. Embora possuam efeitos benéficos, esses medicamentos apresentam vários efeitos adversos, os quais variam de leves a graves, proporcionando a não adesão ao tratamento e a consequente evolução da doença [6]. Neste contexto, estima-se que a maior parte dos indivíduos afetados pela doença necessitará de algum procedimento invasivo, demonstrando que ainda hoje a cirurgia desempenha papel importante para o controle da DC [7]. Portanto, se faz urgentemente necessário o desenvolvimento de novos fármacos anti-inflamatórios que sejam eficazes e com baixa toxicidade para o tratamento de DC [8].

O cajueiro (Annacardium ocidentale L.), amplamente encontrado no Brasil, fornece uma matéria-prima barata e versátil, do ponto de vista químico. O líquido da casca da castanha de caju (LCC) é rico em compostos fenólicos, dentre eles o mais abundante, ácido anacárdico $[9,10]$. O ácido anacárdico (1) está relacionado às propriedades antioxidante, antitumoral, gastroprotetora, antimicrobiana e antiinflamatória [11, 12]. Desse modo, este derivado natural constitui um importante precursor de moléculas com possíveis atividades biológicas relevantes a serem 
avaliadas em modelos experimentais in vitro e in vivo frente a alvos farmacológicos de interesse.

\subsection{DOENÇAS INFLAMATÓRIAS INTESTINAIS}

De acordo com a Organização Mundial de Gastroenterologia, DIl representam um grupo de condições que envolvem inflamação intestinal idiopática e crônica, cuja prevalência mundial atinge $396 / 100.000$ habitantes. Esse termo envolve principalmente a doença de Crohn e a colite ulcerativa. Embora já se saiba que fatores ambientais e genéticos desempenhem papel importante para a desregulação imunitária, a patogênese das DII permanece desconhecida [2, 3].

Tabela 1 - Principais diferenças entre doença de Crohn e colite ulcerativa

\begin{tabular}{|c|c|c|}
\hline Informações & Doença de Crohn & Colite Ulcerativa \\
\hline $\begin{array}{l}\text { Características } \\
\text { clínicas }\end{array}$ & $\begin{array}{l}\text { Diarreia acompanhada de dor } \\
\text { abdominal e desnutrição; } \\
\text { estomatite; manifestações } \\
\text { perianais; massa abdominal; } \\
\text { obstrução intestinal; sintomas } \\
\text { sistêmicos }\end{array}$ & $\begin{array}{l}\text { Diarreia de pouco volume com } \\
\text { urgência, sangue nas fezes }\end{array}$ \\
\hline $\begin{array}{l}\text { Informações } \\
\text { endoscópicas e } \\
\text { radiológicas }\end{array}$ & $\begin{array}{c}\text { Inflamação transmural descontínua } \\
\text { e assimétrica (segmentar); } \\
\text { envolvimento principalmente do } \\
\text { íleo e cólon do lado direito; } \\
\text { aparência Cobblestone; úlcera } \\
\text { longitudinal; fissuras profundas }\end{array}$ & $\begin{array}{c}\text { Inflamação colônica superficial e } \\
\text { difusa; envolvimento do reto; } \\
\text { presença de erosões e úlceras; } \\
\text { sangramento }\end{array}$ \\
\hline $\begin{array}{l}\text { Informações } \\
\text { histopatológicas }\end{array}$ & $\begin{array}{c}\text { Inflamação granulomatosa e } \\
\text { transmural }\end{array}$ & $\begin{array}{l}\text { Inflamação difusa na mucosa ou } \\
\text { submucosa; distorção Crypt }\end{array}$ \\
\hline $\begin{array}{l}\text { Marcadores } \\
\text { sorológicos }\end{array}$ & $\begin{array}{c}\text { Anticorpos anti-Saccharomyces } \\
\text { cerevisiae }\end{array}$ & $\begin{array}{c}\text { Anticorpos anticitoplasma de } \\
\text { neutrófilos }\end{array}$ \\
\hline $\begin{array}{l}\text { Diagnóstico } \\
\text { diferencial }\end{array}$ & $\begin{array}{c}\text { Tuberculose intestinal, Doença de } \\
\text { Behçet, UC, enteropatia por AINEs, } \\
\text { síndrome do intestino irritável, } \\
\text { doença celíaca }\end{array}$ & $\begin{array}{c}\text { Colite auto-limitada aguda, colite } \\
\text { amébica, DC, câncer de cólon, } \\
\text { síndrome do intestino irritável, } \\
\text { tuberculose intestinal, enteropatia } \\
\text { por AINEs }\end{array}$ \\
\hline
\end{tabular}


As doenças inflamatórias intestinais são doenças intermitentes, cujos sintomas variam de leve a grave nas recaídas, podendo desaparecer ou diminuir durante as remissões. $O$ diagnóstico diferencial entre colite ulcerativa e doença de Crohn se baseia no fato de que para cada segmento do TGI envolvido há um sintoma distinto. A presença de sangue nas fezes e muco ocorre principalmente na colite ulcerativa. Diarreia acompanhada de dor e desnutrição, lesões perianais, obstrução intestinal e massa abdominal são características da doença de Crohn, a qual pode ocasionar sintomas extra-intestinais. As DII podem ser confundidas com outras condições clínicas, como por exemplo, colites infecciosas, colite isquêmica e tuberculose intestinal, fazendo-se necessário um diagnóstico diferencial. As características clínicas, informações endoscópicas e radiológicas, informações histopatológicas, marcadores sorológicos e diagnóstico diferencial da doença de Crohn e colite ulcerativa estão dispostos na Tabela 1 [3, 6, 13, 14].

\subsection{DOENÇA DE CROHN}

A DC é uma doença inflamatória transmural e segmentar do trato gastrointestinal. Devido às manifestações extra-intestinais é considerada como uma doença sistêmica, caracterizada pela presença de ulcerações, fístulas, estenoses e granulomas $[7,14,15,16]$.

O primeiro relato da DC se deu em 1612, quando Gullielmus Fabricius Hildenus descreveu um processo de ulceração e fibrose no ceco da autópsia de um garoto com dor sub-hepática. Somente a partir de 1932 é que essa condição clínica seria denominada doença de Crohn. $\mathrm{Na}$ ocasião, dois grupos se uniram para publicação de artigo, fornecendo 14 casos de "ileíte terminal". Antes de 1920, Ginzburg, A. A. Berg e Oppenheimer coletaram 12 casos caracterizados por estenose hipertrófica e ulcerativa no íleo terminal, que terminam abruptamente na válvula ileocecal. Em 1930, Crohn acompanhou 2 jovens irmãos com processos similares (diarreia, febre, dor abdominal e necessidade de ressecção ileocecal). Embora os créditos do artigo tenham sido dados pelos procedimentos cirúrgicos realizados por Berg, a doença de Crohn foi assim denominada porque o nome de Crohn aparece primeiro na lista de autores $[6,15,17,18]$. 
A DC tem apresentado tendência de aumento na sua incidência mundial, o que pode estar relacionado com o aprimoramento das técnicas de diagnóstico ou com um aumento real do número de doentes. A prevalência é maior em áreas urbanas e em classes sociais mais altas. Os sintomas iniciam com maior frequência na segunda e terceira décadas de vida. $A$ incidência mundial da $D C$ varia entre $0,1 \mathrm{e}$ 16 novos casos para cada 100.000 habitantes. As áreas com maiores taxas de incidência são a Escandinávia, Grã-Bretanha e a América do Norte, seguidas pelo Oriente Médio, a África do Sul e a Austrália. A incidência da América do Norte varia entre 3,1 e 14,6 novos casos para cada 100.000 habitantes por ano, sendo a maior no Canadá, 15 novos casos para cada 100.000 pessoas por ano [2, 3, 5, 15].

$\mathrm{Na}$ América do Sul, há uma tendência crescente do número de casos, com 0,7 de casos novos de DC para cada 100.000 habitantes. Porém, não existem dados epidemiológicos oficiais no Brasil, possivelmente devido às deficiências dos sistemas de registro de dados. Relata-se que houve um aumento de $166 \%$ de novos casos do período de 1980-1984 para o período de 1995-1999, no Rio de Janeiro. A incidência na mesma área é de 14,6 casos para cada 100.000 habitantes [2, 4, 19].

Após alguns séculos desde a primeira descrição da doença, a DC tem sido alvo de muitas pesquisas que proporcionaram maior conhecimento acerca dos mecanismos de patogênese. Essas informações permitiram avanços na abordagem terapêutica, essenciais para a melhoria na qualidade de vida dos portadores de DC. No entanto, a etiologia permanece desconhecida e o tratamento pouco eficaz ao longo da vida de remissões e recaídas desses indivíduos, o que contribui para que a DC tenha elevados custos sociais e financeiros [15].

\subsection{ASPECTOS CLÍNICOS DA DOENÇA DE CROHN}

O diagnóstico da DC se baseia na avaliação dos sintomas, na história clínica, no exame físico, em testes laboratoriais e de imagem. Os dados mais determinantes para o diagnóstico de DC na história clínica são diarreia crônica, dor abdominal intensa, perda de peso, febre e manifestações extra-intestinais em indivíduos com idade entre 20 e 30 anos ou 50 e 70 anos. No exame físico, os principais achados são lesões perianais, desnutrição, massa palpável na região abdominal e dor à 
palpação. As principais manifestações extra-intestinais compreendem artrite periférica, eritema nodoso e comprometimento ocular $[3,6,16]$.

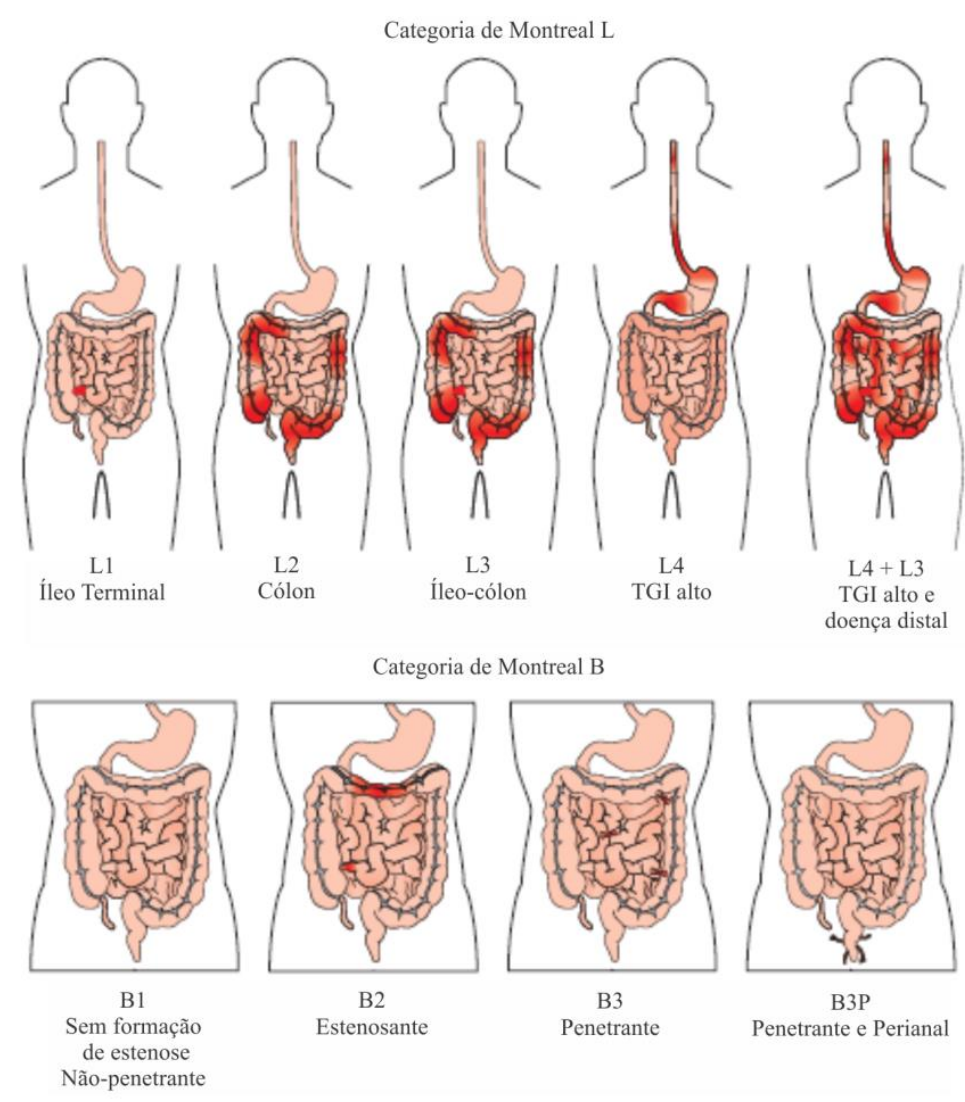

Figura 1: Classificação de Montreal

Fonte: Adaptado de BAUMGART \& SANDBORN, 2012 [14]

Uma vez que o diagnóstico foi realizado, é necessário identificar o fenótipo da DC, o qual pode ser definido por meio da classificação de Montreal (Figura 1). De acordo com a idade de início, pode ser dividida em A1, quando a idade no momento do diagnóstico for de 16 anos ou menos; A2, quando a idade foi entre 17 e 40 anos; e A3, quando a idade do diagnóstico for acima de 40 anos. Com relação à localização, a DC é subdividida em L1, com o envolvimento somente do íleo terminal; L2, com o envolvimento somente do cólon; L3, com o envolvimento do íleo e do cólon; e L4, com envolvimento do TGl alto (boca, língua, esôfago e duodeno). As classificações L1, L2 e L3 podem estar relacionadas ou não com L4. Por fim, de acordo com o comportamento da doença, existem 3 classificações (B1, não estenosante e não penetrante; B2, estenosante; B3, penetrante) e modificador perianal da doença, quando a doença perianal for concomitante $[14,16,20]$. 


\subsection{ETIOPATOGÊNESE DA DOENÇA DE CROHN}

A causa da DC ainda não foi bem estabelecida, porém diversos estudos apontam os fatores genéticos, imunológicos e ambientais como principais agentes dessa condição clínica. A hipótese mais difundida envolve uma resposta imune exacerbada que é desenvolvida em indivíduos geneticamente suscetíveis frente a bactérias entéricas comensais, sendo que fatores ambientais promoveriam o aparecimento da doença ou a sua reativação $[6,15,16,21]$.

\subsubsection{Fatores genéticos}

Muitas são as evidências que corroboram para que o aspecto genético seja considerado importante para o desenvolvimento da DC. Cerca de $20 \%$ de indivíduos com DC tem um ou mais parentes com alguma DIl e a taxa de concordância entre gêmeos monozigóticos é de $45 \%$. Para a DC, existe um padrão de agregação familiar, no qual parentes de primeiro grau de indivíduos com a doença possuem 5 vezes mais risco de a desenvolverem. Além disso, existe uma concordância no tipo e na localização da doença em indivíduos pertencentes a famílias com mais de um caso $[6,15,16,22,23]$.

Desde a última década, muitos genes relacionados à DC foram identificados. O gene CARD15 (do inglês, caspase recruitment domain-containing protein 15, proteína 15 do domínio de recrutamento da caspase) foi primeiramente relatado em 1996 e também é chamado NOD-2 (do inglês, nucleotide oligomerization domain 2, domínio de oligomerização nucleotídea 2). Ele está localizado no cromossomo 16, no lócus de suscetibilidade para DC, denominado IBD1 (do inglês inflammatory bowel disease 1, Doença Inflamatória Intestinal 1) [6, 15, 16, 21].

Três mutações identificadas na região de CARD15/NOD-2 foram associadas ao risco aumentado de desenvolvimento da DC (SNP8 - R702W, SNP12 - G908R e SNP13 - Leu1007insC). Tais mutações estão presentes em aproximadamente um 
terço dos portadores da DC e estão relacionadas com acometimento do íleo distal $[6,15,16,21]$.

Mais de $90 \%$ dessas mutações estão localizadas na região responsável pelo reconhecimento bacteriano. O CARD15/NOD-2 codifica uma proteína de mesmo nome, que é um receptor de reconhecimento padrão citoplasmático do sistema imune inato. A região rica em repetições de leucina da CARD15/NOD-2 se liga a muramildipeptídeo (MDP), encontrado na parede celular de grande parte das bactérias, resultando em ativação do fator de transcrição nuclear kappa B (NF-KB) e na consequente cascata inflamatória. A CARD15/NOD-2 também é responsável pela expressão de defensinas, que representam importante sistema de defesa da imunidade inata $[6,15,16,21]$.

Os polimorfismos SNP8, SNP12 e SNP13 promovem falha na ligação com MDP, a qual proporciona aumento ou perda na função de CARD15/NOD-2. Nesse contexto, o aumento da função origina a ativação exagerada de NF-kB e o consequente aumento de produção de citocinas pró-inflamatórias. Já no caso de perda da função de CARD15/NOD-2, a baixa produção de defensinas e de citocinas (IL1 e IL8) leva à maior suscetibilidade para infecções bacterianas, que poderá provocar uma resposta inflamatória exagerada [6, 15, 24].

Outras mutações em genes específicos também são descritas como importantes fatores relacionados à DC. Mutações no receptor ativado por proliferadores peroxissomais gama (PPAR- $\gamma$ ) foram associadas a ileíte espontânea em modelos de camundongo. Em adição, polimorfismos evidenciados no TLR4 (do inglês, toll-like receptor) estão relacionados com o desenvolvimento de DII em populações caucasianas e tendem a originar a forma mais severa da doença $[6,15$, $21,25]$.

\subsubsection{Barreira epitelial e tolerância oral}

A primeira linha de defesa do sistema imune da mucosa é a barreira epitelial, formada por uma única camada de células epiteliais polarizadas cobertas por um biofilme de muco, o qual é secretado pelas células caliceformes. Esta barreira é 
constituída ainda pelas tight junctions, imunoglobulina A e defensinas. As células epiteliais intestinais (CEI) impedem a exposição direta dos antígenos bacterianos comensais ao tecido folicular. Em situações normais, mecanismos de reparo são acionados quando há qualquer lesão da mucosa [14, 15].

Existem evidências de que o aumento da permeabilidade da barreira epitelial está relacionado à patogênese da DC. Indivíduos com DC possuem expressão diminuída do gene MUC1, sugerindo que a produção de muco é insuficiente. Além disso, alterações nas proteínas das tight junctions são visualizadas na DC e são responsáveis pelo aumento da permeabilidade da barreira epitelial. As tight junctions podem ainda ser alteradas por fatores inflamatórios como o IFN- - , TNF- $\alpha$ e IL-13, o que sugere que um estímulo inflamatório primário possa levar a esse desequilíbrio $[14,15]$.

Mutações de genes como CARD15/NOD-2 também estão relacionadas a falhas na barreira epitelial e no reconhecimento da microbiota. Como já mencionado, polimorfismos desse gene diminuem a secreção de defensinas, muco e imunoglobulinas. Do mesmo modo, mutações observadas no gene TLR4 (receptor do tipo toll like) estão relacionadas ao comprometimento da integridade da barreira epitelial e na consequente susceptibilidade à DC. TLRs são normalmente expressos nas CEI, em quantidades diferentes: maiores de TLR3 e TLR5 e menores de TLR2 e TLR4. Entretanto, na DC, o TLR3 está diminuído e o TLR4 está significantemente aumentado. Sabe-se que TLR2 e TLR4 são potenciais mediadores da sinalização inflamatória contra antígenos bacterianos, por meio da ativação de NF-KB e expressão de citocinas em monócitos. Portanto, o que se vê na DC é uma resposta exagerada à microbiota intestinal $[6,15,25]$.

Neste contexto, relatos sugerem que as bactérias possuem importante papel na etiologia da DC. A perda do equilíbrio entre as bactérias comensais e as bactérias patogênicas possivelmente ocasiona estímulo ao sistema imunológico. $O$ aumento da expressão de TLR4 - que promove o aumento de resposta imune contra antígenos de bactérias comensais - está intimamente ligado à perda da tolerância a estas bactérias. Relatos apontam a diminuição da diversidade das bactérias comensais como uma das possíveis causas da DC [1, 6, 14, 15, 21].

Em situação normal, a microbiota intestinal constitui uma barreira de defesa e exerce importantes funções como síntese de aminoácidos e vitaminas, indução de PPAR-y, indução e manutenção de células reguladoras, manutenção da integridade 
do epitélio intestinal por meio da interação com TLR. Ainda assim, tais bactérias podem ser responsáveis pelo surgimento da DC, desde que o indivíduo tenha predisposição genética num contexto de desregulação imunitária [6, 15].

Outra hipótese etiológica da DC constitui a infecção persistente por microrganismo específico. A Mycobacterium avium paratuberculosis (MAP) é um possível agente etiológico por estar associada a colite bovina. Além disso, anticorpos anti-MAP estão presentes em indivíduos com DC e fármacos antimicobacterianos promoveram melhora do quadro da doença. No entanto, não há consenso se a MAP pode iniciar a DC em indivíduos geneticamente predispostos ou se apenas coloniza a mucosa ulcerada. Outros microrganismos foram associados à doença, tais como Escherichia coli aderente-invasiva, Listeria monocytogenes e Yersinia enterocolitica, porém, estas relações não foram confirmadas $[1,15]$.

\subsubsection{Fatores ambientais}

Determinados fatores ambientais estão relacionados com o aparecimento da DC ou a sua reativação, por meio de mecanismos ainda não elucidados. De uma maneira geral, eles afetam a integridade da barreira da mucosa, alteram a resposta imune ou afetam o microambiente luminal. Os fatores descritos mais relevantes são tabagismo, dieta, infecção e uso de anti-inflamatórios não esteroidais (AINEs) [6, 21].

O uso de tabaco aumenta em até 4 vezes o risco de desenvolver doença de Crohn, bem como o risco de complicações como estenoses e fístulas e as chances de surtos. Nos indivíduos que fumam, a prevalência da doença localizada no íleo é maior que no cólon. No entanto, ainda que o tabaco esteja relacionado com a localização da doença, ele não define diretamente o seu comportamento. O tabaco afeta os fatores imunológicos, tendo em vista que a nicotina reduz a capacidade de fagocitose dos macrófagos, a produção de anticorpos e a permeabilidade intestinal $[6,15,21,22]$.

Não existem evidencias experimentais que justifiquem a influência da dieta na patogênese da DC. No entanto, sugere-se que falhas na permeabilidade das células da mucosa levem à absorção de antígenos provenientes da dieta, o que condiciona 
a perpetuação do processo inflamatório. O uso de AINEs está associado ao aumento da probabilidade de desenvolvimento de novo surto em indivíduos com remissão clínica. Assim como em casos de infecção, o uso de AINEs proporciona a quebra da barreira da mucosa e ativa resposta imunológica inata [6, 15, 21].

Portanto, tais aspectos ambientais estão relacionados com a DC, mas nenhum é capaz de originar a doença de forma isolada, fazendo-se necessária a presença de outros fatores, tais como genéticos e imunológicos [15].

\subsubsection{Fatores imunológicos}

Em resposta a um conjunto de estímulos não totalmente elucidados, a cascata inflamatória é ativada de forma excessiva, promovendo respostas agressivas ao indivíduo com DC. Não se sabe ainda se a atividade do sistema imune aumentada é resposta de uma falha na mucosa ou se essa resposta imune é primariamente desregulada. No entanto, evidencia-se o fato de que a quebra da barreira da mucosa por agentes infecciosos promove uma contínua exposição a antígenos da microbiota e da dieta, que levam ao desencadeamento da cascata inflamatória [1, 6, 16, 22].

$\mathrm{Na}$ DC, estão predominantemente presentes processos mediados por Th1 e Th17. As moléculas de adesão, como a ICAM-1 e intregrinas, estão aumentadas, o que promove maior migração de leucócitos para o local de inflamação. As células dendríticas e os macrófagos também estão aumentados, além de expressarem TLR2 e TLR4 de forma exacerbada. Os macrófagos ativados produzem TNF- $\alpha$ (fator de necrose tumoral $\alpha$ ) e IL-12, que induzem à resposta Th1 de linfócitos T CD4+ e liberam grandes quantidades de IL-2, TNF- $\alpha$ e INF- $\gamma$. Nas lesões crônicas, o INF- $\gamma$ estimula os macrófagos, que em seguida estimula a produção de TNF- $\alpha$. O TNF- $\alpha$ está aumentado no soro, fezes e mucosa intestinal dos indivíduos com DC, o que pode estar relacionado ao desequilíbrio entre secreção e inibição. O NF-kB, também aumentado na DC, leva à expressão de IL-1, IL-6, IL-8, IL-12, IL-23, TNF- $\alpha$, moléculas de adesão e moléculas co-estimuladores (CD40, CD80, CD86) [1, 6, 15, 16, 22]. 
Todos esses eventos proporcionam uma reação inflamatória em cadeia e de forma exacerbada, característica da DC (Figura 2). Assim, os fatores imunológicos constituem um dos principais alvos farmacológicos da DC [14, 21].

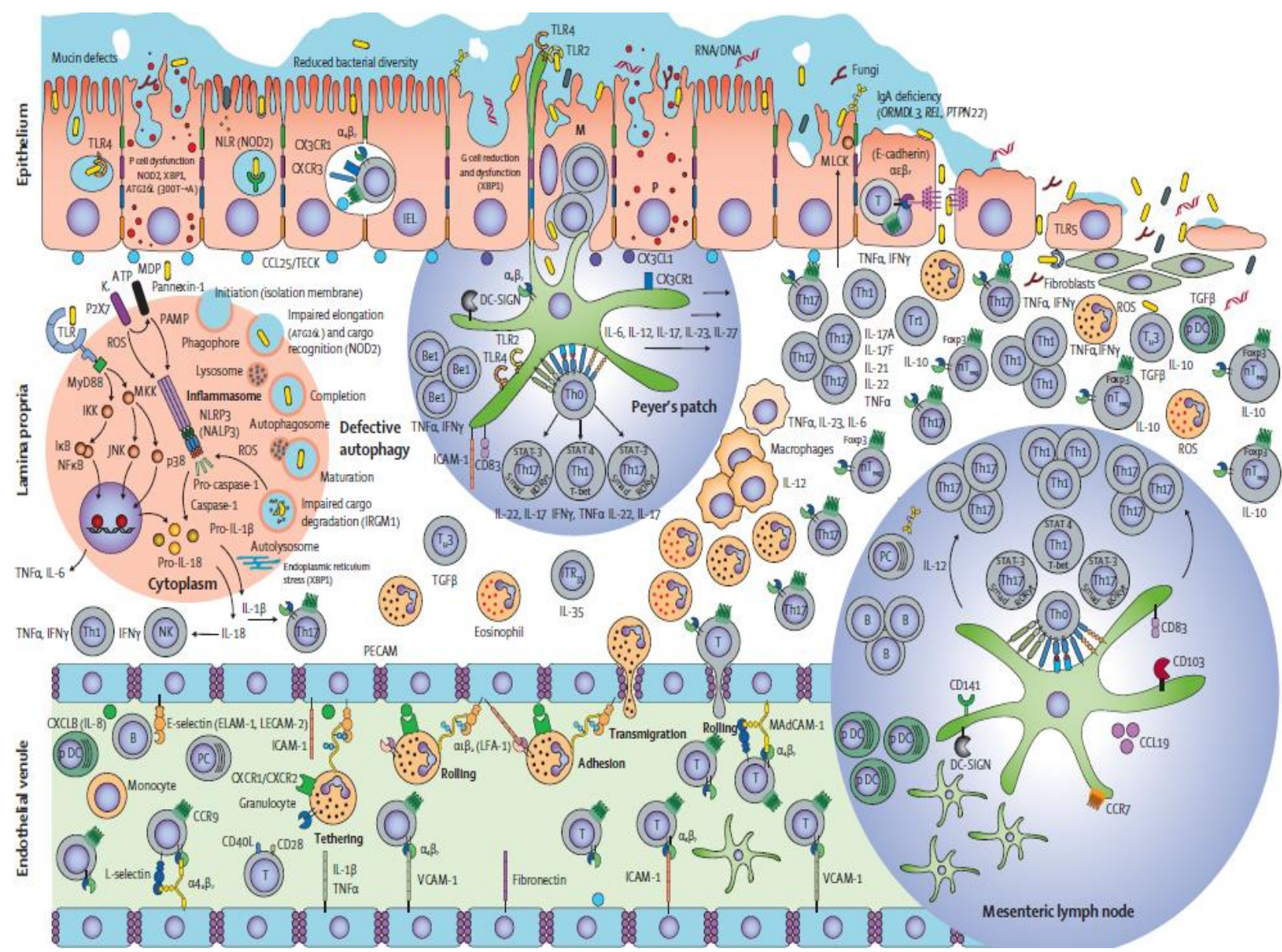

Figura 2: Sistema imunológico na doença de Crohn. Na DC, alterações nas tight junctions e redução na produção de mucina promovem uma maior exposição da lâmina própria aos antígenos luminais. As células de Paneth $(P)$ que carregam a variante $300 T \rightarrow A$ do gene de autofagia ATG16L, associada à indivíduos com $\mathrm{DC}$, possuem menos grânulos, além de dismórficos e funcionalmente prejudicados, originando redução dos mecanismos de defesa contra patógenos. Os materiais microbianos e antígenos da dieta são reconhecidos por TLRs e NLR, o que leva a uma maior ativação do sistema imune. O sistema imune adaptativo, cujas funções na DC são de perpetuar e mediar a inflamação, é caracterizado por desequilíbrio entre as células T efetoras, predominantemente Th1 e Th17, por meio de secreção de INF- $\gamma$, TNF- $\alpha$, IL-17 e IL-22. NF-kB ativado promove expressão de ICAM-1, IL-1, IL-6, IL-8, IL-12, IL-23 e TNF- $\alpha$.

Fonte: BAUMGART \& SANDBORN, 2012 [14] 


\subsection{ALVOS FARMACOLÓGICOS}

No âmbito dos fatores relacionados à etiologia da DC, esforços têm sido convergidos para a obtenção de fármacos que melhorem a qualidade de vida e tratem as complicações da doença. Em face das descobertas acerca da etiologia da doença, um padrão de tratamento multialvo tem sido reconhecido como principal estratégia $[15,26]$.

\subsubsection{Fator nuclear kappa B}

O fator nuclear kappa B é um importante fator de transcrição que está associado a processos inflamatórios. $O$ termo NF-KB pode ser utilizado para se referir à superfamília, à subfamília ou ao heterodímero p50-RelA, o qual é o principal dímero NF-KB em várias células. Nos mamíferos, a família NF-KB de proteínas é composta por duas sub-famílias: as proteínas "NF-kB" e as proteínas "Rel", que compartilham domínio altamente conservado na região $\mathrm{N}$-terminal, chamado domínio de homologia Rel (do inglês, Rel homology domain, RHD). O RHD é formado por cerca de 300 aminoácidos e é responsável pela dimerização, ligação ao DNA e interação com IkBs. A subfamília Rel é constituída por c-Rel, RelB e RelA (também conhecida como p65). A subfamília NF-kB é composta por p50/p105 (também conhecida como NF-kB1) e p52/p100 (também conhecida como NF-KB2) [27-29].

As duas subfamílias se diferenciam pela estrutura e função da região $C$ terminal. As proteínas Rel possuem domínio de transativação, chamado domínio de ativação transcricional (do inglês transcriptional activation domain - TAD), que é responsável pela regulação positiva da transcrição. Já os membros da subfamília NF-kB contêm múltiplas cópias de anquirina em seu longo domínio $C$-terminal. Neste caso, essa região atua inibindo essas proteínas [27, 28].

No citoplasma de células sem estímulo, os cinco membros da família NF-KB estão na forma de homo ou heterodímeros ligados a proteínas da família IKB -

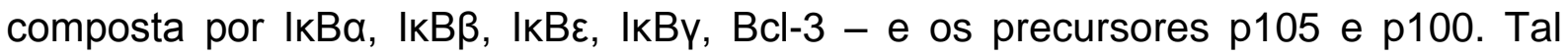


ligação impede que o complexo seja translocado ao núcleo, mantendo o NF-KB em estado inativo. As proteínas IKBs possuem resíduos de serina que servem como sítios de fosforilação, sinalizando a proteína para ubiquitinação e consequente degradação; são compostas por cinco a sete repetições de anquirina, formando um cilindro alongado que se liga ao RHD dos dímeros de NF-kB. Estruturas cristalográficas de IKBa e IKB $\beta$ ligadas a dímeros p65/p50 ou p65/c-Rel mostraram que quando ligadas a dímeros NF-kB, as proteínas IKB ocultam apenas a sequência de localização nuclear (do inglês nuclear localization sequence - NLS) do p65, enquanto que a NLS da p50 permanece acessível. Este NLS - livre em p50 juntamente com as sequências nucleares de exportação (do inglês, nuclear export sequences - NES) presentes na IKBa e p65 - resulta em um constante "vai-e-vem" dos complexos IKBa/NF-kB entre o núcleo e o citoplasma, embora o estado estável seja no citosol. Essa variação de localização é alterada pela degradação de IKBa, já que esta remove a contribuição das NES do IKB e expõe o NLS oculto do p65, resultando na localização predominantemente no núcleo do NF-KB [27, 29, 30].

São descritas duas vias de sinalização do NF-kB que levam à sua ativação: a via canônica (ou clássica) e a não-canônica (ou alternativa) (Figura 3). Por meio de estímulo de fatores pró-inflamatórios, tal como TNF- $\alpha$, a via canônica leva à ativação da subunidade $\beta$ do complexo da kinase IKB (IKK), que fosforila os resíduos de serina da região $C$-terminal das proteínas IKB. Na via canônica, IKKß é necessária e suficiente para fosforilação de resíduos de serina em IkBa (Ser32 e Ser36) e IkB $\beta$ (Ser19 e Ser23). Já o papel da IKKa ainda não é claro, embora existam relatos da regulação de expressão de genes no núcleo por meio da modificação do estado de fosforilação das histonas [28-30].

$\mathrm{Na}$ via não-canônica, a IKKa é ativada em resposta a um subconjunto de indutores incluindo LPS, CD40, linfotoxina $B($ LT $\beta$ ) e fator ativador de células $B$ da superfamília do TNF- $\alpha$ (do inglês $B$-cell activating fator - BAFF), o que então leva à fosforilação de p100. A via alternativa depende somente da subunidade IKKa, que atua fosforilando p100 e culmina no seu processamento à p52. Nessa via, a ligação ao receptor leva à ativação da NIK (do inglês NF-KB inducing kinase), que promove a fosforilação e ativação do complexo IKKa, que por sua vez fosforila serinas adjacentes à repetição de anquirina no domínio $C$-terminal da p100, e leva à sua proteólise parcial e liberação do complexo p52/RelB [27-30]. 

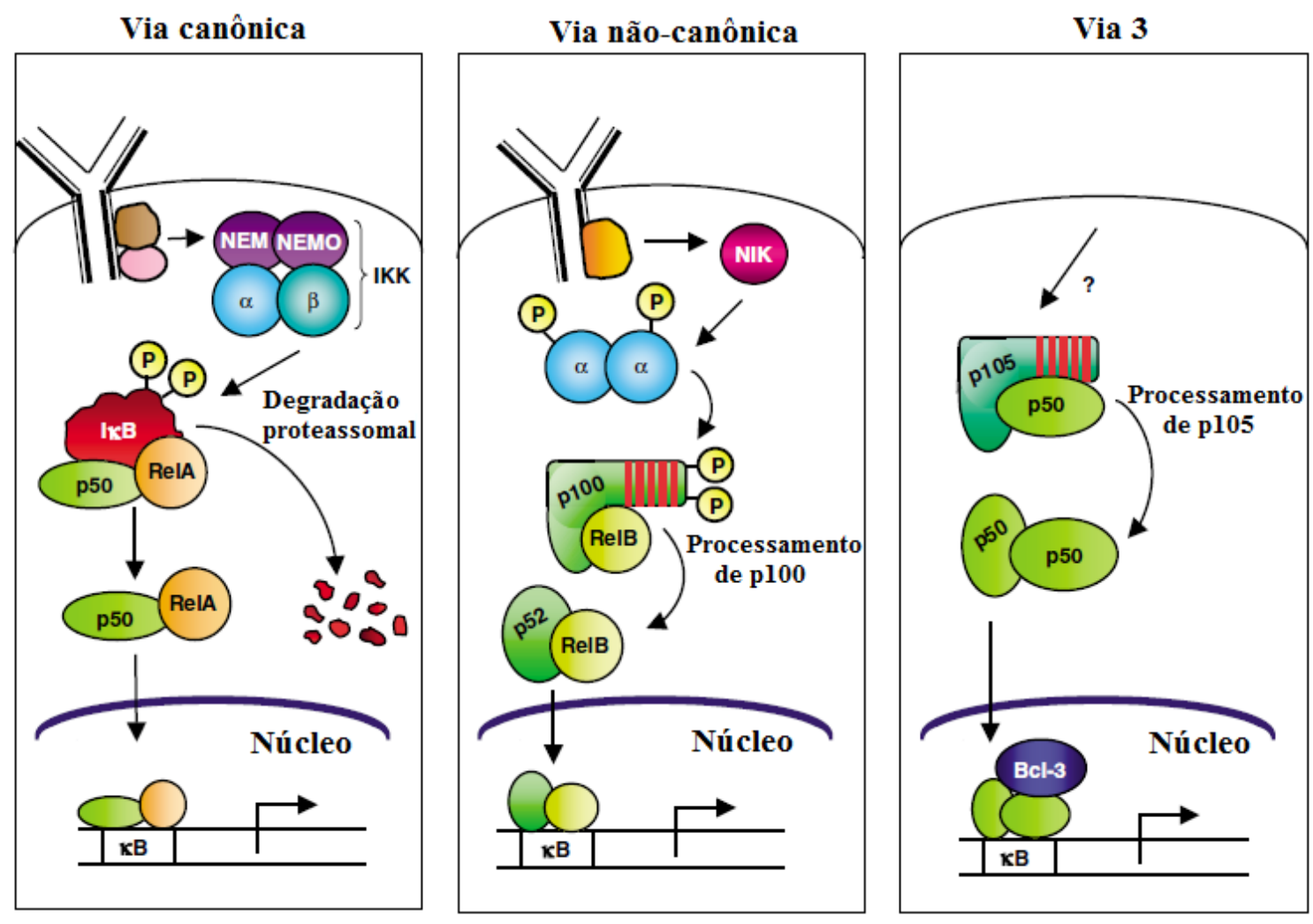

Figura 3: Vias de sinalização do NF-kB

Fonte: Adaptado de GILMORE, T.D., 2006 [28]

O complexo IKK é constituído pelas subunidades IKKa (também conhecida como IKK1), IKKß (também conhecida como IKK2) e várias cópias do modificador essencial do NF-KB (do inglês NF-KB essential modifier - NEMO), regulador também conhecido como IKKy [27, 29].

$\mathrm{Em}$ ambas as vias, as IKBs fosforiladas podem ser reconhecidas pela maquinaria da ubiquitina ligase e, por conseguinte, sofrerem poliubiquitinação e degradação, ou ainda serem processadas, no caso da p100, pelo proteassomo. Então, os dímeros de NF-kB livres são translocados para o núcleo, onde se ligarão a sequências específicas no promotor ou regiões acentuadoras dos genes-alvo. Uma vez ativado, o NF-KB pode ser regulado negativamente por meio de mecanismos de feedback em que o IkBa recém-sintetizado se liga ao NF-kB nuclear e o exporta para o citosol [29, 30].

Existem muitos relatos de que a via de sinalização de transcrição do NF-kB desempenha importante papel na resposta inflamatória nas CEI. Nas últimas décadas, muitos esforços foram direcionados para o desenvolvimento e aplicação de novas terapias contra inflamação. Compostos baseados em esteroides, pequenas 
moléculas e metabólitos secundários de plantas compõem grupo de promissores inibidores NF-KB. No entanto, provavelmente a inibição específica de NF-kB seria insuficiente para 0 tratamento de determinadas doenças multifatoriais, tais como as DII. Ainda assim, o NF-KB como alvo terapêutico pode ser bem sucedido por meio do conhecimento dos diferentes mecanismos que regulam sua cascata de sinalização $[29,30]$.

\subsubsection{Receptores ativados por proliferadores peroxissomais}

Os receptores ativados por proliferadores peroxissomais (PPAR) são receptores nucleares que, em contato com ligantes, atuam como fatores de transcrição, regulando a transcrição de genes. PPARs modulam a expressão de genes por meio da transativação, da repressão basal e da transrepressão da transcrição. Possuem organização estrutural semelhante aos outros membros da superfamília de receptores nucleares, formados por uma região $N$-terminal, um domínio de ligação ao DNA (do inglês, DNA Binding Domain - DBD), uma região de conexão denominada dobradiça ou hinge, um domínio de ligação ao ligante (do inglês, Ligand Binding Domain - LBD) e um domínio C-terminal [41-43, 57, 59, 60].

$\mathrm{Na}$ transativação dependente de ligante, ao interagir com o ligante por meio do LBD, o PPAR localizado no citosol sofre fosforilação e o complexo PPAR-ligante é translocado para o núcleo, onde forma um heterodímero com o receptor $X$ retinóico (RXR). Em seguida, o heterodímero PPAR-RXR se liga a sequências específicas de DNA denominadas elementos responsivos ao PPAR (PPREs). Os receptores sofrem alteração conformacional devido à interação com o ligante agonista, o que permite a dissociação com correpressores e o recrutamento de coativadores, proporcionando ativação da transcrição de determinados genes regulados pelo PPAR ativado. Histonas acetiltransferase (HATs) coativam PPAR por meio de acetilação de histonas, que promove uma modificação na estrutura da cromatina essencial para o início da transcrição. Os PPARs também podem regular a transcrição negativamente. A repressão basal não necessita de ligante e envolve ligação do PPAR aos PPREs e o recrutamento de proteínas correpressoras, tais como HDACs. Já a transrepressão não envolve ligação direta dos PPARs aos 
PPREs, tal como acontece com a inibição da atividade de NF-KB, na qual há interação direta entre PPAR e esse fator nuclear [57, 59-63].

Os PPARs incluem os isotipos PPAR- $\alpha$, PPAR- $\beta / \delta$ e PPAR- - , distribuídos em diferentes tecidos e com diferentes funções. $O$ isotipo PPAR- $\alpha$ está relacionado com a regulação da oxidação de ácidos graxos, sendo considerado fator chave no metabolismo lipídico. Sabe-se que esse isotipo interage com a HAT p300 aumentando atividade transcricional ligante-dependente. É amplamente encontrado em tecidos com taxas elevadas de catabolismo de ácidos graxos como rim, fígado, coração, intestino e tecido adiposo marrom. PPAR-a também é encontrado em células endoteliais, células musculares lisas e macrófagos da parede vascular. Desempenha papel anti-inflamatório nessas células, inibindo produção de marcadores inflamatórios como VCAM-1, IL-6, endotelina 1 e fator tecidual. Em adição, atividade agonista PPAR- $\alpha$ está relacionada ao controle de inflamação hepática, controle da resposta inflamatória frente a LPS, bem como possui papel protetor em DII e aterosclerose. Foi demonstrado que ativação de PPAR- $\alpha$ interfere na ligação de NF-KB com DNA, por meio de interação direta com p65 e indução de expressão de IKBa [43, 59, 61, 63, 64].

$O$ isotipo PPAR- $\beta / \delta$ possui distribuição tecidual ampla e por essa razão possui diversas funções fisiológicas, embora seja mais concentrado em células epiteliais. Ativação de PPAR- $\beta / \delta$ leva à inibição da resposta inflamatória frente a LPS, por meio de inibição de COX e TNF- $\alpha$. Foi demonstrado que a ativação desse isotipo está relacionada à atenuação de toxicidade hepática quimicamente induzida em modelos de rato por meio de interação direta com NF-kB. Além disso, PPAR- $\beta / \delta$ parece limitar repostas inflamatórias de Th1 por meio do controle da homeostase de linfócitos e da produção de IFN-y. Em modelos de colite induzida em camundongos, PPAR- $\beta / \delta$ teve papel protetor contra DII por meio de mecanismo liganteindependente. No entanto, as funções de PPAR- $\beta / \delta$ ainda não foram completamente elucidadas, bem como seu papel na inflamação. A Figura 4 ilustra os mecanismos de ativação do isotipo PPAR- $\beta / \delta$ e seus efeitos regulatórios de transcrição [59, 61, $63,65,66]$. 


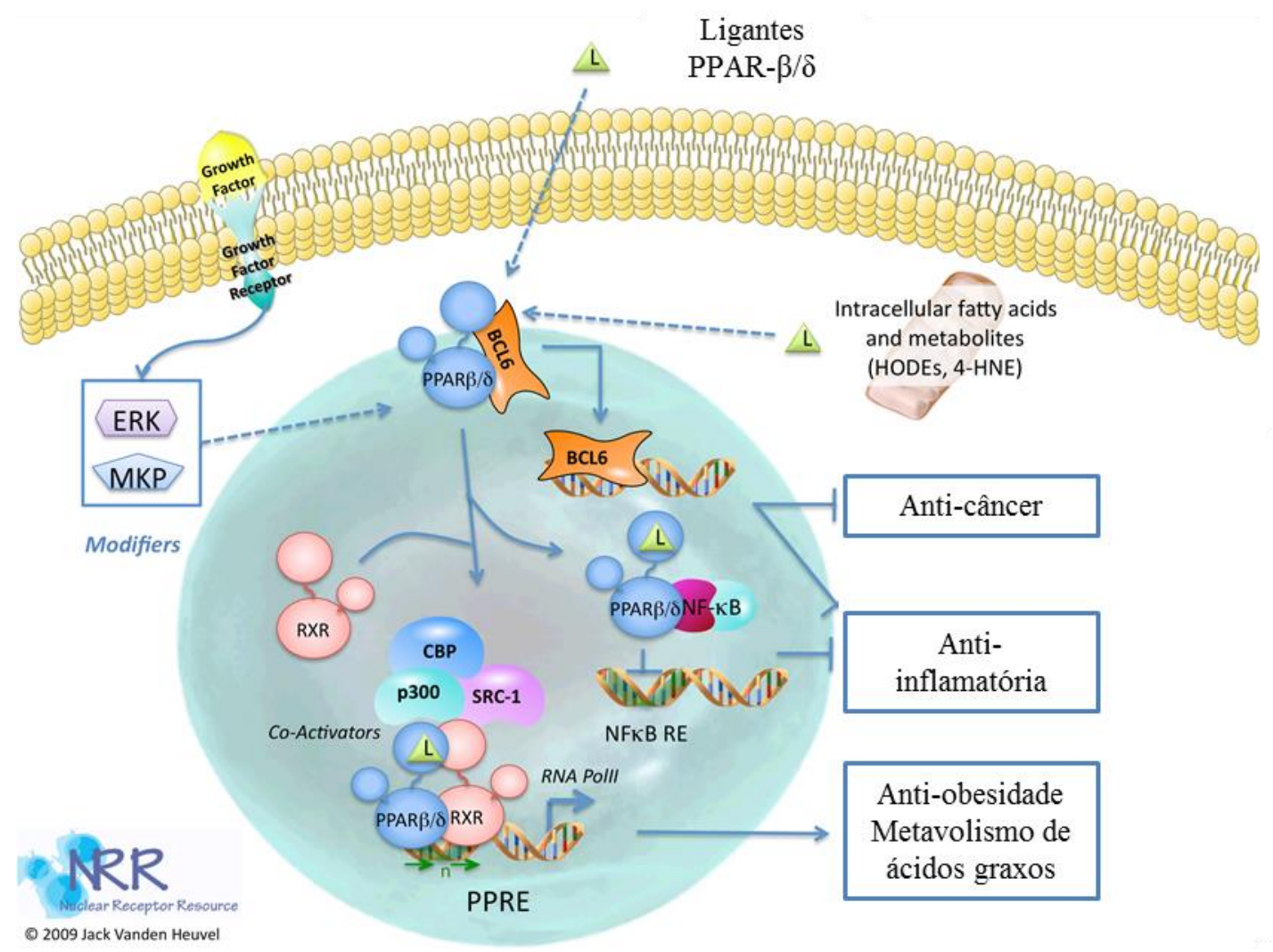

Figura 4: Modulação da expressão gênica por PPAR- $\beta / \delta$

Fonte: Adaptado de Nuclear Receptor Resource, 2009 [67]

O isotipo PPAR-y possui importantes funções no metabolismo e na regulação de processos inflamatórios. Gelman e colaboradores descreveram ligação direta com p300 por meio de interação com os domínios $N$-terminal e $C$-terminal, de forma ligante-dependente e independente. Sua expressão é alta no epitélio intestinal e é proveniente da sinalização dependente de receptores de reconhecimento de padrões (PRRs) da microbiota intestinal e da regulação transcricional direta por meio de metabólitos bacterianos. PPAR-y regula negativamente a sinalização de NF-KB em p65 e ІKB. É proposto que um iniba o outro, resultando na consequente exportação para o citoplasma. Vários relatos demonstram o envolvimento do PPARy com DII. Agonistas PPAR-y foram eficientes no tratamento de DII em modelos de camundongo, além de terem sido associados ao bloqueio na produção de quimiocinas por meio da inibição de NF-KB dependente de IKBa. Tais efeitos protetores parecem ser mediados principalmente pelas CEI. A Figura 5 ilustra os mecanismos de ativação dos isotipos PPAR- $\alpha$ e PPAR-y e seus efeitos regulatórios de transcrição [21, 29, 42, 63, 64]. 


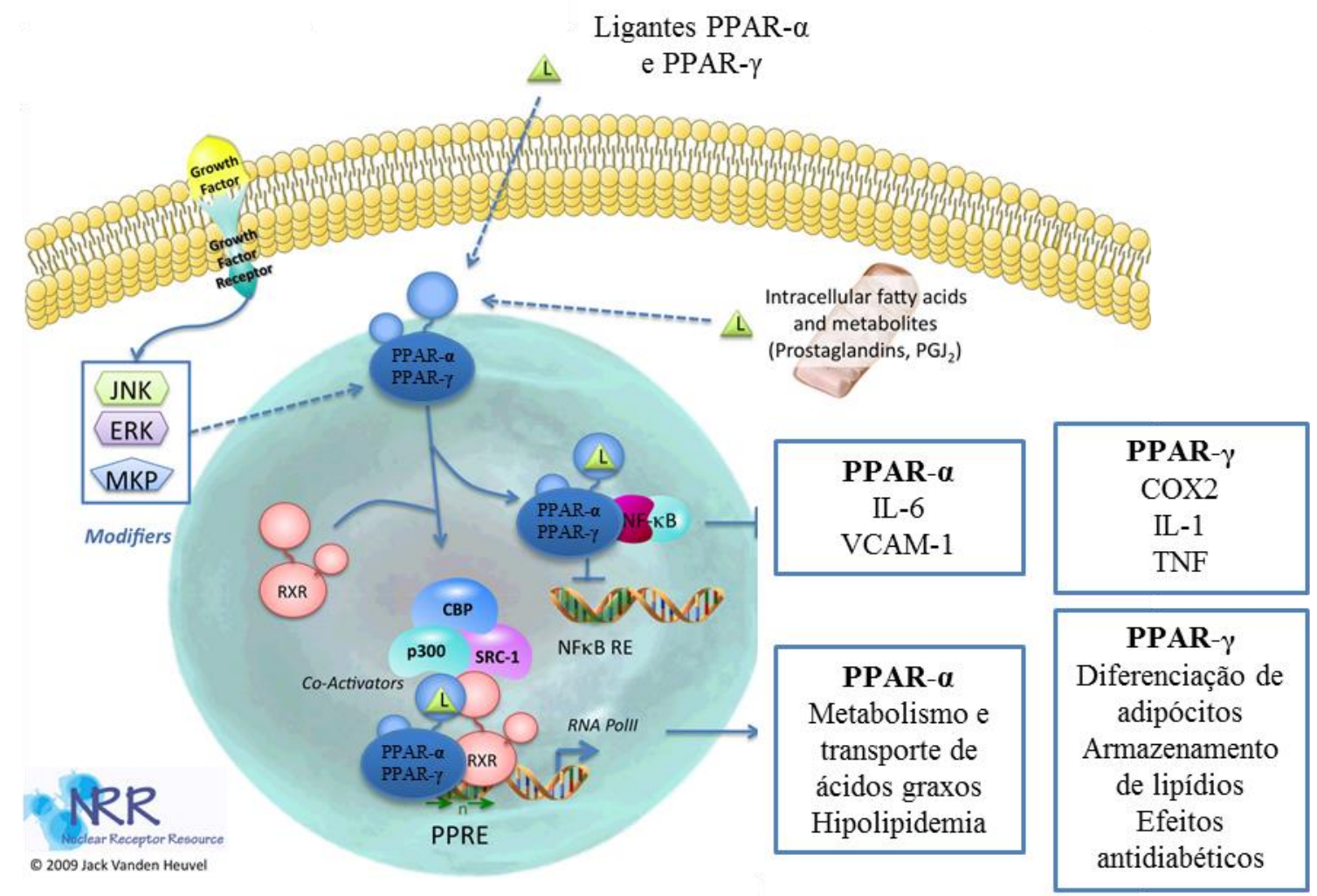

Figura 5: Modulação da expressão gênica por PPAR- $\alpha$ e PPAR-y Fonte: Adaptado de Nuclear Receptor Resource, 2009 [67]

Embora a expressão de PPAR-y esteja normal em indivíduos com DC, esses relatos sugerem que sua ativação constitui uma boa estratégia no manejo da DC, bem como a ativação de PPAR- $\alpha$ e PPAR- $\beta / \delta$. Adicionalmente, a busca de novos agonistas PPARs é uma estratégia promissora para o tratamento da inflamação [21, $29,42]$.

\subsection{3 p300}

Modulação epigenética é definida como alteração de regiões cromossômicas para registrar, sinalizar ou perpetuar estados de atividade alterados. Tais modificações representam importantes contribuições para a regulação da transcrição de genes. São descritas diversas modificações em histonas, incluindo acetilação, metilação, fosforilação e ubiquitinação, as quais promovem ou removem sinais de recrutamento para proteínas envolvidas na atividade transcricional, bem como 
proporcionam mudanças na estrutura da cromatina e consequentemente nas interações histonas-DNA [31-34].

Histona acetiltransferases (HATs) são proteínas coativadoras que, juntamente com histona desacetilases (HDACs), modulam a transcrição de genes, de forma que a acetilação está relacionada com a ativação da transcrição e a desacetilação está relacionada com a repressão da transcrição. As HATs são compostas pelas subfamílias GNAT (GCN5 e PCAF), CBP/p300 e MYST (Tip60, MOZ, Sas2 e Ybf2/Sas3), as quais são agrupadas de acordo com a similaridade estrutural e agem acetilando resíduos de lisina na parte central de histonas por meio da transferência do grupo acetil de acetilcoenzima A (Acetil-CoA). CBP (do inglês CREB binding protein) e p300 são proteínas parálogas e amplamente expressas com atividade intrínseca de HAT. Ambas tem papel importante na coativação de fatores de transcrição, incluindo os receptores nucleares [27, 35-37].

Sabe-se que modificações pós-translacionais possuem importante papel na regulação de diferentes funções de NF-kB. Recentemente, foi demonstrado que acetilações nos resíduos de lisina 218 e 221 da subunidade p65 de NF-KB aumentam a afinidade de ligação do complexo de NF-KB ao DNA e prejudicam a ligação do NF-KB com IKBa promovendo o aumento da duração da ação de NF-KB. Especificamente, acetilação na lisina 310 é necessária para a atividade transcricional completa de p65, mas não afeta a ligação com DNA ou sua ligação com IKBa. Em contraste, a acetilação das lisinas 122 e 123 por p300 reduz a ligação de NF-kB ao DNA e facilita a ligação com IKBa, promovendo a exportação de NF-kB para o citoplasma. Por sua vez, a ação da p300 em resíduos de lisina 431, 440 e 441 em p50 aumenta sua ligação ao DNA, o que promove a ativação transcricional por NF-kB. A acetilação de cofatores envolvidos na regulação de transativação também modula suas interações com as subunidades de NF-kB. Paralelamente, p300/CBP também age como coativador de PPARs, sendo importantes no processo de transativação dependente de ligante, no qual modificam a estrutura da cromatina e facilitam a montagem da maquinaria transcricional. Em adição, a atividade antiinflamatória de PPARs está associada à competição entre NF-kB e PPARs pela quantidade limitada de coativadores [36, 63].

Existem evidências do aumento no padrão de acetilações - em função da expressão elevada de p300 - na DC. Recentemente, inibidores HAT foram descritos com propriedades anti-inflamatórias, o que induz a especulação de que ambas as 
atividades estão diretamente relacionadas. No entanto, é necessário destacar que a inibição de HAT pode influenciar outros alvos, promovendo atividades que não são de interesse. Compostos cinâmicos planejados a partir do inibidor HAT natural curcumina (2), cujos anéis aromáticos possuíam átomos de bromo ou uma subunidade salicílica, foram descritos como potenciais inibidores HAT. Diversos estudos nesse contexto conduzem à conclusão de que os inibidores HAT, tais como os naturais garcinol (3), ácido anacárdico (1) e curcumina (2) e o sintético Lys-CoA, são (4) caracterizados pela presença de uma porção salicílica, um anel catecol e uma subunidade cinâmica, os quais provavelmente estão relacionados à atividade (Figura 4) [34, 36, 38-40].

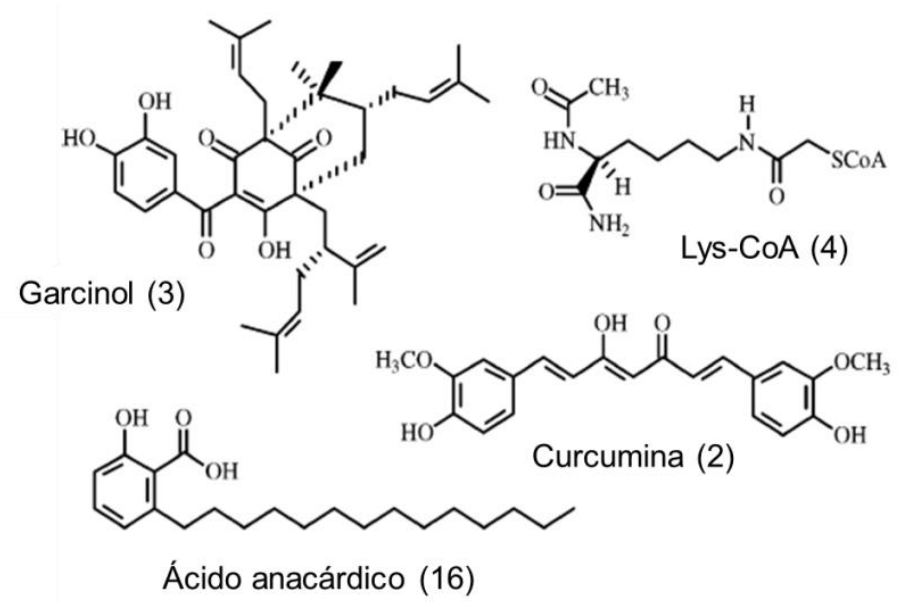

Figura 6: Inibidores HAT relatados na literatura: naturais - garcinol, curcumina e ácido anacárdico - e sintético - Lys-CoA, análogo do substrato da HAT Acetil-CoA

Fonte: Adaptado de Costi et al, 2006 [38]

Em suma, o desenvolvimento de inibidores HAT seletivos à regulação negativa de NF-kB constitui um desafio na busca de novos fármacos para 0 tratamento da DC, bem como de outras patologias de cunho inflamatório.

\subsection{TRATAMENTO DA DOENÇA DE CROHN}

O tratamento atualmente disponível da DC atua no controle dos sintomas e das complicações, bem como na indução e manutenção da remissão da doença, o que promove melhoria na qualidade de vida. Entre as opções de fármacos, a 
escolha se baseia principalmente na severidade de na localização da doença. Os medicamentos utilizados são anti-inflamatórios, corticoides, imunomoduladores e antimicrobianos (Figura 5) $[6,15,16]$.

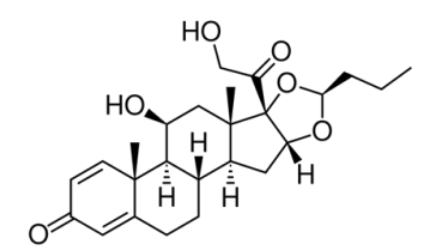

Budesonida (5)

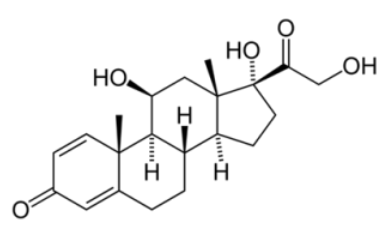

Prednisolona (6)

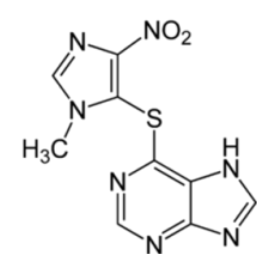

Azatioprina (7)

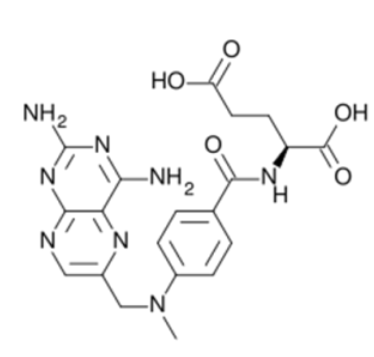

Metotrexato (8)

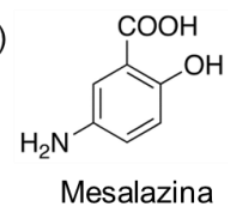

(5-ASA, 11)

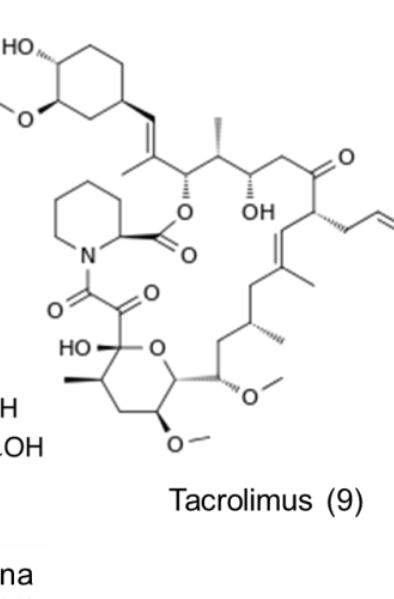

Tacrolimus (9)<smiles>O=C(O)c1cc(N=Nc2ccc(S(=O)(=O)Nc3ccccn3)cc2)ccc1O</smiles><smiles>O=C(NCCc1ccccc1)c1cc(Cl)ccc1O</smiles>

Figura 7: Principais fármacos utilizados para o tratamento da doença de Crohn e inibidor NF-kB 5CSPA

Fonte: Próprio autor

Os corticoides são efetivos na remissão da DC ativa, proporcionando supressão da inflamação e rápido alívio dos sintomas em $70-80 \%$ dos casos. Atuam reduzindo a produção de ácido araquidônico, leucotrienos, prostaglandinas, citocinas inflamatórias e NF-KB. No entanto, o uso de corticoides não está associado à manutenção da remissão, além do fato de que não é recomendado o seu uso a longo prazo devido aos efeitos adversos que apresenta (hiperglicemia, osteoporose, retardo no crescimento de crianças, aumento do risco de infecções). Entre os corticoides, a prescrição da Budesonida (5) é direcionada ao tratamento do cólon direito e íleo, enquanto a Prednisolona (6) é utilizada preferencialmente em indivíduos com doença íleo-cecal [3, 6, 15, 16, 26].

Os imunomoduladores agem reduzindo a inflamação por meio da supressão da resposta imunológica. As mais utilizadas são azatioprina (7), metotrexato (8) e tacrolimus (9). Estes agentes são capazes de manter a remissão da DC e é o 
primeiro tratamento no caso de fístulas. Os efeitos adversos incluem náusea, vômito, pancreatite, infecção e toxicidade hepática $[3,6,15,16]$.

A terapia biológica com anticorpos monoclonais constitui uma estratégia terapêutica de eficácia demonstrada em vários estudos. O infliximab é um anticorpo anti-TNFa utilizado nos tratamentos de DC fistulizante e nos casos de indução e remissão de indivíduos com DC moderada a grave - não responsivos aos imunossupressores e corticoides. A escolha desses agentes depende da acessibilidade, via de administração, preferência do paciente e custo. Os efeitos adversos são náuseas dor de cabeça, febre, risco de infecções graves e reativação de infecções latentes $[3,6,15,16]$.

Antimicrobianos são comumente utilizados para o tratamento da DC. No entanto, existem poucas evidências de que eles sejam efetivos de forma geral na DC. São úteis no tratamento de complicações da doença, tais como fístulas, massa inflamatória, crescimento bacteriano no ambiente de estenose e doença perianal [3, $6,15,16]$.

Os aminossalicilatos são anti-inflamatórios utilizados para DC com acometimento do cólon. Não possuem função na manutenção da remissão da doença e possuem efeitos adversos, como dor de cabeça, náusea e diarreia. Os principais representantes são a sulfassalazina (10) e a mesalazina (11), cujo composto ativo é o ácido 5-aminosalicílico (5-ASA, 11). O 5-ASA age inibindo a cicloxigenase, a lipoxigenase, as células $B$ e citocinas inflamatórias. Existem muitos relatos que associam a sua atividade anti-inflamatória à ativação PPAR-y. 11 é um funcional ligante PPAR-y, cuja ligação leva à sua ativação e possui grande especificidade aos expressos por células epiteliais, em detrimento de outros ligantes PPAR-y que possuem efeito sistêmico. O 5-ASA mesmo quando administrado de forma oral tem maior concentração no íleo terminal e cólon. Quando 11 atravessa a barreira intestinal, sua maior parte sofre $N$-acetilação, o que proporciona a não ativação de PPAR-y em outras partes do organismo [3, 6, 15, 16, 26, 36, 44].

O papel da dieta no tratamento da DC ainda é pouco compreendido, no entanto recomenda-se a baixa ingestão de fibras. Uma dieta líquida pode reduzir sintomas de obstrução. Em adição, um maior cuidado com a saúde mental e a atenção a outras co-morbidades são imprescindíveis para o bom estado do indivíduo com DC $[3,16]$. 
Alguns autores consideram que o tratamento da DC se contrapõe aos muitos efeitos adversos que origina, o que leva a não adesão terapêutica. Em adição, cerca de $70-75 \%$ necessitam de cirurgia para o alívio dos sintomas e complicações que a farmacoterapia não foi capaz de controlar. A cirurgia não é curativa e a DC reaparece dentro de 5 anos. Portanto, ainda há grande necessidade de desenvolvimento de novos fármacos que combatam a doença refratária, que ajudem a melhorar a qualidade de vida e que não apresentem efeitos adversos tão desconfortáveis $[3,6,15,26,41]$.

Estudos recentes desenvolvidos por Kim e colaboradores (2012) demostraram que o derivado salicílico 5-clorofenetilamida (12) foi mais efetivo que 5ASA (11) em modelos experimentais de colite induzida pelo ácido 2,4,6trinitrobenzenossulfônico (TNBS). Em ensaios com luciferase, 12 inibiu a atividade NF-KB com IC $5015 \mu \mathrm{M}[50]$.

\subsection{DERIVADOS DO LCC}

Plantas medicinais são importantes fontes de compostos que podem ser usados como alternativas a fármacos no tratamento de várias desordens. De acordo com a Organização Mundial da Saúde, mais de $80 \%$ da população dos países em desenvolvimento depende principalmente de plantas medicinais para assistência médica básica. Neste contexto, a casca do fruto do cajueiro (Anacardium occidentale), popularmente conhecido como castanha de caju é repleta de um líquido escuro, cáustico e inflamável, denominado líquido da casca da castanha de caju (LCC) $[9,10]$.

O LCC constitui um subproduto do agronegócio de baixo valor agregado. É rico em lipídeos fenólicos não-isoprenoides (Figura 6), sendo classificado como natural ou técnico de acordo com as técnicas de extração empregadas. O LCC natural pode ser obtido por extração à frio com solvente e é composto de misturas de ácidos anacárdicos (1) (71-82\%), cardanóis (13) (2-9\%), cardóis (14) (13-20\%) e traços de metilcardóis (15). Já o LCC técnico é obtido por processo termo-mecânico, submetido a temperaturas de 185-195 ํㅡ, o que causa a descarboxilação do ácido 
anacárdico (1), que se converte em cardanol (13), tornando-se o componente majoritário $[9,45]$.

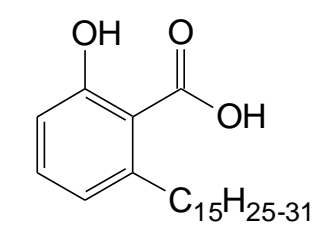

Ácidos anacárdicos (1)

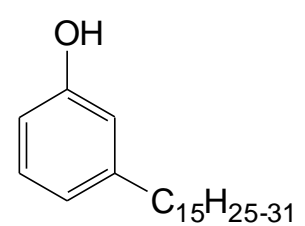

Cardanóis (13)

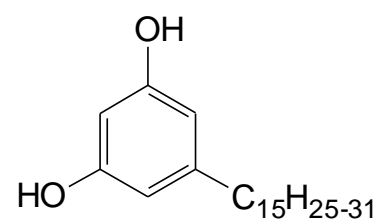

Cardoís (14)

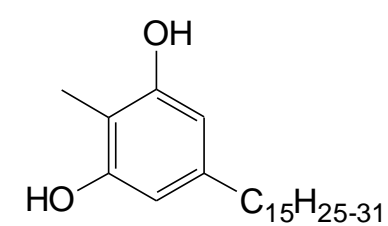

Metilcardóis (15)

$$
\begin{aligned}
& \mathrm{C}_{15} \mathrm{H}_{31} \\
& \mathrm{C}_{15} \mathrm{H}_{29} \\
& \mathrm{C}_{15} \mathrm{H}_{27} \\
& \mathrm{C}_{15} \mathrm{H}_{25}
\end{aligned}
$$
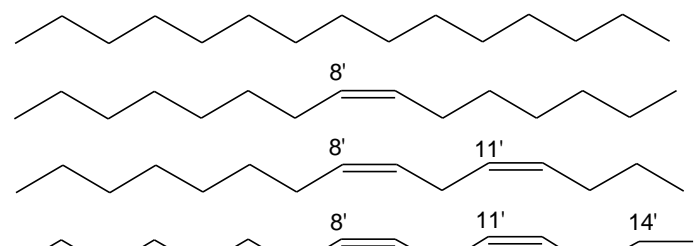

Figura 8: Principais componentes do líquido da casca da castanha de caju

Fonte: Próprio autor

\subsection{1 Ácido anacárdico}

Os ácidos anacárdicos (1) constituem uma mistura de ácidos salicílicos que apresentam, na posição 6 do núcleo aromático, uma cadeia alquílica de 15 carbonos de diferentes graus de instauração. 1 possui várias propriedades farmacológicas já descritas, tais como atividade antitumoral, gastroprotetora, antimicrobiana, antioxidante e anti-inflamatória [10,12].

Particularmente, o ácido anacárdico saturado (16) foi capaz de inibir acetilação de p65 e suprimir a indução e a constitutiva ativação de NF-kB, com consequente redução da expressão de genes NF-KB-dependente. Embora o ácido anacárdico não afete diretamente a transcrição de DNA, a transcrição HATdependente é fortemente inibida. $\mathrm{O}$ ácido anacárdico suprimiu NF-kB ativado por carcinógenos, fatores de crescimento e estímulos inflamatórios por meio de inibição da ativação de IKK, fosforilação e degradação de IKBa, fosforilação de p65 e expressão gênica dependente de NF-KB. Foi demonstrado também que 16 
potencializa a apoptose induzida por TNF e agentes quimioterápicos, adquirindo potencial atividade anticâncer [10, 12, 36].

A atividade anti-inflamatória do ácido anacárdico deve-se à regulação negativa de p300 (Figura 7), sendo que este e seus derivados interrompem não competitivamente a atividade de p300 e pCAF. Neste contexto, análogos do ácido anacárdico foram testados visando à comparação do perfil de inibição e seletividade quanto às diferentes HATs, concluindo que compostos com cadeia alifática flexível e hidrofóbica, bem como a subunidade salicílica possuem maior potencial na habilidade de inibir HAT. Em contrapartida, foi descrito um derivado amídico do ácido anacárdico que foi capaz de ativar p300 [10, 12, 33, 34, 36].

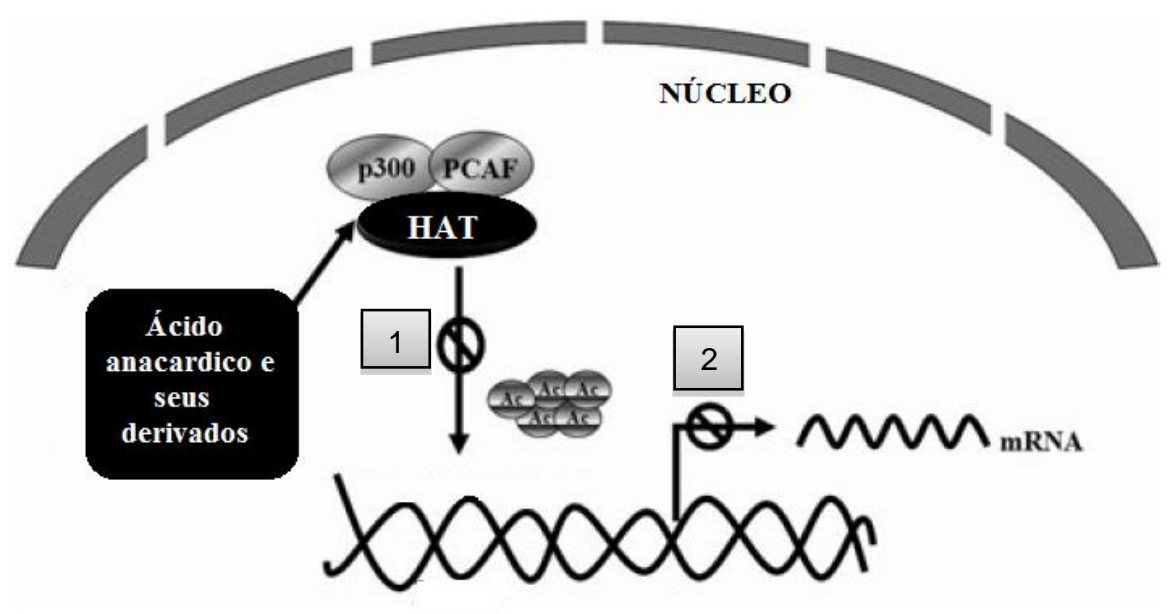

Figura 9: Prováveis mecanismos de ação do ácido anacárdico e seus derivados na inibição de HAT Fonte: Adaptado de HEMSHEKHAR et al, 2011 [10]

O ácido anacárdico constitui uma matéria-prima versátil, permitindo inúmeras modificações químicas (Figura 8). A presença da cadeia alquílica hidrofóbica com diferentes graus de instauração, bem como a subunidade aromática e salicílica conferem natureza dualística a esse componente do LCC. Na cadeia alquílica hidrogenada, reações de substituição ou eliminação no carbono benzílico podem ser realizadas; a cadeia alquenila, por sua vez, está sujeita a clivagem oxidativa ou a redução das duplas ligações por meio de reações de hidrogenação [46-48]. 


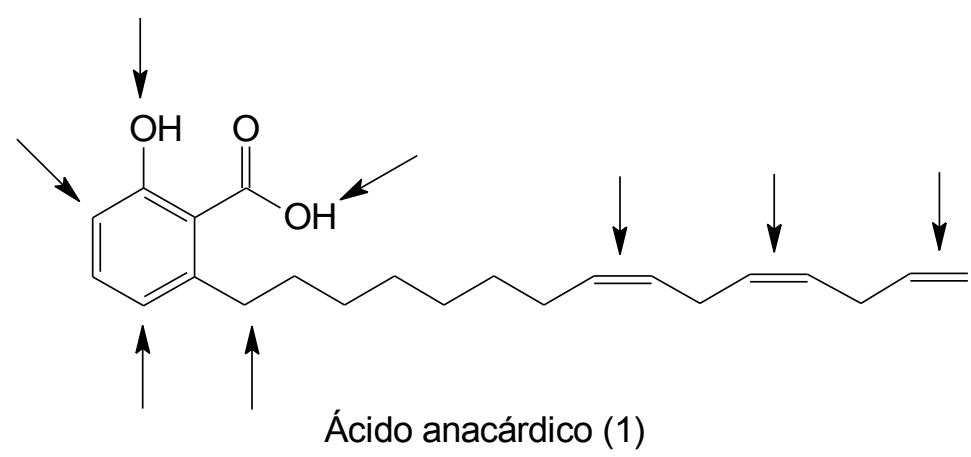

Figura 10: Principais sítios de reação do ácido anacárdico (1) Fonte: Próprio autor

Portanto, o ácido anacárdico é um bióforo natural que desempenha papel multi-terapêutico e cujas propriedades podem ser moduladas por meio de modificações químicas, constituindo assim uma matéria prima de interesse no âmbito da linha de pesquisa que visa à realização de estudos estrutura-atividade e a obtenção de novos agentes terapêuticos [46-49]. 


\subsection{OBJETIVO GERAL}

O presente estudo objetiva a obtenção racional de novos agentes terapêuticos planejados a partir do ácido anacárdico para o tratamento da doença de Crohn, no âmbito de uma linha de pesquisa que visa o desenvolvimento de ligantes anti-inflamatórios por meio da estratégia de ligantes multialvo dirigidos.

\subsubsection{Objetivos específicos}

Compreendem os objetivos específicos:

- A síntese e a caracterização dos produtos finais.

- A avaliação biológica in vitro frente à enzima p300.

- A avaliação biológica in vitro frente a PPAR-a/PPAR-y.

- Estabelecimento de relações estrutura-atividade. 
Planejamento Estrutural 


\section{PLANEJAMENTO ESTRUTURAL}

Os compostos-alvo foram planejados a partir da similaridade estrutural entre os inibidores NF-KB 5-ASA (11) e 5-CSPA (12) [50], de forma a gerar novos padrões moleculares a partir do ácido anacárdico saturado com arcabouço estrutural complementar aos alvos moleculares (Figura 11).

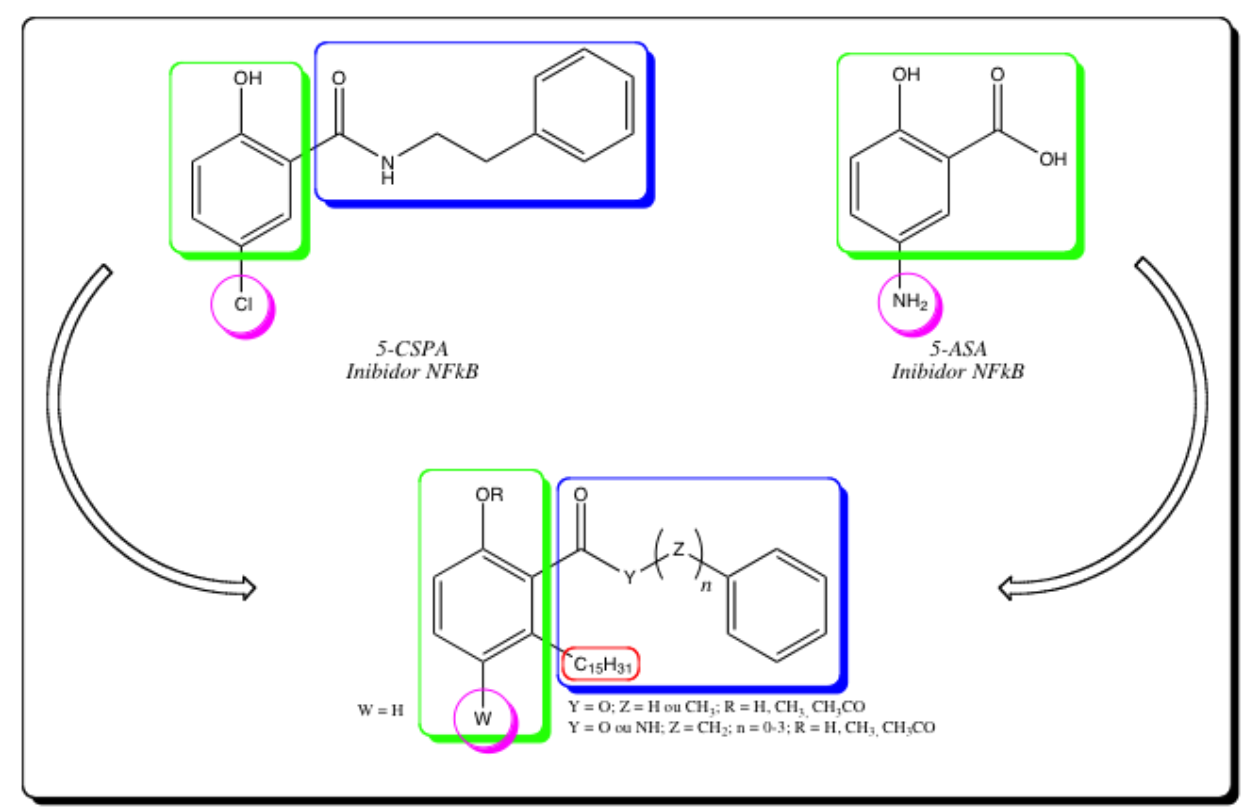

Figura 11: Planejamento racional de novos derivados anti-inflamatórios Fonte: Próprio autor

A primeira série está relacionada a variações em $R$, hidroxila, metoxila e acetoxila visando a obtenção de derivados ácidos carboxílicos e metil ésteres.

A segunda série está relacionada à fenetilamida 5-CSPA (12) e compreende a obtenção de aril e aralquilamidas secundárias com variação entre o número de carbonos metileno $(n=0-3)$ entre os grupos carbamoíla e fenila. Os análogos ésteres bioisósteros - que compreendem a terceira série - visam compreender a relevância do grupo amida quanto à participação da subunidade $\mathrm{NH}$ como doadores de ligação de hidrogênio. Adicionalmente, as variações na hidroxila fenólica planejadas para a primeira série serão empregadas nas demais séries visando avaliar a contribuição desta subunidade na modulação do perfil desejado. 
Planejamento Metodológico 


\section{PLANEJAMENTO METODOLÓGICO}

\subsection{ESTRATÉGIAS SINTÉTICAS}

A rota sintética foi estruturada com base em metodologias sintéticas clássicas, sob condições experimentais variáveis (à temperatura ambiente, sob refluxo e radiação micro-ondas), desenvolvidas no Laboratório de Desenvolvimento de Estratégias Terapêuticas (LADETER) e adequações da literatura.

A primeira série de compostos foi planejada a partir da obtenção do ácido anacárdico saturado (LDT11) por meio de hidrogenação catalítica da mistura de ácidos anacárdicos. A síntese de derivados acetóxi, hidróxi e metoxiácidos bem como seus correspondentes metilésteres foi desenhada a partir do derivado ácido LDT11 por meio de reações de acetilação, alquilação e esterificação. A obtenção do derivado 2'-metoxiácido (LDT30) foi planejada pela metodologia descrita por Chandregowda e colaboradores [46]. (Esquema 1).

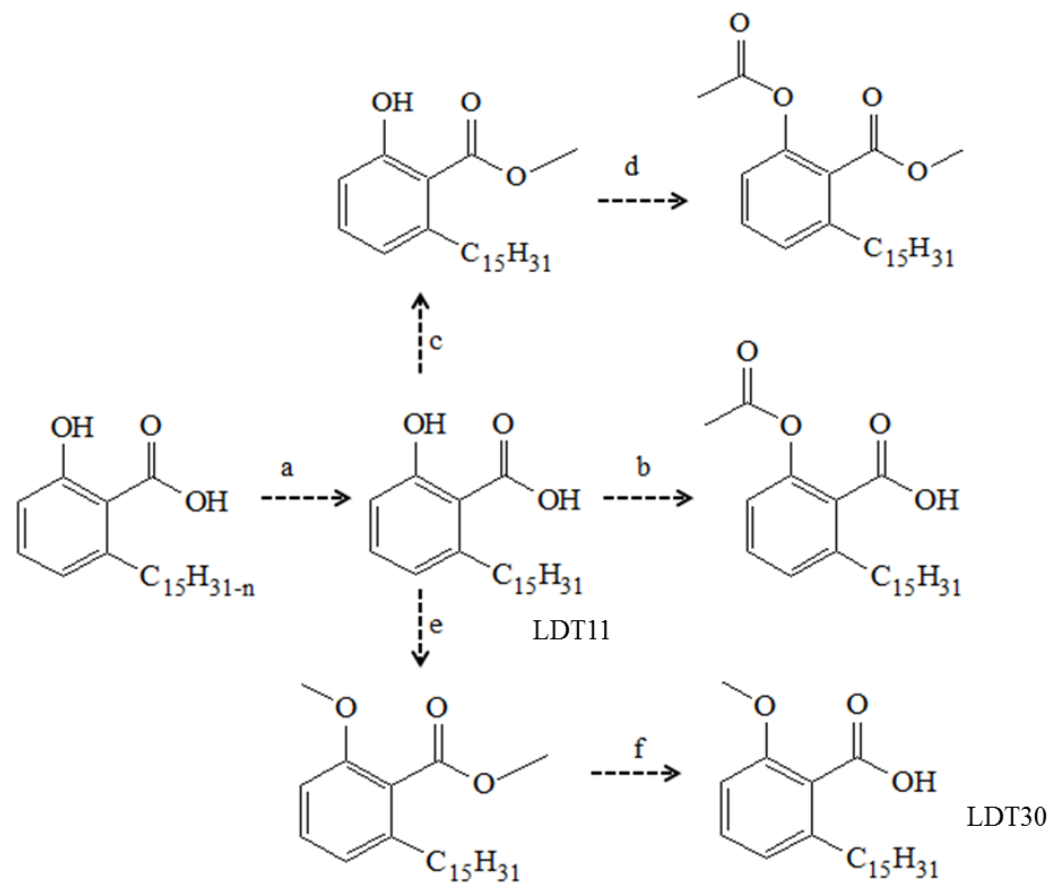

a. $\mathrm{H}_{2}, \mathrm{Pd} / \mathrm{C}$, EtOH; b. $\mathrm{Ac}_{2} \mathrm{O}, \mathrm{H}_{3} \mathrm{PO}_{4}, \mathrm{MO}$; c. $\mathrm{H}_{2} \mathrm{SO}_{4}, \mathrm{MeOH}$; d. AcCl, TEA, DCM; e. $\mathrm{CH}_{3} \mathrm{I}, \mathrm{K}_{2} \mathrm{CO}_{3}$, Acn; f. t-BuOK, DMSO

Esquema 1: Planejamento sintético dos derivados 2-acetóxi, hidróxi e metóxiácidos ou metilésteres Fonte: Próprio autor 
A estratégia sintética para a obtenção das amidas e ésteres foi planejada a partir da conversão do ácido LDT30 em seu cloreto de ácido correspondente seguido de reações de condensação com as aminas, álcoois e fenol selecionados, conforme realizado por Chandregowda e colaboradores [46].

Para a série dos derivados 2'-hidroxiamídico e 2'-hidroxiésteres foi planejada a reação de $O$-desmetilação com $\mathrm{BBr}_{3}$. Por fim, a reação dos hidróxiderivados com cloreto de acetila forneceria a série dos derivados acetilados (Esquema 2).

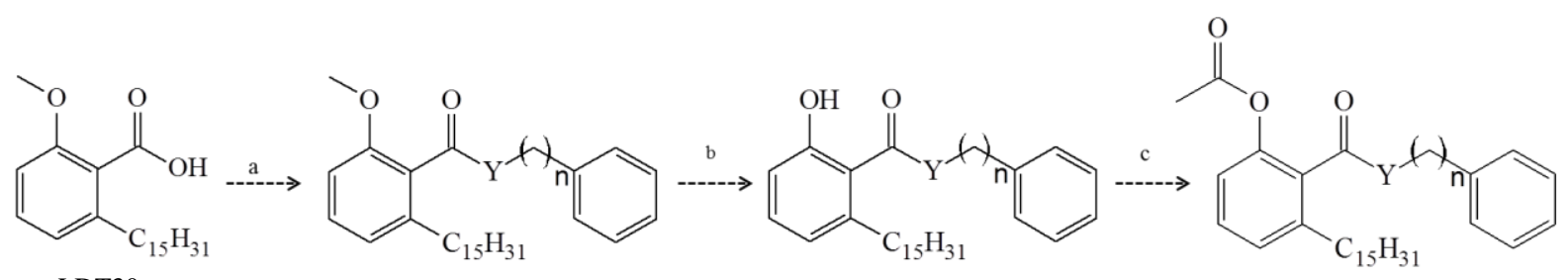

LDT30

a. I. $\mathrm{SOCl}_{2}$, DMF, Hex; II. R-NH $\mathrm{N}_{2}$ ou R-OH, TEA, DCM; b. $\mathrm{BBr}_{3}$, DCM; c. AcCl, TEA, DCM.

$\mathrm{Y}=\mathrm{NH}, \mathrm{O} ; \mathrm{n}=0,1,2,3$

Esquema 2: Planejamento sintético dos derivados 2'-acetóxi, hidróxi e metóxi amidas e ésteres

Fonte: Próprio autor 
Parte Experimental 


\section{PARTE EXPERIMENTAL}

\subsection{GENERALIDADES, MATERIAIS E MÉTODOS}

Os procedimentos experimentais em Síntese Orgânica foram realizados no Laboratório de Desenvolvimento de Estratégias Terapêuticas (LADETER) da Universidade Católica de Brasília (UCB), no período entre janeiro de 2013 e dezembro de 2014.

Os reagentes e solventes químicos utilizados neste trabalho foram adquiridos das indústrias Sigma-Aldrich ${ }^{\circledR}$ (EUA) e Tedia $^{\circledR}$ (EUA). Trietilamina (TEA) e diclorometano (DCM) foram previamente secos com hidreto de cálcio e destilados antes do uso.

As reações foram realizadas sob agitação magnética, à temperatura ambiente ou em aquecimento. Para as reações realizadas sob radiação micro-ondas foi utilizado micro-ondas doméstico Brastemp ${ }^{\circledR}$, modelo BMK38ABHNA JetDeFrost com capacidade de $38 \mathrm{~L}$ e potência de $900 \mathrm{~W}$ sem agitação magnética. A reação de hidrogenação foi realizada em aparelho da série 3910 da Parr Instrument Company ${ }^{\odot}$.

As reações foram monitoradas por cromatografia em camada delgada (CCD) por meio de cromatofolhas $(5,0 \times 1,5 \mathrm{~cm})$ de alumínio de Kieselgel 60 F254 com espessura de 0,25 mm (SILICYCLE®) e reveladas em de lâmpada de UV (254-366 $\mathrm{nm}$ ), o que permitiu o cálculo do fator de retenção (Rf) de cada substância. Para a purificação dos compostos, utilizou-se cromatografia em coluna de sílica gel G60 (70-230 mesh) SILICYCLE ${ }^{\circledR}$. O método de recristalização também foi utilizado para purificação de alguns derivados. Os pontos de fusão, não corrigidos, foram determinados em aparelho MQAPF-302.

A evaporação dos solventes foi realizada em evaporador rotatório Tecnal ${ }^{\circledR} \mathrm{TE}$ 211 , à pressão reduzida, variando entre 10 e $0,1 \mathrm{mmHg}$, e em temperaturas entre 40 e $60 \stackrel{\circ}{\circ}$.

Os espectros de ressonância magnética nuclear de hidrogênio ( ${ }^{1} \mathrm{H}$ RMN - 300 $\mathrm{MHz}$ ou $500 \mathrm{MHz}$ ) e carbono-13 $\left({ }^{13} \mathrm{C} \mathrm{RMN}-75 \mathrm{MHz}\right.$ ou $125 \mathrm{MHz}$ ) foram obtidos em aparelho Brucker Avance DRX300 e DRX500 do Centro Nordestino de Aplicação da Ressonância Magnética Nuclear (CENAUREMN) da Universidade Federal do Ceará 
(UFC), utilizando tetrametilsilano (TMS) como referência interna. Os valores de deslocamento químico $(\delta)$ são referidos em parte por milhão $(\mathrm{ppm})$ em relação ao TMS e as constantes de acoplamento $(\mathcal{J})$ em Hertz $(\mathrm{Hz})$. As áreas dos sinais foram obtidas por integração eletrônica e suas multiplicidades descritas como: simpleto (s); sinal largo (sl); dupleto (d); tripleto (t); quarteto (q); quinteto (qi) e multipleto (m).

Os espectros na região do infravermelho (IV) foram realizados na Central Analítica da UCB e foram obtidos por espectrofotômetro Perkin Elmer Spectrum BX, utilizando pastilhas de brometo de potássio $(\mathrm{KBr})$ ou na forma de filme líquido em placa de cloreto de sódio $(\mathrm{NaCl})$. Os valores para as absorções $\left(v_{\text {máx }}\right)$ são referidos em números de ondas, utilizando como unidade o centímetro recíproco $\left(\mathrm{cm}^{-1}\right)$.

As estruturas gerais foram padronizadas para facilitar análise dos espectros, como mostradas na Figura 12.

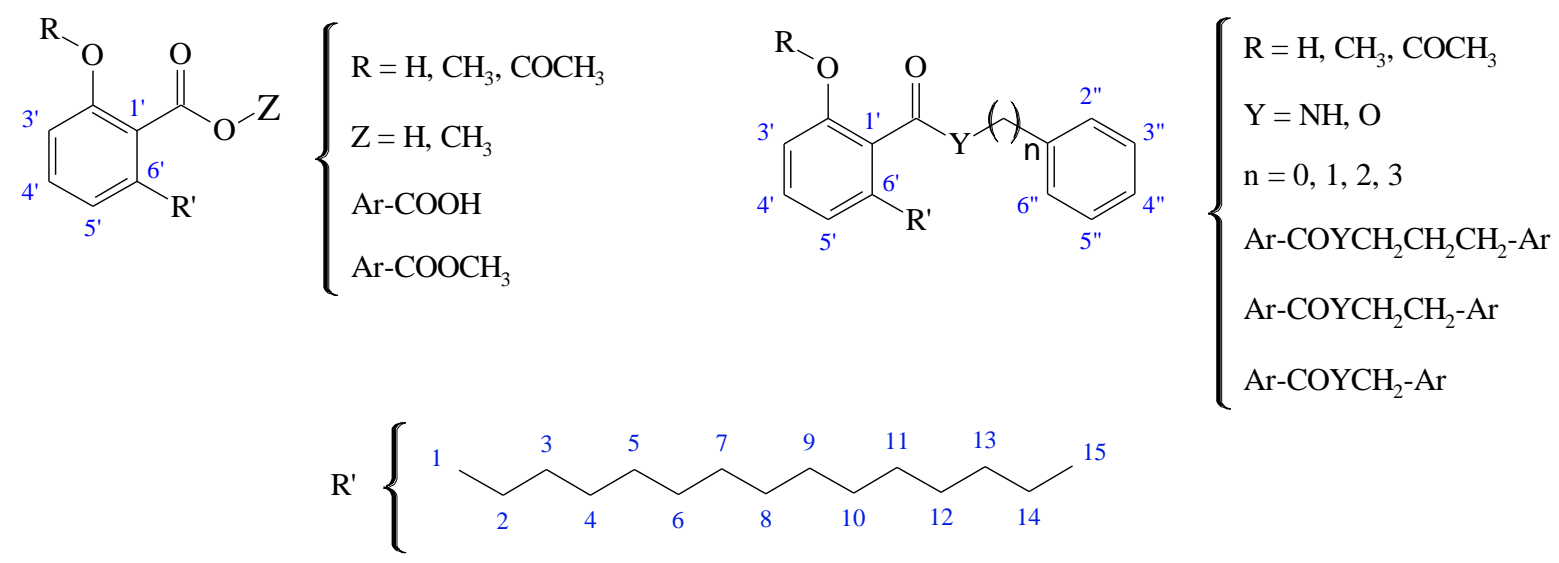

Figura 12: Numeração e legendas empregadas no assinalamento de sinais em $\mathrm{RMN}{ }^{1} \mathrm{H}$ e $\mathrm{RMN}{ }^{13} \mathrm{C}$ Fonte: Próprio autor

A avaliação biológica frente à p300 foi realizada pelo grupo do Prof. Masoud Vedadi do Structural Genomics Consortium (SGC) da Universidade de Toronto por meio de ensaio baseado em radioatividade, em que se avaliou a atividade da enzima na presença dos compostos testados por meio da transferência do grupo acetil de ${ }^{3} \mathrm{H}$-AcetilCoa para a histona H3. Para avaliação biológica frente a PPAR- $\alpha$ e PPAR$\mathrm{Y}$, o ensaio de gene repórter foi realizado foi realizada no Nuclear Hormone Receptors in Human Health and Disease Laboratory coordenado pela Dra. Carolyn Cummins da Faculdade de Farmácia Leslie Dan da Universidade de Toronto, a fim de visualizar a capacidade de emissão de luz luciferase, indicativa da indução da transcrição gênica do receptor. 


\subsection{METODOLOGIA SINTÉTICA E CARACTERIZAÇÃO DOS COMPOSTOS}

\subsubsection{Extração de LCC}

Ao sistema de extração Soxhlet foram adicionadas $150,00 \mathrm{~g}$ de casca da castanha de caju e etanol absoluto $(400,0 \mathrm{~mL})$. O sistema foi mantido em aquecimento em manta por 4 horas. Em seguida, o balão coletor foi trocado e uma nova extração realizada nas mesmas condições. Em ambos os casos, o solvente foi evaporado à pressão reduzida, fornecendo $60,00 \mathrm{~g}$ de LCC natural, como um líquido marrom, em rendimento de $40 \%$ em relação à massa de casca de castanhas.

\subsubsection{Obtenção de Ácidos Anacárdicos a Partir do LCC Natural}

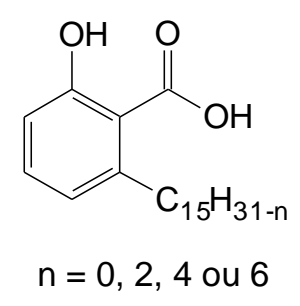

Em um balão $(50 \mathrm{~mL}$ ) foram adicionados $30,00 \mathrm{~g}$ de LCC natural ( 86,08 $\mathrm{mmol}), 15,00 \mathrm{~g}$ de $\mathrm{Ca}(\mathrm{OH})_{2}(202,45 \mathrm{mmol})$ em mistura de metanol $(180,0 \mathrm{~mL})$ e água $(30,0 \mathrm{~mL})$. O sistema reacional permaneceu em agitação e refluxo por 3 horas. Em seguida, a mistura foi resfriada à temperatura ambiente e filtrada. $O$ sólido obtido foi lavado com acetato de etila para a remoção dos outros componentes do LCC. Os sais de cálcio formados foram tratados com solução de $\mathrm{HCl} 50 \%$ até $\mathrm{pH} 1,0$ visando a liberação da mistura de ácidos anacárdicos, os quais foram extraídos com acetato de etila $(3 \times 50,0 \mathrm{~mL})$. As fases orgânicas reunidas foram lavadas com solução saturada de cloreto de sódio e secas em sulfato de sódio anidro. Após remoção do solvente à pressão reduzida, a mistura foi purificada em coluna cromatográfica de gel de sílica, eluída em mistura de hexano e acetato de etila $20 \%$, fornecendo a mistura de ácidos anacárdicos (1) em rendimento de $70 \%$. 


\subsubsection{Obtenção do Derivado Ácido 2-Hidróxi-6-pentadecilbenzóico (LDT11, 16)}

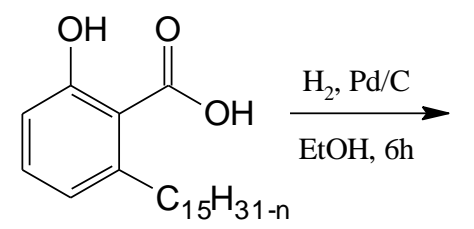

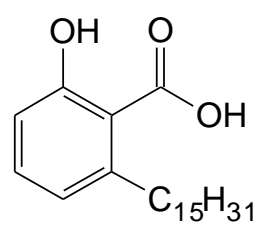

LDT11

Em frasco de hidrogenação foram adicionados $5,00 \mathrm{~g}$ da mistura de ácidos anacárdicos ( 14,35 mmol), 0,20 g de catalisador paládio-carvão a 10\% $(\mathrm{Pd} / \mathrm{C}) \mathrm{e}$ etanol $(50,0 \mathrm{~mL})$. O sistema foi submetido à pressão de 60 psi em reator Paar, à temperatura ambiente por 6 horas. Em seguida, a mistura foi filtrada em funil sinterizado e o solvente removido à pressão reduzida. O resíduo foi recristalizado em hexano, fornecendo 3,50 g do ácido 2-hidróxi-6-pentadecilbenzóico (LDT11, 16).

\section{Derivado Ácido 2-hidróxi-6-pentadecilbenzóico (LDT11, 16)}

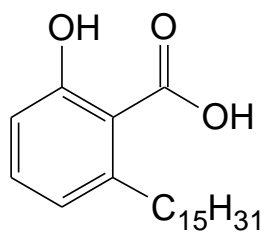

Sólido branco

Rendimento $70 \%$

$R_{f}: 0,48$ (Hex $80 \%:$ AcOEt $\left._{20 \%}\right)$

Ponto de fusão: $81-84^{\circ} \mathrm{C}$

Fórmula molecular: $\mathrm{C}_{22} \mathrm{H}_{36} \mathrm{O}_{3}$

IV (KBr) $v_{\text {máx }} \mathrm{cm}^{-1}: 3326\left(\mathrm{v}_{\mathrm{OH}}\right) ; 2954\left(v_{\mathrm{asCH} 3}\right) ; \quad$ Massa Molar: 348,519 g/mol $2920\left(v_{\text {asCH2 }}\right) ; 2850\left(v_{\mathrm{SCH}}\right) ; 1610\left(v_{\mathrm{C}=0}\right) ; 1560,1542,1498$ e $1466\left(v_{\mathrm{C}=\mathrm{C}}\right) ; 1287\left(v_{\text {asC }}\right.$ o); $1086\left(v_{\text {Sc-o }}\right)$.

RMN ${ }^{1} \mathrm{H}\left(300 \mathrm{MHz}, \mathrm{CDCl}_{3}\right): \delta 0,89$ (t, $\left.J=6,5 \mathrm{~Hz}, 3 \mathrm{H}, 15\right) ; 1,26$ (sl, 24H, 3-14); 1,571,62 (m, 2H, 2); 3,00 (t, $J=7,7 \mathrm{~Hz}, 2 \mathrm{H}, 1) ; 6,79$ (d, $J=7,4 \mathrm{~Hz}, 1 \mathrm{H}, 3$ ); 6,89 (d, $J=$ $\left.8,0 \mathrm{~Hz}, 1 \mathrm{H}, 5^{\prime}\right) ; 7,37\left(\mathrm{t}, J=7,9 \mathrm{~Hz}, 1 \mathrm{H}, 4^{\prime}\right) ; 10,79$ (s, 1H, $\left.\mathrm{ArO} \underline{\mathrm{H}}\right)$.

RMN ${ }^{13} \mathrm{C}\left(75 \mathrm{MHz}, \mathrm{CDCl}_{3}\right): \delta$ 14,3 $\left(\underline{\mathrm{CH}}_{3}, 15\right) ; 22,9\left(\underline{\mathrm{CH}}_{2}, 14\right) ; 29,6-30,0\left(\underline{\mathrm{CH}} \mathrm{H}_{2}, 3-12\right)$; $32,1\left(\underline{\mathrm{C}} \mathrm{H}_{2}, 2\right) ; 32,2\left(\underline{\mathrm{C}} \mathrm{H}_{2}, 13\right) ; 36,7\left(\underline{\mathrm{CH}}_{2}, 1\right) ; 110,6$ (Ar $\left.\underline{\mathrm{C}}, 1^{\prime}\right) ; 116,1$ (Ar$\left.\underline{\mathrm{CH}}, 3^{\prime}\right) ; 123,0$

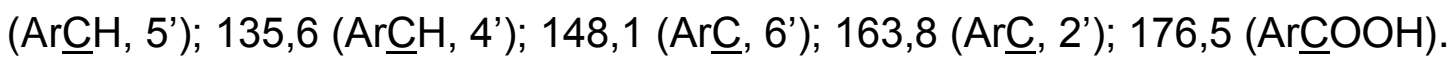




\subsubsection{Obtenção do Derivado Ácido 2-Acetóxi-6-pentadecilbenzóico (LDT13, 17)}

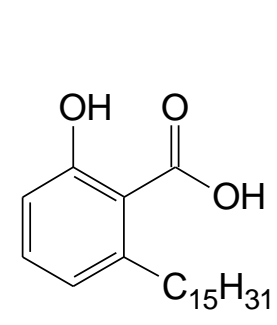

LDT11

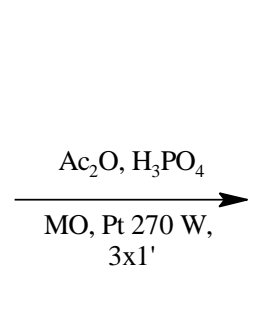<smiles>CC(=O)Oc1cccc(C(C)(F)F)c1C(=O)O</smiles>

LDT13

Em erlenmeyer $(50 \mathrm{~mL}$ ) foram adicionados $3,00 \mathrm{~g}$ do derivado LDT11 (16) (8,61 mmol), ácido fosfórico (6 gotas) e 3,24 $\mathrm{mL}$ de anidrido acético $(34,43 \mathrm{mmol})$. A mistura foi submetida à radiação micro-ondas por 3 minutos $\left(3 \times 1^{\prime}\right)$ em potência de $30 \%$ (270 W). Em seguida, a mistura foi solubilizada em acetato de etila $(20,0 \mathrm{~mL}) \mathrm{e}$ lavada com soluções de bicarbonato de sódio $5 \%$ (3 × 20,0 mL), HCl 10\% (20,0 mL), saturada de cloreto de sódio $(20,0 \mathrm{~mL})$, e seca com sulfato de sódio. Após o solvente ser removido à pressão reduzida, o resíduo foi purificado em coluna cromatográfica de gel de sílica, eluída em mistura de hexano e acetato de etila em diferentes concentrações (5-50\%), fornecendo 2,55 g do derivado ácido 2-acetóxi-6pentadecilbenzóico (LDT13, 17).

\section{Derivado Ácido 2-Acetóxi-6-pentadecilbenzóico (LDT13, 17)}<smiles>CC(=O)Oc1cccc(C(C)=O)c1C(=O)O</smiles>

Sólido branco

Rendimento $76 \%$

$\mathrm{R}_{\mathrm{f}}:$ 0,20 (Hex (Ho\%: $\left._{80 \mathrm{AcO}} \mathrm{A}_{20 \%}\right)$

Ponto de fusão: $65-69^{\circ} \mathrm{C}$

Fórmula molecular: $\mathrm{C}_{24} \mathrm{H}_{38} \mathrm{O}_{4}$

Massa Molar: 390,556 g/mol

IV (KBr) $v_{\text {máx }} \mathrm{Cm}^{-1}: 2922\left(v_{\mathrm{asCH} 2}\right) ; 2850\left(v_{\mathrm{SCH} 2}\right) ; 1763\left(v_{\mathrm{C}=\mathrm{O}}\right) ; 1701\left(v_{\mathrm{C}=\mathrm{O}}\right) ; 1465\left(v_{\mathrm{C}=\mathrm{C}}\right)$; $1369\left(v_{\mathrm{CH} 3}\right) ; 1221$ ( $\left.v_{\text {asC-O }}\right)$.

RMN ${ }^{1} \mathrm{H}\left(300 \mathrm{MHz}, \mathrm{CDCl}_{3}\right): \delta 0,89$ (t, $\left.J=6,6 \mathrm{~Hz}, 3 \mathrm{H}, 15\right) ; 1,26-1,31$ (m, 24H, 3-14); 1,60-1,67 (m, 2H, 2); 2,30 (s, 3H, ArOCOCH $\left.{ }_{3}\right) ; 2,81(\mathrm{t}, J=7,8 \mathrm{~Hz}, 2 \mathrm{H}, 1) ; 7,01$ (d, $J=$ $\left.8,0 \mathrm{~Hz}, 1 \mathrm{H}, 3^{\prime}\right) ; 7,17$ (d, J=7,5 Hz, 1H, 5'); 7,41 (t, $J=7,9 \mathrm{~Hz}, 1 \mathrm{H}, 4^{\prime}$ ).

$\operatorname{RMN}{ }^{13} \mathrm{C}\left(75 \mathrm{MHz}, \mathrm{CDCl}_{3}\right): \delta 14,3\left(\underline{\mathrm{CH}}_{3}, 15\right) ; 21,0\left(\mathrm{ArOCOCH}_{3}\right) ; 22,9\left(\underline{\mathrm{CH}}_{2}, 14\right) ; 29,5-$ $29,9\left(\underline{\mathrm{CH}}_{2}, 3-12\right) ; 31,6\left(\underline{\mathrm{C}} \mathrm{H}_{2}, 2\right) ; 32,1\left(\underline{\mathrm{CH}}_{2}, 13\right) ; 34,1\left(\underline{\mathrm{CH}}_{2}, 1\right) ; 120,8(\mathrm{Ar} \underline{\mathrm{CH}}, 3)$ ); 125,0 


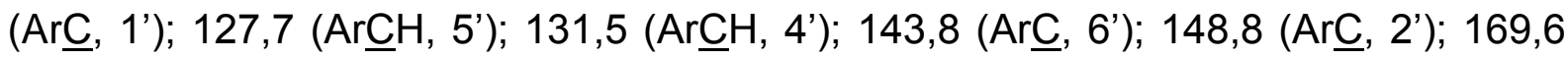
$\left(\mathrm{ArO}_{\mathbf{C O C H}}\right) ; 172,1$ (Ar $\left.\underline{\mathrm{COOH}}\right)$.

\subsubsection{Obtenção do Derivado 2-Metóxi-6-pentadecilbezoato de metila (LDT28, 18)}

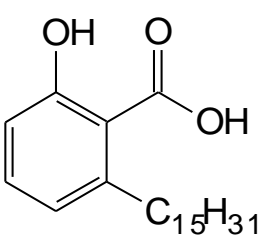

LDT11

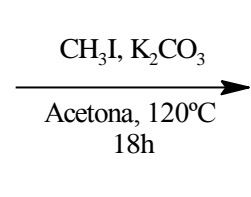

Em um balão (100 $\mathrm{mL}$ ) foram adicionados $2,00 \mathrm{~g}$ do derivado LDT11 (16) (5,74 mmol), 2,38 $\mathrm{g}$ de carbonato de potássio $(17,22 \mathrm{mmol})$ e acetona $(50,0 \mathrm{~mL})$. A mistura permaneceu sob agitação magnética por 20 minutos e a ela foram adicionados $1,49 \mathrm{~mL}$ de iodeto de metila $(22,95 \mathrm{mmol})$. Em seguida, o sistema reacional foi mantido sob agitação vigorosa, em banho de óleo à $120^{\circ} \mathrm{C}$, com resfriamento do condensador em circulador a $-8^{\circ} \mathrm{C}$, por 18 horas. Após esse período, o solvente foi evaporado à pressão reduzida e ao resíduo foram adicionados éter etílico (30,0 mL) e água destilada para a solubilização do carbonato de potássio. Após separação de fases, a fase aquosa foi retirada, a fase orgânica foi lavada com soluções de $\mathrm{HCl} 10 \%(2 \times 15,0 \mathrm{~mL})$ e concentrada de cloreto de sódio $(20,0 \mathrm{~mL})$, e então seca com sulfato de sódio. Após o solvente ser removido à pressão reduzida, a mistura foi purificada em coluna cromatográfica de gel de sílica, eluída em diferentes concentrações de mistura hexano-acetato de etila (5-35\%), fornecendo 2,09 g do derivado 2-metóxi-6-pentadecilbezoato de metila (LDT28, 18).

Derivado 2-Metóxi-6-pentadecilbezoato de metila (LDT28, 18)

Sólido branco<smiles>CCCCCCc1cccc(OC)c1C(=O)OC</smiles>

Rendimento $97 \%$

$\mathrm{R}_{\mathrm{f}}:$ 0,40 (Hex ${ }_{90 \%}:$ AcOEt $_{10 \%}$ )

Ponto de fusão: $32-33^{\circ} \mathrm{C}$

Fórmula molecular: $\mathrm{C}_{24} \mathrm{H}_{40} \mathrm{O}_{3}$

Massa Molar: $376,573 \mathrm{~g} / \mathrm{mol}$ 
IV (KBr) $v_{\text {máx }} \mathrm{cm}^{-1}: 2918\left(v_{\text {asCH2}}\right) ; 2850\left(v_{\mathrm{SCH} 2}\right) ; 1733\left(v_{\mathrm{C}=\mathrm{O}}\right) ; 1586,1466\left(v_{\mathrm{C}=\mathrm{C}}\right) ; 1266$ $\left(v_{\text {asc-o }}\right)$.

RMN ${ }^{1} \mathrm{H}\left(300 \mathrm{MHz}, \mathrm{CDCl}_{3}\right): \delta \quad 0,89(\mathrm{t}, J=6,3 \mathrm{~Hz}, 3 \mathrm{H}, 15) ; 1,26$ (m, 24H, 3-14); 1,53$1,61(\mathrm{~m}, 2 \mathrm{H}, 2) ; 2,55$ (t, $J=7,8 \mathrm{~Hz}, 2 \mathrm{H}, 1) ; 3,82$ (s, $\left.3 \mathrm{H}, \operatorname{ArOC}_{3}\right) ; 3,91$ (s, $3 \mathrm{H}$, $\left.\operatorname{ArCOOC} \underline{H}_{3}\right) ; 6,76\left(\mathrm{~d}, J=8,3 \mathrm{~Hz}, 1 \mathrm{H}, 3^{\prime}\right) ; 6,82\left(\mathrm{~d}, J=7,6 \mathrm{~Hz}, 1 \mathrm{H}, 5^{\prime}\right) ; 7,27$ (t, $J=7,9$ $\left.\mathrm{Hz}, 1 \mathrm{H}, 4^{\prime}\right)$.

$\mathrm{RMN}{ }^{13} \mathrm{C}\left(75 \mathrm{MHz}, \mathrm{CDCl}_{3}\right): \delta 14,2\left(\underline{\mathrm{CH}}_{3}, 15\right) ; 22,8\left(\underline{\mathrm{CH}}_{2}, 14\right) 29,5-29,8\left(\underline{\mathrm{C}} \mathrm{H}_{2}, 3-12\right)$; $31,3\left(\underline{\mathrm{CH}}_{2}, 2\right) ; 32,1\left(\underline{\mathrm{CH}}_{2}, 13\right) ; 33,6\left(\underline{\mathrm{C}} \mathrm{H}_{2}, 1\right) ; 52,2\left(\mathrm{ArCOO} \underline{C H}_{3}\right) ; 56,0\left(\mathrm{ArO}^{2} \mathrm{H}_{3}\right) ; 108,5$

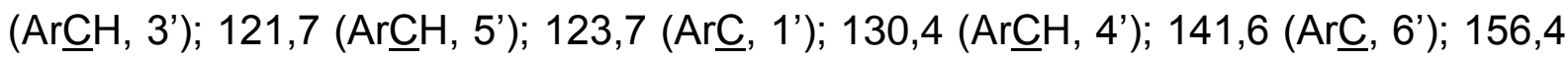

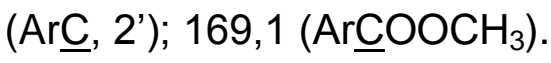

\subsubsection{Obtenção do Derivado 2-Hidróxi-6-pentadecilbenzoato de metila (LDT29,} 19)<smiles>[13CH3]c1cccc(O)c1C(=O)O</smiles>

LDT11<smiles>CCCCCCCCOc1ccccc1</smiles>

LDT29

Em um balão (100 $\mathrm{mL})$ foram adicionados $0,20 \mathrm{~g}$ de LDT11 (16) $(0,57 \mathrm{mmol})$, $1,50 \mathrm{~mL}$ de $\mathrm{H}_{2} \mathrm{SO}_{4}$ e metanol $(8,0 \mathrm{~mL})$. O sistema reacional permaneceu em agitação e refluxo por 18 horas. Em seguida, a mistura foi extraída com diclorometano $(3 \times 10,0 \mathrm{~mL})$ e a fase orgânica lavada com solução saturada de cloreto de sódio $(10,0 \mathrm{~mL})$ e seca com sulfato de sódio. Após o solvente ser removido sob pressão reduzida, a mistura foi purificada em coluna cromatográfica de gel de sílica, eluída com mistura de hexano e acetato de etila (5-55\%), fornecendo 0,18 g do derivado 2-hidróxi-6-pentadecilbenzoato de metila (LDT29, 19). 
Derivado 2-Hidróxi-6-pentadecilbenzoato de metila

Sólido branco

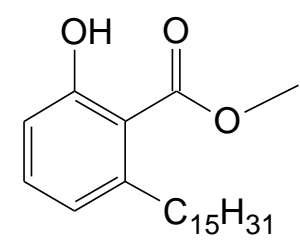

Rendimento $86 \%$

$\mathrm{R}_{\mathrm{f}}:$ 0,60 (Hex $\left.\mathrm{H}_{80 \%}: \mathrm{AcOEt}_{20 \%}\right)$

Ponto de fusão: $37-40^{\circ} \mathrm{C}$

Fórmula molecular: $\mathrm{C}_{23} \mathrm{H}_{38} \mathrm{O}_{3}$

Massa Molar: $362,546 \mathrm{~g} / \mathrm{mol}$

IV $(\mathrm{KBr}) v_{\text {máx }} \mathrm{Cm}^{-1}: 3433\left(v_{\mathrm{OH}}\right) ; 2917\left(v_{\mathrm{asCH} 2}\right) ; 2851\left(v_{\mathrm{SCH} 2}\right) ; 1663\left(v_{\mathrm{C}=\mathrm{O}}\right) ; 1451\left(v_{\mathrm{C}=\mathrm{C}}\right)$; $1250,1203\left(v_{\text {asc }}-0\right)$.

RMN ${ }^{1} \mathrm{H}\left(500 \mathrm{MHz}, \mathrm{CDCl}_{3}\right): \delta 0,89$ (t, $\left.J=6,8 \mathrm{~Hz}, 3 \mathrm{H}, 15\right) ; 1,27-1,32(\mathrm{~m}, 29 \mathrm{H}, 3-14)$; 1,51-1,55 (m, 2H, 2); 2,89 (t, $J=7,8 \mathrm{~Hz}, 2 \mathrm{H}, 1), 3,96\left(\mathrm{~s}, 1 \mathrm{H}, \operatorname{ArCOOC}_{3}\right) ; 6,73(\mathrm{~d}, J=$ $\left.7,3 \mathrm{~Hz}, 1 \mathrm{H}, 3^{\prime}\right) ; 6,84\left(\mathrm{~d}, J=8,1 \mathrm{~Hz}, 1 \mathrm{H}, 5^{\prime}\right) ; 7,27-7,31\left(\mathrm{~m}, 1 \mathrm{H}, 4^{\prime}\right) ; 11,06(\mathrm{~s}, 1 \mathrm{H}$, $\mathrm{ArOH})$.

$\mathrm{RMN}{ }^{13} \mathrm{C}\left(125 \mathrm{MHz}, \mathrm{CDCl}_{3}\right): \delta 14,2\left(\underline{\mathrm{CH}}_{3}, 15\right) ; 22,9\left(\underline{\mathrm{CH}}_{2}, 14\right) ; 29,5-30,1\left(\underline{\mathrm{C}}_{2}, 3-12\right)$; $32,1\left(\underline{\mathrm{CH}}_{2}, 2\right) ; 32,3\left(\underline{\mathrm{CH}}_{2}, 13\right) ; 36,8\left(\underline{\mathrm{CH}}_{2}, 1\right) ; 52,3\left(\mathrm{ArCOO} \underline{\mathrm{C}} \mathrm{H}_{3}\right) ; 112,0(\mathrm{Ar} \underline{\mathrm{C}}, 1$ '); 115,8

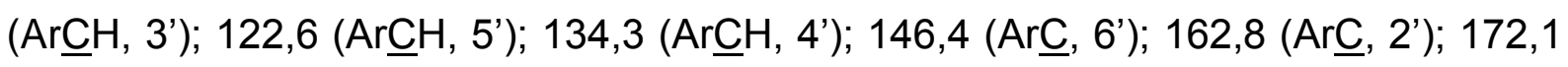
$(\mathrm{Ar} \underline{\mathrm{COOCH}})_{3}$.

\subsubsection{Obtenção do Derivado Ácido 2-Metóxi-6-pentadecilbenzóico (LDT30, 20)}

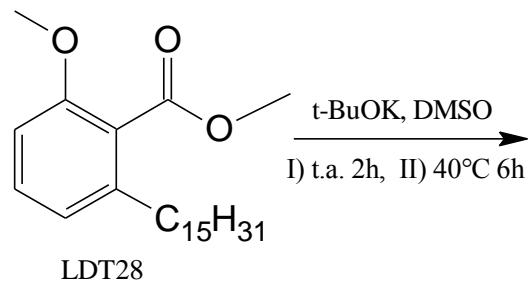

LDT28

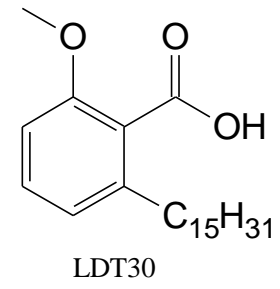

LDT30

Em um balão (100 mL) foram adicionados $4,00 \mathrm{~g}$ do derivado LDT28 (18) (10,62 mmol), 1,29 g de tert-butóxido de potássio $(10,62 \mathrm{mmol})$ e DMSO $(20,0 \mathrm{~mL})$ e foi mantido sob agitação à temperatura ambiente por 2 horas. Em seguida, foi 
submetido ao aquecimento de $40^{\circ} \mathrm{C}$ em banho de óleo por 16 horas. A mistura foi extraída com acetado de etila $(3 \times 15,0 \mathrm{~mL})$ e a fase orgânica lavada com água destilada $(20,0 \mathrm{~mL})$ e acidificada a pH 2,0 com solução de $\mathrm{HCl} 10 \%$. Finalmente, a fase orgânica foi lavada com solução saturada de cloreto de sódio $(20,0 \mathrm{~mL})$, seca com sulfato de sódio e o solvente evaporado à pressão reduzida. O resíduo foi purificado em coluna cromatográfica de gel de sílica, eluída em diferentes concentrações de hexano e acetato de etila (5-50\%), fornecendo $3,77 \mathrm{~g}$ do derivado ácido 2-metóxi-6-pentadecilbenzóico (LDT30, 20).

\section{Derivado Ácido 2-Metóxi-6-pentadecilbenzóico (LDT30, 20)}

Sólido branco<smiles>COc1cccc(C(C)(C)C)c1C(=O)O</smiles>

Rendimento $98 \%$

$\mathrm{R}_{\mathrm{f}}:$ 0,28 (Hex $\left.\mathrm{H}_{80 \%}: \mathrm{AcOEt}_{20 \%}\right)$

Ponto de fusão: $74-77^{\circ} \mathrm{C}$

Fórmula molecular: $\mathrm{C}_{23} \mathrm{H}_{38} \mathrm{O}_{3}$

Massa Molar: $362,546 \mathrm{~g} / \mathrm{mol}$

IV (KBr) $v_{\text {máx }} \mathrm{cm}^{-1}: 3365\left(v_{\mathrm{OH}}\right) ; 2954\left(v_{\mathrm{asCH}}\right) ; 2920\left(v_{\mathrm{asCH}}\right) ; 2848\left(v_{\mathrm{SCH} 2}\right) ; 1715\left(v_{\mathrm{C}=\mathrm{O}}\right)$; 1585, 1473, 1460, $1437\left(v_{\mathrm{C}=\mathrm{C}}\right) ; 1316\left(v_{\mathrm{CH} 3}\right) ; 1266$ ( $\left.v_{\text {asC }-\mathrm{O}}\right)$;

$\mathrm{RMN}^{1} \mathrm{H}\left(300 \mathrm{MHz}, \mathrm{CDCl}_{3}\right): \delta 0,89$ (t, $\left.J=6,6 \mathrm{~Hz}, 3 \mathrm{H}, 15\right) ; 1,26-1,33(\mathrm{~m}, 24 \mathrm{H}, 3-14)$; 1,60-1,67 (m, 2H, 2); 2,73 (t, $J=7,8 \mathrm{~Hz}, 2 \mathrm{H}, 1$ ); 3,89 (s, 3H, $\operatorname{ArOC}_{3}$ ); 6,81 (d, $J=$ $\left.8,2 \mathrm{~Hz}, 1 \mathrm{H}, 3^{\prime}\right) ; 6,88\left(\mathrm{~d}, J=7,6 \mathrm{~Hz}, 1 \mathrm{H}, 5^{\prime}\right) ; 7,27-7,34\left(\mathrm{~m}, 1 \mathrm{H}, 4^{\prime}\right)$.

$\mathrm{RMN}{ }^{13} \mathrm{C}\left(75 \mathrm{MHz}, \mathrm{CDCl}_{3}\right): \delta 14,3\left(\underline{\mathrm{CH}}_{3}, 15\right) ; 22,9\left(\underline{\mathrm{C}} \mathrm{H}_{2}, 14\right) ; 29,5-29,9\left(\underline{\mathrm{CH}}_{2}, 3-12\right)$; $31,5\left(\underline{\mathrm{CH}}_{2}, 2\right) ; 32,1\left(\underline{\mathrm{CH}}_{2}, 13\right) ; 33,9\left(\underline{\mathrm{CH}}_{2}, 1\right) ; 56,2\left(\mathrm{ArO} \underline{\mathrm{C}} \mathrm{H}_{3}\right) ; 108,8$ (Ar $\left.\underline{\mathrm{CH}}, 3\right) ; 122,2$

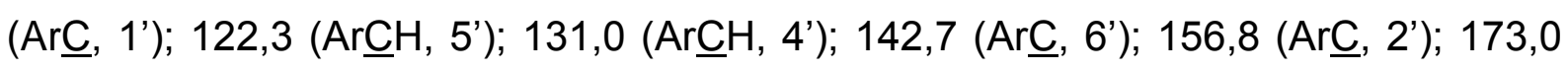
$(\mathrm{Ar} \underline{\mathrm{COOH}})$. 


\subsubsection{Obtenção do Derivado 2-(Acetóxi)-6-pentadecilbenzoato de metila (LDT208, 21)}

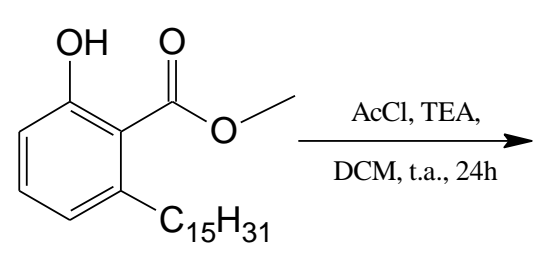

LDT29

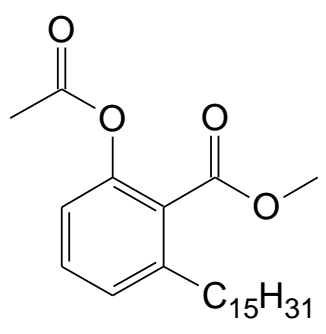

LDT208

Em um balão (25 mL) foram adicionados $0,20 \mathrm{~g}$ do derivado LDT29 (19) $(0,55$ $\mathrm{mmol}$ ), 0,23 $\mathrm{mL}$ de TEA (1,67 mmol) e 0,06 $\mathrm{mL}$ cloreto de acetila, em diclorometano seco $(6,0 \mathrm{~mL})$. A mistura permaneceu sob agitação à temperatura ambiente por 24 horas. Em seguida, foi lavada com água destilada e extraída com acetato de etila (3 $x 10,0 \mathrm{~mL}$ ). As fases orgânicas reunidas foram lavadas com soluções de bicarbonato de sódio $5 \%(3 \times 10,0 \mathrm{~mL}), \mathrm{HCl} 10 \%(2 \times 10,0 \mathrm{~mL})$ e saturada de cloreto de sódio $(10,0 \mathrm{~mL})$. Após de secagem em sulfato de sódio e remoção do solvente à pressão reduzida, o resíduo foi purificado em coluna cromatográfica de gel de sílica, eluída em mistura de hexano e acetato de etila em diferentes concentrações (5-50\%), fornecendo 0,13 g do derivado 2-(acetóxi)-6-pentadecilbenzoato de metila (LDT208, 21).

Derivado 2-(Acetóxi)-6-pentadecilbenzoato de metila (LDT208, 21)

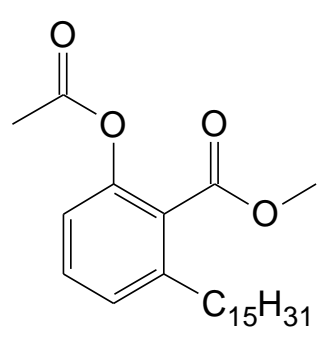

Sólido branco

Rendimento $58 \%$

$\mathrm{R}_{\mathrm{f}}:$ 0,44 (Hex $\left.\mathrm{H}_{80 \%}: \mathrm{AcOEt}_{20 \%}\right)$

Ponto de fusão: $30-35^{\circ} \mathrm{C}$

Fórmula molecular: $\mathrm{C}_{25} \mathrm{H}_{40} \mathrm{O}_{4}$

Massa Molar: 404,583 g/mol

IV $(\mathrm{KBr}) v_{\text {máx }} \mathrm{Cm}^{-1}: 2916\left(v_{\mathrm{asCH} 2}\right) ; 2850\left(v_{\mathrm{SCH} 2}\right) ; 1731\left(v_{\mathrm{C}=\mathrm{O}}\right) ; 1473\left(v_{\mathrm{C}=\mathrm{C}}\right) ; 1368\left(v_{\mathrm{CH} 3}\right)$; 1246 ( $\left.v_{\text {asc-o }}\right)$; 
$\mathrm{RMN}^{1} \mathrm{H}\left(300 \mathrm{MHz}, \mathrm{CDCl}_{3}\right): \delta 0,89$ (t, $\left.J=6,3 \mathrm{~Hz}, 3 \mathrm{H}, 15\right) ; 1,26$ (m, 24H, 3-14); 1,55$1,58(\mathrm{~m}, 2 \mathrm{H}, 2) ; 2,26\left(\mathrm{~s}, 3 \mathrm{H}, \operatorname{ArOCOC}_{3}\right) ; 2,67$ (t, $\left.J=7,8 \mathrm{~Hz}, 2 \mathrm{H}, 1\right) ; 3,87$ (s, 3H, $\left.\operatorname{ArCOOC}_{3}\right) ; 6,97(\mathrm{~d}, J=8,0 \mathrm{~Hz}, 1 \mathrm{H}, 3$ '); 7,12 (d, $J=7,6 \mathrm{~Hz}, 1 \mathrm{H}, 5$ '); 7,35 (t, $J=7,9$ $\left.\mathrm{Hz}, 1 \mathrm{H}, 4^{\prime}\right)$.

$\mathrm{RMN}{ }^{13} \mathrm{C}\left(75 \mathrm{MHz}, \mathrm{CDCl}_{3}\right): \delta$ 14,2 $\left(\underline{\mathrm{CH}}_{3}, 15\right) ; 20,9\left(\mathrm{ArOCO} \mathrm{H}_{3}\right) ; 22,8\left(\underline{\mathrm{CH}}_{2}, 14\right) ; 29,5-$ $29,8\left(\underline{\mathrm{CH}}_{2}, 3-12\right) ; 31,5\left(\underline{\mathrm{C}} \mathrm{H}_{2}, 2\right) ; 32,1\left(\underline{\mathrm{C}} \mathrm{H}_{2}, 13\right) ; 34,9\left(\underline{\mathrm{CH}}_{2}, 1\right) ; 52,3\left(\mathrm{ArCOO} \underline{\mathrm{C}} \mathrm{H}_{3}\right)$;

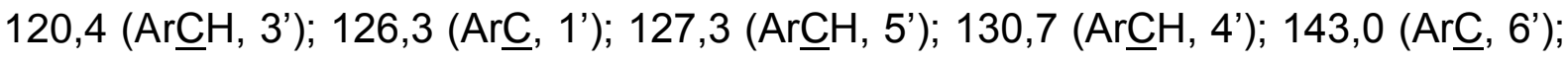

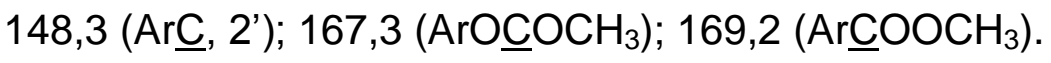

\subsubsection{Obtenção dos Derivados Amidas e Ésteres: 2'-Metoxissubstituídos}<smiles>CCCCCCc1cccc(OC)c1C(=O)O</smiles>
LDT30

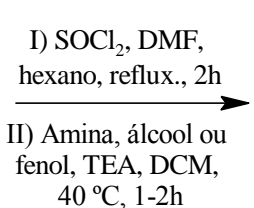
$40{ }^{\circ} \mathrm{C}, 1-2 \mathrm{~h}$

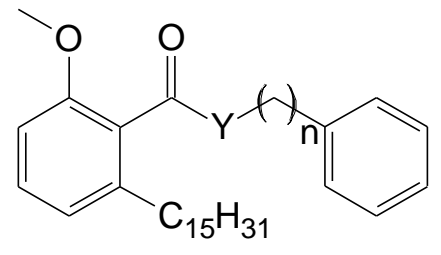

$\mathrm{n}=0,1,2$ e 3

$\mathrm{Y}=\mathrm{NH}($ LDT651, LDT653, LDT655, LDT657)

$\mathrm{Y}=\mathrm{O}($ LDT667, LDT669, LDT671, LDT673)

Em um balão $(25 \mathrm{~mL})$ foram adicionados $0,20 \mathrm{~g}$ do derivado LDT30 (20) $(0,55$ $\mathrm{mmol}), 1,50 \mathrm{~mL}$ de $\mathrm{SOCl}_{2}(17,31 \mathrm{mmol})$, DMF (1 gota) e hexano $(10,0 \mathrm{~mL})$. O sistema reacional permaneceu em agitação, à temperatura de refluxo por 2 horas. Em seguida, o excesso de $\mathrm{SOCl}_{2}$ e hexano foram destilados. O cloreto de ácido formado foi então diluído em diclorometano seco $(5,0 \mathrm{~mL})$ e lentamente adicionado a um balão $(25,0 \mathrm{~mL})$ contendo a amina, ou fenol, ou álcool correspondente $(2,00$ eqv.), $0,15 \mathrm{~mL}$ de TEA (1,10 mmol) e diclorometano (5,0 mL). A mistura permaneceu sob agitação, à temperatura de $40^{\circ} \mathrm{C}$, por 1 a 2 horas. Após esse período, a mistura foi extraída com acetato de etila $(3 \times 10,0 \mathrm{~mL})$ e as fases orgânicas reunidas lavadas com soluções de bicarbonato de sódio $5 \%(20,0 \mathrm{~mL}), \mathrm{HCl} 10 \%(20,0 \mathrm{~mL})$, saturada de cloreto de sódio $(10,0 \mathrm{~mL})$, e seca com sulfato de sódio. Após evaporação do solvente à pressão reduzida, os derivados foram purificados em coluna 
cromatográfica de gel de sílica, eluída em mistura de hexano e acetato de etila em diferentes concentrações, fornecendo os derivados correspondentes.

\section{Derivado N-Fenil-2-metóxi-6-pentadecilbenzilamida (LDT651, 22)}

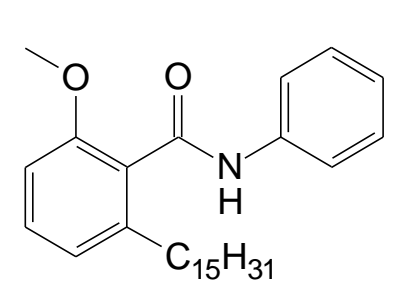

Sólido branco

Rendimento $76 \%$

$\mathrm{R}_{\mathrm{f}}:$ 0,33 (Hex $\left.\mathrm{H}_{80 \%}: \mathrm{AcOEt}_{20 \%}\right)$

Ponto de fusão: $78-85^{\circ} \mathrm{C}$

Fórmula molecular: $\mathrm{C}_{29} \mathrm{H}_{43} \mathrm{NO}_{2}$

Massa Molar: 437,657 g/mol

IV (KBr) $v_{\text {máx }} \mathrm{cm}^{-1}: 3276\left(v_{\mathrm{NH}}\right) ; 3069\left(v_{=\mathrm{CH}}\right) ; 2919\left(v_{\mathrm{asCH} 2}\right) ; 2850\left(v_{\mathrm{SCH} 2}\right) ; 1653\left(v_{\mathrm{C}=\mathrm{O}}\right)$; $1604,1583,1551,1534,1490,1470,1438\left(v_{\mathrm{C}=\mathrm{C}}\right) ; 1264\left(v_{\mathrm{asC}-\mathrm{o}}\right)$.

$\mathrm{RMN}^{1} \mathrm{H}\left(500 \mathrm{MHz}, \mathrm{CDCl}_{3}\right): \delta 0,90(\mathrm{t}, J=6,8 \mathrm{~Hz}, 3 \mathrm{H}, 15) ; 1,23-1,33(\mathrm{~m}, 24 \mathrm{H}, 3-14)$; 1,61-1,67 (m, 2H, 2); 2,71 (t, $J=7,8 \mathrm{~Hz}, 2 \mathrm{H}, 1$ ); 3,83 (s, 3H, ArOC$\left.{ }_{3}\right) ; 6,79$ (d, J = $8,2 \mathrm{~Hz}, 1 \mathrm{H}, 3^{\prime}$ ); 6,89 (d, $\left.J=7,6 \mathrm{~Hz}, 1 \mathrm{H}, 5^{\prime}\right) ; 7,15$ (t, $J=7,3 \mathrm{~Hz}, 1 \mathrm{H}, 4$ )); 7,30 (t, $J=8,0$ $\left.\mathrm{Hz}, 1 \mathrm{H}, 4^{\prime}\right) ; 7,37$ (t, $J=7,8 \mathrm{~Hz}, 2 \mathrm{H}, 2$ " e 6"); 7,51 (s, 1H, ArCON브Ar); 7,63 (d, $J=7,7$ $\mathrm{Hz}, 2 \mathrm{H}, 3$ " e 5").

RMN ${ }^{13} \mathrm{C}\left(125 \mathrm{MHz}, \mathrm{CDCl}_{3}\right): \delta$ 14,3 $\left(\underline{\mathrm{CH}}_{3}, 15\right) ; 22,8\left(\underline{\mathrm{CH}}_{2}, 14\right) ; 29,5-29,8\left(\underline{\mathrm{CH}}_{2}, 3-12\right)$; $31,6\left(\underline{\mathrm{CH}}_{2}, 2\right) ; 32,1\left(\underline{\mathrm{CH}}_{2}, 13\right) ; 33,3\left(\underline{\mathrm{CH}}_{2}, 1\right) ; 56,0\left(\mathrm{ArO}^{\mathrm{C}} \mathrm{H}_{3}\right) ; 108,6(\mathrm{Ar} \underline{\mathrm{CH}}, 3) ; 120,0$

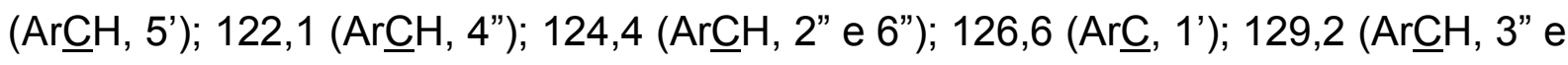

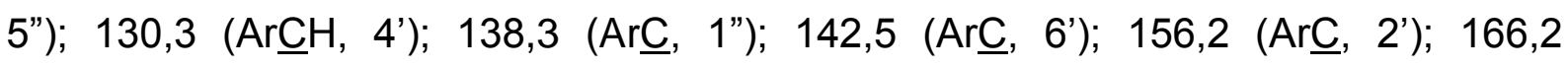
(ArㅡNNAr).

\section{Derivado N-Benzil-2-metóxi-6-pentadecilbenzilamida (LDT653, 23)}

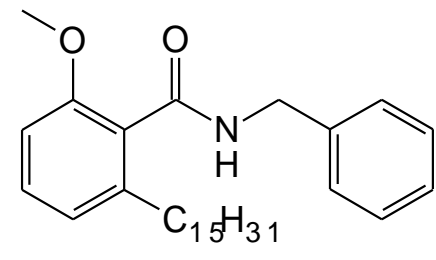

Sólido branco

Rendimento $77 \%$

$\mathrm{R}_{\mathrm{f}}:$ 0,21 (Hex $\mathrm{H}_{80 \%}: \mathrm{AcOEt}_{20 \%}$ )

Ponto de fusão: $90-99^{\circ} \mathrm{C}$

Fórmula molecular: $\mathrm{C}_{30} \mathrm{H}_{45} \mathrm{NO}_{2}$

Massa Molar: 451,684 g/mol 
IV (KBr) $v_{\text {máx }} \mathrm{cm}^{-1}: 3289\left(v_{\mathrm{NH}}\right) ; 3062\left(v_{=\mathrm{CH}}\right) ; 2919\left(v_{\mathrm{asCH} 2}\right) ; 2849\left(v_{\mathrm{SCH} 2}\right) ; 1634\left(v_{\mathrm{C}=\mathrm{O}}\right)$; 1596, 1581, 1533, 1495, 1469, $1454\left(v_{\mathrm{C}=\mathrm{C}}\right) ; 1258$ ( $\left.\mathrm{v}_{\mathrm{asC}-\mathrm{o}}\right)$.

RMN ${ }^{1} \mathrm{H}\left(300 \mathrm{MHz}, \mathrm{CDCl}_{3}\right): \delta 0,89(\mathrm{t}, J=6,4 \mathrm{~Hz}, 3 \mathrm{H}, 15) ; 1,27$ (s, 24H, 3-14); 1,56$1,60(\mathrm{~m}, 2 \mathrm{H}, 2) ; 2,63(\mathrm{t}, J=7,9 \mathrm{~Hz}, 2 \mathrm{H}, 1) ; 3,81\left(\mathrm{~s}, 3 \mathrm{H}, \operatorname{ArOC}_{3}\right) ; 4,67$ (d, $J=5,7 \mathrm{~Hz}$, $\left.2 \mathrm{H}, \operatorname{ArCONHC} \underline{H}_{2} \mathrm{Ar}\right) ; 6,01\left(\mathrm{t}, J=5,3 \mathrm{~Hz}, 1 \mathrm{H}, \operatorname{ArCON} \underline{H C H}_{2} \mathrm{Ar}\right) ; 6,74(\mathrm{~d}, J=8,2 \mathrm{~Hz}, 1 \mathrm{H}$, 3'); 6,83 (d, $\left.J=7,6 \mathrm{~Hz}, 1 \mathrm{H}, 5^{\prime}\right) ; 7,21-7,41$ (m, 6H, 4', 2", 3", 4", 5" e 6").

RMN ${ }^{13} \mathrm{C}\left(125 \mathrm{MHz}, \mathrm{CDCl}_{3}\right): \delta$ 14,3 $\left(\underline{\mathrm{CH}}_{3}, 15\right) ; 22,9\left(\underline{\mathrm{CH}} \mathrm{H}_{2}, 14\right) ; 29,5-29,9\left(\underline{\mathrm{C}} \mathrm{H}_{2}, 3-12\right)$; $31,8\left(\underline{\mathrm{CH}}_{2}, 2\right) ; 32,1\left(\underline{\mathrm{CH}}_{2}, 13\right) ; 33,4\left(\underline{\mathrm{CH}}_{2}, 1\right) ; 44,0\left(\mathrm{ArCONH} \underline{C H}_{2} \mathrm{Ar}\right) ; 55,9\left(\mathrm{ArO}^{\mathrm{C}} \mathrm{H}_{3}\right)$;

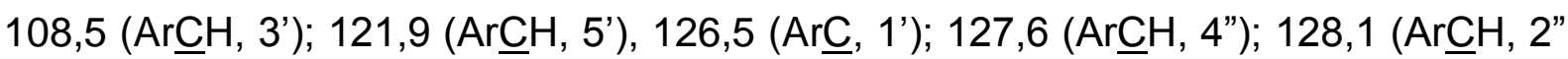

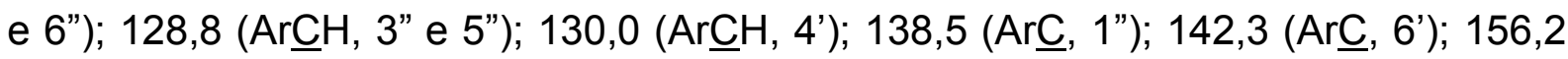

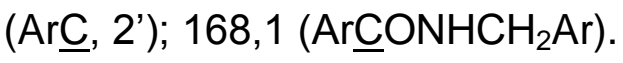

Derivado N-(2-Fenetil)-2-metóxi-6-pentadecilbenzilamida (LDT655, 24)

Sólido branco<smiles>CCCCCCCCCCCCCCCc1cccc(OC)c1C(=O)NCCc1ccccc1</smiles>

Rendimento $71 \%$

$\mathrm{R}_{\mathrm{f}}:$ 0,22 (Hex ${ }_{80 \%}:$ AcOEt $\left._{20 \%}\right)$

Ponto de fusão: $53-56^{\circ} \mathrm{C}$

Fórmula molecular: $\mathrm{C}_{31} \mathrm{H}_{47} \mathrm{NO}_{2}$

Massa Molar: $465,710 \mathrm{~g} / \mathrm{mol}$

IV (KBr) Umáx cm ${ }^{-1}: 3434\left(v_{\mathrm{NH}}\right) ; 3060\left(v_{=\mathrm{CH}}\right) ; 2918\left(v_{\mathrm{asCH} 2}\right) ; 2850\left(v_{\mathrm{SCH} 2}\right) ; 1735\left(v_{\mathrm{C}=\mathrm{O}}\right)$; $1599,1583,1497,1534,1470\left(v_{\mathrm{C}=\mathrm{C}}\right) ; 1267$ ( $\left.v_{\text {asc-o }}\right)$.

RMN ${ }^{1} \mathrm{H}\left(300 \mathrm{MHz}, \mathrm{CDCl}_{3}\right): \delta 0,89(\mathrm{t}, J=6,5 \mathrm{~Hz}, 3 \mathrm{H}, 15) ; 1,27$ (m, 24H, 3-14); 1,54$1,57(\mathrm{~m}, 2 \mathrm{H}, 2) ; 2,57(\mathrm{t}, J=7,9 \mathrm{~Hz}, 2 \mathrm{H}, 1) ; 2,94(\mathrm{t}, J=6,8 \mathrm{~Hz}, 3 \mathrm{H}$, ArCONHCH${ }_{2} \underline{\mathrm{H}}_{2} \mathrm{Ar}$ ) 3,70-3,85 (m, 5H, ArOC $\left.\underline{H}_{3}, \mathrm{ArCONHC}_{2} \mathrm{CH}_{2} \mathrm{Ar}\right) ; 5,79$ (t, $J=5,4$ $\left.\mathrm{Hz}, 1 \mathrm{H}, \operatorname{ArCON} \underline{\mathrm{H} C H} \mathrm{CH}_{2} \mathrm{Ar}\right) ; 6,71\left(\mathrm{~d}, J=8,3 \mathrm{~Hz}, 1 \mathrm{H}, 3^{\prime}\right) ; 6,81\left(\mathrm{~d}, J=7,6 \mathrm{~Hz}, 1 \mathrm{H}, 5^{\prime}\right)$; 7,19-7,33 (m, 6H, 4', 2", 3", 4", 5" e 6"). 
RMN ${ }^{13} \mathrm{C}\left(75 \mathrm{MHz}, \mathrm{CDCl}_{3}\right): \delta$ 14,2 $\left(\underline{\mathrm{CH}}_{3}, 15\right) ; 22,8\left(\underline{\mathrm{CH}} \mathrm{H}_{2}, 14\right) ; 29,5-29,8\left(\underline{\mathrm{C}} \mathrm{H}_{2}, 3-12\right)$; $31,6\left(\underline{\mathrm{CH}}_{2}, 2\right) ; 32,1\left(\underline{\mathrm{CH}}_{2}, 13\right) ; 33,2\left(\underline{\mathrm{CH}} \mathrm{H}_{2}, 1\right) ; 35,8\left(\mathrm{ArCONHCH}{ }_{2} \underline{\mathrm{C}} \mathrm{H}_{2} \mathrm{Ar}\right) ; 40,8$

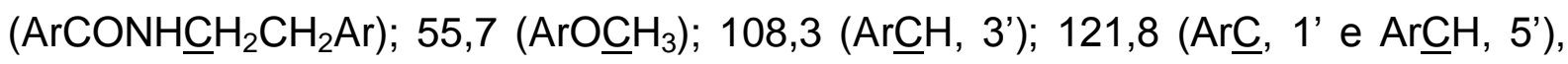

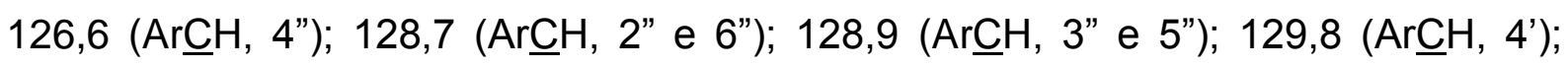

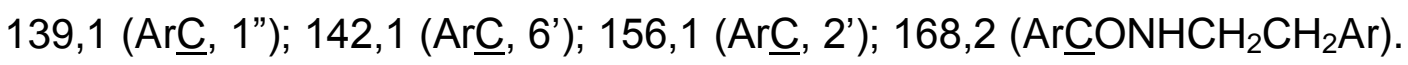

\section{Derivado N-(3-Fenilpropil)-2-metóxi-6-pentadecilbenzilamida (LDT657, 25)}

Sólido branco<smiles>COc1cccc(C)c1C(=O)NCCCc1ccccc1</smiles>

Rendimento $96 \%$

$\mathrm{R}_{\mathrm{f}}:$ 0,24 (Hex $\left.{ }_{80 \%}: \mathrm{AcOEt}_{20 \%}\right)$

Ponto de fusão: $60-67^{\circ} \mathrm{C}$

Fórmula molecular: $\mathrm{C}_{32} \mathrm{H}_{49} \mathrm{NO}_{2}$

Massa Molar: $479,737 \mathrm{~g} / \mathrm{mol}$

IV $(\mathrm{KBr}) v_{\text {máx }} \mathrm{cm}^{-1}: 3278\left(v_{\mathrm{NH}}\right) ; 3085\left(v_{=\mathrm{CH}}\right) ; 2918\left(v_{\mathrm{asCH} 2}\right) ; 2848\left(v_{\mathrm{SCH} 2}\right) ; 1636\left(v_{\mathrm{C}=\mathrm{O}}\right)$; $1595,1585,1550,1534,1497,1469\left(v_{\mathrm{C}=\mathrm{C}}\right) ; 1264$ ( $\left.v_{\text {asC-o }}\right)$.

RMN ${ }^{1} \mathrm{H}\left(300 \mathrm{MHz}, \mathrm{CDCl}_{3}\right): \delta 0,89$ (t, $\left.J=6,5 \mathrm{~Hz}, 3 \mathrm{H}, 15\right) ; 1,26$ (sl, 24H, 3-14); 1,551,60 (m, 2H, 2); 1,95 (qi, $J=7,7 \mathrm{~Hz}, 2 \mathrm{H}, \operatorname{ArCONHCH}_{2} \mathrm{CH}_{2} \mathrm{CH}_{2} \mathrm{Ar}$ ); 2,62 (t, $J=7,8 \mathrm{~Hz}$, $2 \mathrm{H}, \mathrm{ArCONHCH}_{2} \mathrm{CH}_{2} \mathrm{CH}_{2} \mathrm{Ar}$ ); 2,73 (t, $J=7,7 \mathrm{~Hz}, 2 \mathrm{H}, 1$ ); 3,49 (q, $J=6,5 \mathrm{~Hz}, 2 \mathrm{H}$, $\left.\operatorname{ArCONHC{}_{2}} \mathrm{CH}_{2} \mathrm{CH}_{2} \mathrm{Ar}\right) ; 3,79\left(\mathrm{~s}, 3 \mathrm{H}, \operatorname{ArOC}_{3}\right) ; 5,79$ (t, $J=5,7 \mathrm{~Hz}, 1 \mathrm{H}$, ArCON $\underline{H} \mathrm{CH}_{2} \mathrm{CH}_{2} \mathrm{CH}_{2} \mathrm{Ar}$ ); 6,74 (d, J = 8,2 Hz, $\left.1 \mathrm{H}, 3^{\prime}\right) ; 6,83\left(\mathrm{~d}, J=7,6 \mathrm{~Hz}, 1 \mathrm{H}, 5^{\prime}\right)$; 7,19-7,32 (m, 6H, 4', 2", 3", 4", 5" e 6").

RMN ${ }^{13} \mathrm{C}\left(75 \mathrm{MHz}, \mathrm{CDCl}_{3}\right): \delta$ 14,3 $\left(\underline{\mathrm{CH}}_{3}, 15\right) ; 22,8\left(\underline{\mathrm{CH}}_{2}, 14\right) ; 29,5-29,8\left(\underline{\mathrm{C}} \mathrm{H}_{2}, 3-12\right)$; $31,5 \quad\left(\mathrm{ArCONHCH}_{2} \underline{\mathrm{C}} \mathrm{H}_{2} \mathrm{CH}_{2} \mathrm{Ar}\right) ; \quad 31,7 \quad\left(\underline{\mathrm{CH}}_{2}, \quad 2\right) ; \quad 32,1 \quad\left(\underline{\mathrm{CH}_{2},} \quad 13\right) ; \quad 33,3$ (ArCONHCH$\left.{ }_{2} \mathrm{CH}_{2} \underline{\mathrm{C}} \mathrm{H}_{2} \mathrm{Ar}\right) ; \quad 33,3 \quad\left(\underline{\mathrm{CH}}_{2}, 1\right) ; 39,4 \quad\left(\mathrm{ArCONH} \underline{\mathrm{C}} \mathrm{H}_{2} \mathrm{CH}_{2} \mathrm{CH}_{2} \mathrm{Ar}\right) ; 55,8$

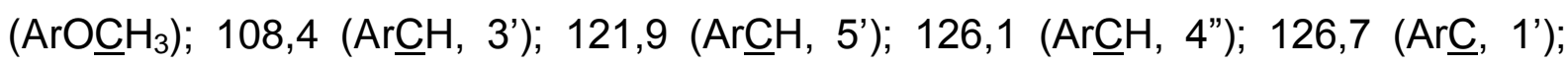

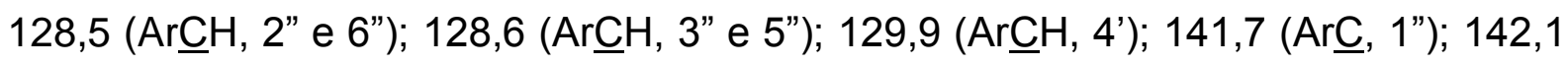

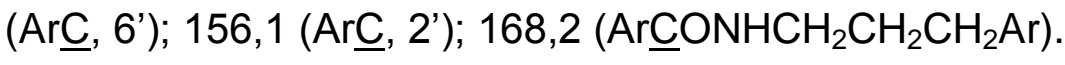


Derivado 2-Metóxi-6-pentadecilbenzoato de fenila (LDT667, 26)

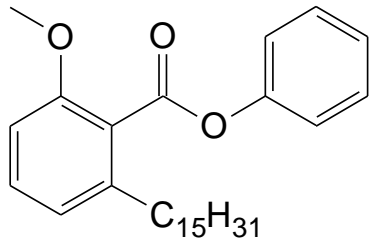

Sólido branco

Rendimento 59\%

$\mathrm{R}_{\mathrm{f}}: 0,55\left(\mathrm{Hex}_{80 \%}: \mathrm{AcOEt}_{20 \%}\right)$

Ponto de fusão: $34-38^{\circ} \mathrm{C}$

Fórmula molecular: $\mathrm{C}_{29} \mathrm{H}_{42} \mathrm{O}_{3}$

Massa Molar: 438,642 g/mol

IV (KBr) $v_{\text {máx }} \mathrm{cm}^{-1}: 2919\left(v_{\mathrm{asCH} 2}\right) ; 2851\left(v_{\mathrm{SCH} 2}\right) ; 1746\left(v_{\mathrm{C}=\mathrm{O}}\right) ; 1587,1490,1473,1458$ $\left(v_{\mathrm{C}=\mathrm{C}}\right) ; 1279\left(v_{\mathrm{asC}-\mathrm{O}}\right)$.

$\mathrm{RMN}^{1} \mathrm{H}\left(500 \mathrm{MHz}, \mathrm{CDCl}_{3}\right): \delta$ 0,90 (t, $\left.J=6,8 \mathrm{~Hz}, 3 \mathrm{H}, 15\right) ; 1,26(\mathrm{~m}, 24 \mathrm{H}, 3-14) ; 1,37-$ $1,39(\mathrm{~m}, 2 \mathrm{H}, 12) ; 1,66-1,72(\mathrm{~m}, 2 \mathrm{H}, 2) ; 2,73(\mathrm{t}, J=7,8 \mathrm{~Hz}, 2 \mathrm{H}, 1) ; 3,90(\mathrm{~s}, 3 \mathrm{H}$, $\left.\operatorname{ArOCH}_{3}\right) ; 6,83\left(\mathrm{~d}, J=8,2 \mathrm{~Hz}, 1 \mathrm{H}, 3^{\prime}\right) ; 6,89$ (d, $J=7,6 \mathrm{~Hz}, 1 \mathrm{H}, 5$ '); 7,25-7,30 (m, 3H, 2", 4" e 6"); 7,34 (t, J=8,0 Hz, 1H, 4'); 7,45 (t, J= 7,8 Hz, 2H, 3" e 5").

RMN ${ }^{13} \mathrm{C}\left(125 \mathrm{MHz}, \mathrm{CDCl}_{3}\right): \delta$ 14,3 $\left(\underline{\mathrm{CH}}_{3}, 15\right) ; 22,9\left(\underline{\mathrm{CH}}_{2}, 14\right) ; 29,5-29,9\left(\underline{\mathrm{CH}}_{2}, 3-12\right)$; $31,5\left(\underline{\mathrm{CH}}_{2}, 2\right) ; 32,1\left(\underline{\mathrm{CH}}_{2}, 13\right) ; 33,7\left(\underline{\mathrm{CH}}_{2}, 1\right) ; 56,2\left(\mathrm{ArO}_{\mathrm{CH}}\right) ; 108,7(\mathrm{Ar} \underline{\mathrm{CH}}, 3)$ ') 121,8

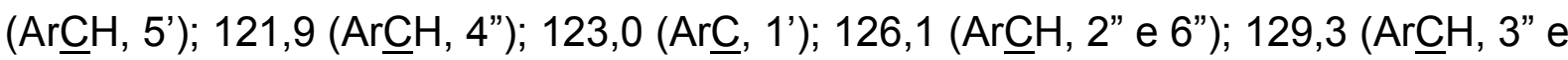

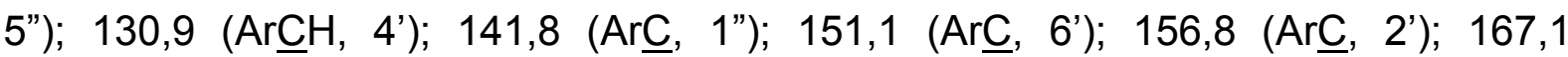
(ArOOㅅ).

Derivado 2-Metóxi-6-pentadecilbenzoato de benzila (LDT669, 27)

Sólido branco

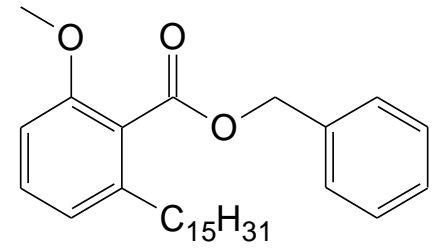

Rendimento 34\%

$\mathrm{R}_{\mathrm{f}}:$ 0,54 (Hex $80 \%:$ AcOEt $\left._{20 \%}\right)$

Ponto de fusão: $35-38^{\circ} \mathrm{C}$

Fórmula molecular: $\mathrm{C}_{30} \mathrm{H}_{44} \mathrm{O}_{3}$

Massa Molar: 452,669 g/mol

IV $(\mathrm{KBr}) v_{\text {máx }} \mathrm{cm}^{-1}: 3065\left(v_{=} \mathrm{CH}\right) ; 2917\left(v_{\mathrm{asCH} 2}\right) ; 2849\left(v_{\mathrm{SCH}}\right) ; 1729\left(v_{\mathrm{C}=\mathrm{O}}\right) ; 1599,1585$, 1507,1497, 1471, $1458\left(v_{\mathrm{C}=\mathrm{C}}\right) ; 1269$ ( $\left.v_{\mathrm{asC}-\mathrm{O}}\right)$. 
$\mathrm{RMN}^{1} \mathrm{H}\left(300 \mathrm{MHz}, \mathrm{CDCl}_{3}\right): \delta 0,91$ (t, $\left.J=6,6 \mathrm{~Hz}, 3 \mathrm{H}, 15\right) ; 1,29$ (s, 24H, 3-14); 1,49$1,54(\mathrm{~m}, 2 \mathrm{H}, 12) ; 2,50(\mathrm{t}, J=7,9 \mathrm{~Hz}, 2 \mathrm{H}, 1) ; 3,81$ (s, 3H, $\left.\operatorname{ArOC}_{3}\right) ; 5,39(\mathrm{~s}, 2 \mathrm{H}$, $\left.\operatorname{ArCOOC} \underline{H}_{2} \operatorname{Ar}\right) ; 6,76\left(\mathrm{~d}, J=8,3 \mathrm{~Hz}, 1 \mathrm{H}, 3^{\prime}\right) ; 6,81\left(\mathrm{~d}, J=7,6 \mathrm{~Hz}, 1 \mathrm{H}, 5^{\prime}\right) ; 7,27$ (t, $J=$ $8,0 \mathrm{~Hz}, 1 \mathrm{H}, 4$ "); 7,34-7,41 (m, 3H, 2", 6", 4'); 7,46-7,48 (m, 2H, 3" e 5").

$\mathrm{RMN}{ }^{13} \mathrm{C}\left(75 \mathrm{MHz}, \mathrm{CDCl}_{3}\right): \delta$ 14,3 $\left(\underline{\mathrm{CH}}_{3}, 15\right) ; 22,8\left(\underline{\mathrm{CH}}_{2}, 14\right) ; 29,5-29,9\left(\underline{\mathrm{C}} \mathrm{H}_{2}, 3-12\right)$; $31,4\left(\underline{\mathrm{CH}}_{2}, 2\right) ; 32,1\left(\underline{\mathrm{CH}}_{2}, 13\right) ; 33,6\left(\underline{\mathrm{C}} \mathrm{H}_{2}, 1\right) ; 55,9\left(\mathrm{ArO} \underline{C H}_{3}\right) ; 67,0\left(\mathrm{ArCOO} \underline{C H}_{2} \mathrm{Ar}\right)$;

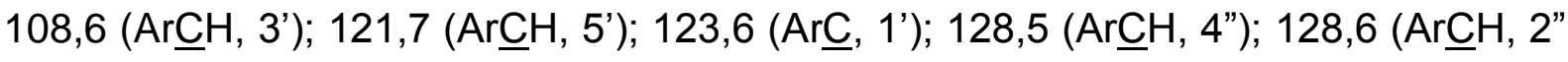

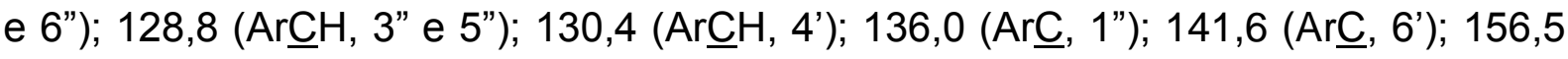
$\left(\operatorname{Ar} \underline{\mathrm{C}}, 2^{\prime}\right) ; 168,4\left(\mathrm{Ar} \underline{\mathrm{COOCH}} \mathrm{H}_{2} \mathrm{Ar}\right)$.

\section{Derivado 2-Metóxi-6-pentadecilbenzoato de 2-fenetila (LDT671, 28)}

Sólido branco

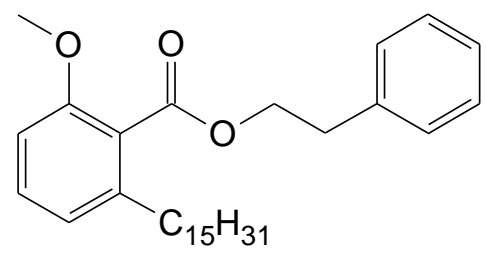

Rendimento $69 \%$

$\mathrm{R}_{\mathrm{f}}: 0,58\left(\mathrm{Hex}_{80 \%}: \mathrm{AcOEt}_{20 \%}\right)$

Ponto de fusão: $28-32^{\circ} \mathrm{C}$

Fórmula molecular: $\mathrm{C}_{31} \mathrm{H}_{46} \mathrm{O}_{3}$

Massa Molar: 466,695 g/mol

IV (KBr) $v_{\text {máx }} \mathrm{Cm}^{-1}: 3026\left(v_{=\mathrm{CH}}\right) ; 2922\left(v_{\mathrm{asCH} 2}\right) ; 2848\left(v_{\mathrm{SCH} 2}\right) ; 1733\left(v_{\mathrm{C}=0}\right) ; 1580,1497$, $1468,1458\left(v_{\mathrm{C}=\mathrm{C}}\right) ; 1271$ ( $\left.v_{\text {asc }}-\mathrm{o}\right)$.

RMN ${ }^{1} \mathrm{H}\left(300 \mathrm{MHz}, \mathrm{CDCl}_{3}\right): \delta 0,90(\mathrm{t}, J=6,6 \mathrm{~Hz}, 3 \mathrm{H}, 15) ; 1,26(\mathrm{~m}, 24 \mathrm{H}, 3-14) ; 1,52-$ $1,54(\mathrm{~m}, 2 \mathrm{H}, 12) ; 2,48(\mathrm{t}, J=7,8 \mathrm{~Hz}, 2 \mathrm{H}, 1) ; 3,08(\mathrm{t}, J=7,1 \mathrm{~Hz}, 2 \mathrm{H}$, $\operatorname{ArCOOCH}_{2} \mathrm{C}_{2} \mathrm{Ar}$ ); 3,79 (s, 3H, $\left.\operatorname{ArOC}_{3}\right) ; 4,56\left(\mathrm{t}, J=7,1 \mathrm{~Hz}, 2 \mathrm{H}, \operatorname{ArCOOC}_{2} \mathrm{CH}_{2} \mathrm{Ar}\right.$ ); $6,76\left(\mathrm{~d}, J=8,2 \mathrm{~Hz}, 1 \mathrm{H}, 3^{\prime}\right) ; 6,81$ (d, $J=7,6 \mathrm{~Hz}, 1 \mathrm{H}, 5$ '); 7,24-7,32 (m, 6H, 4', 2", 3", 4", 5" e 6").

$\mathrm{RMN}{ }^{13} \mathrm{C}\left(75 \mathrm{MHz}, \mathrm{CDCl}_{3}\right): \delta$ 14,3 $\left(\underline{\mathrm{C}}_{3}, 15\right) ; 22,9\left(\underline{\mathrm{C}} \mathrm{H}_{2}, 14\right) ; 29,5-29,9\left(\underline{\mathrm{C}} \mathrm{H}_{2}, 3-12\right)$; $31,3\left(\underline{\mathrm{CH}}_{2}, 2\right) ; 32,1\left(\underline{\mathrm{C}} \mathrm{H}_{2}, 13\right) ; 33,5\left(\underline{\mathrm{CH}}_{2}, 1\right) ; 35,2\left(\mathrm{ArCOOCH}{ }_{2} \underline{\mathrm{CH}}_{2} \mathrm{Ar}\right) ; 56,0\left(\mathrm{ArO}^{2} \mathrm{H}_{3}\right)$;

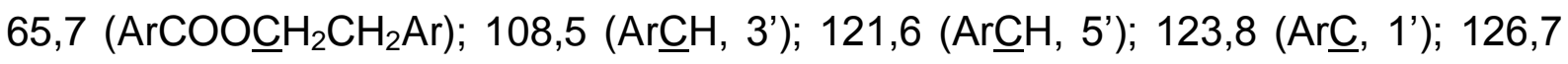




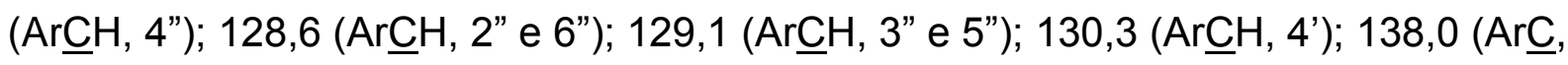

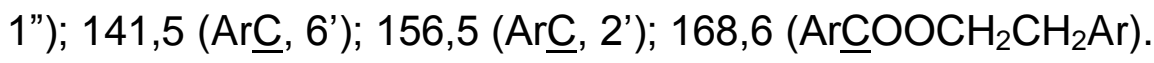

\section{Derivado 2-Metóxi-6-pentadecilbenzoato de 3-fenilpropila (LDT673, 29)}

Sólido branco<smiles>CCCCCCCCCOC(=O)c1c(OC)cccc1OC</smiles>

Rendimento $27 \%$

$\mathrm{R}_{\mathrm{f}}:$ 0,62 (Hex $\left.\mathrm{H}_{80 \%}: \mathrm{AcOEt}_{20 \%}\right)$

Ponto de fusão: $31-34^{\circ} \mathrm{C}$

Fórmula molecular: $\mathrm{C}_{32} \mathrm{H}_{48} \mathrm{O}_{3}$

Massa Molar: 480,722 g/mol

IV (KBr) $v_{\text {máx }} \mathrm{cm}^{-1}: 3029\left(v_{=\mathrm{CH}}\right) ; 2917\left(v_{\text {asCH2}}\right) ; 2850\left(v_{\mathrm{SCH} 2}\right) ; 1735\left(v_{\mathrm{C}=\mathrm{O}}\right) ; 1599,1583$, $1507,1497,1470\left(v_{\mathrm{C}=\mathrm{C}}\right) ; 1267\left(v_{\mathrm{asc}-\mathrm{O}}\right)$.

$\mathrm{RMN}^{1} \mathrm{H}\left(300 \mathrm{MHz}, \mathrm{CDCl}_{3}\right): \delta$ 0,88-0,92 (m, 3H, 15); 1,26-1,27 (m, 24H, 3-14); 1,591,64 (m, 2H, 12); 2,04-2,11 (m, 2H, ArCOOCH$\left.{ }_{2} \underline{\mathrm{H}}_{2} \mathrm{CH}_{2} \mathrm{Ar}\right) ; 2,59(\mathrm{t}, J=7,8 \mathrm{~Hz}, 2 \mathrm{H}$, $2 \mathrm{H}, 1$ ); 2,79 (t, $J=7,6 \mathrm{~Hz}, 2 \mathrm{H}, \operatorname{ArCOOCH}_{2} \mathrm{CH}_{2} \mathrm{CH}_{2} \mathrm{Ar}$ ); 3,84 (s, 3H, $\operatorname{ArOC}_{3}$ ); 4,354,39 (m, $\left.2 \mathrm{H}, \operatorname{ArCOOC} \underline{H}_{2} \mathrm{CH}_{2} \mathrm{CH}_{2} \mathrm{Ar}\right) ; 6,79\left(\mathrm{~d}, J=8,3 \mathrm{~Hz}, 1 \mathrm{H}, 3^{\prime}\right) ; 6,85$ (d, $J=7,7 \mathrm{~Hz}$, $\left.1 \mathrm{H}, 5^{\prime}\right) ; 7,19-7,33$ (m, 6H, 2", 3", 4", 5", 6" e 4').

$\mathrm{RMN}{ }^{13} \mathrm{C}\left(75 \mathrm{MHz}, \mathrm{CDCl}_{3}\right): \delta$ 14,3 $\left(\underline{\mathrm{CH}}_{3}, 15\right) ; 22,9\left(\underline{\mathrm{CH}}_{2}, 14\right) ; 29,5-29,9\left(\underline{\mathrm{CH}}_{2}, 3-12\right)$; $30,5 \quad\left(\mathrm{ArCOOCH}_{2} \underline{\mathrm{C}} \mathrm{H}_{2} \mathrm{CH}_{2} \mathrm{Ar}\right) ; \quad 31,5 \quad\left(\underline{\mathrm{CH}}_{2}, \quad 2\right) ; \quad 32,1 \quad\left(\underline{\mathrm{CH}}_{2}, \quad 13\right) ; \quad 32,3$ $\left(\mathrm{ArCOOCH} \mathrm{CH}_{2} \underline{\mathrm{C}} \mathrm{H}_{2} \mathrm{Ar}\right) ; 33,7\left(\underline{\mathrm{C}} \mathrm{H}_{2}, 1\right) ; 56,0\left(\mathrm{ArO} \mathrm{CH}_{3}\right) ; 64,5\left(\mathrm{ArCOO} \underline{\mathrm{C}} \mathrm{H}_{2} \mathrm{CH}_{2} \mathrm{CH}_{2} \mathrm{Ar}\right)$;

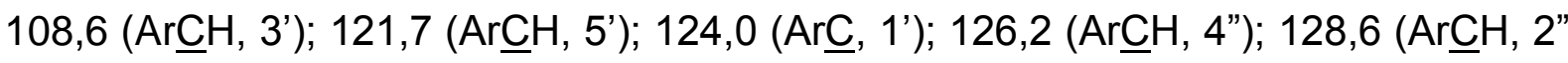

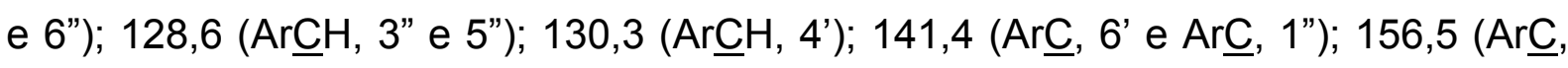
2'); 168,7 ( $\left.\mathrm{Ar} \underline{\mathrm{COOCH}} \mathrm{CH}_{2} \mathrm{CH}_{2} \mathrm{Ar}\right)$. 


\subsubsection{Obtenção dos Derivados Amidas e Éster LDT659: 2'- Hidroxissubstituídos}

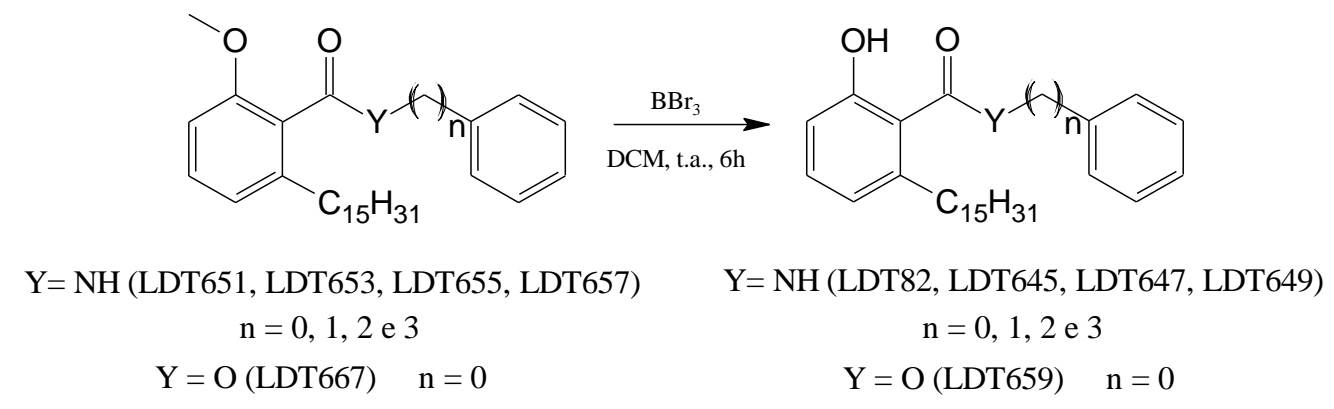

Em um balão $(25 \mathrm{~mL})$ foram adicionados $0,20 \mathrm{~g}$ dos derivados amidas e éster 2'-metoxilados, solução de $\mathrm{BBr}_{3} 1 \mathrm{M}$ (4,00 eqv.) e diclorometano seco $(4,0 \mathrm{~mL})$, sob atmosfera de nitrogênio. $O$ sistema reacional permaneceu sob agitação magnética à temperatura ambiente por 6 horas. Em seguida, a mistura foi vertida em béquer com gelo e extraída com acetato de etila $(3 \times 10,0 \mathrm{~mL})$. A fração orgânica foi lavada com solução concentrada de cloreto de sódio $(10,0 \mathrm{~mL})$, seca com sulfato de sódio e o solvente evaporado à pressão reduzida. Os resíduos foram purificados em coluna de gel de sílica com mistura de hexano e acetato de etila em diferentes concentrações, fornecendo os derivados.

\section{Derivado N-Fenil-2-hidróxi-6-pentadecilbenzilamida (LDT82, 30)}

Sólido branco

Rendimento $80 \%$<smiles>O=C(c1ccccc1)c1cccc(O)c1C(=O)Nc1ccccc1</smiles>

$\mathrm{R}_{\mathrm{f}}:$ 0,28 (Hex (Ho\%: $_{\text {:AcOEt }}$ 20\%)

Ponto de fusão: $71-74^{\circ} \mathrm{C}$

Fórmula molecular: $\mathrm{C}_{28} \mathrm{H}_{41} \mathrm{NO}_{2}$

Massa Molar: 423,631 g/mol

IV (KBr) $v_{\text {máx }} \mathrm{cm}^{-1}: 3284\left(v_{\mathrm{NH}}\right) ; 3143\left(v_{\mathrm{OH}}\right) ; 2920\left(v_{\mathrm{asCH}}\right) ; 2851\left(v_{\mathrm{SCH}}\right) ; 1595\left(v_{\mathrm{C}=\mathrm{O}}\right)$; 1559, $1443\left(v_{\mathrm{C}=\mathrm{C}}\right)$.

RMN ${ }^{1} \mathrm{H}\left(300 \mathrm{MHz}, \mathrm{CDCl}_{3}\right): \delta 0,90$ (t, $\left.J=6,6 \mathrm{~Hz}, 3 \mathrm{H}, 15\right) ; 1,24-1,32(\mathrm{~m}, 24 \mathrm{H}, 3-14)$; 1,64-1,74 (m, 2H, 2); 2,85 (t, $J=7,8 \mathrm{~Hz}, 2 \mathrm{H}, 1$ ); 6,82 (t, $J=7,0 \mathrm{~Hz}, 2 \mathrm{H}, 3^{\prime}$ e 5'); 7,18- 
7,28 (m, 2H, 4' e 4"); 7,40 (t, J= 7,8 Hz, 2H, 3" e 5"); 7,57 (d, J= 7,8 Hz, 2H, 2" e 6");

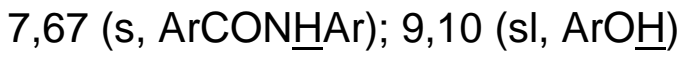

$\mathrm{RMN}{ }^{13} \mathrm{C}\left(75 \mathrm{MHz}, \mathrm{CDCl}_{3}\right): \delta 14,3\left(\underline{\mathrm{C}} \mathrm{H}_{3}, 15\right) ; 22,9\left(\underline{\mathrm{CH}}_{2}, 14\right) ; 29,5-29,8\left(\underline{\mathrm{CH}}_{2}, 3-12\right)$;

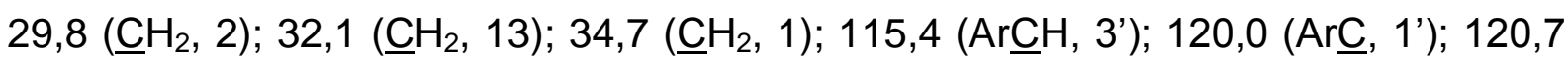

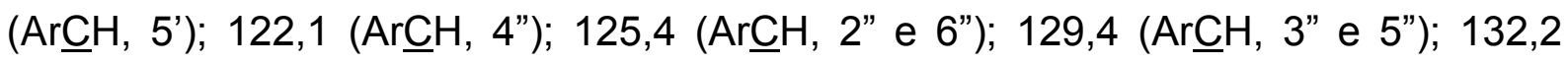

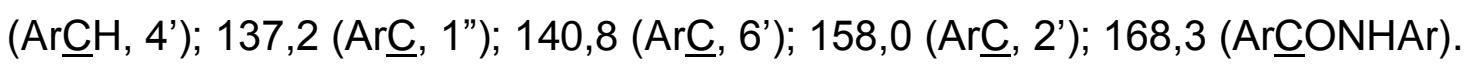

\section{Derivado N-Benzil-2-hidróxi-6-pentadecilbenzilamida (LDT645, 31)}

Sólido branco

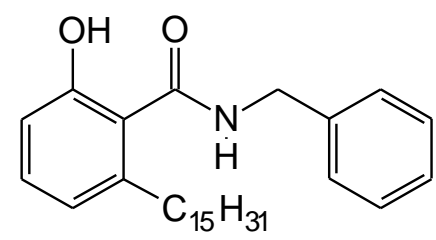

Rendimento $77 \%$

$\mathrm{R}_{\mathrm{f}}: 0,25$ (Hex $\left.\mathrm{H}_{80 \%}: \mathrm{AcOEt}_{20 \%}\right)$

Ponto de fusão: $85-87^{\circ} \mathrm{C}$

Fórmula molecular: $\mathrm{C}_{29} \mathrm{H}_{43} \mathrm{NO}_{2}$

Massa Molar: 437,657 g/mol

IV (KBr) $v_{\text {máx }} \mathrm{Cm}^{-1}: 3405\left(v_{\mathrm{NH}}\right) ; 3152\left(v_{=\mathrm{CH}}\right) ; 2917\left(v_{\mathrm{asCH}}\right) ; 2849\left(v_{\mathrm{SCH}}\right) ; 1609\left(v_{\mathrm{C}=\mathrm{O}}\right)$; $1533,1466\left(v_{\mathrm{C}=\mathrm{C}}\right)$.

RMN ${ }^{1} \mathrm{H}\left(300 \mathrm{MHz}, \mathrm{CDCl}_{3}\right): \delta 0,90$ (t, $\left.J=6,6 \mathrm{~Hz}, 3 \mathrm{H}, 15\right) ; 1,20-1,32(\mathrm{~m}, 24 \mathrm{H}, 3-14)$; $1,53(\mathrm{~m}, 2 \mathrm{H}, 2) ; 2,69(\mathrm{t}, J=8,0 \mathrm{~Hz}, 2 \mathrm{H}, 1) ; 4,67\left(\mathrm{~d}, J=5,5 \mathrm{~Hz}, 2 \mathrm{H}, \operatorname{ArCONHCH}_{2} \mathrm{Ar}\right)$; 6,01 (t, $J=4,9 \mathrm{~Hz}, 1 \mathrm{H}, \operatorname{ArCON} \underline{H C H}_{2} \operatorname{Ar}$ ); 6,71 (d, $J=7,5 \mathrm{~Hz}, 1 \mathrm{H}, 3$ ); 6,81 (d, $J=7,9$ $\mathrm{Hz}, 1 \mathrm{H}, 5^{\prime}$ ); 7,20 (t, $J=7,8 \mathrm{~Hz}, 1 \mathrm{H}, 4$ '); 7,30-7,37 (m, 5H, 2", 3", 4", 5" e 6"); 9,79 (sl, $\mathrm{ArOH})$.

RMN ${ }^{13} \mathrm{C}\left(75 \mathrm{MHz}, \mathrm{CDCl}_{3}\right): \delta$ 14,3 $\left(\underline{\mathrm{CH}}_{3}, 15\right) ; 22,8\left(\underline{\mathrm{CH}} \mathrm{H}_{2}, 14\right) ; 29,5-29,9\left(\underline{\mathrm{CH}}_{2}, 3-12\right)$; $32,1\left(\underline{\mathrm{CH}}_{2}, 2\right) ; 32,2\left(\underline{\mathrm{CH}}_{2}, 13\right) ; 34,8\left(\underline{\mathrm{CH}}_{2}, 1\right) ; 44,4\left(\mathrm{ArCONH} \underline{C H}_{2} \mathrm{Ar}\right) ; 115,3$ (Ar $\left.\underline{\mathrm{CH}}, 3^{\prime}\right)$;

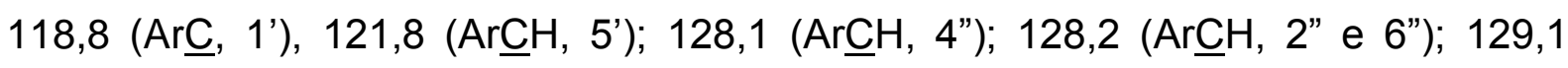

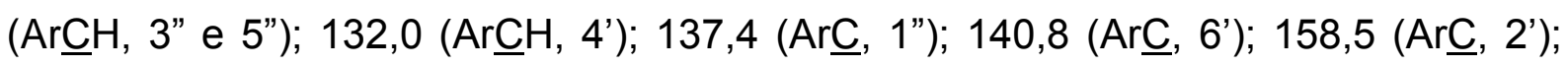
$169,9\left(\mathrm{Ar} \underline{\mathrm{CONHCH}} \mathrm{H}_{2} \mathrm{Ar}\right)$. 


\section{Derivado N-(2-Fenetil)-2-hidróxi-6-pentadecilbenzilamida (LDT647, 32)}

Sólido branco

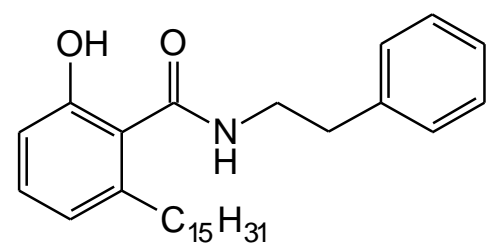

Rendimento $98 \%$

$\mathrm{R}_{\mathrm{f}}: 0,24$ (Hex $\left.\mathrm{H}_{80 \%}: \mathrm{AcOEt}_{20 \%}\right)$

Ponto de fusão: $72-75^{\circ} \mathrm{C}$

Fórmula molecular: $\mathrm{C}_{30} \mathrm{H}_{45} \mathrm{NO}_{2}$

Massa Molar: 451,684 g/mol

IV (KBr) $v_{\text {máx }} \mathrm{cm}^{-1}: 3429\left(v_{\mathrm{NH}}\right) ; 3326\left(v_{\mathrm{OH}}\right) ; 2954\left(v_{=\mathrm{CH}}\right) ; 2920\left(v_{\mathrm{asCH}}\right) ; 2850\left(v_{\mathrm{SCH}}\right)$; $1610\left(v_{\mathrm{C}=0}\right) ; 1560,1542,1498,1466\left(v_{\mathrm{C}=\mathrm{C}}\right)$.

$\mathrm{RMN}^{1} \mathrm{H}\left(300 \mathrm{MHz}, \mathrm{CDCl}_{3}\right): \delta 0,90(\mathrm{t}, J=6,6 \mathrm{~Hz}, 3 \mathrm{H}, 15) ; 1,23-1,29(\mathrm{~m}, 24 \mathrm{H}, 3-14)$; 1,42-1,52 (m, 2H, 2); 2,56 (t, $J=7,9 \mathrm{~Hz}, 2 \mathrm{H}, 1) ; 2,95$ (t, $J=6,8 \mathrm{~Hz}, 2 \mathrm{H}$, $\operatorname{ArCONHCH}{ }_{2} \underline{C H}_{2} \mathrm{Ar}$ ); 3,78 (q, $J=6,4 \mathrm{~Hz}, 2 \mathrm{H}, \operatorname{ArCONHCH}_{2} \mathrm{CH}_{2} \mathrm{Ar}$ ); $6,02(\mathrm{t}, J=5,2 \mathrm{~Hz}$, $1 \mathrm{H}, \operatorname{ArCON} \underline{H_{C H}} \mathrm{CH}_{2} \mathrm{Ar}$ ); 6,69 (d, $\left.J=7,5 \mathrm{~Hz}, 1 \mathrm{H}, 3^{\prime}\right) ; 6,79\left(\mathrm{~d}, J=7,5 \mathrm{~Hz}, 1 \mathrm{H} 5^{\prime}\right) ; 7,18$ (t, $J=7,9 \mathrm{~Hz}, 1 \mathrm{H}, 4$ '); 7,23-7,27 (m, 3H, 2", 4" e 6"); 7,31-7,36 (m, 2H, 3" e 5"), 9,86 (sl, $\mathrm{ArOH})$

RMN ${ }^{13} \mathrm{C}\left(75 \mathrm{MHz}, \mathrm{CDCl}_{3}\right): \delta$ 14,3 $\left(\underline{\mathrm{CH}}_{3}, 15\right) ; 22,8\left(\underline{\mathrm{CH}}_{2}, 14\right) ; 29,5-29,9\left(\underline{\mathrm{CH}}{ }_{2}, 3-12\right)$; $31,7\left(\underline{\mathrm{C}} \mathrm{H}_{2}, 2\right) ; 32,1 \quad\left(\underline{\mathrm{C}} \mathrm{H}_{2}, 13\right) ; 34,4\left(\underline{\mathrm{CH}}_{2}, 1\right) ; 35,4 \quad\left(\operatorname{ArCONHCH}_{2} \underline{\mathrm{C}} \mathrm{H}_{2} \mathrm{Ar}\right) ; 41,1$

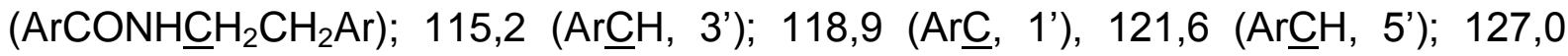

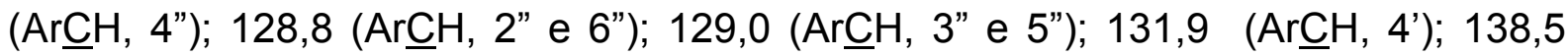

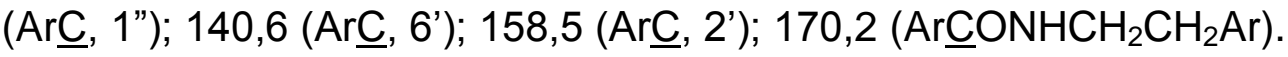

Derivado $\mathrm{N}$-(3-Fenilpropil)-2-hidróxi-6-pentadecilbenzilamida (LDT649, 33)

Sólido branco

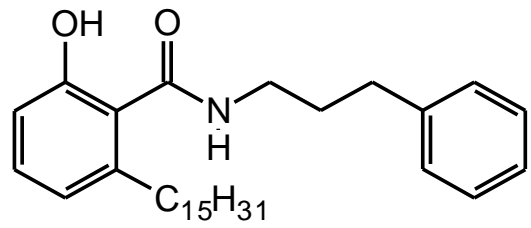

Rendimento $97 \%$

$\mathrm{R}_{\mathrm{f}}:$ 0,28 (Hex ${ }_{80 \%}:$ AcOEt $_{20 \%}$ )

Ponto de fusão: $59-65^{\circ} \mathrm{C}$

Fórmula molecular: $\mathrm{C}_{31} \mathrm{H}_{47} \mathrm{NO}_{2}$

Massa Molar: 465,710 g/mol 
IV (KBr) $v_{\text {máx }} \mathrm{cm}^{-1}: 3288\left(v_{\mathrm{NH}}\right) ; 3062\left(v_{=\mathrm{CH}}\right) ; 2954\left(v_{\mathrm{asCH}}\right) ; 2922\left(v_{\mathrm{asCH}}\right) ; 2851\left(v_{\mathrm{SCH}}\right)$; $1637\left(v_{\mathrm{C}=0}\right) ; 1583,1560,1471,1457\left(v_{\mathrm{C}=\mathrm{C}}\right)$.

$\mathrm{RMN}{ }^{1} \mathrm{H}\left(300 \mathrm{MHz}, \mathrm{CDCl}_{3}\right): \delta 0,90(\mathrm{t}, J=6,6 \mathrm{~Hz}, 3 \mathrm{H}, 15) ; 1,27$ (s, 24H, 3-14); 1,561,66 (m, 2H, 2); 1,96 (qi, $J=7,5 \mathrm{~Hz}, 2 \mathrm{H}, \operatorname{ArCONHCH}_{2} \mathrm{CH}_{2} \mathrm{CH}_{2} \mathrm{Ar}$ ); 2,73 (m, 4H, $\underline{\mathrm{C}}_{2}$, 1 e $\operatorname{ArCONHCH}{ }_{2} \mathrm{CH}_{2} \mathrm{C}_{2} \mathrm{Ar}$ ); 3,50 (q, $J=6,6 \mathrm{~Hz}, 2 \mathrm{H}, \operatorname{ArCONHCH}_{2} \mathrm{CH}_{2} \mathrm{CH}_{2} \mathrm{Ar}$ ); 6,06 (t, $J=5,7 \mathrm{~Hz}, 1 \mathrm{H}, \operatorname{ArCON} \underline{\mathrm{H} C H} \mathrm{CH}_{2} \mathrm{CH}_{2} \mathrm{Ar}$ ); $6,73\left(\mathrm{~d}, J=7,5 \mathrm{~Hz}, 1 \mathrm{H}, 3^{\prime}\right) ; 6,79$ (d, $J=$ 7,5 Hz, 1H, 5'); 7,17-7,22 (m, 4H, 4', 2", 4" e 6"); 7,27-7,32 (m, 2H, 3" e 5"); 9,66 (sl, $\mathrm{ArOH})$.

RMN ${ }^{13} \mathrm{C}\left(75 \mathrm{MHz}, \mathrm{CDCl}_{3}\right): \delta$ 14,3 $\left(\underline{\mathrm{CH}}_{3}, 15\right) ; 22,8\left(\underline{\mathrm{CH}}_{2}, 14\right) ; 29,5-29,8\left(\underline{\mathrm{C}} \mathrm{H}_{2}, 3-12\right)$; $31,2 \quad\left(\mathrm{ArCONHCH}_{2} \underline{\mathrm{CH}}_{2} \mathrm{CH}_{2} \mathrm{Ar}\right) ; \quad 32,0 \quad\left(\underline{\mathrm{CH}} \mathrm{H}_{2}, \quad 2\right) ; \quad 32,1 \quad\left(\underline{\mathrm{C}}_{2}, \quad 13\right) ; \quad 33,5$

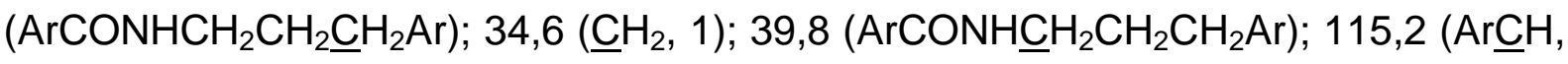

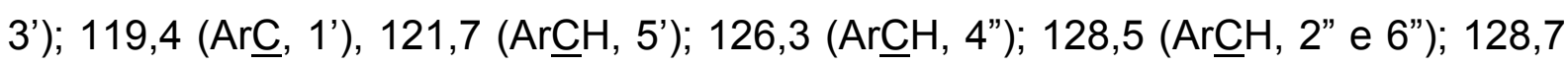

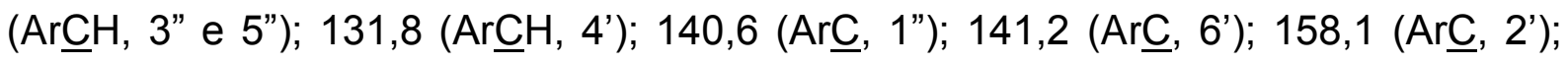
$170,1\left(\mathrm{Ar} \underline{\mathrm{CONHCH}} \mathrm{CH}_{2} \mathrm{CH}_{2} \mathrm{Ar}\right)$.

\section{Derivado 2-Metóxi-6-pentadecilbenzoato de fenila (LDT659, 34)}

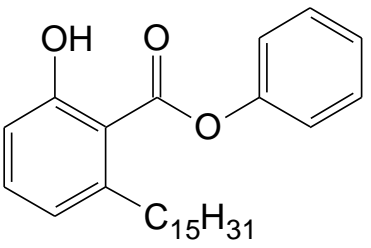

Sólido branco

Rendimento $55 \%$

$\mathrm{R}_{\mathrm{f}}: 0,61\left(\mathrm{Hex}_{80 \%}: \mathrm{AcOEt}_{20 \%}\right)$

Ponto de fusão: $35-38^{\circ} \mathrm{C}$

Fórmula molecular: $\mathrm{C}_{28} \mathrm{H}_{40} \mathrm{O}_{3}$

Massa Molar: 424,615 g/mol

IV $(\mathrm{KBr}) v_{\text {máx }} \mathrm{Cm}^{-1}: 3445\left(v_{\mathrm{OH}}\right) ; 2924\left(v_{\mathrm{asCH}}\right) ; 1688\left(v_{\mathrm{C}=\mathrm{O}}\right) ; 1525\left(v_{\mathrm{C}=\mathrm{C}}\right)$.

RMN ${ }^{1} \mathrm{H}\left(500 \mathrm{MHz}, \mathrm{CDCl}_{3}\right): \delta 0,90(\mathrm{~m}, 3 \mathrm{H}, 15) ; 1,23-1,36(\mathrm{~m}, 24 \mathrm{H}, 3-14) ; 1,70(\mathrm{~m}$, $2 \mathrm{H}, 12$ ); 3,07 (t, $J=7,5 \mathrm{~Hz}, 2 \mathrm{H}, 1$ ); $6,83(\mathrm{~d}, J=7,1 \mathrm{~Hz}, 1 \mathrm{H}, 3$ ); $6,92(\mathrm{~d}, J=7,9 \mathrm{~Hz}$, $\left.1 \mathrm{H}, 5^{\prime}\right) ; 7,21-7,26$ (m, 2H, 4' e 4"); 7,34-7,40 (m, 2H, 2" e 6"); 7,47-7,50 (m, 2H, 3" e 5"); 10,92 (s, ArOH). 
$\mathrm{RMN}{ }^{13} \mathrm{C}\left(125 \mathrm{MHz}, \mathrm{CDCl}_{3}\right): \delta 14,3\left(\underline{\mathrm{CH}}_{3}, 15\right) ; 22,9\left(\underline{\mathrm{CH}}_{2}, 14\right) ; 29,5-30,0\left(\underline{\mathrm{CH}}_{2}, 3-12\right)$; $32,1\left(\underline{\mathrm{CH}}_{2}, 2\right) ; 32,7\left(\underline{\mathrm{CH}}_{2}, 13\right) ; 37,1\left(\underline{\mathrm{CH}}_{2}, 1\right) ; 111,4\left(\mathrm{Ar} \underline{\mathrm{C}}, 1\right.$ '); 116,1 (Ar $\left.\underline{\mathrm{CH}}, 3^{\prime}\right) ; 121,8$

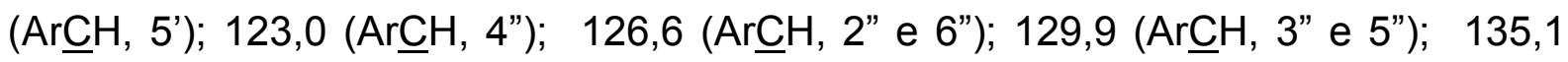

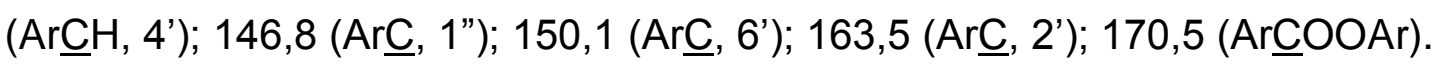

\subsubsection{Obtenção dos Derivados 2'-Metoxiésteres via Brometos de Aralquila}

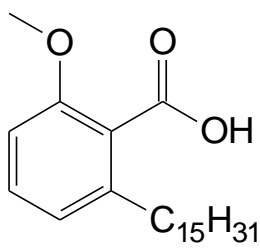

LDT30

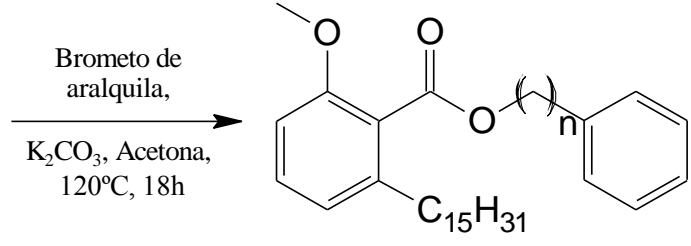

$\mathrm{n}=1,2$ e 3

$\mathrm{Y}=\mathrm{O}($ LDT669, LDT671, LDT673)

Em um balão $(25 \mathrm{~mL})$ foram adicionados $0,20 \mathrm{~g}$ do derivado LDT30 (20) $(0,57$ $\mathrm{mmol})$, carbonato de potássio (2,00 eqv), brometo de aralquila correspondente (3,00 eqv.) e acetona $(8,0 \mathrm{~mL})$. A mistura permaneceu sob agitação, à temperatura de $120^{\circ} \mathrm{C}$, por 18 horas. Em seguida, o solvente foi evaporado à pressão reduzida e o resíduo extraído com acetato de etila $(3 \times 10,0 \mathrm{~mL})$. As frações orgânicas reunidas foram lavadas com soluções de $\mathrm{HCl} 10 \%(2 \times 10,0 \mathrm{~mL})$, saturada de cloreto de sódio $(10,0 \mathrm{~mL})$ e secas com sulfato de sódio. Após o solvente ser removido à pressão reduzida, a mistura foi purificada em coluna cromatográfica de gel de sílica, eluída em diferentes concentrações de hexano e acetato de etila, fornecendo os derivados.

\section{Derivado 2-Metóxi-6-pentadecilbenzoato de benzila (LDT669, 27)}

Sólido branco<smiles>COc1cccc(C(C)(C)C)c1C(=O)OCc1ccccc1</smiles>

Rendimento $64 \%$

$\mathrm{R}_{\mathrm{f}}: 0,54\left(\mathrm{Hex}_{80 \%}: \mathrm{AcOEt}_{20 \%}\right)$

Ponto de fusão: $35-38^{\circ} \mathrm{C}$

Fórmula molecular: $\mathrm{C}_{30} \mathrm{H}_{44} \mathrm{O}_{3}$

Massa Molar: 452,669 g/mol 
IV $(\mathrm{KBr}) v_{\text {máx }} \mathrm{Cm}^{-1}: 3065\left(v_{=\mathrm{CH}}\right) ; 2917\left(v_{\text {asCH2}}\right) ; 2849\left(v_{\mathrm{SCH} 2}\right) ; 1729\left(v_{\mathrm{C}=0}\right) ; 1599,1585$, $1507,1497,1471,1458\left(v_{\mathrm{C}=\mathrm{C}}\right) ; 1269\left(v_{\mathrm{asC}-\mathrm{o}}\right)$.

RMN ${ }^{1} \mathrm{H}\left(300 \mathrm{MHz}, \mathrm{CDCl}_{3}\right): \delta 0,91$ (t, $\left.J=6,6 \mathrm{~Hz}, 3 \mathrm{H}, 15\right) ; 1,29$ (s, 24H, 3-14); 1,49$1,54(\mathrm{~m}, 2 \mathrm{H}, 12) ; 2,50$ (t, $J=7,9 \mathrm{~Hz}, 2 \mathrm{H}, 1$ ); 3,81 (s, 3H, $\operatorname{ArOC}_{3}$ ); 5,39 (s, 2H, $\left.\operatorname{ArCOOC} \underline{H}_{2} \mathrm{Ar}\right) ; 6,76\left(\mathrm{~d}, J=8,3 \mathrm{~Hz}, 1 \mathrm{H}, 3^{\prime}\right) ; 6,81\left(\mathrm{~d}, J=7,6 \mathrm{~Hz}, 1 \mathrm{H}, 5^{\prime}\right) ; 7,27$ (t, $J=$ $8,0 \mathrm{~Hz}, 1 \mathrm{H}, 4$ "); 7,34-7,41 (m, 3H, 2", 6", 4'); 7,46-7,48 (m, 2H, 3" e 5").

$\mathrm{RMN}{ }^{13} \mathrm{C}\left(75 \mathrm{MHz}, \mathrm{CDCl}_{3}\right): \delta$ 14,3 $\left(\underline{\mathrm{C}}_{3}, 15\right) ; 22,8\left(\underline{\mathrm{C}} \mathrm{H}_{2}, 14\right) ; 29,5-29,9\left(\underline{\mathrm{C}} \mathrm{H}_{2}, 3-12\right)$; $31,4\left(\underline{\mathrm{CH}}_{2}, 2\right) ; 32,1\left(\underline{\mathrm{CH}}_{2}, 13\right) ; 33,6\left(\underline{\mathrm{CH}} \mathrm{H}_{2}, 1\right) ; 55,9\left(\mathrm{ArO} \underline{\mathrm{C}} \mathrm{H}_{3}\right) ; 67,0\left(\mathrm{ArCOO} \underline{\mathrm{C}} \mathrm{H}_{2} \mathrm{Ar}\right)$;

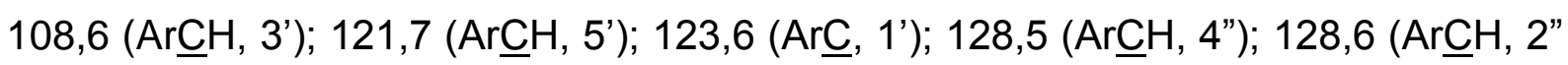

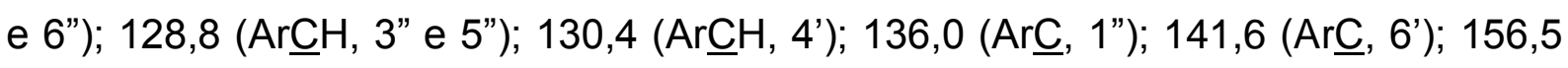
$\left(\operatorname{Ar} \underline{\mathrm{C}}, 2^{\prime}\right) ; 168,4\left(\mathrm{Ar} \underline{\mathrm{COOCH}} \mathrm{Ar}_{2}\right)$.

Derivado 2-Metóxi-6-pentadecilbenzoato de 2-fenetila (LDT671, 28)

Sólido branco

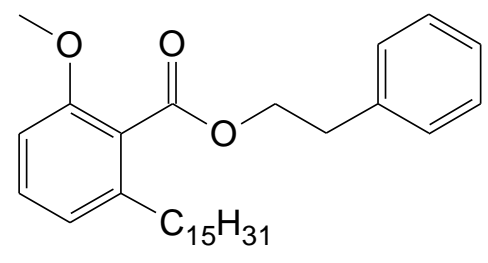

Rendimento $57 \%$

$\mathrm{R}_{\mathrm{f}}: 0,58$ (Hex $\left.\mathrm{H}_{80 \%}: \mathrm{AcOEt}_{20 \%}\right)$

Ponto de fusão: $28-32^{\circ} \mathrm{C}$

Fórmula molecular: $\mathrm{C}_{31} \mathrm{H}_{46} \mathrm{O}_{3}$

Massa Molar: 466,695 g/mol

IV (KBr) $v_{\text {máx }} \mathrm{Cm}^{-1}: 3026\left(v_{=\mathrm{CH}}\right) ; 2922\left(v_{\mathrm{asCH}}\right) ; 2848\left(v_{\mathrm{SCH} 2}\right) ; 1733\left(v_{\mathrm{C}=0}\right) ; 1580,1497$, $1468,1458\left(v_{\mathrm{C}=\mathrm{C}}\right) ; 1271$ ( $\left.v_{\text {asc }}-\mathrm{o}\right)$.

$\mathrm{RMN}^{1} \mathrm{H}\left(300 \mathrm{MHz}, \mathrm{CDCl}_{3}\right): \delta 0,90(\mathrm{t}, J=6,6 \mathrm{~Hz}, 3 \mathrm{H}, 15) ; 1,26(\mathrm{~m}, 24 \mathrm{H}, 3-14) ; 1,52-$ $1,54(\mathrm{~m}, 2 \mathrm{H}, 12) ; 2,48(\mathrm{t}, J=7,8 \mathrm{~Hz}, 2 \mathrm{H}, 1) ; 3,08(\mathrm{t}, J=7,1 \mathrm{~Hz}, 2 \mathrm{H}$, $\operatorname{ArCOOCH} \mathrm{CH}_{2} \mathrm{Ar}$ ); 3,79 (s, 3H, $\left.\operatorname{ArOC} \underline{H}_{3}\right) ; 4,56\left(\mathrm{t}, J=7,1 \mathrm{~Hz}, 2 \mathrm{H}, \operatorname{ArCOOC} \underline{H}_{2} \mathrm{CH}_{2} \mathrm{Ar}\right.$ ); $6,76\left(\mathrm{~d}, J=8,2 \mathrm{~Hz}, 1 \mathrm{H}, 3^{\prime}\right) ; 6,81$ (d, $\left.J=7,6 \mathrm{~Hz}, 1 \mathrm{H}, 5^{\prime}\right) ; 7,24-7,32$ (m, 6H, 4', 2", 3", $4 ", 5$ " e 6"). 
RMN ${ }^{13} \mathrm{C}\left(75 \mathrm{MHz}, \mathrm{CDCl}_{3}\right): \delta$ 14,3 $\left(\underline{\mathrm{CH}}_{3}, 15\right) ; 22,9\left(\underline{\mathrm{CH}} \mathrm{H}_{2}, 14\right) ; 29,5-29,9\left(\underline{\mathrm{C}}_{2}, 3-12\right)$; $31,3\left(\underline{\mathrm{CH}}_{2}, 2\right) ; 32,1\left(\underline{\mathrm{CH}}_{2}, 13\right) ; 33,5\left(\underline{\mathrm{CH}}_{2}, 1\right) ; 35,2\left(\mathrm{ArCOOCH}{ }_{2} \underline{\mathrm{C}} \mathrm{H}_{2} \mathrm{Ar}\right) ; 56,0\left(\mathrm{ArO} \underline{\mathrm{C}} \mathrm{H}_{3}\right)$;

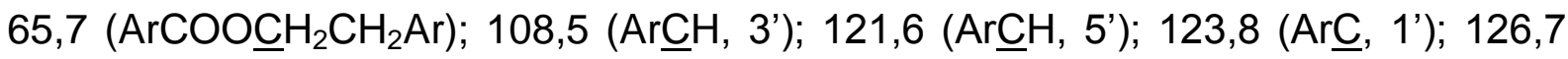

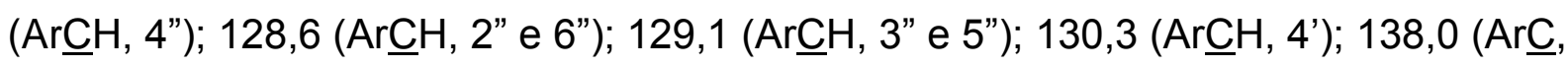

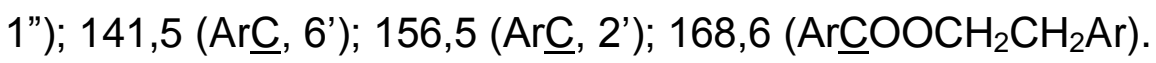

\section{Derivado 2-Metóxi-6-pentadecilbenzoato de 3-fenilpropila (LDT673, 29)}

Sólido branco

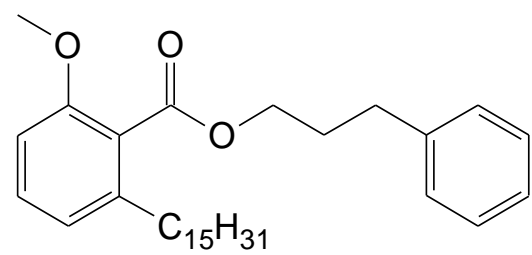

Rendimento $35 \%$

$\mathrm{R}_{\mathrm{f}}:$ 0,62 (Hex $\left.\mathrm{H}_{80 \%}: \mathrm{AcOEt}_{20 \%}\right)$

Ponto de fusão: $31-34^{\circ} \mathrm{C}$

Fórmula molecular: $\mathrm{C}_{32} \mathrm{H}_{48} \mathrm{O}_{3}$

Massa Molar: 480,722 g/mol

IV (KBr) $v_{\text {máx }} \mathrm{cm}^{-1}: 3029\left(v_{=\mathrm{CH}}\right) ; 2917\left(v_{\text {asCH2}}\right) ; 2850\left(v_{\mathrm{SCH}}\right) ; 1735\left(v_{\mathrm{C}=\mathrm{O}}\right) ; 1599,1583$, $1507,1497,1470\left(v_{\mathrm{C}=\mathrm{C}}\right) ; 1267$ ( $\left.v_{\text {asC-O}}\right)$.

RMN ${ }^{1} \mathrm{H}\left(300 \mathrm{MHz}, \mathrm{CDCl}_{3}\right): \delta$ 0,88-0,92 (m, 3H, 15); 1,26-1,27 (m, 24H, 3-14); 1,591,64 (m, 2H, 12); 2,04-2,11 (m, $2 \mathrm{H}, \mathrm{ArCOOCH}_{2} \mathrm{CH}_{2} \mathrm{CH}_{2} \mathrm{Ar}$ ); 2,59 (t, $J=7,8 \mathrm{~Hz}, 2 \mathrm{H}$, $2 \mathrm{H}, 1$ ); 2,79 (t, $J=7,6 \mathrm{~Hz}, 2 \mathrm{H}, \operatorname{ArCOOCH}_{2} \mathrm{CH}_{2} \mathrm{CH}_{2} \mathrm{Ar}$ ); 3,84 (s, 3H, $\operatorname{ArOC}_{3}$ ); 4,354,39 (m, 2H, ArCOOC $\left.\underline{H}_{2} \mathrm{CH}_{2} \mathrm{CH}_{2} \mathrm{Ar}\right) ; 6,79(\mathrm{~d}, J=8,3 \mathrm{~Hz}, 1 \mathrm{H}, 3$ ); $6,85(\mathrm{~d}, J=7,7 \mathrm{~Hz}$, $\left.1 \mathrm{H}, 5^{\prime}\right) ; 7,19-7,33$ (m, 6H, 2", 3", 4", 5", 6" e 4').

RMN ${ }^{13} \mathrm{C}\left(75 \mathrm{MHz}, \mathrm{CDCl}_{3}\right): \delta$ 14,3 $\left(\underline{\mathrm{CH}}_{3}, 15\right) ; 22,9\left(\underline{\mathrm{CH}}_{2}, 14\right) ; 29,5-29,9\left(\underline{\mathrm{C}} \mathrm{H}_{2}, 3-12\right)$; $30,5 \quad\left(\mathrm{ArCOOCH}_{2} \underline{\mathrm{C}} \mathrm{H}_{2} \mathrm{CH}_{2} \mathrm{Ar}\right) ; \quad 31,5 \quad\left(\underline{\mathrm{C}} \mathrm{H}_{2}, \quad 2\right) ; \quad 32,1 \quad\left(\underline{\mathrm{CH}}_{2}, \quad 13\right) ; \quad 32,3$ (ArCOOCH$\left.{ }_{2} \mathrm{CH}_{2} \underline{\mathrm{C}} \mathrm{H}_{2} \mathrm{Ar}\right)$; 33,7 $\left(\underline{\mathrm{C}} \mathrm{H}_{2}, 1\right)$; 56,0 $\left(\mathrm{ArO} \underline{\mathrm{C}} \mathrm{H}_{3}\right) ; 64,5\left(\mathrm{ArCOO} \underline{\mathrm{C}} \mathrm{H}_{2} \mathrm{CH}_{2} \mathrm{CH}_{2} \mathrm{Ar}\right)$;

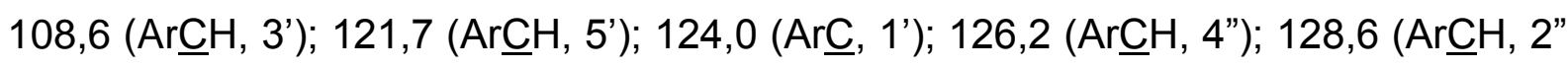

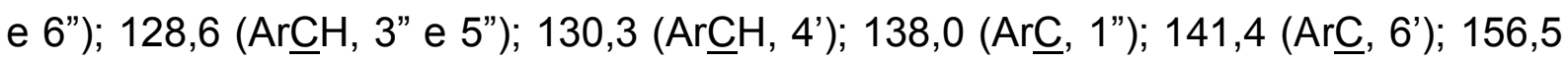

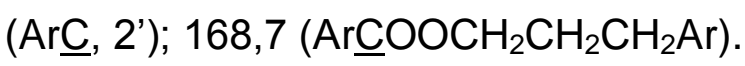


5.2.12 Obtenção dos Derivados 2'-hidróxiésteres LDT661 (35), LDT663 (36) e LDT665 (37)

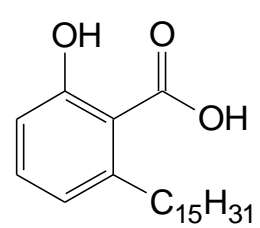

LDT11

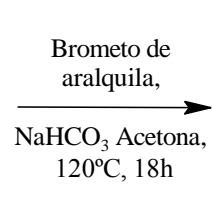

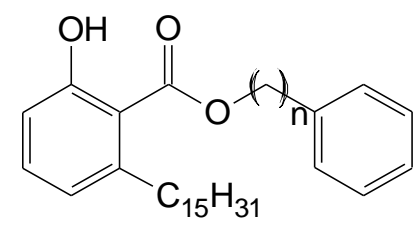

$\mathrm{n}=1,2$ e 3

$\mathrm{Y}=\mathrm{O}(\mathrm{LDT} 661, \mathrm{LDT} 663, \mathrm{LDT} 665)$

Em um balão (25 mL) foram adicionados $0,20 \mathrm{~g}$ do derivado LDT11 (16) $(0,57$ $\mathrm{mmol}$ ), bicarbonato de sódio (2,00 eqv), brometo de aralquila correspondente (3,00 eqv.) e acetona $(8,0 \mathrm{~mL})$. A mistura permaneceu sob agitação, à temperatura de $120^{\circ} \mathrm{C}$, por 18 horas. Em seguida, o solvente foi evaporado à pressão reduzida e 0 resíduo extraído com acetato de etila $(3 \times 10,0 \mathrm{~mL})$. As frações orgânicas reunidas foram lavadas com soluções de $\mathrm{HCl} 10 \%(2 \times 10,0 \mathrm{~mL})$, saturada de cloreto de sódio $(10,0 \mathrm{~mL})$ e seca com sulfato de sódio. Após o solvente ser evaporado à pressão reduzida, a mistura foi purificada em coluna cromatográfica de gel de sílica, eluída em diferentes concentrações de hexano e acetato de etila, fornecendo os derivados.

\section{Derivado 2-Hidróxi-6-pentadecilbenzoato de benzila (LDT661, 35)}

Sólido branco

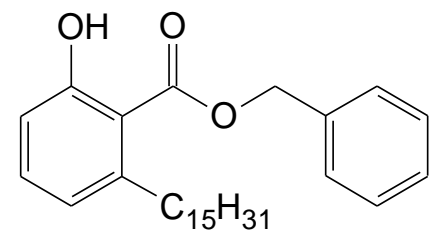

Rendimento $60 \%$

$\mathrm{R}_{\mathrm{f}}:$ 0,65 (Hex $\left.\mathrm{H}_{80 \%}: \mathrm{AcOEt}_{20 \%}\right)$

Ponto de fusão: $29-36^{\circ} \mathrm{C}$

Fórmula molecular: $\mathrm{C}_{29} \mathrm{H}_{42} \mathrm{O}_{3}$

Massa Molar: 438,642 g/mol

IV $(\mathrm{KBr}) v_{\text {máx }} \mathrm{cm}^{-1}: 3447\left(v_{\mathrm{OH}}\right) ; 2924\left(v_{\mathrm{asCH} 2}\right) ; 2853\left(v_{\mathrm{SCH}}\right) ; 1661\left(v_{\mathrm{C}=0}\right) ; 1455\left(v_{\mathrm{C}=\mathrm{C}}\right)$; $1248\left(v_{\text {asC-o }}\right)$.

$\mathrm{RMN}^{1} \mathrm{H}\left(500 \mathrm{MHz}, \mathrm{CDCl}_{3}\right): \delta 0,91(\mathrm{~m}, 3 \mathrm{H}, 15) ; 1,10-1,42(\mathrm{~m}, 26 \mathrm{H}, 2-14) ; 2,82-2,84$ (m, 2H, 1); 5,40 (s, 2H, ArCOOC $\left.\underline{H}_{2} A r\right) ; 6,70(\mathrm{~d}, J=7,1 \mathrm{~Hz}, 1 \mathrm{H}, 3$ ) $) ; 6,85$ (d, $J=8,1$ 
$\left.\mathrm{Hz}, 1 \mathrm{H}, 5^{\prime}\right) ; 7,29$ (t, J= 7,8 Hz, 1H, 4"); 7,40-7,41 (m, 3H, 2", 6", 4'); 7,45 (m, 2H, 3" e 5"); 11,20 (s, ArOㅡㅡ).

RMN ${ }^{13} \mathrm{C}\left(125 \mathrm{MHz}, \mathrm{CDCl}_{3}\right): \delta$ 14,3 $\left(\underline{\mathrm{CH}}_{3}, 15\right) ; 22,9\left(\underline{\mathrm{CH}}_{2}, 14\right) ; 29,5-30,0\left(\underline{\mathrm{CH}}_{2}, 3-12\right)$; $32,1\left(\underline{\mathrm{CH}}_{2}, 2\right) ; 32,6\left(\underline{\mathrm{CH}}_{2}, 13\right) ; 36,9\left(\underline{\mathrm{CH}}_{2}, 1\right) ; 67,0\left(\operatorname{ArCOO} \underline{C}_{2} \mathrm{Ar}\right) ; 112,0\left(\operatorname{Ar} \underline{\mathrm{C}}, 1^{\prime}\right)$;

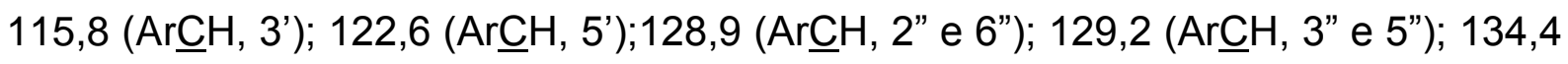

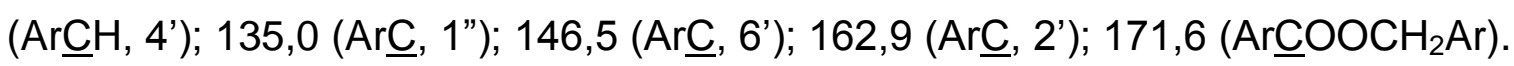

\section{Derivado 2-Hidróxi-6-pentadecilbenzoato de 2-fenetila (LDT663, 36)}

Sólido branco

Rendimento $71 \%$

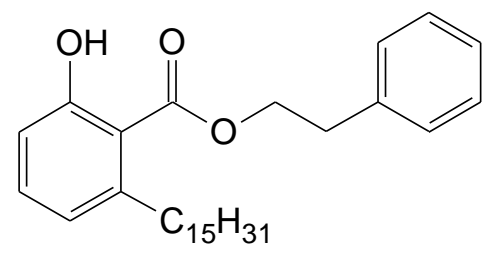

$R_{f}: 0,64$ (Hex $80 \%:$ AcOEt $\left._{20 \%}\right)$

Ponto de fusão: $25-27^{\circ} \mathrm{C}$

Fórmula molecular: $\mathrm{C}_{30} \mathrm{H}_{44} \mathrm{O}_{3}$

Massa Molar: 452,669 $\mathrm{g} / \mathrm{mol}$

IV $(\mathrm{KBr}) v_{\text {máx }} \mathrm{Cm}^{-1}: 3446\left(\mathrm{v}_{\mathrm{OH}}\right) ; 2923\left(\mathrm{vasCH}_{2}\right) ; 2852\left(v_{\mathrm{SCH}}\right) ; 1660\left(v_{\mathrm{C}=\mathrm{O}}\right) ; 1576,1497$, $1449\left(v_{\mathrm{C}=\mathrm{C}}\right) ; 1248\left(v_{\text {asC-O}}\right)$.

$\mathrm{RMN}^{1} \mathrm{H}\left(500 \mathrm{MHz}, \mathrm{CDCl}_{3}\right): \delta 0,91(\mathrm{t}, J=6,6 \mathrm{~Hz}, 3 \mathrm{H}, 15) ; 1,28$ (s, 24H, 3-14); 1,49 (sl, 2H, 2); 2,83 (t, $J=7,6 \mathrm{~Hz}, 2 \mathrm{H}, 1$ ); 3,13 (t, $J=7,0 \mathrm{~Hz}, 2 \mathrm{H}, \operatorname{ArCOOCH}_{2} \mathrm{CH}_{2} \mathrm{Ar}$ ); 4,63 (t, $\left.J=7,1 \mathrm{~Hz}, 2 \mathrm{H}, \operatorname{ArCOOC} \underline{H}_{2} \mathrm{CH}_{2} \mathrm{Ar}\right) ; 6,72(\mathrm{~d}, J=7,0 \mathrm{~Hz}, 1 \mathrm{H}, 3$ '); 6,85 (d, J=7,6 Hz, $\left.1 \mathrm{H}, 5^{\prime}\right) ; 7,28-7,29$ (m, 4H, 4', 2", 4" e 6”); 7,33-7,35 (m, 2H, 3" e 5").

$\mathrm{RMN}{ }^{13} \mathrm{C}(125 \mathrm{MHz}, \mathrm{CDCl})$ ): $\delta 14,3\left(\underline{\mathrm{CH}}_{3}, 15\right) ; 22,9\left(\underline{\mathrm{CH}}_{2}, 14\right) ; 29,5-30,0\left(\underline{\mathrm{CH}}_{2}, 3-12\right)$; $32,1\left(\underline{\mathrm{C}} \mathrm{H}_{2}, 2\right) ; 32,2\left(\underline{\mathrm{CH}}_{2}, 13\right) ; 35,1 \quad\left(\underline{\mathrm{CH}}_{2}, 1\right) ; 36,6 \quad\left(\operatorname{ArCOOCH}{ }_{2} \underline{\mathrm{CH}}_{2} \mathrm{Ar}\right) ; 66,2$

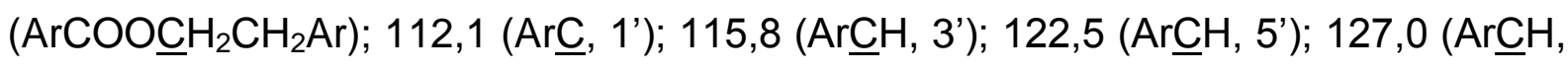

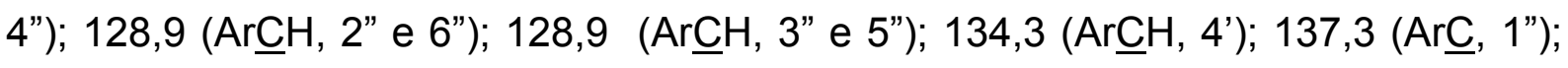

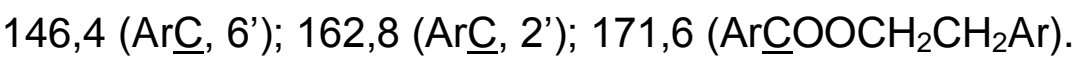




\section{Derivado 2-Hidróxi-6-pentadecilbenzoato de 3-fenilpropila (LDT665, 37)}

Sólido branco

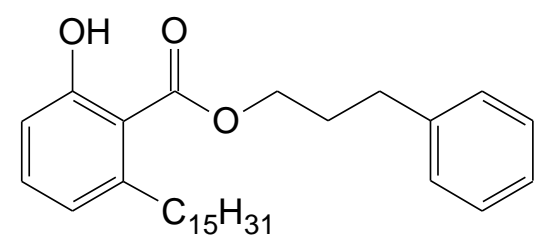

Rendimento $77 \%$

$\mathrm{R}_{\mathrm{f}}:$ 0,64 (Hex $\left.\mathrm{H}_{80 \%}: \mathrm{AcOEt}_{20 \%}\right)$

Ponto de fusão: $35-38^{\circ} \mathrm{C}$

Fórmula molecular: $\mathrm{C}_{31} \mathrm{H}_{46} \mathrm{O}_{3}$

Massa Molar: 466,695 g/mol

IV (KBr) $v_{\text {máx }} \mathrm{Cm}^{-1}: 3424\left(v_{\mathrm{OH}}\right) ; 2951$ ( $\left.v_{\mathrm{asCH}}\right) ; 2918\left(v_{\mathrm{asCH} 2}\right) ; 2850\left(v_{\mathrm{SCH}}\right) ; 1661\left(v_{\mathrm{C}=\mathrm{O}}\right)$; $1450\left(v_{\mathrm{C}=\mathrm{C}}\right) ; 1247\left(v_{\mathrm{asC}-\mathrm{o}}\right)$.

RMN ${ }^{1} \mathrm{H}\left(300 \mathrm{MHz}, \mathrm{CDCl}_{3}\right): \delta 0,91$ (t, $\left.J=6,6 \mathrm{~Hz}, 3 \mathrm{H}, 15\right) ; 1,28-1,33(\mathrm{~m}, 24 \mathrm{H}, 3-14)$; 1,60 (qi, $J=7,5 \mathrm{~Hz}, 2 \mathrm{H}, 2$ ); 2,11-2,20 (m, 2H, $\operatorname{ArCOOCH}_{2} \mathrm{CH}_{2} \mathrm{CH}_{2} \mathrm{Ar}$ ); 2,81 (t, $J=7,6$ $\mathrm{Hz}, 2 \mathrm{H}, 2 \mathrm{H}, 1$ ); 2,96 (t, $J=7,7 \mathrm{~Hz}, 2 \mathrm{H}, \mathrm{ArCOOCH}_{2} \mathrm{CH}_{2} \mathrm{C}_{2} \mathrm{Ar}$ ); 4,42 (t, $J=6,6 \mathrm{~Hz}$, $\left.2 \mathrm{H}, \mathrm{ArCOOC} \underline{H}_{2} \mathrm{CH}_{2} \mathrm{CH}_{2} \mathrm{Ar}\right) ; 6,74-6,76\left(\mathrm{~m}, 1 \mathrm{H}, 3^{\prime}\right) ; 6,85-6,88\left(\mathrm{~m}, 1 \mathrm{H}, 5^{\prime}\right) ; 7,21-7,26$ (m, 3H, 2", 4" e 6"); 7,29-7,35 (m, 3H, 3", 5" e 4'); 11,24 (s, ArOㅡㄴ).

RMN ${ }^{13} \mathrm{C}\left(75 \mathrm{MHz}, \mathrm{CDCl}_{3}\right): \delta$ 14,3 $\left(\underline{\mathrm{CH}}_{3}, 15\right) ; 22,9\left(\underline{\mathrm{C}} \mathrm{H}_{2}, 14\right) ; 29,5-30,1\left(\underline{\mathrm{C}} \mathrm{H}_{2}, 3-12\right)$; $30,3 \quad\left(\mathrm{ArCOOCH}_{2} \underline{\mathrm{CH}_{2}} \mathrm{CH}_{2} \mathrm{Ar}\right) ; \quad 32,1 \quad\left(\underline{\mathrm{CH}}_{2}, \quad 2\right) ; \quad 32,4 \quad\left(\underline{\mathrm{C}} \mathrm{CH}_{2}, \quad 13\right) ; \quad 32,6$ $\left(\operatorname{ArCOOCH}{ }_{2} \mathrm{CH}_{2} \underline{\mathrm{C}} \mathrm{H}_{2} \mathrm{Ar}\right) ; 36,8\left(\underline{\mathrm{C}} \mathrm{H}_{2}, 1\right) ; 65,3\left(\mathrm{ArCOO} \underline{\mathrm{C}} \mathrm{H}_{2} \mathrm{CH}_{2} \mathrm{CH}_{2} \mathrm{Ar}\right) ; 112,2$ (Ar $\left.\underline{\mathrm{C}}, 1^{\prime}\right)$;

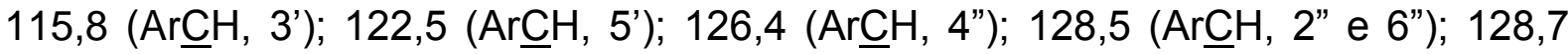

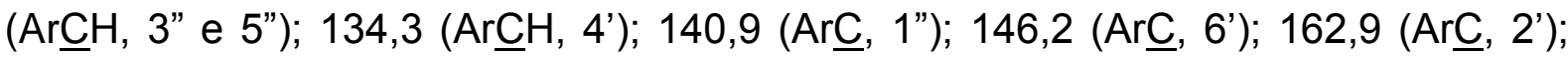
$171,9\left(\mathrm{Ar} \underline{\mathrm{COOCH}} \mathrm{CH}_{2} \mathrm{Ar}\right)$.

\subsubsection{Obtenção dos Derivados Amidas e Ésteres: 2'-acetoxissubstituídos}
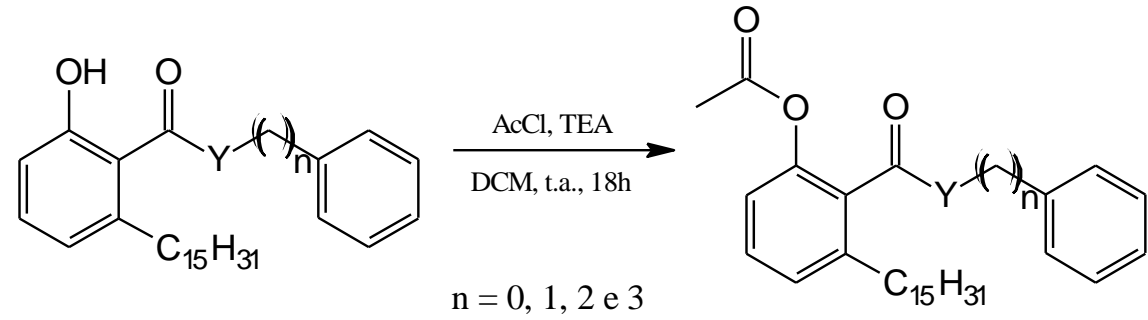

$\mathrm{Y}=\mathrm{NH}(\mathrm{LDT} 82, \mathrm{LDT} 645, \mathrm{LDT} 647, \mathrm{LDT} 649)$

$\mathrm{Y}=\mathrm{NH}(\mathrm{LDT} 675$, LDT677, LDT679, LDT681)

$\mathrm{Y}=\mathrm{O}$ (LDT659, LDT661, LDT663, LDT665)

$\mathrm{Y}=\mathrm{O}$ (LDT683, LDT685, LDT687, LDT689) 
Em um balão ( $25 \mathrm{~mL}$ ) foram adicionados $0,20 \mathrm{~g}$ do derivado hidroxilado, TEA (2,5 eqv.), cloreto de acetila (1,5 eqv.) e diclorometano seco $(6,0 \mathrm{~mL})$. O sistema reacional permaneceu sob agitação magnética à temperatura ambiente por 18 horas. Após esse período, a mistura foi extraída com acetato de etila $(3 \times 10,0 \mathrm{~mL})$, e a fase orgânica reunida lavada com soluções de bicarbonato de sódio 5\% (3 x 10,0 $\mathrm{mL}$ ), solução de $\mathrm{HCl} 10 \%$ ( $2 \times 10,0 \mathrm{~mL})$, saturada de cloreto de sódio $(10,0 \mathrm{~mL})$, e seca com sulfato de sódio. Após remoção do solvente à pressão reduzida, o resíduo foi purificado em coluna cromatográfica de gel de sílica, eluída em mistura de hexano e acetato de etila em diferentes concentrações, fornecendo os derivados.

\section{Derivado Acetato de 3-Pentadecil-2-(fenillcarbamoil)fenila (LDT675, 38)}

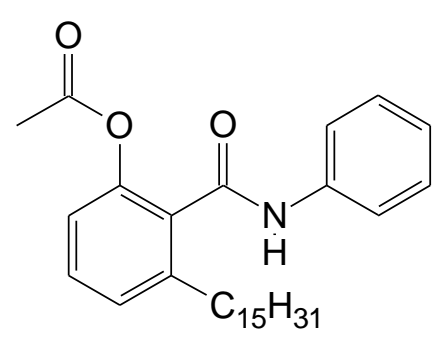

Sólido branco

Rendimento $75 \%$

$\mathrm{R}_{\mathrm{f}}:$ 0,33 (Hex $\left.\mathrm{H}_{80 \%}: \mathrm{AcOEt}_{20 \%}\right)$

Ponto de fusão: $44-47^{\circ} \mathrm{C}$

Fórmula molecular: $\mathrm{C}_{30} \mathrm{H}_{43} \mathrm{NO}_{3}$

Massa Molar: 465,667 g/mol

IV (KBr) $v_{\text {máx }} \mathrm{Cm}^{-1}: 3255\left(v_{\mathrm{NH}}\right) ; 2958\left(v_{\mathrm{asCH}}\right) ; 2919\left(v_{\mathrm{asCH} 2}\right) ; 2848\left(v_{\mathrm{SCH}}\right) ; 1761\left(v_{\mathrm{C}=\mathrm{O}}\right)$; 1528, $1499\left(v_{\mathrm{C}=\mathrm{C}}\right) ; 1214\left(\mathrm{v}_{\mathrm{asc}-\mathrm{O}}\right)$.

RMN ${ }^{1} \mathrm{H}\left(500 \mathrm{MHz}, \mathrm{CDCl}_{3}\right): \delta 0,89(\mathrm{t}, J=6,8 \mathrm{~Hz}, 3 \mathrm{H}, 15) ; 1,22-1,33(\mathrm{~m}, 24 \mathrm{H}, 3-14)$; 1,64-1,68 (m, 2H, 2); 2,22 (s, 3H, ArOCOC $\left.\underline{H}_{3}\right) ; 2,73(\mathrm{t}, J=7,9 \mathrm{~Hz}, 2 \mathrm{H}, 1) ; 6,95$ (d, $J=$ $\left.8,1 \mathrm{~Hz}, 1 \mathrm{H}, 3^{\prime}\right) ; 7,17-7,20$ (m, 2H, 5' e 4"); 7,37 (t, $J=7,8 \mathrm{~Hz}, 3 \mathrm{H}, 2$ ", 6" e 4'); 7,50 (s, $1 \mathrm{H}, \operatorname{ArCON} \underline{H A r}) ; 7,57$ (d, $J=8,0 \mathrm{~Hz}, 2 \mathrm{H}, 3$ " e 5").

RMN ${ }^{13} \mathrm{C}\left(125 \mathrm{MHz}, \mathrm{CDCl}_{3}\right): \delta 14,3\left(\underline{\mathrm{CH}}_{3}, 15\right) ; 21,1\left(\mathrm{ArOCO}^{\mathrm{C}} \mathrm{H}_{3}\right) ; 22,9\left(\underline{\mathrm{C}} \mathrm{H}_{2}, 14\right)$;

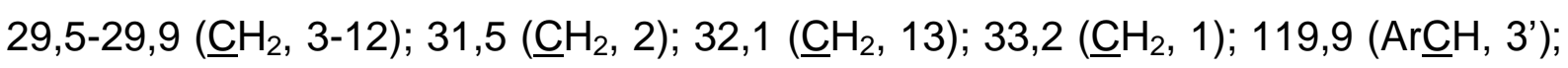

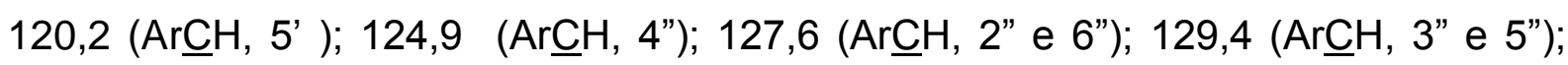

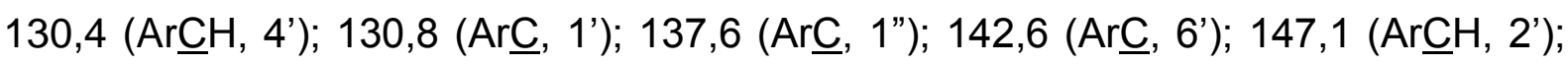

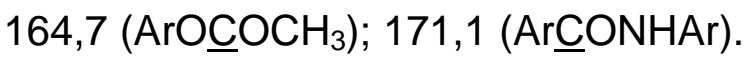




\section{Derivado Acetato de 2-(Benzilcarbamoil)-3-pentadecilfenila (LDT677, 39)}

Sólido branco

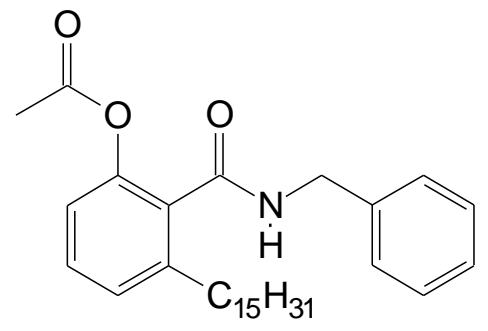

Rendimento $85 \%$

$\mathrm{R}_{\mathrm{f}}:$ 0,28 (Hex $\left.{ }_{80 \%}: \mathrm{AcOEt}_{20 \%}\right)$

Ponto de fusão: $73-76^{\circ} \mathrm{C}$

Fórmula molecular: $\mathrm{C}_{31} \mathrm{H}_{45} \mathrm{NO}_{3}$

Massa Molar: 479,694 g/mol

IV (KBr) $v_{\text {máx }} \mathrm{cm}^{-1}: 3395\left(v_{\mathrm{NH}}\right) ; 2956\left(v_{\mathrm{asCH} 3}\right) ; 2918\left(v_{\mathrm{asCH} 2}\right) ; 2850\left(v_{\mathrm{SCH} 2}\right) ; 1768\left(v_{\mathrm{C}=0}\right)$; $1527,1458,\left(v_{\mathrm{C}=\mathrm{C}}\right) ; 1208\left(v_{\text {asC }}-\mathrm{o}\right)$.

RMN ${ }^{1} \mathrm{H}\left(500 \mathrm{MHz}, \mathrm{CDCl}_{3}\right): \delta 0,89(\mathrm{~m}, 3 \mathrm{H}, 15) ; 1,26(\mathrm{~m}, 24 \mathrm{H}, 3-14) ; 1,56-1,62(\mathrm{~m}$, $2 \mathrm{H}, 2) ; 1,98-1,99\left(\mathrm{~m}, 3 \mathrm{H}, \operatorname{ArOCOC}_{3}\right) ; 2,63-2,66(\mathrm{~m}, 2 \mathrm{H}, 1) ; 4,57-4,58(\mathrm{~m}, 2 \mathrm{H}$, $\operatorname{ArCONHCH}_{2} \mathrm{Ar}$ ); 6,14 (sl, $\operatorname{ArCON} \underline{H C H}_{2} \mathrm{CH}_{2} \mathrm{Ar}$ ); $6,87\left(\mathrm{~d}, J=8,0 \mathrm{~Hz}, 1 \mathrm{H}, 3^{\prime}\right) ; 7,12$ (d, J $=7,6 \mathrm{~Hz}, 1 \mathrm{H}, 5$ '); 7,27-7,30 (m, 3H, 2" e 6"); 7,35-7,36 (m, 4H, 4', 3", 4" e 5").

$\mathrm{RMN}{ }^{13} \mathrm{C}\left(125 \mathrm{MHz}, \mathrm{CDCl}_{3}\right): \delta$ 14,3 $\left(\underline{\mathrm{CH}}_{3}, 15\right) ; 20,7\left(\mathrm{ArOCO}^{\mathrm{C}} \mathrm{H}_{3}\right) ; 22,9\left(\underline{\mathrm{C}} \mathrm{H}_{2}, 14\right)$; $29,5-29,9 \quad\left(\underline{\mathrm{C}}_{2}, 3-12\right) ; 31,6 \quad\left(\underline{\mathrm{C}} \mathrm{H}_{2}, 2\right) ; 32,1 \quad\left(\underline{\mathrm{C}}_{2}, 13\right) ; 33,3 \quad\left(\underline{\mathrm{C}} \mathrm{H}_{2}, 1\right) ; 43,9$

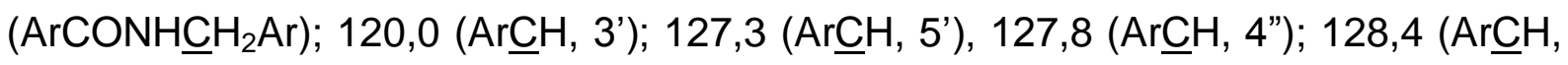

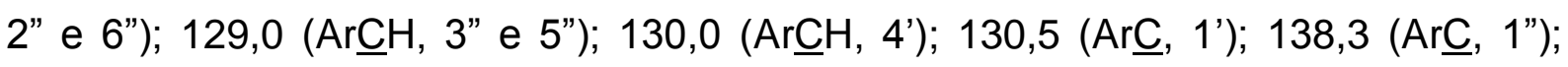

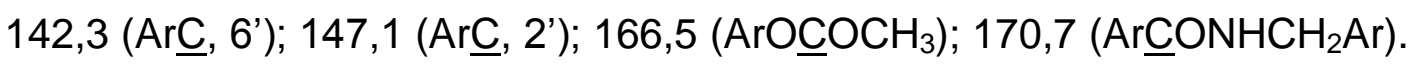

\section{Derivado Acetato de 2-(Fenetilcarbamoil)-3-pentadecilfenila (LDT679, 40)}

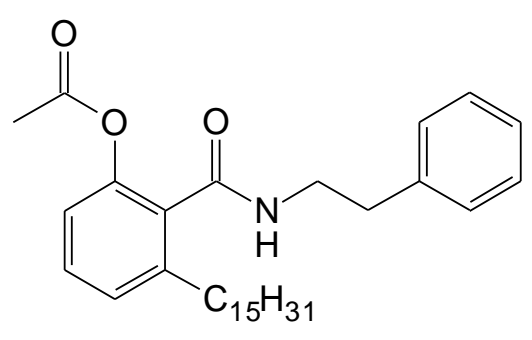

Sólido branco

Rendimento $73 \%$

$\mathrm{R}_{\mathrm{f}}:$ 0,36 (Hex $\left.{ }_{80 \%}: \mathrm{AcOEt}_{20 \%}\right)$

Ponto de fusão: $53-65^{\circ} \mathrm{C}$

Fórmula molecular: $\mathrm{C}_{32} \mathrm{H}_{47} \mathrm{NO}_{3}$

Massa Molar: 493,720 g/mol

IV (KBr) $v_{\text {máx }} \mathrm{Cm}^{-1}: 3287\left(v_{\mathrm{NH}}\right) ; 2921\left(v_{\mathrm{asCH} 2}\right) ; 2851\left(v_{\mathrm{SCH} 2}\right) ; 1767\left(v_{\mathrm{C}=\mathrm{O}}\right) ; 1640\left(v_{\mathrm{C}=\mathrm{O}}\right)$; $1549,1458\left(v_{\mathrm{C}=\mathrm{C}}\right) ; 1193\left(v_{\text {asc }}-\mathrm{o}\right)$. 
$\mathrm{RMN}^{1} \mathrm{H}\left(500 \mathrm{MHz}, \mathrm{CDCl}_{3}\right): \delta 0,89(\mathrm{t}, J=6,9 \mathrm{~Hz}, 3 \mathrm{H}, 15) ; 1,26-1,20$ (m, 24H, 3-14); 1,55-1,58 (m, 2H, 2); 2,21 (s, 3H, $\left.\operatorname{ArOCOC}_{3}\right) ; 2,58(\mathrm{t}, J=7,9 \mathrm{~Hz}, 2 \mathrm{H}, 1) ; 2,89$ (t, $J=$ $7,2 \mathrm{~Hz}, 2 \mathrm{H}, \operatorname{ArCONHCH}{ }_{2} \underline{\mathrm{H}}_{2} \mathrm{Ar}$ ); 3,69 (q, $J=6,7 \mathrm{~Hz}, 2 \mathrm{H}, \operatorname{ArCONHC}_{2} \mathrm{CH}_{2} \mathrm{Ar}$ ); 5,82 (t, $\left.J=5,7 \mathrm{~Hz}, 1 \mathrm{H}, \operatorname{ArCON} \underline{\mathrm{H}} \mathrm{CH}_{2} \mathrm{CH}_{2} \mathrm{Ar}\right) ; 6,88\left(\mathrm{~d}, J=8,1 \mathrm{~Hz}, 1 \mathrm{H}, 3^{\prime}\right) ; 7,11$ (d, $J=7,7$ Hz, 1H, 5'); 7,23-7,25 (m, 3H, 4', 2" e 6"); 7,30-7,33 (m, 3H, 3", 4" e 5").

$\operatorname{RMN}{ }^{13} \mathrm{C}\left(125 \mathrm{MHz}, \mathrm{CDCl}_{3}\right): \delta 14,3\left(\underline{\mathrm{CH}}_{3}, 15\right) ; 21,0\left(\operatorname{ArOCO} \underline{\mathrm{CH}} \mathrm{H}_{3}\right) ; 22,8\left(\underline{\mathrm{CH}}_{2}, 14\right)$; 29,5-29,8 $\left(\underline{\mathrm{CH}}_{2}, 3-12\right) ; 31,5 \quad\left(\underline{\mathrm{CH}}_{2}, 2\right) ; 32,1 \quad\left(\underline{\mathrm{CH}}_{2}, 13\right) ; 33,1 \quad\left(\underline{\mathrm{C}} \mathrm{H}_{2}, 1\right) ; 35,9$

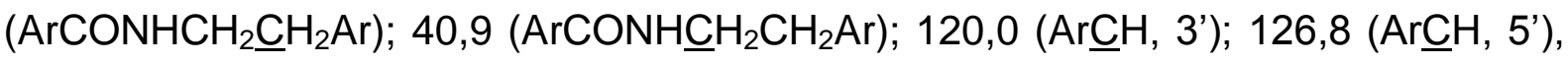

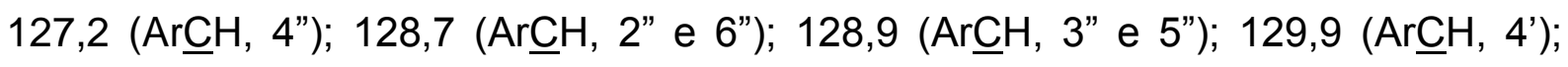

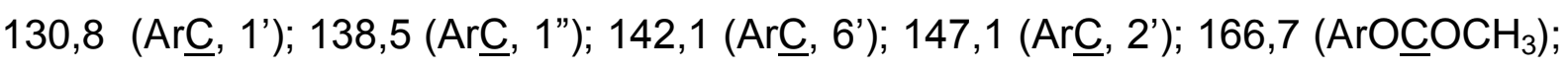
$170,5\left(\mathrm{Ar} \underline{\mathrm{CONHCH}} \mathrm{CH}_{2} \mathrm{Ar}\right)$.

Derivado Acetato de 2-(3-fenilpropilcarbamoil)-3-pentadecilfenila (LDT681, 41)

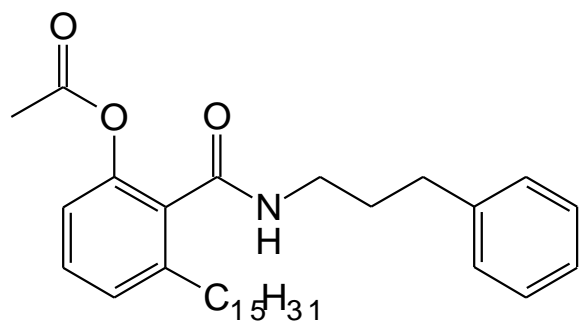

Sólido branco

Rendimento $80 \%$

$R_{f}: 0,36\left(\right.$ Hex $_{80 \%}:$ AcOEt $\left._{20 \%}\right)$

Ponto de fusão: $61-66^{\circ} \mathrm{C}$

Fórmula molecular: $\mathrm{C}_{33} \mathrm{H}_{49} \mathrm{NO}_{3}$

Massa Molar: 507,747 g/mol

IV $(\mathrm{KBr}) v_{\text {máx }} \mathrm{cm}^{-1}: 3273\left(v_{\mathrm{NH}}\right) ; 2920\left(v_{\mathrm{asCH} 2}\right) ; 2848\left(v_{\mathrm{SCH} 2}\right) ; 1645\left(v_{\mathrm{C}=\mathrm{O}}\right) ; 1542,1458$ $\left(v_{\mathrm{C}=\mathrm{C}}\right) ; 1211\left(v_{\mathrm{asC}-\mathrm{O}}\right)$.

$\mathrm{RMN}^{1} \mathrm{H}\left(300 \mathrm{MHz}, \mathrm{CDCl}_{3}\right): \delta 0,90(\mathrm{t}, J=7,5 \mathrm{~Hz}, 3 \mathrm{H}, 15) ; 1,27$ (s, 24H, 3-14); 1,57$1,64\left(\mathrm{~m}, 2 \mathrm{H}, 2\right.$ ); 1,90 (qi, $J=8,2 \mathrm{~Hz}, 2 \mathrm{H}, \operatorname{ArCONHCH}_{2} \underline{\mathrm{H}}_{2} \mathrm{CH}_{2} \mathrm{Ar}$ ); 2,25 (s, 3H, $\left.\operatorname{ArOCOC} \underline{H}_{3}\right) ; 2,62-2,73$ (m, 4H, 1 e $\operatorname{ArCONHCH}{ }_{2} \mathrm{CH}_{2} \underline{C H}_{2} \mathrm{Ar}$ ); 3,44 (q, J=6,0 Hz, 2H, $\operatorname{ArCONHCH}{ }_{2} \underline{\mathrm{H}}_{2} \mathrm{CH}_{2} \mathrm{Ar}$ ); 5,85 (t, $J=6,0 \mathrm{~Hz}, 1 \mathrm{H}, \operatorname{ArCON} \underline{\mathrm{HCH}} \mathrm{CH}_{2} \mathrm{CH}_{2} \mathrm{Ar}$ ); 6,90 (d, J = 6,0 Hz, 1H, 3'); 7,13 (d, J = 9,0 Hz, 1H, 5'); 7,19-7,23 (m, 3H, 4', 2" e 6"); 7,28-7,34 (m, 3H, 3", 4" e 5"). 
$\mathrm{RMN}{ }^{13} \mathrm{C}\left(75 \mathrm{MHz}, \mathrm{CDCl}_{3}\right): \delta 14,2\left(\underline{\mathrm{CH}}_{3}, 15\right) ; 21,1\left(\mathrm{ArOCO}_{\mathrm{C}} \mathrm{H}_{3}\right) ; 22,8\left(\underline{\mathrm{CH}}_{2}, 14\right) ; 29,5-$ 29,8 ( $\left.\underline{\mathrm{CH}}_{2}, 3-12\right) ; 31,5\left(\operatorname{ArCONHCH}{ }_{2} \underline{\mathrm{C}} \mathrm{H}_{2} \mathrm{CH}_{2} \mathrm{Ar}\right) ; 31,6\left(\underline{\mathrm{C}} \mathrm{H}_{2}, 2\right) ; 32,1\left(\underline{\mathrm{C}} \mathrm{H}_{2}, 13\right) ; 33,2$

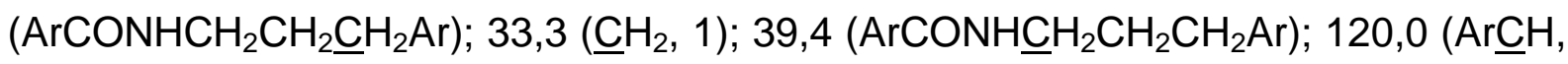

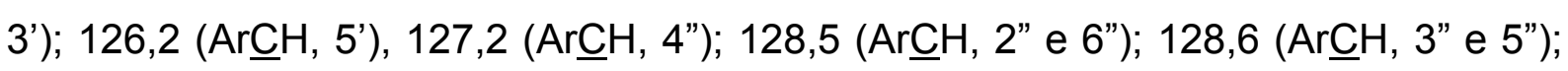

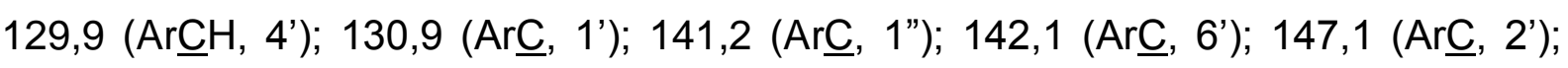
$\left.166,7\left(\mathrm{ArO}^{\mathrm{COCH}}\right)_{3}\right) ; 170,5\left(\mathrm{Ar} \underline{\mathrm{CONHCH}} \mathrm{CH}_{2} \mathrm{CH}_{2} \mathrm{Ar}\right)$.

\section{Derivado 2-(Acetóxi)-6-pentadecilbenzoato de fenila (LDT683, 42)}

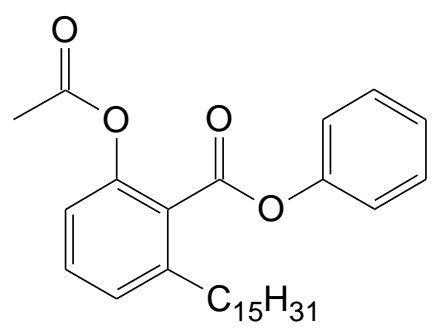

Sólido branco

Rendimento $76 \%$

$R_{f}: 0,48$ (Hex $80 \%:$ AcOEt $\left._{20 \%}\right)$

Ponto de fusão: $48-52^{\circ} \mathrm{C}$

Fórmula molecular: $\mathrm{C}_{30} \mathrm{H}_{42} \mathrm{O}_{4}$

Massa Molar: 466,652 g/mol

IV (KBr) $v_{\text {máx }} \mathrm{Cm}^{-1}: 2954\left(v_{\mathrm{asCH} 2}\right) ; 2921\left(v_{\mathrm{asCH} 2}\right) ; 2848\left(v_{\mathrm{SCH}}\right) ; 1763\left(v_{\mathrm{C}=\mathrm{O}}\right) ; 1589,1468$ $\left(v_{\mathrm{C}=\mathrm{C}}\right) ; 1212\left(v_{\text {asC }}-\mathrm{O}\right)$.

RMN ${ }^{1} \mathrm{H}\left(500 \mathrm{MHz}, \mathrm{CDCl}_{3}\right): \delta 0,89(\mathrm{t}, J=6,8 \mathrm{~Hz}, 3 \mathrm{H}, 15) ; 1,25-1,39(\mathrm{~m}, 24 \mathrm{H}, 3-14)$; 1,67-1,70 (qi, $J=7,7 \mathrm{~Hz}, 2 \mathrm{H}, 2$ ); 2,29 (s, 3H, $\operatorname{ArOCOC} \underline{H}_{3}$ ); 2,83 (t, $J=7,9 \mathrm{~Hz}, 2 \mathrm{H}, 1$ ); 7,06 (d, J = 8,1 Hz, 1H, 3'); 7,21 (m, 3H, 5' e 2" e 6"); 7,30 (m, 1H, 4'); 7,42-7,47 (m, $3 \mathrm{H}, 3$ ", 4" e 5").

$\mathrm{RMN}{ }^{13} \mathrm{C}\left(125 \mathrm{MHz}, \mathrm{CDCl}_{3}\right): \delta$ 14,3 $\left(\underline{\mathrm{CH}}_{3}, 15\right) ; 21,1\left(\mathrm{ArOCO}^{\mathrm{C}} \mathrm{H}_{3}\right) ; 22,9\left(\underline{\mathrm{C}} \mathrm{H}_{2}, 14\right)$;

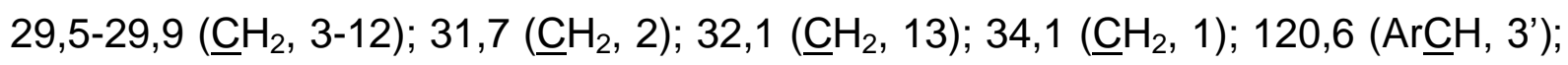

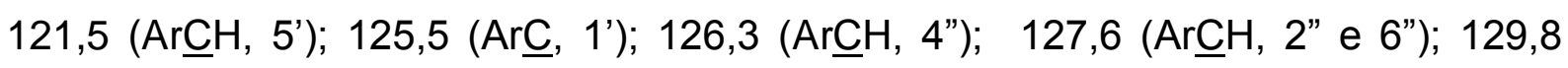

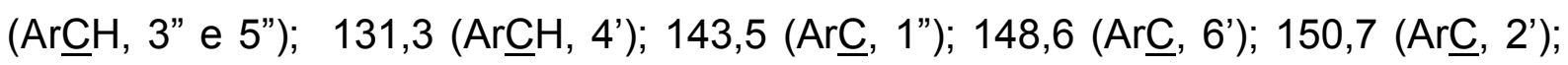

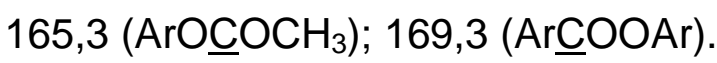




\section{Derivado 2-(Acetóxi)-6-pentadecilbenzoato de benzila (LDT685, 43)}

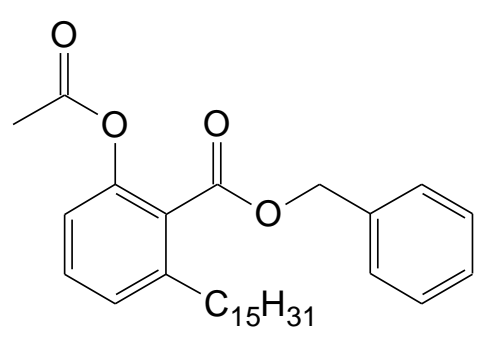

Sólido branco

Rendimento $88 \%$

$\mathrm{R}_{\mathrm{f}}:$ 0,34 (Hex ${ }_{90 \%}:$ AcOEt $\left._{10 \%}\right)$

Ponto de fusão: $37-43^{\circ} \mathrm{C}$

Fórmula molecular: $\mathrm{C}_{31} \mathrm{H}_{44} \mathrm{O}_{4}$

Massa Molar: 480,679 g/mol

IV (KBr) $v_{\text {máx }} \mathrm{Cm}^{-1}: 2915\left(v_{\mathrm{asCH} 2}\right) ; 2850\left(v_{\mathrm{SCH} 2}\right) ; 1727\left(v_{\mathrm{C}=0}\right) ; 1580,1472\left(v_{\mathrm{C}=\mathrm{C}}\right) ; 1269$ $\left(v_{\text {asc-o }}\right)$.

$\mathrm{RMN}^{1} \mathrm{H}\left(500 \mathrm{MHz}, \mathrm{CDCl}_{3}\right): \delta 0,89(\mathrm{~m}, 3 \mathrm{H}, 15) ; 1,23-1,27(\mathrm{~m}, 24 \mathrm{H}, 3-14) ; 1,51-1,52$ $(\mathrm{m}, 2 \mathrm{H}, 12) ; 1,99\left(\mathrm{~s}, 3 \mathrm{H}, \operatorname{ArOCOC}_{3}\right) ; 2,61-2,65(\mathrm{~m}, 2 \mathrm{H}, 1) ; 5,35(\mathrm{~s}, 2 \mathrm{H}$, $\left.\operatorname{ArCOOC} \underline{H}_{2} \mathrm{Ar}\right) ; 6,96\left(\mathrm{~d}, J=8,1 \mathrm{~Hz}, 1 \mathrm{H}, 3^{\prime}\right) ; 7,11(\mathrm{~d}, J=7,6 \mathrm{~Hz}, 1 \mathrm{H}, 5) ; 7,33-7,41(\mathrm{~m}$, $4 \mathrm{H}, 4$ ', 2", 4" e 6"); 7,45-7,46 (m, 2H, 3" e 5");

$\mathrm{RMN}{ }^{13} \mathrm{C}\left(125 \mathrm{MHz}, \mathrm{CDCl}_{3}\right): \delta 14,3\left(\underline{\mathrm{CH}}_{3}, 15\right) ; 20,7\left(\mathrm{ArOCO}_{\mathrm{C}} \mathrm{H}_{3}\right) 22,9\left(\underline{\mathrm{CH}}_{2}, 14\right)$; $29,5-29,9 \quad\left(\underline{\mathrm{C}} \mathrm{H}_{2}, 3-12\right) ; 31,6 \quad\left(\underline{\mathrm{C}} \mathrm{H}_{2}, 2\right) ; 32,1 \quad\left(\underline{\mathrm{C}}_{2}, 13\right) ; 33,9\left(\underline{\mathrm{C}} \mathrm{H}_{2}, 1\right) ; 67,2$

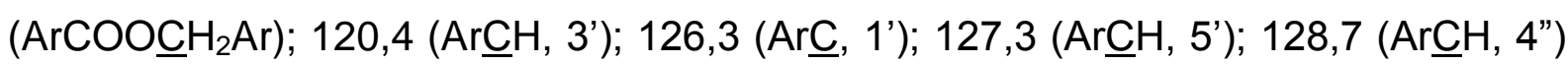

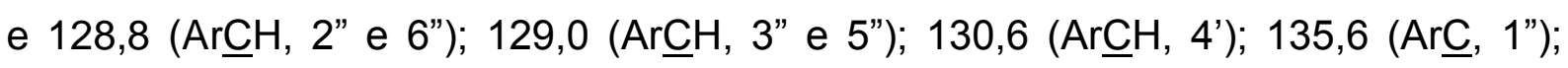

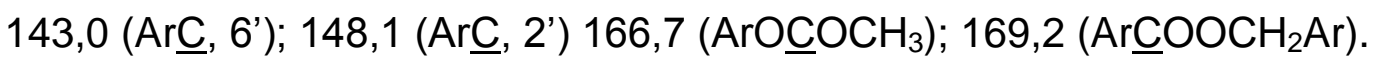

\section{Derivado 2-(Acetóxi)-6-pentadecilbenzoato de 2-fenetila (LDT687, 44)}

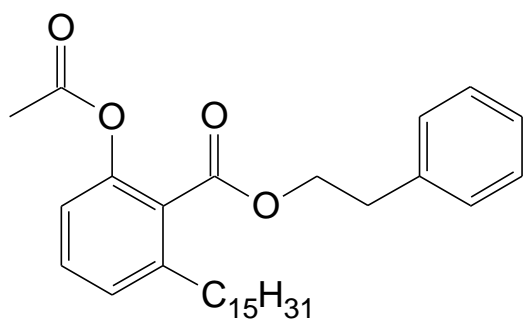

Sólido branco

Rendimento $77 \%$

$\mathrm{R}_{\mathrm{f}}: 0,50$ (Hex $\left.\mathrm{H}_{80 \%}: \mathrm{AcOEt}_{20 \%}\right)$

Ponto de fusão: $25-28^{\circ} \mathrm{C}$

Fórmula molecular: $\mathrm{C}_{32} \mathrm{H}_{46} \mathrm{O}_{4}$

Massa Molar: 494,705 g/mol 
IV (KBr) $v_{\text {máx }} \mathrm{Cm}^{-1}: 2921\left(v_{\text {asCH2}}\right) ; 2851\left(v_{\mathrm{SCH} 2}\right) ; 1762\left(v_{\mathrm{C}=0}\right) ; 1726\left(v_{\mathrm{C}=\mathrm{O}}\right) ; 1458\left(v_{\mathrm{C}=\mathrm{C}}\right)$; $1270\left(v_{\text {asc-o }}\right)$.

$\mathrm{RMN}^{1} \mathrm{H}\left(300 \mathrm{MHz}, \mathrm{CDCl}_{3}\right): \delta 0,90(\mathrm{t}, J=6,6 \mathrm{~Hz}, 3 \mathrm{H}, 15) ; 1,26-1,32(\mathrm{~s}, 29 \mathrm{H}, 3-14)$; 1,51-1,54 (m, 2H, 12); 2,17 (s, 3H, ArOCOCH $\left.{ }_{3}\right) ; 2,60$ (t, $\left.J=7,8 \mathrm{~Hz}, 2 \mathrm{H}, 1\right) ; 3,05$ (t, $J$ $\left.=7,1 \mathrm{~Hz}, 2 \mathrm{H}, \mathrm{ArCOOCH}_{2} \underline{\mathrm{CH}}_{2} \mathrm{Ar}\right) ; 4,52\left(\mathrm{t}, J=7,2 \mathrm{~Hz}, 2 \mathrm{H}, \mathrm{ArCOOC}_{2} \mathrm{CH}_{2} \mathrm{Ar}\right.$ ); 6,98 (d, $\left.J=8,0 \mathrm{~Hz}, 1 \mathrm{H}, 3^{\prime}\right) ; 7,11$ (d, $J=7,5 \mathrm{~Hz}, 1 \mathrm{H}, 5$ '); 7,25-7,38 (m, 6H, 4', 2" , 3", 4", 5" e $6 ")$.

$\mathrm{RMN}{ }^{13} \mathrm{C}\left(75 \mathrm{MHz}, \mathrm{CDCl}_{3}\right): \delta$ 14,3 $\left(\underline{\mathrm{CH}}_{3}, 15\right) ; 20,9\left(\mathrm{ArOCO} \mathrm{H}_{3}\right) ; 22,9\left(\underline{\mathrm{CH}}_{2}, 14\right) ; 29,5-$ $29,9 \quad\left(\underline{\mathrm{C}} \mathrm{H}_{2}, \quad 3-12\right) ; 31,4 \quad\left(\underline{\mathrm{C}} \mathrm{H}_{2}, \quad 2\right) ; 32,1 \quad\left(\underline{\mathrm{CH}}_{2}, \quad 13\right) ; \quad 33,8 \quad\left(\underline{\mathrm{C}}_{2}, \quad 1\right) ; 35,2$

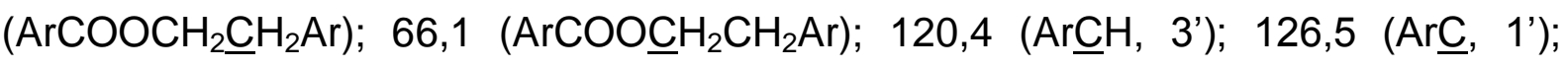

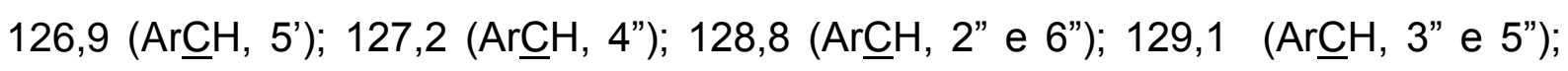

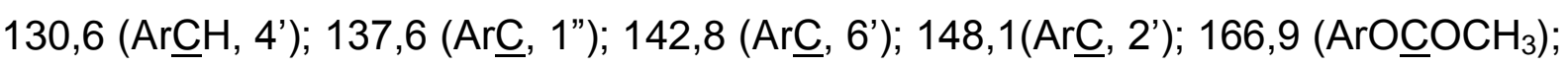
$169,1\left(\mathrm{Ar} \underline{\mathrm{COOCH}} \mathrm{CH}_{2} \mathrm{Ar}\right)$.

\title{
Derivado 2-(Acetóxi)-6-pentadecilbenzoato de 3-fenilpropila (LDT689, 45)
}

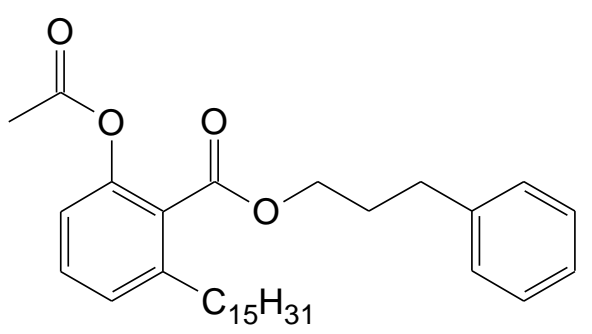

\author{
Líquido transparente \\ Rendimento $61 \%$ \\ $\mathrm{R}_{\mathrm{f}}:$ 0,50 (Hex $\left.\mathrm{H}_{80 \%}: \mathrm{AcOEt}_{20 \%}\right)$ \\ Fórmula molecular: $\mathrm{C}_{33} \mathrm{H}_{48} \mathrm{O}_{4}$ \\ Massa Molar: $508,732 \mathrm{~g} / \mathrm{mol}$
}

IV (KBr) $v_{\text {máx }} \mathrm{Cm}^{-1}: 3028\left(v_{=\mathrm{CH}}\right) ; 2924\left(v_{\mathrm{asCH} 2}\right) ; 2854\left(v_{\mathrm{SCH} 2}\right) ; 1731\left(v_{\mathrm{C}=0}\right) ; 1456\left(v_{\mathrm{C}=\mathrm{C}}\right)$; $1269\left(v_{\text {asc-o }}\right)$.

RMN ${ }^{1} \mathrm{H}\left(300 \mathrm{MHz}, \mathrm{CDCl}_{3}\right): \delta$ 0,89 (t, $\left.J=7,5 \mathrm{~Hz}, 3 \mathrm{H}, \mathrm{CH}_{3}, 15\right) ; 1,26-1,27(\mathrm{~m}, 29 \mathrm{H}$, $\mathrm{C}_{2}$, 3-14); 1,56-1,66 (m, 2H, 12); 2,06 (qi, $J=7,1 \mathrm{~Hz}, 2 \mathrm{H}, \operatorname{ArCOOCH}_{2} \mathrm{CH}_{2} \mathrm{CH}_{2} \mathrm{Ar}$ ); 2,25 (s, 3H, ArOCOCH $\left.{ }_{3}\right) ; 2,66-2,78\left(\mathrm{~m}, 4 \mathrm{H}, 1, \mathrm{ArCOOCH}_{2} \mathrm{CH}_{2} \mathrm{CH}_{2} \mathrm{Ar}\right) ; 4,33$ (t, $J=6,5$ $\mathrm{Hz}, 2 \mathrm{H}, \operatorname{ArCOOC}_{2} \mathrm{CH}_{2} \mathrm{CH}_{2} \mathrm{Ar}$ ); $6,99\left(\mathrm{~d}, J=8,0 \mathrm{~Hz}, 1 \mathrm{H}, 3^{\prime}\right) ; 7,14(\mathrm{~d}, J=7,6 \mathrm{~Hz}, 1 \mathrm{H}$, 5'); 7,19-7,23 (m, 3H, 2", 4" e 6"); 7,27-7,30 (m, 2H, 3" e 5"); 7,34-7,39 (m, 1H, 4'). 
$\mathrm{RMN}{ }^{13} \mathrm{C}\left(75 \mathrm{MHz}, \mathrm{CDCl}_{3}\right): \delta 14,3\left(\underline{\mathrm{CH}}_{3}, 15\right) ; 21,0\left(\mathrm{ArOCOCH}_{3}\right) 22,9\left(\underline{\mathrm{CH}} \mathrm{H}_{2}, 14\right) ; 29,5-$ $29,8\left(\underline{\mathrm{C}} \mathrm{H}_{2}, 3-12\right) ; 30,5\left(\operatorname{ArCOOCH}{ }_{2} \underline{\mathrm{C}} \mathrm{H}_{2} \mathrm{CH}_{2} \mathrm{Ar}\right) ; 31,6\left(\underline{\mathrm{C}} \mathrm{H}_{2}, 2\right) ; 32,1\left(\underline{\mathrm{C}} \mathrm{H}_{2}, 13\right) ; 32,3$

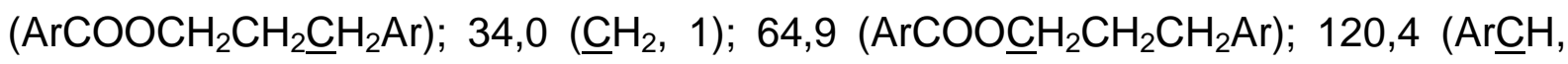

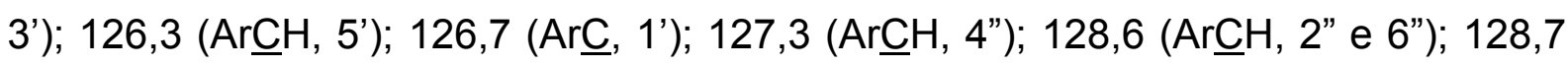

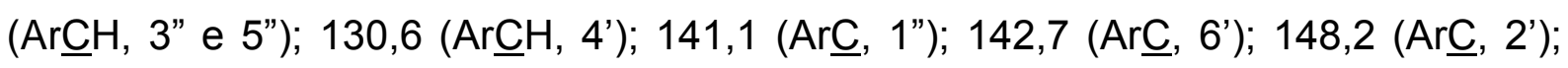
$167,0\left(\mathrm{ArO}_{\mathrm{COCH}}\right) ; 169,1\left(\mathrm{Ar} \underline{\mathrm{COOCH}} \mathrm{CH}_{2} \mathrm{CH}_{2} \mathrm{Ar}\right)$.

\subsubsection{Avaliação biológica frente à enzima p300}

Os procedimentos de síntese, purificação e caracterização foram realizados de acordo com os protocolos do SGC [68]. Os compostos foram testados em três diferentes concentrações (10, 30 e $100 \mu \mathrm{M})$ e o ensaio foi baseado em radioatividade. $O$ ensaio de avaliação da inibição enzimática da histona acetiltransferase p300 foi realizado com $10 \mathrm{nM}$ de p300, $2 \mu \mathrm{M}$ da histona $\mathrm{H} 3$ (1-25) e 2,5 $\mu \mathrm{M}{ }^{3} \mathrm{H}$-AcetylCoA em $50 \mathrm{mM}$ de Hepes pH 7,5, 0,2 mM de EDTA e 0,01\% de Triton, com 90 minutos de incubação à temperatura ambiente.

\subsubsection{Avaliação biológica frente a PPAR- $\alpha$ e PPAR-y}

As células do rim embrionário humano HEK293 foram mantidas em DMEM suplementado com $10 \%$ de soro fetal bovino. A transfecção foi realizada com $10 \%$ de soro fetal bovino tratado com carvão ativo utilizando fosfato de cálcio em 96 poços. O plasmídeo (150 ng por poço) incluiu $50 \mathrm{ng}$ do repórter UAS-luc , $20 \mathrm{ng}$ de $\beta$-galactosidase, $15 \mathrm{ng}$ do receptor nuclear (GAL4-hPPARa e GAL4-hPPARY) e pGEM. Os compostos foram acrescentados após 6-8 horas da transfecção. As células foram testadas após 14-16 horas quanto à atividade de luciferase e $\beta$ galactosidase. 


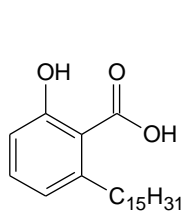

LDT11 (16)

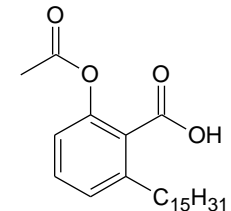

LDT13 (17)<smiles>COC(=O)c1c([13CH3])cccc1OC</smiles>

LDT28 (18)<smiles>CCCCCCCCc1cccc(O)c1C(=O)OC</smiles>

LDT29 (19)<smiles>COc1cccc(C#N)c1C(=O)O</smiles>

LDT30 (20)<smiles>COC(=O)c1c([13CH3])cccc1OC(C)=O</smiles>

LDT208 (21)<smiles>CCCCCCCCCCCCCCCc1cccc(OC)c1C(=O)Nc1ccccc1</smiles>

LDT651 (22)<smiles>COc1cccc(C#N)c1C(=O)NCc1ccccc1</smiles>

LDT653 (23)<smiles>COc1cccc(C#N)c1C(=O)NCCc1ccccc1</smiles>

LDT655 (24)<smiles>COc1cccc(C#N)c1C(=O)NCCCc1ccccc1</smiles><smiles>C#Cc1cccc(OC)c1C(=O)Oc1ccccc1</smiles>

LDT657 (25)

LDT667 (26)<smiles>COc1cccc(C#N)c1C(=O)OCc1ccccc1</smiles>

LDT669 (27)<smiles>COc1cccc(C#N)c1C(=O)OCCc1ccccc1</smiles>

LDT671 (28)<smiles>COc1cccc(C#N)c1C(=O)OCCCc1ccccc1</smiles><smiles>CC(F)(F)c1cccc(O)c1C(=O)Nc1ccccc1</smiles>

LDT82 (30)<smiles>N#Cc1cccc(O)c1C(=O)NCc1ccccc1</smiles>
LDT645 (31)

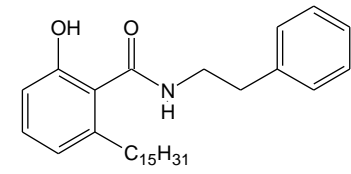

LDT647 (32)<smiles>N#Cc1cccc(O)c1C(=O)NCCCc1ccccc1</smiles><smiles>Cc1cccc(O)c1C(=O)Oc1ccccc1</smiles>

LDT659 (34)<smiles>C#Cc1cccc(O)c1C(=O)OCc1ccccc1</smiles><smiles>Cc1cccc(O)c1C(=O)OCCc1ccccc1</smiles>

LDT649 (33)<smiles>CCc1cccc(OC(C)=O)c1C(=O)Nc1ccccc1</smiles>

LDT675 (38)<smiles>CCc1cccc(OC(C)=O)c1C(=O)NCc1ccccc1</smiles>

LDT677 (39)<smiles>CC(=O)Oc1cccc(C)c1C(=O)NCCc1ccccc1</smiles>

LDT679 (40)<smiles>CC(=O)Oc1cccc(C(C)C)c1C(=O)NCCCc1ccccc1</smiles>

LDT681 (41)<smiles>CC(=O)Oc1cccc(C#N)c1C(=O)Oc1ccccc1</smiles>

LDT683 (42)<smiles>CCc1cccc(OC(C)=O)c1C(=O)OCc1ccccc1</smiles>

LDT685 (43)<smiles>CCc1cccc(OC(C)=O)c1C(=O)OCCc1ccccc1</smiles>

LDT687 (44)<smiles>CCCCCCCCOC(=O)c1c(CCCc2ccccc2)cccc1OC(C)=O</smiles>

LDT689 (45)

Figura 13: Derivados-alvo sintetizados a partir do ácido anacárdico

Fonte: Próprio autor 
Resultados e Discussão 


\section{RESULTADOS E DISCUSSÃO}

\subsection{SÍNTESE E CARACTERIZAÇÃO DOS COMPOSTOS}

As rotas sintéticas para obtenção dos derivados-alvo se basearam em metodologias sintéticas clássicas, em condições experimentais que variaram de acordo com a necessidade do experimento (à temperatura ambiente, sob refluxo e radiação micro-ondas). Os compostos foram caracterizados por meio de espectros na região do infravermelho (IV), bem como espectros de $\mathrm{RMN}{ }^{1} \mathrm{H}$ e ${ }^{13} \mathrm{C}$. As características físico-químicas PSA, $\log S, \log P, \log \mathrm{D}$ e pKa foram calculadas no programa Percepta/ACD Labs, versão 2014.

\subsubsection{Série dos Derivados 2-Acetóxi, hidróxi e metoxiácidos ou metil ésteres}

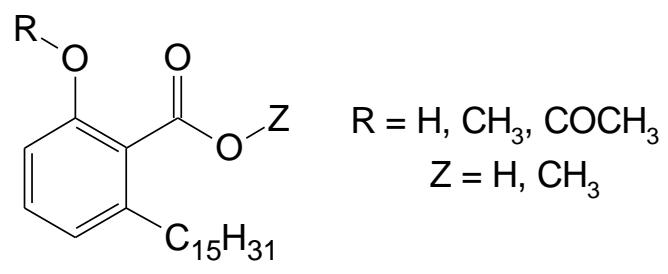

A mistura de ácidos anacárdicos (1) foi obtida por meio de extração a partir do LCC natural, segundo metodologia de quelação com hidróxido de cálcio [39, 42], em rendimento de $70 \%$ como um óleo castanho claro. Embora não tenha sido submetida à caracterização por métodos espectroscópicos, a mistura foi caracterizada por CCD apresentando única mancha azulada com Rf 0,48 (Hex:AcOEt 20\%). A metodologia se mostrou eficiente e limpa: eficiente devido à habilidade da subunidade salicílica - exclusiva dos ácidos anacárdicos dentre os compostos do LCC - de formar quelatos com íons metálicos divalentes; e limpa em detrimento da técnica anteriormente realizada, a qual se baseava na precipitação com hidróxido de chumbo. 


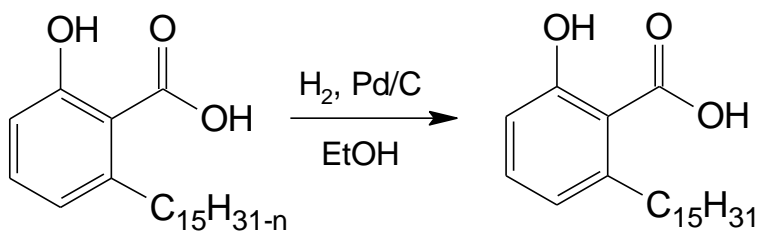

LDT11 (16)

A síntese dos derivados da série se deu a partir da hidrogenação catalítica da mistura de ácidos anacárdicos. Após purificação por recristalização em hexano, o derivado saturado LDT11 (16) foi obtido em rendimento de 70\%, como um sólido branco floculoso. 16 foi caracterizado por meio da mudança de estado físico e ponto de fusão compatível com a literatura $\left(81-84^{\circ} \mathrm{C}\right)$. Na análise espectroscópica por RMN os sinais característicos de 16 foram evidenciados por deslocamentos químicos referente ao grupo metila em 0,89 ppm (RMN ${ }^{1} \mathrm{H}$, Anexo 2, pág. 124) e 14,3 ppm (RMN ${ }^{13} \mathrm{C}$, Anexo 3, pág. 124). Os sinais entre 6,89 e 7,37 ppm no espectro de RMN ${ }^{1} \mathrm{H}$ demonstram a presença do anel aromático, corroborado pelos deslocamentos químicos entre 110,6 a 163,8 ppm no espectro de $\mathrm{RMN}{ }^{13} \mathrm{C}$. A cadeia alquílica está relacionada aos sinais entre 1,26 a 3,00 ppm nos espectros de hidrogênio; e 22,9 a 36,7 ppm nos espectros de carbono-13. O grupo carboxila foi identificado por deslocamento químico em 176,5 ppm $\left(\mathrm{RMN}{ }^{13} \mathrm{C}\right)$ e pela presença de absorção em $1610 \mathrm{~cm}^{-1}$ no Infravermelho. A absorção em $3326 \mathrm{~cm}^{-1}$ no espectro no IV (Anexo 1, pág. 123) foi atribuída às hidroxilas do fenol e do ácido carboxílico corroborou para a caracterização do derivado LDT11.

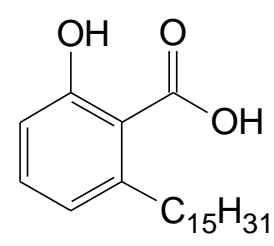

LDT11 (16)

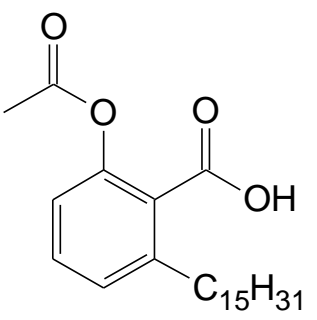

LDT13 (17)

O derivado 16 foi submetido à reação de acetilação com anidrido acético e ácido fosfórico como catalisador sob radiação micro-ondas em forno doméstico. Após purificação em coluna de gel de sílica eluída em mistura de hexano e acetato de etila em diferentes concentrações, LDT13 (17) foi obtido como sólido branco, caracterizado em CCD como uma única mancha com Rf 0,20 (Hex: AcOEt 20\%) em rendimento de $76 \%$. A presença do grupo acetila foi evidenciada pelos sinais em 2,30 ppm (metila) e 169,6 ppm (carbonila) nos espectros de RMN ${ }^{1} \mathrm{H}$ (Anexo 5, pág. 
127) e RMN ${ }^{13} \mathrm{C}$ (Anexo 6, pág. 128). Dois assinalamentos em $1763 \mathrm{~cm}^{-1}$ e $1701 \mathrm{~cm}$ ${ }^{1}$ em seu espectro no infravermelho (Anexo 4, pág. 126) demonstram a presença de duas carbonilas referentes aos grupos acetila e carboxila, o que contribuiu para a caracterização do derivado 17.

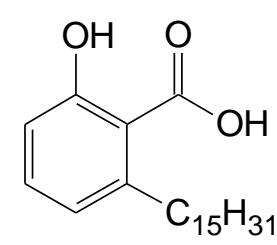

LDT11 (16)

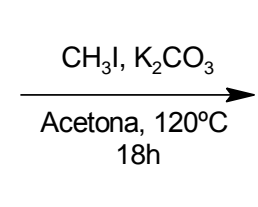

LDT28 (18)

A partir de LDT11 também foi obtido o derivado LDT28 (18), por meio da reação de dimetilação com iodeto de metila e carbonato de potássio em acetona, à temperatura de $120^{\circ} \mathrm{C}$ e resfriamento do condensador em circulador a $-8^{\circ} \mathrm{C}$. O LDT28 foi purificado em coluna cromatográfica eluída em diferentes concentrações de hexano/acetato de etila e obtido em rendimento de $97 \%$, como um sólido branco de baixo ponto de fusão $\left(32-33^{\circ} \mathrm{C}\right.$ ) e $\operatorname{Rf} 0,40$ (Hex:AcOEt $10 \%$ ). Na análise espectroscópica, 18 apresentou deslocamentos químicos como simpletos em 3,82 ppm e 3,91 ppm no espectro de RMN ${ }^{1} \mathrm{H}$ (Anexo 8, pág. 130) evidenciam a presença das metilas (metoxila e éster metílico), a qual foi confirmada pelos sinais em 52,2 ppm e 56,0 ppm do espectro de $\mathrm{RMN}^{13} \mathrm{C}$ (Anexo 9, pág. 131). O espectro na região do infravermelho (Anexo 7, pág. 129) apresentou banda em $1732 \mathrm{~cm}^{-1}$ referente ao estiramento do grupo carbometoxila, o que corroborou para a caracterização do éster metílico LDT28.

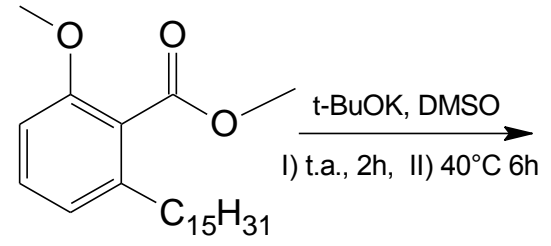

LDT28 (18)<smiles>CCCCCCCCCCCCCCCCCc1cccc(OC)c1C(=O)O</smiles>

LDT30 (20)

De posse do derivado LDT28 (18), este foi submetido à reação de hidrólise, na presença de tert-butóxido de potássio e DMSO, sob aquecimento de $40^{\circ} \mathrm{C}$ em banho de óleo por 18 horas [46]. O derivado LDT30 (20) foi purificado em coluna cromatográfica de gel de sílica e obtido como um sólido branco em rendimento de $98 \%$. A conversão reacional de $\mathbf{1 8}$ para $\mathbf{2 0}$ foi evidenciada na mudança de Rf $(0,28$ Hex:AcOEt $20 \%$ ) em CCD e ponto de fusão $\left(74-77^{\circ} \mathrm{C}\right)$. O grupo funcional ácido carboxílico foi evidenciado pela ausência de sinais correspondentes à metila do 
éster em 3,91 ppm e 52,2 ppm em seus espectros de RMN ${ }^{1} \mathrm{H}$ (Anexo 11, pág. 133) e RMN ${ }^{13} \mathrm{C}$ (Anexo 12, pág. 134). Adicionalmente, o espectro na região do infravermelho (Anexo 10, pág. 132) apresentou sinal em $3265 \mathrm{~cm}^{-1}$ e $1715 \mathrm{~cm}^{-1}$ referentes ao grupo hidroxila e carboxila da subunidade ácida, o que contribuiu para a caracterização do composto 20.

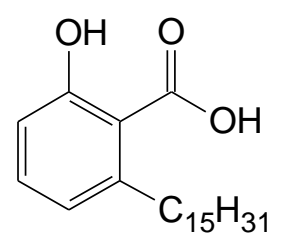

LDT11 (16)

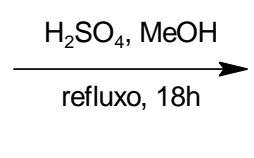

Partindo novamente do derivado LDT11 (16), este foi submetido à reação de esterificação por meio de catálise ácida com ácido sulfúrico, em metanol, sob refluxo. Após purificação em coluna cromatográfica, o derivado LDT29 (19) foi obtido em rendimento de $86 \%$, como um sólido branco com ponto de fusão entre $37 \mathrm{e}$ $40^{\circ} \mathrm{C}$. Foi caracterizado em CCD como uma única mancha (Rf 0,60 Hex:AcOEt 20\%). Este composto apresentou em seus espectros de RMN ${ }^{1} \mathrm{H}$ (Anexo 14, pág. 136) e RMN ${ }^{13} \mathrm{C}$ (Anexo 15, pág. 137) sinais em 3,96 ppm e 52,3 ppm, respectivamente, característicos para a metila do éster. $\mathrm{Na}$ avaliação do seu espectro no infravermelho (Anexo 13, pág. 135), a presença de assinalamentos em $1250 \mathrm{~cm}^{-1}$ e $1203 \mathrm{~cm}^{-1}$ referentes ao estiramento C-O, e em $1663 \mathrm{~cm}^{-1}$ referente à carbonila. A hidroxila fenólica de 19 foi caracterizada como simpleto em 11,13 ppm em RMN ${ }^{1} \mathrm{H}$, característico de ligação de hidrogênio intramolecular e absorção em $3433 \mathrm{~cm}^{-1}$ no infravermelho.

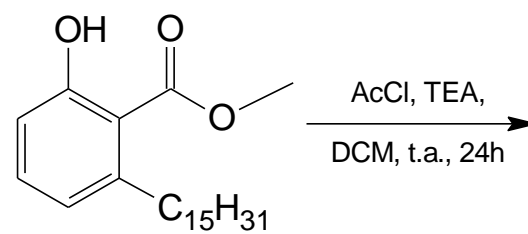

LDT29 (19)<smiles>CCCCCCC(C)(C)c1cccc(OC(C)=O)c1C(=O)OC</smiles>

LDT208 (21)

De posse do derivado LDT29 (19), este foi submetido à reação de acetilação com cloreto de acetila, na presença de TEA, à temperatura ambiente. Após 24 horas de reação e seguinte purificação, o derivado LDT208 (21) foi obtido em rendimento de 58\% como um sólido branco. $\mathrm{Na}$ análise espectroscópica, o composto apresentou deslocamentos referentes à metila do grupo acetila em 2,26 ppm e 20,9 
ppm em seus espectros de RMN ${ }^{1} \mathrm{H}$ (Anexo 17, pág. 139) e RMN ${ }^{13} \mathrm{C}$ (Anexo 18, pág. 140). O grupo acetil foi confirmado pela presença de sinal em 167,3 ppm no espectro de $\mathrm{RMN}{ }^{13} \mathrm{C}$ correspondente à carbonila. A presença das bandas em 1731 $\mathrm{cm}^{-1}, 1368 \mathrm{~cm}^{-1}$ e $1246 \mathrm{~cm}^{-1}$ no espectro no infravermelho (Anexo 16, pág, 138), correspondentes à carbonila, à metila e ao estiramento C-O, corrobora a caracterização do derivado 21.

O resumo dos principais sinais que caracterizaram os compostos LDT11(16), LDT13 (17), LDT28 (18), LDT29 (19), LDT30 (20) e LDT208 (21) em seus espectros de $\mathrm{RMN}{ }^{1} \mathrm{H}$ e RMN ${ }^{13} \mathrm{C}$ estão dispostos na Tabela 2.

Tabela 2 - Principais deslocamentos químicos de RMN ${ }^{1} \mathrm{H}$ e $\mathrm{RMN}{ }^{13} \mathrm{C}$ e no infravermelho (IV) para a caracterização da série dos derivados 2-acetóxi, hidróxi e metoxiácidos ou metilésteres

\begin{tabular}{|c|c|c|c|c|c|c|c|}
\hline \multirow[b]{2}{*}{ RMN } & \multirow{2}{*}{ Grupos } & \multicolumn{6}{|c|}{$\mathrm{RMN}{ }^{1} \mathrm{H} / \mathrm{RMN}^{13} \mathrm{C}\left(\mathrm{ppm}, \mathrm{CDCl}_{3}\right)$} \\
\hline & & $\begin{array}{l}\text { LDT11 } \\
(16)\end{array}$ & $\begin{array}{l}\text { LDT13 } \\
(17)\end{array}$ & $\begin{array}{l}\text { LDT28 } \\
(18)\end{array}$ & $\begin{array}{l}\text { LDT29 } \\
(19)\end{array}$ & $\begin{array}{l}\text { LDT30 } \\
(20)\end{array}$ & $\begin{array}{l}\text { LDT208 } \\
(21)\end{array}$ \\
\hline${ }^{1} \mathrm{H}$ & & $6,89-7,37$ & $7,01-7,41$ & $6,76-7,27$ & $6,73-7,31$ & $6,81-7,34$ & $6,97-7,35$ \\
\hline${ }^{13} \mathrm{C}$ & $\mathrm{Ar}$ & $\begin{array}{l}110,6- \\
163,8\end{array}$ & $\begin{array}{c}120,8- \\
148,8\end{array}$ & $\begin{array}{l}108,5- \\
156,4\end{array}$ & $\begin{array}{l}112,0- \\
162,8\end{array}$ & $\begin{array}{c}108,8- \\
156,8\end{array}$ & $\begin{array}{c}120,4- \\
148,3\end{array}$ \\
\hline${ }^{1} H$ & $\mathrm{C}_{15} \mathrm{H}_{31}$ & $0,89-3,00$ & $0,89-2,81$ & $0,89-2,55$ & $0,89-2,89$ & $0,89-2,73$ & $0,89-2,67$ \\
\hline${ }^{13} \mathrm{C}$ & $(1-15)$ & $14,3-36,7$ & $14,3-34,1$ & $14,2-33,6$ & $14,2-36,8$ & $14,3-33,9$ & $14,2-34,9$ \\
\hline${ }^{1} \mathrm{H}$ & ArçOOH / & -- & -- & -- & -- & -- & -- \\
\hline${ }^{13} \mathrm{C}$ & $\mathrm{ArCOOCH}_{3}$ & 176,5 & 172,1 & 169,1 & 172,1 & 173,0 & 169,2 \\
\hline${ }^{1} \mathrm{H}$ & $\mathrm{ArCOOCH}_{2}$ & -- & -- & 3,91 & 3,96 & -- & 3,87 \\
\hline${ }^{13} \mathrm{C}$ & 3 & -- & -- & 52,2 & 52,3 & -- & 52,3 \\
\hline${ }^{1} \mathrm{H}$ & & -- & -- & 3,82 & -- & 3,89 & -- \\
\hline${ }^{13} \mathrm{C}$ & $\operatorname{ArOCn_{3}}$ & -- & -- & 56,0 & -- & 56,2 & -- \\
\hline${ }^{1} \mathrm{H}$ & $\mathrm{ArOCOCH}_{2}$ & -- & 2,30 & -- & -- & -- & 2,26 \\
\hline${ }^{13} \mathrm{C}$ & ArU드는 3 & -- & 21,0 & -- & -- & -- & 20,9 \\
\hline
\end{tabular}

\subsubsection{Série dos Derivados Amídicos}

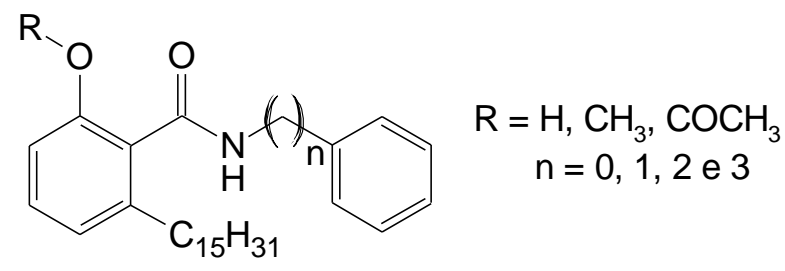


Os estudos iniciais visando a síntese das 2'-hidróxiamidas foi realizado utilizando benzotriazol de acordo com a referência 51. Os testes com o derivado LDT11 (16) apresentaram conversão incompleta, formação de misturas complexas de difícil purificação e baixos rendimentos. Em seguida, foi adaptada a metodologia de formação do anidrido misto com cloreto de mesila visando síntese de 2'metóxiamidas a partir do derivado LDT30. A nova estratégia apresentou as mesmas características de complexidade e baixos rendimentos. Finalmente, a síntese das 2'metóxiamidas foi realizada de forma bem-sucedida por meio da formação do intermediário cloreto de ácido.

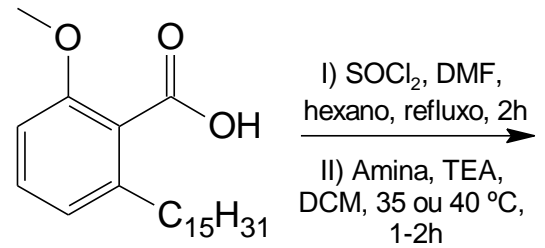

LDT30 (20)<smiles>COc1cccc(C(=O)NCc2ccccc2)c1C(=O)NCc1ccccc1</smiles>

$\mathrm{n}=0,1,2$ e 3

LDT651 (22), LDT653 (23), LDT655 (24), LDT657 (25)

A síntese da série das amidas se deu a partir da reação do LDT30 (20) com $\mathrm{SOCl}_{2}$ e DMF para a formação do cloreto de ácido intermediário, segundo metodologia realizada por Chandregowda et al [46]. Em seguida, este reagiu com a amina correspondente para formação das 2'-metóxiamidas (LDT651, LDT653, LDT655 e LDT657), que variaram quanto ao número de espaçadores metilênicos entre o grupo funcional e o anel aromático $(0,1,2$ ou 3 , respectivamente). As amidas-alvo foram obtidas em rendimentos que variaram de $71 \%$ a $96 \%$ como sólidos brancos. Em CCD, cada composto se apresentou como única mancha com Rfs muito próximos entre si. Esses compostos foram caracterizados por assinalamentos característicos referentes à metoxila, aos anéis aromáticos e aos espaçadores. Nos espectros de RMN ${ }^{1} \mathrm{H}$ (Anexos 20, 23, 26 e 29, págs. 142, 145, 148 e 151), os grupos metoxila foram evidenciados pelos sinais entre 3,70 e 3,83 ppm, os anéis aromáticos entre 6,74 e 7,63 ppm e os grupos metilenos - nas aralquilamidas - entre 1,95 e 4,67 ppm. Nos espectros de RMN ${ }^{13} \mathrm{C}$ (Anexo 21, 24, 27 e 30, págs. 143, 146, 149 e 152), tais subunidades foram confirmadas pelos assinalamentos entre 55,7 e $56,0 \mathrm{ppm}, 108,3$ e 156,2 ppm e 31,5 e 44,0 ppm, respectivamente. Os espectros no infravermelho (Anexos 19, 22, 25 e 28, págs. 141, 
144, 147 e 150) apresentaram absorções entre $3276 \mathrm{~cm}^{-1}$ e $3434 \mathrm{~cm}^{-1}$ relativas à amida secundária, o que contribuiu adicionalmente para a caracterização das 2'metóxiamidas (22-25). Um resumo dos principais sinais que caracterizam as amidasalvo está ilustrado na Tabela 3.

Tabela 3 - Principais deslocamentos químicos de RMN ${ }^{1} \mathrm{H}$ e RMN ${ }^{13} \mathrm{C}$ para a caracterização das 2'metóxiamidas

\begin{tabular}{|c|c|c|c|c|c|}
\hline \multirow{2}{*}{ RMN } & \multirow{2}{*}{ Grupos } & \multicolumn{4}{|c|}{$\mathrm{RMN}{ }^{1} \mathrm{H} / \mathrm{RMN}^{13} \mathrm{C}\left(\mathrm{ppm}, \mathrm{CDCl}_{3}\right)$} \\
\hline & & LDT651 (22) & LDT653 (23) & LDT655 (24) & LDT657 (25) \\
\hline${ }^{1} \mathrm{H}$ & \multirow{2}{*}{ Ar"' } & $7,15-7,63$ & $7,21-7,41$ & $7,19-7,33$ & $7,19-7,32$ \\
\hline${ }^{13} \mathrm{C}$ & & $122,1-138,3$ & $127,6-138,5$ & $126,6-139,1$ & $126,1-141,7$ \\
\hline${ }^{1} \mathrm{H}$ & \multirow{2}{*}{$\mathrm{ArO} \underline{\mathrm{CH}}_{3}$} & 3,83 & 3,81 & $3,70-3,85(\mathrm{~m})$ & 3,79 \\
\hline${ }^{13} \mathrm{C}$ & & 56,0 & 55,9 & 55,7 & 55,8 \\
\hline${ }^{1} \mathrm{H}$ & \multirow{2}{*}{ ArCONHAr } & 7,51 & 6,01 & 5,79 & 5,79 \\
\hline${ }^{13} \mathrm{C}$ & & -- & -- & -- & -- \\
\hline${ }^{1} \mathbf{H}$ & \multirow{2}{*}{$\operatorname{ArCONH}\left(\underline{\mathrm{CH}}_{2}\right)_{\mathrm{n}} \mathrm{Ar}$} & -- & 4,67 & $2,94 / 5,79$ & $1,95 / 2,62 / 3,49$ \\
\hline${ }^{13} \mathrm{C}$ & & -- & 44,0 & $35,8 / 40,8$ & $31,5 / 33,3 / 39,4$ \\
\hline
\end{tabular}

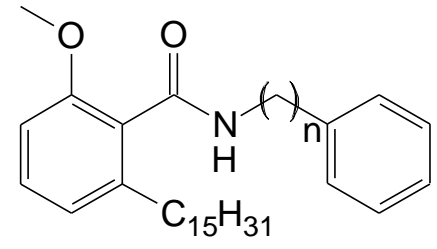

LDT651 (22), LDT653 (23), LDT655 (24), LDT657 (25)

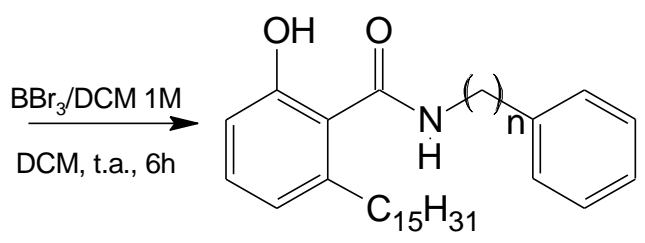

LDT82 (30), LDT645 (31), LDT647 (32), LDT649 (33)

$$
\mathrm{n}=0,1,2 \text { e } 3
$$

A partir das 2'-metóxiamidas foi realizada a reação de 0 -desmetilação na presença de $\mathrm{BBr}_{3}$ à temperatura ambiente, por 6 horas. As respectivas 2'hidróxiamidas (LDT82, LDT645, LDT647 e LDT649) foram obtidas em rendimentos que variaram de $77 \%$ a $98 \%$ como sólidos brancos de diferentes pontos de fusão. A conversão reacional foi confirmada em CCD por meio da diminuição de $\operatorname{Rf}(0,24-0,28$ Hex: AcOEt 20\%) e revelação com $\mathrm{FeCl}_{3}$, o qual permite a identificação de fenóis. $\mathrm{Na}$ análise espectroscópica, a desmetilação foi evidenciada pela ausência de sinais referentes ao grupo metoxila entre 3,70 e 3,83 ppm em $\mathrm{RMN}^{1} \mathrm{H}$ (Anexos 32, 35, 38 e 41, págs. 154, 157, 160 e 163) e 55,7 e 56,0 ppm em $\mathrm{RMN}^{13} \mathrm{C}$ (Anexos 33, 36, 39 e 42, págs. 155, 158, 161 e 164). Adicionalmente, o grupo hidroxila foi evidenciado 
por sinal largo entre 9,10 e 9,86 ppm em RMN ${ }^{1} \mathrm{H}$. Absorções no IV (Anexos 31, 34, 37 e 40, págs. 153, 156, 159 e 162) entre 3482 e $3405 \mathrm{~cm}^{-1}$ referentes ao grupo hidroxila; e 3387 e $3143 \mathrm{~cm}^{-1}$ referentes às ligação $\mathrm{NH}$, corroboram para a caracterização desses compostos. Um resumo dos principais sinais que caracterizam as 2'-hidroxamidas (30-33) está ilustrado na Tabela 4.

Tabela 4 - Principais deslocamentos químicos de $\mathrm{RMN}{ }^{1} \mathrm{H}$ e $\mathrm{RMN}{ }^{13} \mathrm{C}$ para a caracterização das 2'hidróxiamidas

\begin{tabular}{|c|c|c|c|c|c|}
\hline \multirow{2}{*}{ RMN } & \multirow{2}{*}{ Grupos } & \multicolumn{4}{|c|}{$\mathrm{RMN}{ }^{1} \mathrm{H} / \mathrm{RMN}^{13} \mathrm{C}\left(\mathrm{ppm}, \mathrm{CDCl}_{3}\right)$} \\
\hline & & LDT82 (30) & LDT645 (31) & LDT647 (32) & LDT649 (33) \\
\hline${ }^{1} \mathrm{H}$ & \multirow{2}{*}{ Ar" } & $7,40-7,57$ & $7,30-7,37$ & $7,23-7,36$ & $7,17-7,32$ \\
\hline${ }^{13} \mathrm{C}$ & & $122,1-137,2$ & $128,1-137,4$ & $127,0-138,5$ & $126,3-140,6$ \\
\hline${ }^{1} \mathrm{H}$ & \multirow{2}{*}{ ArCONHAr } & 7,67 & 6,01 & 6,02 & 6,06 \\
\hline${ }^{13} \mathrm{C}$ & & -- & -- & -- & -- \\
\hline${ }^{1} \mathrm{H}$ & \multirow{2}{*}{$\operatorname{ArCONH}\left(\underline{\mathrm{CH}}_{2}\right)_{\mathrm{n}} \mathrm{Ar}$} & -- & 4,67 & $2,95 / 3,78$ & $1,96 / 2,73 / 3,50$ \\
\hline${ }^{13} \mathrm{C}$ & & -- & 44,4 & $35,4 / 41,1$ & 31,2 / 33,5 / 39,8 \\
\hline
\end{tabular}

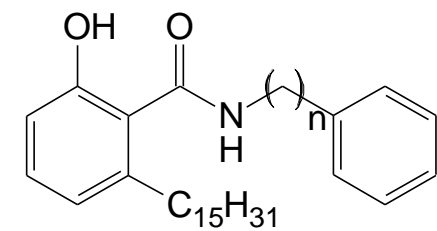

LDT82 (30), LDT645 (31), LDT647 (32), LDT649 (33)

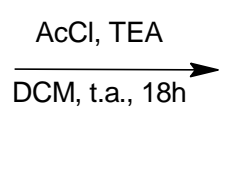

$n=0,1,2$ e 3<smiles>CC(=O)Oc1cccc(C(F)(F)F)c1C(=O)NCc1ccccc1</smiles>

LDT675 (38), LDT677 (39), LDT679 (40), LDT681 (41)

De posse das 2'-hidroxamidas, estas foram submetidas à reação de acetilação com cloreto de acetila e TEA, à temperatura ambiente por 18 horas. Após purificação, os derivados LDT675 (38), LDT677 (39), LDT679 (40) e LDT681 (41) foram obtidos em rendimentos $75-85 \%$ como sólidos brancos. Estes compostos foram caracterizados pela presença de sinais referentes aos grupos acetila, evidenciados como simpletos entre 2,21 e 2,25 ppm em RMN ${ }^{1} \mathrm{H}$ (Anexos 44, 47, 50 e 53, págs. 166, 169, 172 e 175) e sinais entre 21,0 e 21,1 ppm em $\mathrm{RMN}{ }^{13} \mathrm{C}$ (Anexos 45, 48, 51 e 54, págs. 167, 170, 173 e 176) referentes ao grupo metila do acetato. Adicionalmente, os grupos carbonila do éster foram evidenciados por sinais 
em RMN de carbono-13 pelos sinais entre 164,7 a 166,7 ppm bem como pelas absorções em 1645-1768 $\mathrm{cm}^{-1}$ nos espectros no infravermelho (Anexos 43, 46, 49 e 52, Págs. 165, 168, 171 e 174), o que contribuiu para a caracterização das 2'acetoxiamidas. Um resumo dos principais sinais que caracterizam as amidas-alvo está ilustrado na Tabela 5.

Tabela 5 - Principais deslocamentos químicos de RMN ${ }^{1} \mathrm{H}$ e RMN ${ }^{13} \mathrm{C}$ para a caracterização das 2'acetóxiamidas

\begin{tabular}{|c|c|c|c|c|c|}
\hline \multirow{2}{*}{ RMN } & \multirow{2}{*}{ Grupos } & \multicolumn{4}{|c|}{$\mathrm{RMN}{ }^{1} \mathrm{H} / \mathrm{RMN}^{13} \mathrm{C}\left(\mathrm{ppm}, \mathrm{CDCl}_{3}\right)$} \\
\hline & & LDT675 (38) & LDT677 (39) & LDT679 (40) & LDT681 (41) \\
\hline${ }^{1} \mathrm{H}$ & \multirow{2}{*}{ Ar" } & $7,17-7,57$ & $7,27-7,36$ & $7,23-7,33$ & $7,19-7,34$ \\
\hline${ }^{13} \mathrm{C}$ & & $124,9-137,6$ & $127,8-138,3$ & $127,2-138,5$ & $127,2-141,2$ \\
\hline${ }^{1} \mathrm{H}$ & \multirow[t]{2}{*}{$\mathrm{ArOCOCH}$} & 2,22 & $\begin{array}{l}1,98-1,99 \\
(\mathrm{~m})\end{array}$ & 2,21 & 2,25 \\
\hline${ }^{13} \mathrm{C}$ & & 21,1 & 20,7 & 21,0 & 21,1 \\
\hline${ }^{1} \mathrm{H}$ & \multirow{2}{*}{ ArCONHAr } & 7,50 & 6,14 & 5,82 & 5,85 \\
\hline${ }^{13} \mathrm{C}$ & & -- & -- & -- & -- \\
\hline${ }^{1} \mathrm{H}$ & \multirow[t]{2}{*}{$\operatorname{ArCONH}\left(\underline{\mathrm{CH}}_{2}\right)_{n} \mathrm{Ar}$} & -- & $\begin{array}{c}4,57-4,58 \\
(\mathrm{~m})\end{array}$ & 2,89 / 3,69 & $\begin{array}{c}1,90 / 2,62-2,73(\mathrm{~m}) \\
/ 3,44\end{array}$ \\
\hline${ }^{13} \mathrm{C}$ & & -- & 43,9 & $35,9 / 40,9$ & 31,5 / 33,2 / 39,4 \\
\hline
\end{tabular}

\subsubsection{Série dos Derivados Ésteres}

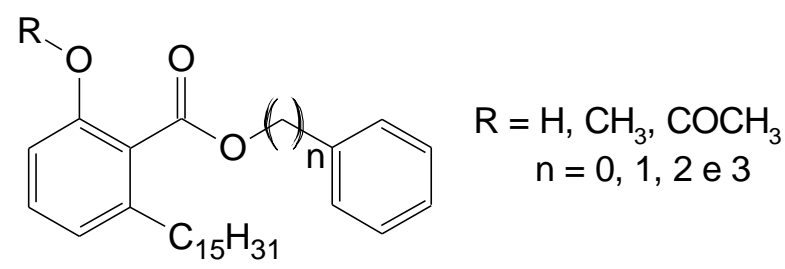<smiles>CCCCCCCCCCCCCCCCCCc1cccc(OC)c1C(=O)O</smiles>
\begin{tabular}{c} 
I) $\mathrm{SOCl}_{2}, \mathrm{DMF}$, \\
hexano, refluxo, $2 \mathrm{~h}$ \\
\hline II) Álcool ou fenol, \\
TEA, DCM, 35 ou \\
$40^{\circ} \mathrm{C}, 1-2 \mathrm{~h}$
\end{tabular} LDT30 (20)

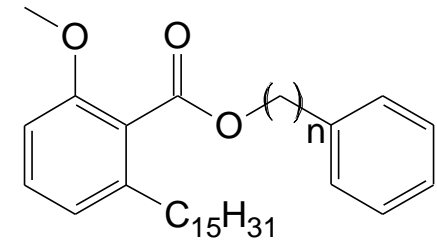
$\mathrm{n}=0,1,2$ e 3

LDT667 (26), LDT669 (27), LDT671 (28), LDT673 (29) 
Do mesmo modo, a síntese da série dos ésteres também teve início com a reação do LDT30 (20) na presença de $\mathrm{SOCl}_{2}$ e DMF para obtenção do intermediário cloreto de ácido. Na sequência, este reagiu com o fenol e os álcoois benzílico, fenetílico e 3-fenilpropílico para obtenção dos 2'-metoxiésteres. LDT667 (26), LDT669 (27), LDT671 (28) e LDT673 (29) foram obtidos em rendimentos que variaram entre $27 \%$ e $69 \%$ como sólidos brancos de baixos pontos de fusão (28$\left.38^{\circ} \mathrm{C}\right)$.

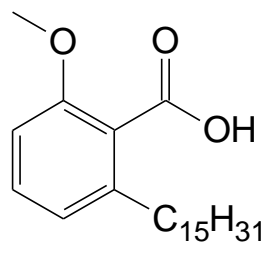

LDT30 (20)

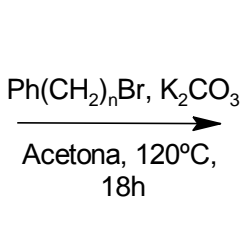

$\mathrm{n}=1,2$ e 3

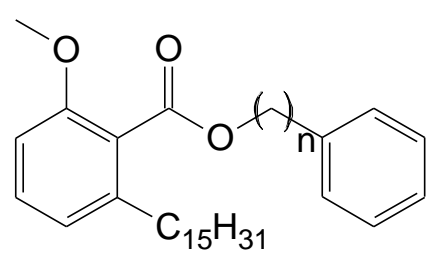

LDT669 (27), LDT671 (28), LDT673 (29)

Tendo em vista a difícil purificação, em coluna cromatográfica, desses compostos, bem como os baixos rendimentos, uma nova metodologia foi investigada quanto a eficiência e a facilidade de purificação. Desse modo, 20 foi submetido a reação com brometos de aralquila (brometo de benzila, bromoetilbenzeno e bromopropilbenzeno) na presença de carbonato de potássio para a obtenção dos derivados 27, 28 e 29. Estes foram facilmente purificados e obtidos em melhores rendimentos para 27 e 29. Em adição, esta última metodologia, embora não possa ser empregada para a síntese de 26, se mostrou mais simples, com apenas uma etapa de reação. Os derivados 2'-metoxiésteres foram caracterizados por sinais correspondentes à metoxila, aos anéis aromáticos e aos espaçadores metilênicos. Em seus respectivos espectros de RMN ${ }^{1} \mathrm{H}$ (Anexos 56, 59, 62 e 65, págs. 178, 181, 184 e 187) e RMN ${ }^{13} \mathrm{C}$ (Anexos 57, 60, 63 e 66, págs. 179, 182, 185 e 188), os grupos metila foram evidenciados entre $3,79-3,90$ ppm e 55,9-56,2 ppm; os anéis aromáticos entre 6,76-7,48 ppm e 108,5-156,8 ppm; e os grupos metilenos espaçadores entre 2,04-5,39 ppm e 30,5-67,0 ppm. Os espectros no infravermelho (Anexos 55, 58, 61 e 64, págs. 177, 180, 183 e 186) apresentaram sinais em 1729$1746 \mathrm{~cm}^{-1}$ correspondentes à carbonila dos ésteres, que contribuíram adicionalmente para a caracterização dos ésteres-alvo. Um resumo dos principais sinais que caracterizam os 2'-metoxiésteres está ilustrado na Tabela 6. 
Tabela 6 - Principais deslocamentos químicos de RMN ${ }^{1} \mathrm{H}$ e RMN ${ }^{13} \mathrm{C}$ para a caracterização dos 2'metoxiésteres

\begin{tabular}{|c|c|c|c|c|c|}
\hline \multirow{2}{*}{ RMN } & \multirow{2}{*}{ Grupos } & \multicolumn{4}{|c|}{$\mathrm{RMN}{ }^{1} \mathrm{H} / \mathrm{RMN}{ }^{13} \mathrm{C}\left(\mathrm{ppm}, \mathrm{CDCl}_{3}\right)$} \\
\hline & & LDT667 (26) & LDT669 (27) & LDT671 (28) & LDT673 (29) \\
\hline${ }^{1} \mathrm{H}$ & \multirow{2}{*}{$A r "$} & $7,25-7,45$ & $7,27-7,48$ & $7,24-7,32$ & $7,19-7,33$ \\
\hline${ }^{13} \mathrm{C}$ & & $121,9-141,8$ & $128,5-136,0$ & $126,7-138,0$ & $126,2-141,4$ \\
\hline${ }^{1} \mathrm{H}$ & \multirow{2}{*}{$\mathrm{ArOC \textrm {H } _ { 3 }}$} & 3,90 & 3,81 & 3,79 & 3,84 \\
\hline${ }^{13} \mathrm{C}$ & & 56,2 & 55,9 & 56,0 & 56,0 \\
\hline${ }^{1} \mathrm{H}$ & \multirow{2}{*}{ ArcoOAr } & -- & -- & -- & -- \\
\hline${ }^{13} \mathrm{C}$ & & 167,1 & 168,4 & 168,6 & 168,7 \\
\hline${ }^{1} \mathrm{H}$ & \multirow[t]{2}{*}{$\operatorname{ArCOO}\left(\underline{\mathrm{CH}}_{2}\right)_{n} \mathrm{Ar}$} & -- & 5,39 & $3,08 / 4,56$ & $\begin{array}{c}2,04-2,11(\mathrm{~m}) / 2,79 / \\
4,35-4,49(\mathrm{~m})\end{array}$ \\
\hline${ }^{13} \mathrm{C}$ & & -- & 67,0 & $35,2 / 65,7$ & $30,5 / 32,3 / 64,5$ \\
\hline
\end{tabular}

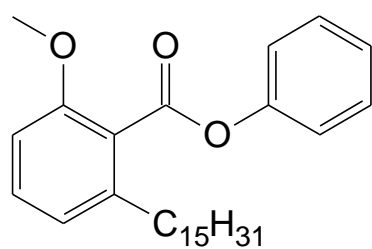

LDT667 (26)<smiles>CCCCCc1cccc(O)c1C(=O)Oc1ccccc1</smiles>

LDT659 (34)

A síntese dos 2'-hidroxiésteres se deu por meio de duas metodologias. Para a síntese do derivado LDT659 (34), o LDT667 foi submetido ao mesmo protocolo de desmetilação realizado para a síntese da série das hidróxiamidas, sendo obtido em rendimento de 55\% como um sólido branco.

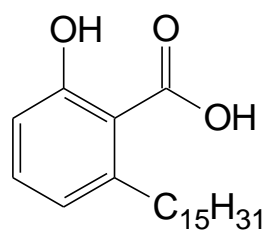

LDT11 (16)

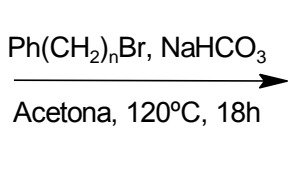

O LDT661 (35), LDT663 (36) e LDT665 (37) foram sintetizados a partir da reação do derivado LDT11 (16) com os respectivos brometos de aralquila (brometo de benzila, bromoetilbenzeno e bromopropilbenzeno) na presença de bicarbonato de sódio e foram obtidos em rendimentos de $60 \%$ a $77 \%$ como sólidos brancos. $\mathrm{Na}$ 
análise espectroscópica, a desmetilação de $\mathbf{3 4}$ foi evidenciada pela ausência dos sinais em 3,90 ppm e 56,2 ppm nos espectros de RMN ${ }^{1} \mathrm{H}$ (Anexos 68, 71, 74 e 77, pág. 190, 193, 196 e 199) e RMN ${ }^{13} \mathrm{C}$ (Anexos 69, 72, 75 e 78, pág. 191, 194, 197 e 200), respectivamente. Os compostos 35,36 e 37 foram caracterizados pela presença dos sinais em RMN ${ }^{1} \mathrm{H}$ (Anexos 71, 74 e 77, pág. 193, 196 e 199) entre 2,11-5,40 ppm e 6,70-7,45 ppm referentes aos grupos metilenos espaçadores e anéis aromáticos, confirmados pelos sinais entre 30,3-67,0 ppm e 112,0-162,9 ppm nos espectros de RMN ${ }^{13} \mathrm{C}$ (Anexos 72, 75 e 78, pág. 194, 197 e 200). Adicionalmente, o grupo hidroxila foi evidenciado como simpleto entre 10,92 e 11,24 ppm em RMN ${ }^{1} \mathrm{H}$, característico de ligação de hidrogênio intramolecular. As

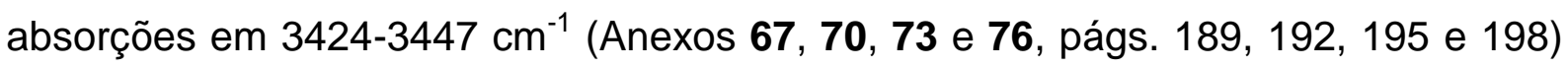
referentes à hidroxila fenólica, corroboraram para a caracterização desses compostos. Um resumo dos principais sinais que caracterizam os 2'-hidroxiésteres está ilustrado na Tabela 7.

Tabela 7 - Principais deslocamentos químicos de RMN ${ }^{1} \mathrm{H}$ e RMN ${ }^{13} \mathrm{C}$ para a caracterização dos 2'hidroxiésteres

\begin{tabular}{|c|c|c|c|c|c|}
\hline \multirow{2}{*}{ RMN } & \multirow{2}{*}{ Grupos } & \multicolumn{4}{|c|}{$\mathrm{RMN}{ }^{1} \mathrm{H} / \mathrm{RMN}^{13} \mathrm{C}\left(\mathrm{ppm}, \mathrm{CDCl}_{3}\right)$} \\
\hline & & LDT659 (34) & LDT661 (35) & LDT663 (36) & LDT665 (37) \\
\hline${ }^{1} \mathrm{H}$ & \multirow{2}{*}{ Ar" } & $7,21-7,50$ & $7,97-7,45$ & $7,28-7,35$ & $7,21-7,35$ \\
\hline${ }^{13} \mathrm{C}$ & & $123,0-146,8$ & $128,9-135,0$ & $127,0-137,3$ & $126,4-140,9$ \\
\hline $\begin{array}{l}{ }^{1} \mathrm{H} \\
{ }^{13} \mathrm{C}\end{array}$ & ArcoOAr & $\begin{array}{c}-- \\
170,5\end{array}$ & $\begin{array}{c}-- \\
171,6\end{array}$ & $\begin{array}{c}-- \\
171,6\end{array}$ & $\begin{array}{c}-- \\
171,9\end{array}$ \\
\hline${ }^{1} \mathrm{H}$ & \multirow[t]{2}{*}{$\operatorname{ArCOO}\left(\underline{\mathrm{CH}}_{2}\right)_{n} \mathrm{Ar}$} & -- & 5,40 & $3,13 / 4,63$ & $\begin{array}{c}2,11-2,20(\mathrm{~m}) / 2,96 / \\
4,42\end{array}$ \\
\hline${ }^{13} \mathrm{C}$ & & -- & 67,0 & $36,6 / 66,2$ & $30,3 / 32,6 / 65,3$ \\
\hline
\end{tabular}

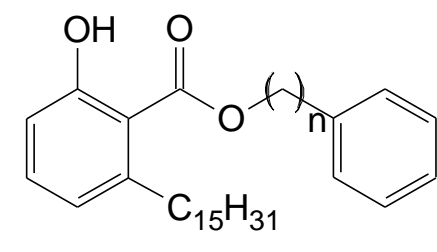

LDT659 (34), LDT661 (35), LDT663 (36), LDT665 (37)

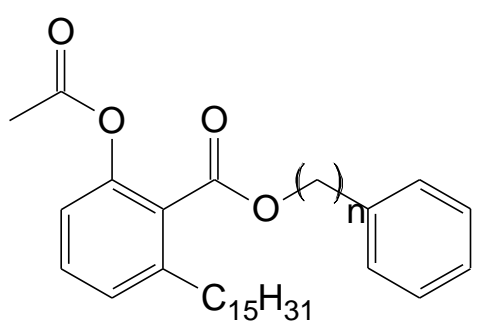

LDT683 (42), LDT685 (43), LDT687 (44), LDT689 (45) $\mathrm{n}=0,1,2$ e 3 
De posse dos ésteres 34-37, estes foram submetidos ao mesmo protocolo de acetilação realizado para a síntese das 2'-acetilamidas. Os derivados LDT683 (42), LDT685 (43), LDT687 (44) e LDT689 (45) foram obtidos em rendimentos que variaram de $61 \%$ a $88 \%$ como sólidos brancos com baixos pontos de fusão $(42,43$ e 44) ou líquido incolor (45). A conversão reacional foi confirmada em CCD por meio da diminuição de $\operatorname{Rf}(0,34-0,50 \mathrm{Hex}$ : AcOEt 20\%). Na análise espectroscópica, a metila do grupo acetila foi evidenciada pelos sinais entre 1,99-2,29 ppm e 20,7-21,0 nos espectros de RMN ${ }^{1} \mathrm{H}$ (Anexos 80, 83, 86 e 89, págs. 202, 205, 208 e 211) e RMN ${ }^{13} \mathrm{C}$ (Anexos 81, 84, 87 e 90, págs. 203, 206, 209 e 2012), respectivamente. Adicionalmente, os espectros no infravermelho (Anexos 79, 82, 85 e 88, págs. 201, 204, 207 e 210) apresentaram absorções em $1727-1763 \mathrm{~cm}^{-1}$ correspondentes às carbonilas, que corroboraram para a caracterização dos diésteres-alvo. Um resumo dos principais sinais que caracterizam os 2'-acetoxiésteres está ilustrado na Tabela 8.

Tabela 8 - Principais deslocamentos químicos de $\mathrm{RMN}{ }^{1} \mathrm{H}$ e $\mathrm{RMN}{ }^{13} \mathrm{C}$ para a caracterização dos 2'-acetoxiésteres

\begin{tabular}{|c|c|c|c|c|c|}
\hline \multirow{2}{*}{ RMN } & \multirow{2}{*}{ Grupos } & \multicolumn{4}{|c|}{$\mathrm{RMN}{ }^{1} \mathrm{H} / \mathrm{RMN}^{13} \mathrm{C}\left(\mathrm{ppm}, \mathrm{CDCl}_{3}\right)$} \\
\hline & & LDT683 (42) & LDT685 (43) & LDT687 (44) & LDT689 (45) \\
\hline${ }^{1} \mathrm{H}$ & \multirow{2}{*}{ Ar" } & $7,21-7,47$ & $7,33-7,46$ & $7,25-7,38$ & $7,19-7,30$ \\
\hline${ }^{13} \mathrm{C}$ & & $126,3-143,5$ & $128,7-135,6$ & $127,2-137,6$ & $127,3-141,1$ \\
\hline${ }^{1} \mathrm{H}$ & \multirow{2}{*}{$\mathrm{ArOCOCH} \underline{\mathrm{CH}}_{3}$} & 2,29 & 1,99 & 2,17 & 2,25 \\
\hline${ }^{13} \mathrm{C}$ & & 21,1 & 20,7 & 20,9 & 21,0 \\
\hline${ }^{1} \mathrm{H}$ & \multirow{2}{*}{$\operatorname{Ar} \underline{C} O O A r$} & -- & -- & -- & -- \\
\hline${ }^{13} \mathrm{C}$ & & 169,3 & 169,2 & 169,1 & 169,1 \\
\hline${ }^{1} \mathrm{H}$ & \multirow[t]{2}{*}{$\operatorname{ArCOO}\left(\underline{\mathrm{CH}}_{2}\right)_{\mathrm{n}} \mathrm{Ar}$} & -- & 5,35 & $3,05 / 4,52$ & $\begin{array}{c}2,06 / 2,66-2,78(\mathrm{~m}) / \\
4,33\end{array}$ \\
\hline${ }^{13} \mathrm{C}$ & & -- & 67,2 & $35,2 / 66,1$ & $30,5 / 32,3 / 64,9$ \\
\hline
\end{tabular}

\subsection{PARÂMETROS FÍSICO-QUÍMICOS}

Os aspectos físico-químicos dos derivados foram obtidos com o auxílio do programa Percepta/ACD labs. Sabe-se que as propriedades físico-químicas de um composto são capazes de modificar seu perfil de atividade biológica. As principais 
são coeficiente de partição $(\log \mathrm{P})$ e o coeficiente de ionização ácida $(\mathrm{pKa})$. O coeficiente de partição (logP) expressa a lipofilicidade relativa de uma substância, propriedade amplamente relacionada a atividade biológica. $\mathrm{O} \log \mathrm{P}$ pode ser determinado por meio da partição de um composto entre uma fase aquosa e outra orgânica num determinado $\mathrm{pH}$ onde as moléculas encontram-se na forma neutra. Para compostos ionizáveis, a partição é modificada em função de um pH específico, denominada coeficiente de distribuição $(\log \mathrm{D})$. $\mathrm{O} \log \mathrm{D}$ calculado em $\mathrm{pH} 7,4$ é considerado um indicador de comportamento do composto na biofase aquosa (plasma). O pKa, por sua vez, expressa o percentual relativo das espécies na sua forma ácida e de sua base conjugada de cada molécula. A importância do pKa na absorção está na sua relação com a lipofilicidade, de forma que as espécies nãoionizadas atravessam membranas mais facilmente, por serem mais lipofílicas [51, 52, 53].

A área de superfície polar (PSA) de uma molécula corresponde ao somatório da superfície de todos os seus átomos polares, principalmente oxigênio e nitrogênio. Este parâmetro possui correlação com a absorção intestinal humana e penetração pela barreira hemato-encefálica [52, 53].

O logs corresponde ao logaritmo de solubilidade em água de compostos orgânicos, no qual $S$ é a concentração do composto em mol/L. Moléculas polares estão associadas a valores de log $S$ acima de -1 e, consequentemente, possui baixa permeabilidade de membrana na ausência de transporte ativo. É necessário que um fármaco possua polaridade razoável, solubilidade aquosa e lipofilicidade necessária para atravessar membranas $[53,55]$.

As características físico-químicas $\log \mathrm{P}, \log \mathrm{D}, \log \mathrm{S}, \mathrm{pKa}$ e PSA - calculadas no programa Percepta/ACD Labs - bem como fórmula molecular, massa molar, rendimentos, fatores de retenção e pontos de fusão dos compostos-alvo estão resumidos nas Tabelas $\mathbf{9 , 1 0}$ e $\mathbf{1 1}$. 
Tabela 9 - Características químicas, rendimentos e ponto de fusão da série acetóxi, hidróxi e metoxiácidos ou metilésteres

\begin{tabular}{|c|c|c|c|c|c|c|c|c|c|c|c|c|}
\hline Derivado & $\mathbf{R}$ & $\mathbf{Z}$ & $R f$ & $\begin{array}{c}\text { MM } \\
(\mathrm{g} / \mathrm{mol})\end{array}$ & $\mathbf{F M}$ & $\begin{array}{c}\text { Rend. } \\
(\%)\end{array}$ & $\operatorname{PF}\left({ }^{\circ} \mathrm{C}\right)$ & $\log P$ & $\begin{array}{c}\log D \\
(\mathrm{pH} 7,4)\end{array}$ & $\begin{array}{c}\text { LogS } \\
(\mathrm{pH} \mathrm{7,4)}\end{array}$ & pKa & $\begin{array}{c}\text { PSA } \\
\left(\AA^{2}\right) \\
\end{array}$ \\
\hline LDT11 & $\mathrm{H}$ & $\mathrm{H}$ & $0,48\left(\operatorname{Hex}_{80 \%}: \mathrm{AcOEt}_{20 \%}\right)$ & 348,519 & $\mathrm{C}_{22} \mathrm{H}_{36} \mathrm{O}_{3}$ & 70 & $81-84$ & 9,96 & 6,48 & $-5,62$ & 3,1 & 57,53 \\
\hline LDT13 & $\mathrm{COCH}_{3}$ & $\mathrm{H}$ & $0,20\left(\operatorname{Hex}_{80 \%}: \mathrm{AcOEt}_{20 \%}\right)$ & 390,556 & $\mathrm{C}_{24} \mathrm{H}_{38} \mathrm{O}_{4}$ & 76 & $65-69$ & 9,09 & 6,26 & $-5,08$ & 3,5 & 63,60 \\
\hline LDT28 & $\mathrm{CH}_{3}$ & $\mathrm{CH}_{3}$ & $0,40\left(\mathrm{Hex}_{90 \%}: \mathrm{AcOEt}_{10 \%}\right)$ & 376,573 & $\mathrm{C}_{24} \mathrm{H}_{40} \mathrm{O}_{3}$ & 97 & $32-33$ & 9,94 & * & $-8,65$ & ** & 35,53 \\
\hline LDT29 & $\mathrm{H}$ & $\mathrm{CH}_{3}$ & $0,60\left(\operatorname{Hex}_{80 \%}: \mathrm{AcOEt}_{20 \%}\right)$ & 362,546 & $\mathrm{C}_{23} \mathrm{H}_{38} \mathrm{O}_{3}$ & 86 & $37-40$ & 10,13 & * & $-8,72$ & 9,9 & 46,53 \\
\hline LDT30 & $\mathrm{CH}_{3}$ & $\mathrm{H}$ & $0,28\left(\operatorname{Hex}_{80 \%}: \mathrm{AcOEt}_{20 \%}\right)$ & 362,546 & $\mathrm{C}_{23} \mathrm{H}_{38} \mathrm{O}_{3}$ & 98 & $74-77$ & 9,39 & 6,57 & $-5,63$ & 4,1 & 46,53 \\
\hline LDT208 & $\mathrm{COCH}_{3}$ & $\mathrm{CH}_{3}$ & 0,44 $\left(\mathrm{Hex}_{80 \%}: \mathrm{AcOEt}_{20 \%}\right)$ & 404,583 & $\mathrm{C}_{25} \mathrm{H}_{40} \mathrm{O}_{4}$ & 58 & $30-35$ & 9,37 & * & $-8,28$ & $* *$ & 52,60 \\
\hline
\end{tabular}

* Não calculado; ${ }^{*}$ Não possui

Tabela 10 - Características químicas, rendimentos e ponto de fusão dos derivados da série dos derivados amídicos

\begin{tabular}{|c|c|c|c|c|c|c|c|c|c|c|c|}
\hline Derivado & $\mathbf{R}$ & $\mathbf{n}$ & $\mathbf{R f}$ & $\begin{array}{c}\text { MM } \\
(\mathrm{g} / \mathrm{mol}) \\
\end{array}$ & FM & $\begin{array}{l}\text { Rend. } \\
(\%)\end{array}$ & $\operatorname{PF}\left({ }^{\circ} \mathrm{C}\right)$ & $\log P$ & $\begin{array}{c}\text { LogS } \\
(\mathrm{pH} \mathrm{7,4)}\end{array}$ & pKa & $\begin{array}{l}\text { PSA } \\
\left(\AA^{2}\right) \\
\end{array}$ \\
\hline LDT651 & $\mathrm{CH}_{3}$ & 0 & 0,33 $\left(\mathrm{Hex}_{80 \%}: \mathrm{AcOEt}_{20 \%}\right)$ & 437,657 & $\mathrm{C}_{29} \mathrm{H}_{43} \mathrm{NO}_{2}$ & 76 & $78-85$ & 10,25 & $-9,47$ & 13,7 & 38,33 \\
\hline LDT563 & $\mathrm{CH}_{3}$ & 1 & $0,21\left(\mathrm{Hex}_{80 \%}: \mathrm{AcOEt}_{20 \%}\right)$ & 451,684 & $\mathrm{C}_{30} \mathrm{H}_{45} \mathrm{NO}_{2}$ & 77 & $90-99$ & 10,66 & $-9,45$ & 15,0 & 38,33 \\
\hline LDT655 & $\mathrm{CH}_{3}$ & 2 & $0,22\left(\mathrm{Hex}_{80 \%}: \mathrm{AcOEt}_{20 \%}\right)$ & 465,710 & $\mathrm{C}_{31} \mathrm{H}_{47} \mathrm{NO}_{2}$ & 71 & $53-56$ & 10,59 & $-9,97$ & 14,7 & 38,33 \\
\hline LDT657 & $\mathrm{CH}_{3}$ & 3 & $0,24\left(\mathrm{Hex}_{80 \%}: \mathrm{AcOEt}_{20 \%}\right)$ & 479,737 & $\mathrm{C}_{32} \mathrm{H}_{49} \mathrm{NO}_{2}$ & 96 & $60-67$ & 11,20 & $-9,99$ & 14,9 & 38,33 \\
\hline LDT82 & $\mathrm{OH}$ & 0 & $0,28\left(\mathrm{Hex}_{80 \%}: \mathrm{AcOEt}_{20 \%}\right)$ & 423,631 & $\mathrm{C}_{28} \mathrm{H}_{41} \mathrm{NO}_{2}$ & 80 & $71-74$ & 11,17 & $-9,09$ & 7,2 & 49,33 \\
\hline LDT645 & $\mathrm{OH}$ & 1 & $0,25\left(\mathrm{Hex}_{80 \%}: \mathrm{AcOEt}_{20 \%}\right)$ & 437,657 & $\mathrm{C}_{29} \mathrm{H}_{43} \mathrm{NO}_{2}$ & 77 & $85-87$ & 11,19 & $-9,41$ & 8,5 & 49,33 \\
\hline LDT647 & $\mathrm{OH}$ & 2 & $0,24\left(\mathrm{Hex}_{80 \%}: \mathrm{AcOEt}_{20 \%}\right)$ & 451,684 & $\mathrm{C}_{30} \mathrm{H}_{45} \mathrm{NO}_{2}$ & 98 & $72-75$ & 11,11 & $-9,67$ & 8,4 & 49,33 \\
\hline LDT649 & $\mathrm{OH}$ & 3 & $0,28\left(\operatorname{Hex}_{80 \%}: \mathrm{AcOEt}_{20 \%}\right)$ & 465,710 & $\mathrm{C}_{31} \mathrm{H}_{47} \mathrm{NO}_{2}$ & 97 & $59-65$ & 11,72 & $-9,84$ & 8,5 & 49,33 \\
\hline LDT675 & $\mathrm{COCH}_{3}$ & 0 & 0,33 $\left(\mathrm{Hex}_{80 \%}: \mathrm{AcOEt}_{20 \%}\right)$ & 465,667 & $\mathrm{C}_{30} \mathrm{H}_{43} \mathrm{NO}_{3}$ & 75 & $44-47$ & 9,67 & $-9,44$ & 13,4 & 55,40 \\
\hline LDT677 & $\mathrm{COCH}_{3}$ & 1 & 0,33 (-Hex $80 \%:$ AcOEt $\left._{20 \%}\right)$ & 479,694 & $\mathrm{C}_{31} \mathrm{H}_{45} \mathrm{NO}_{3}$ & 85 & $73-76$ & 10,00 & $-9,45$ & 14,8 & 55,40 \\
\hline LDT679 & $\mathrm{COCH}_{3}$ & 2 & 0,36 $\left(\mathrm{Hex}_{80 \%}: \mathrm{AcOEt}_{20 \%}\right)$ & 493,720 & $\mathrm{C}_{32} \mathrm{H}_{47} \mathrm{NO}_{3}$ & 73 & $53-65$ & 9,93 & $-9,72$ & 14,5 & 55,40 \\
\hline LDT681 & $\mathrm{COCH}_{3}$ & 3 & 0,36 $\left(\mathrm{Hex}_{80 \%}: \mathrm{AcOEt}_{20 \%}\right)$ & 507,747 & $\mathrm{C}_{33} \mathrm{H}_{49} \mathrm{NO}_{3}$ & 80 & $61-66$ & 10,53 & $-9,94$ & 14,7 & 55,40 \\
\hline
\end{tabular}


Tabela 11 - Características químicas, rendimentos e ponto de fusão dos derivados da série dos derivados ésteres

\begin{tabular}{|c|c|c|c|c|c|c|c|c|c|c|c|}
\hline Derivado & $\mathbf{R}$ & $\mathbf{n}$ & Rf & $\begin{array}{c}\mathrm{MM} \\
(\mathrm{g} / \mathrm{mol})\end{array}$ & FM & $\begin{array}{l}\text { Rend. } \\
(\%)\end{array}$ & $\operatorname{PF}\left({ }^{\circ} \mathrm{C}\right)$ & $\log P$ & $\begin{array}{c}\text { LogS } \\
(\mathrm{pH} 7,4)\end{array}$ & pKa & $\begin{array}{l}\text { PSA } \\
\left(\AA^{2}\right)\end{array}$ \\
\hline LDT669 & $\mathrm{CH}_{3}$ & 1 & $0,54\left(\mathrm{Hex}_{80 \%}: \mathrm{AcOEt}_{20 \%}\right)$ & 452,669 & $\mathrm{C}_{30} \mathrm{H}_{44} \mathrm{O}_{3}$ & $64^{*}$ & $35-38$ & 11,71 & $-9,74$ & $* * *$ & 35,53 \\
\hline LDT673 & $\mathrm{CH}_{3}$ & 3 & $0,62\left(\mathrm{Hex}_{80 \%}: \mathrm{AcOEt}_{20 \%}\right)$ & 480,722 & $\mathrm{C}_{32} \mathrm{H}_{48} \mathrm{O}_{3}$ & $35^{*}$ & $31-34$ & 12,54 & $-10,30$ & $* * *$ & 35,53 \\
\hline LDT659 & $\mathrm{OH}$ & 0 & $0,61\left(\mathrm{Hex}_{80 \%}: \mathrm{AcOEt}_{20 \%}\right)$ & 424,615 & $\mathrm{C}_{28} \mathrm{H}_{40} \mathrm{O}_{3}$ & 55 & $35-38$ & 11,45 & $-9,64$ & 8,8 & 46,53 \\
\hline LDT661 & $\mathrm{OH}$ & 1 & $0,65\left(\mathrm{Hex}_{80 \%}: \mathrm{AcOEt}_{20 \%}\right)$ & 438,642 & $\mathrm{C}_{29} \mathrm{H}_{42} \mathrm{O}_{3}$ & 60 & $29-36$ & 11,91 & $-9,67$ & 8,1 & 46,53 \\
\hline LDT665 & $\mathrm{OH}$ & 3 & $0,64\left(\mathrm{Hex}_{80 \%}: \mathrm{AcOEt}_{20 \%}\right)$ & 466,695 & $\mathrm{C}_{31} \mathrm{H}_{46} \mathrm{O}_{3}$ & 77 & $35-38$ & 12,74 & $-9,96$ & 8,1 & 46,53 \\
\hline LDT683 & $\mathrm{COCH}_{3}$ & 0 & $0,48\left(\mathrm{Hex}_{80 \%}: \mathrm{AcOEt}_{20 \%}\right)$ & 466,652 & $\mathrm{C}_{30} \mathrm{H}_{42} \mathrm{O}_{4}$ & 76 & $48-52$ & 10,78 & $-9,60$ & $* * *$ & 52,60 \\
\hline LDT685 & $\mathrm{COCH}_{3}$ & 1 & $0,34\left(\operatorname{Hex}_{90 \%}: \mathrm{AcOEt}_{10 \%}\right)$ & 480,679 & $\mathrm{C}_{31} \mathrm{H}_{44} \mathrm{O}_{4}$ & 88 & $37-43$ & 11,14 & $-9,81$ & $* * *$ & 52,60 \\
\hline LDT687 & $\mathrm{COCH}_{3}$ & 2 & $0,50\left(\mathrm{Hex}_{80 \%}: \mathrm{AcOEt}_{20 \%}\right)$ & 494,705 & $\mathrm{C}_{32} \mathrm{H}_{46} \mathrm{O}_{4}$ & 77 & $25-28$ & 11,39 & $-10,10$ & $* * *$ & 52,60 \\
\hline LDT689 & $\mathrm{COCH}_{3}$ & 3 & $0,50\left(\mathrm{Hex}_{80 \%}: \mathrm{AcOEt}_{20 \%}\right)$ & 508,732 & $\mathrm{C}_{33} \mathrm{H}_{48} \mathrm{O}_{4}$ & 61 & $* *$ & 11,97 & $-10,30$ & $* * *$ & 52,60 \\
\hline
\end{tabular}

* Melhores rendimentos; ** Obtido como líquido; ${ }^{* * *}$ Não possui 


\subsection{AVALIAÇÃO BIOLÓGICA E RELAÇÕES ESTRUTURA-ATIVIDADE}

Uma vez sintetizados e caracterizados por métodos espectroscópicos, os derivados foram avaliados in vitro frente aos alvos de interesse p300 e PPAR- $\alpha / P P A R-y$.

\subsection{1 p300}

A avaliação do perfil inibitório dos derivados-alvo frente à enzima p300 foi realizada pelo grupo do Prof. Masoud Vedadi do Structural Genomics Consortium (SGC) da Universidade de Toronto. Os derivados-alvo das três séries foram avaliados frente à enzima p300 nas concentrações de 10, 30 e $100 \mu \mathrm{m}$. Os derivados ácidos LDT11 (16), LDT13 (17), e LDT30 (20) foram avaliados em 3 experimentos e foram capazes de inibir $50 \%$ da atividade de p300 nas concentrações de $50 \mu \mathrm{m}$ e $100 \mu \mathrm{m}$.

No ensaio realizado para a primeira série à concentração de $50 \mu \mathrm{m}$, LDT11 (16), LDT13 (17), e LDT30 (20) apresentaram elevada atividade inibitória da enzima p300 em torno de $95 \%$, 91\% e $88 \%$, respectivamente. Por sua vez, os derivados ésteres LDT28 (18) e LDT29 (19) inibiram a p300 com respectivos percentuais de $12 \%$ e $3 \%$, enquanto LDT208 (21) aumentou a atividade de p300 em 16\% (Figura 14).

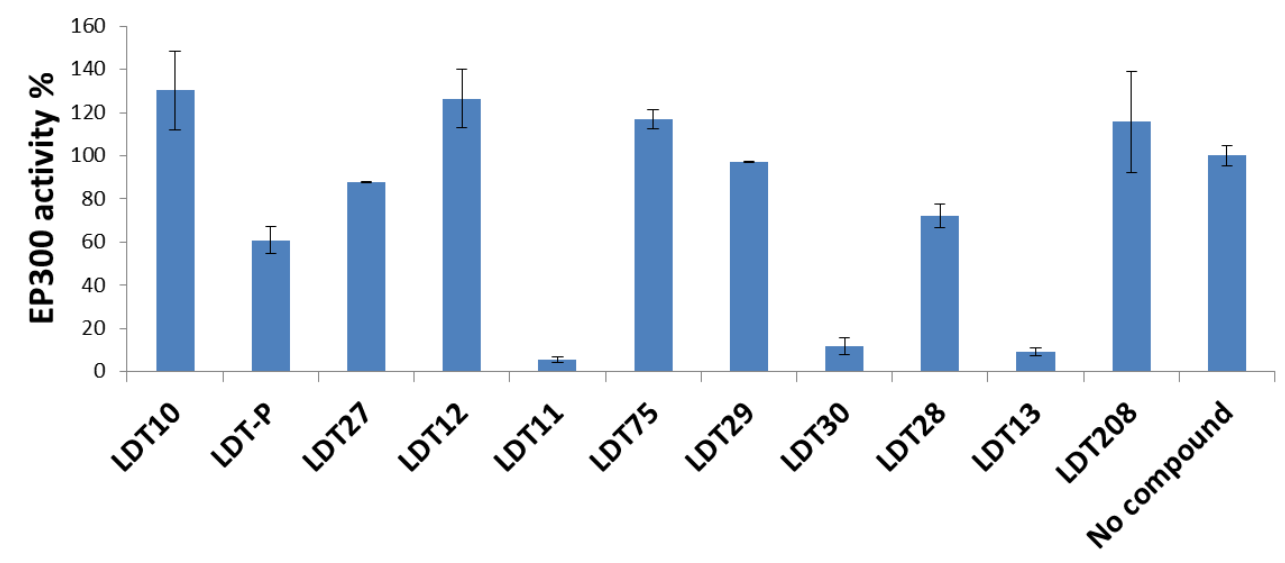

Figura 14: Atividade inibitória frente à enzima p300 dos compostos da série da série acetóxi, hidróxi e metoxiácidos ou metilésteres testados a $50 \mu \mathrm{M}$ 


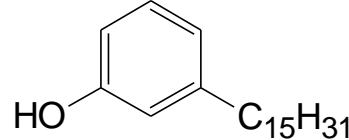

LDT10 (46)

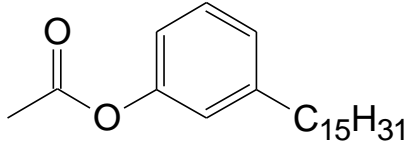

LDT12 (47)

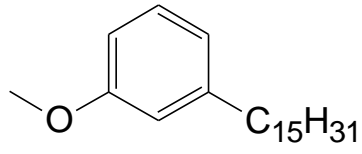

LDT27 (48)

Figura 15: Derivados LDT10 (46), LDT12 (47) e LDT27 (48)

Fonte: Próprio autor

No segundo experimento, somente LDT13 (17) apresentou perfil inibitório com $\mathrm{IC}_{50} 13,0 \mu \mathrm{M}$. Em nova avaliação a $100 \mu \mathrm{M}$, os ácidos LDT11 (16), LDT13 (17), e LDT30 (20) inibiram a p300 em mais de 50\% e tiveram suas $\mathrm{IC}_{50}$ determinadas (Tabela 12).

Tabela 12 - Valores de $\mathrm{IC}_{50}$ para os derivados 16-21

\begin{tabular}{|c|c|c|c|c|c|c|c|c|c|}
\hline Derivado & $\begin{array}{c}\text { \% } \\
\text { Inibição } \\
\text { p300 }^{\mathrm{a}}\end{array}$ & $\begin{array}{c}\mathrm{IC}_{50} \\
(\mu \mathrm{M})^{\mathrm{a}}\end{array}$ & $\begin{array}{l}\mathrm{IC}_{50} \\
(\mu \mathrm{M})^{\mathrm{b}}\end{array}$ & $\begin{array}{c}\mathrm{IC}_{50} \\
(\mu \mathrm{M})^{\mathrm{C}}\end{array}$ & LogP & $\begin{array}{c}\log D \\
(\mathrm{pH} \\
7,4) \\
\end{array}$ & $\begin{array}{c}\text { LogS } \\
(\mathrm{pH} \\
7,4) \\
\end{array}$ & pKa & $\begin{array}{l}\text { PSA } \\
\left(\AA^{2}\right)\end{array}$ \\
\hline LDT11 (16) & 95 & 3,0 & -- & 21,0 & 9,96 & 6,48 & $-5,62$ & 3,1 & 53,3 \\
\hline LDT13 (17) & 91 & 3,0 & 13,0 & 20,0 & 9,09 & 6,26 & $-5,08$ & 3,5 & 63,6 \\
\hline LDT30 (20) & 88 & 10,0 & -- & 15,0 & 9,39 & 6,57 & $-5,63$ & 4,1 & 35,5 \\
\hline LDT28 (18) & 12 & -- & -- & -- & 9,94 & -- & $-8,65$ & -- & 46,5 \\
\hline LDT29 (19) & 3 & -- & -- & -- & 10,13 & -- & $-8,72$ & 9,9 & 46,5 \\
\hline $\begin{array}{l}\text { LDT208 } \\
(\mathbf{2 1})\end{array}$ & -16 & -- & -- & -- & 9,37 & -- & $-8,28$ & -- & 52,6 \\
\hline
\end{tabular}

a. $50 \mu \mathrm{M} ;$ b. 1,5 a $100 \mu \mathrm{M}$; c. $100 \mu \mathrm{M}$

Em todos os experimentos foi reportada a baixa solubilidade dos compostos nas condições empregadas, o que não permite o estabelecimento de relações estrutura-atividade de forma precisa e detalhada. De acordo com os dados teóricos, os derivados ativos apresentaram LogS $(\mathrm{pH} 7,4)$ entre $-5,63$ e -5,08; enquanto os valores deste parâmetro para os ésteres-derivados variaram entre $-8,72$ e $-8,28$. A diferença entre os dados demostra a maior solubilidade dos derivados ácidos em cerca de 1200 vezes.

Os dados teóricos de pKa para os derivados ácidos LDT11 (16), LDT13 (17), e LDT30 (20) revelam que estas espécies estão como íons carboxilato em pH 7,4 utilizado nos experimentos. Desta forma, esta subunidade pode ser reconhecida pelo resíduo de arginina 1410 (R1410) da p300 - responsável pelo reconhecimento de íons fosfato da Acetil-CoA - por interações do tipo íon-íon ou íon-dipolo (Figura 16). Uma vez que os ésteres não apresentam esta 
característica iônica, o grupo carboxilato é considerado como farmacofórico para esta classe de compostos.

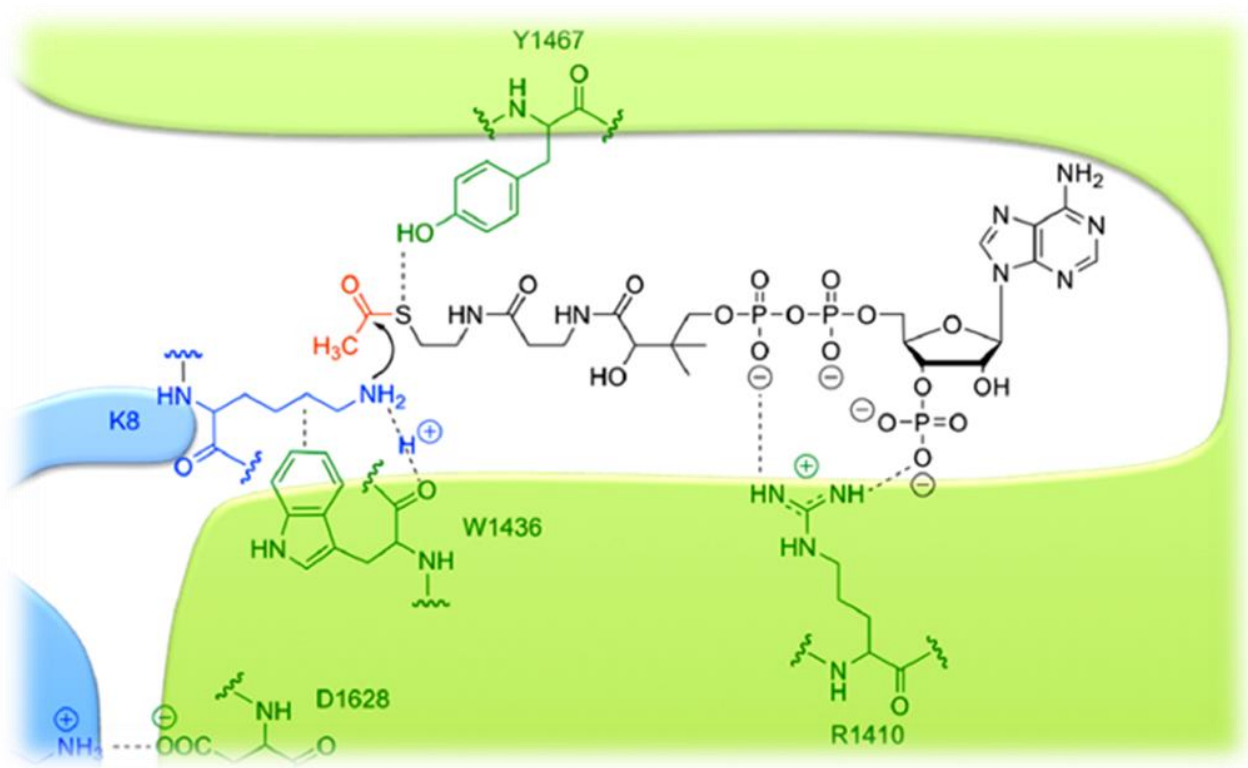

Figura 16: Sítio ativo da p300 com Acetil-CoA

Fonte: Adaptado de DANCY \& COLE, 2015 [56]

Adicionalmente, a hidroxila fenólica - considerando sua ligação de hidrogênio intramolecular com a carbonila no sistema salicílico - e seus derivados metoxila e acetila podem atuar como aceptores de ligação de hidrogênio (ALH) quando do reconhecimento pela p300 por meio de interações íon-dipolo e dipolo-dipolo com o resíduo R1410.

Considerando o parâmetro PSA (Tabela 12), os dados revelam a inexistência de relações lineares com o perfil de atividade encontrado.

Os compostos das séries 2 e 3 (amidas e ésteres) foram inativos ou apresentaram percentual de inibição máximo de 30\% na concentração de 100 $\mu \mathrm{M}$. Estes dados reforçam a subunidade carboxila como farmacofórica, uma vez que estes derivados não apresentam grupos ionizáveis em pH 7,4.

Adicionalmente, a baixa solubilidade destes compostos - LogS variando entre -9,99 e - -9,09 para as amidas e -10,30 e - -9,63 para os ésteres - e os altos valores de LogP - entre 9,67 e 11,72 para as amidas e 10,78 e 12,74 para os ésteres - indicam que estes compostos interagirão preferencialmente com regiões hidrofóbicas da enzima. Já para os derivados LDT11 (16), LDT13 (17), e LDT30 (20), a presença do íon carboxilato modula o perfil de hidrofobicidade 
destes compostos, os quais apresentando LogD na faixa entre 6,26 e 6,57, são, pelo menos, mil vezes menos hidrofóbicos.

\subsubsection{PPAR}

A avaliação da atividade biológica preliminar frente a PPAR - finalizada apenas para a primeira série - foi realizada por Lilia Magomedova no Nuclear Hormone Receptors in Human Health and Disease Laboratory coordenado pela Dra. Carolyn Cummins da Faculdade de Farmácia Leslie Dan da Universidade de Toronto.

O ensaio de gene repórter e avaliação da atividade luciferase em diferentes concentrações para PPAR- $\alpha$ e PPAR- $\gamma$ realizado para a primeira série - derivados 16 a $\mathbf{2 1}$ - revelou que os derivados ácidos LDT11 (16), LDT13 (17), e LDT30 (20) apresentam perfil agonista parcial frente a PPAR- $\alpha$ quando comparados ao agonista pleno GW590735, com valores de $E_{50}$ variando entre 1,5 a 32,0 $\mu \mathrm{M}$. Os dados demonstram que o ácido carboxílico na forma de carboxilato - é farmacofórico para o reconhecimento molecular e ativação do receptor PPAR-a por meio de interações íon-íon e íon-dipolo. Esta afirmação é reforçada pelos resultados obtidos por Ferreira em sua Dissertação de Mestrado [57], na qual cardanol saturado (LDT10, 46) e seus acetil- (LDT12, 47) e metóxi- (LDT27, 48) derivados - respectivos análogos LDT11 (16), LDT13 (17), e LDT30 (20) sem o grupo carboxila - não apresentaram atividade para PPAR- $\alpha$ (Figura 15).

Os dados ainda revelam a modulação do perfil PPAR-a em função do padrão de substituição na hidroxila fenólica, em que os grupos hidroxila, acetila e metoxila podem atuar com ALH. O perfil de atividade apresentado por LDT13 (17) sugere que a presença dos grupos carboxilato (iônico) e acetila (ALH) distantes $3,72 \AA$ e $3,78 \AA$ do centróide do anel aromático (dados não publicados) são relevantes para o reconhecimento pelo receptor PPAR- $\alpha$.

De acordo com os estudos de ancoramento molecular (molecular docking) desenvolvidos por Poda, Bhattacharyya e Uehling para estes compostos (58, em publicação), LDT13 (17) é reconhecido pelo sítio ativo do 
receptor PPAR- $\alpha$ por meio de interações com os resíduos de serina 280, tirosinas 314 e 464 e histidina 440 no bolsão polar no domínio de ligação do ligante (LBD), com adicional interação pi-pi stacking com a fenilalanina 273 no mesmo LBD (Figura 17).

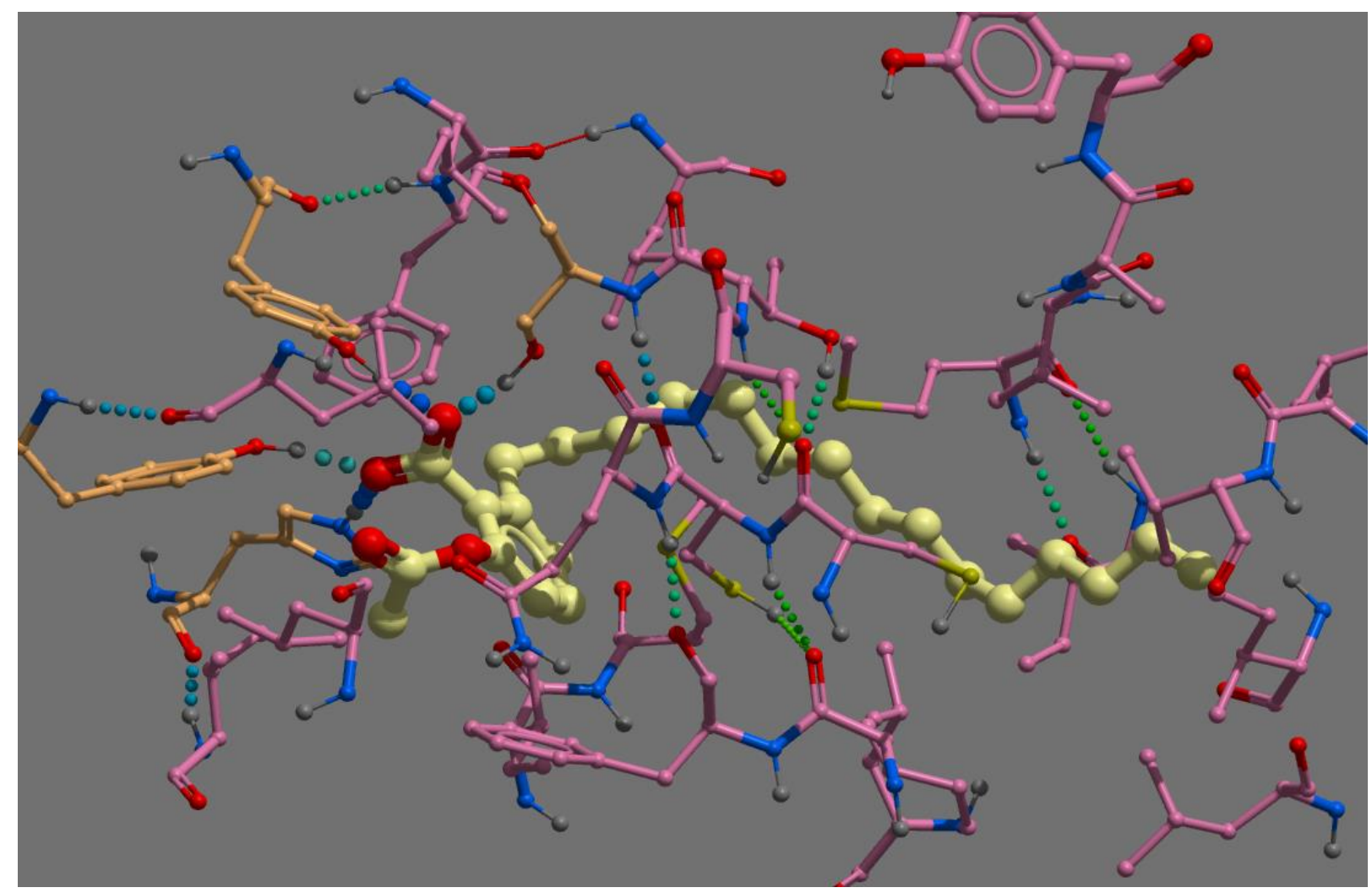

Figura 17: Ancoragem de LDT13 (17) no LBD de PPAR- $\alpha$ Fonte: Poda, Bhattacharyya e Uehling (em publicação), 2015 [58]

Considerando o perfil de atividade frente ao receptor PPAR- $\gamma$, apenas os derivados LDT11 (16), LDT13 (17) ativaram parcialmente o receptor com EC $\mathrm{E}_{50}$ em torno de 12,0 $\mu \mathrm{M}$. Estes dados sugerem que a inatividade de LDT30 (20) pode estar relacionada à redução da área de superfície polar para $35,5 \AA^{2}$ pela presença do grupo metoxila, encontrada na faixa de 53,3 a $63,6 \AA^{2}$ nos derivados ativos. Adicionalmente, a presença do grupo metoxila - por meio do efeito orto e inexistência de grupo ALH acessível - pode influenciar na adoção de conformação inapropriada ao reconhecimento pelo receptor.

Estudos de ancoragem molecular (molecular docking) desenvolvidos por Poda, Bhattacharyya e Uehling para os compostos ativos em PPAR-y (em publicação) sugerem que LDT11 (16) é reconhecido pelo sítio ativo do receptor 
PPAR-y por meio de interações com os resíduos de serina 289, tirosina 473 e histidinas 323 e 449 no bolsão polar no domínio de ligação do ligante (DLL), com interações pi-pi stacking com as fenilalanina 282 e 363 no mesmo DLL (Figura 18).

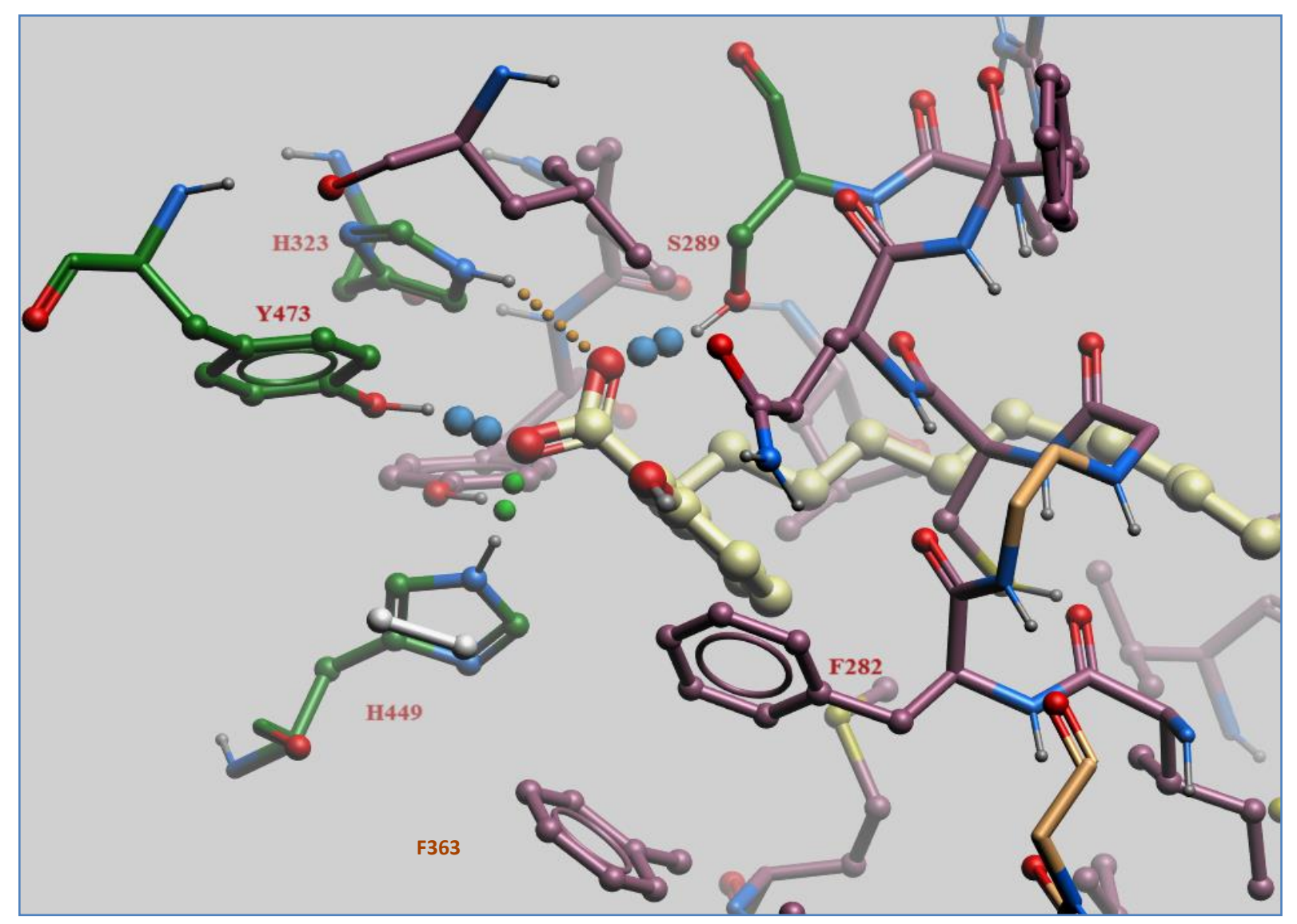

Figura 18: Ancoragem de LDT11 (16) no LBD de PPAR-Y

Fonte: Poda, Bhattacharyya e Uehling (em publicação), 2015 [58]

Os valores de $\mathrm{EC}_{50}$ para ambos PPAR- $\alpha$ e PPAR- $\gamma$ e propriedades físico-químicas teóricas estão dispostos na Tabela 13.

Tabela 13 - Valores de $\mathrm{EC}_{50}$ para os derivados 16-21

\begin{tabular}{lccccccc}
\hline \multirow{2}{*}{ Derivado } & \multicolumn{2}{c}{$\mathrm{EC}_{\mathbf{5 0}}(\boldsymbol{\mu} \mathrm{M})$} & \multirow{2}{*}{ LogP } & $\begin{array}{c}\text { LogD } \\
(\mathbf{p H ~ 7 , 4 )}\end{array}$ & $\begin{array}{c}\text { LogS } \\
(\mathbf{p H ~ 7 , 4 )}\end{array}$ & pKa & $\begin{array}{c}\text { PSA } \\
\left(\AA^{2}\right)\end{array}$ \\
\hline LDT11 (16) & 9,1 & 12,4 & 9,96 & 6,48 & $-5,62$ & 3,1 & 53,3 \\
LDT13 (17) & 1,5 & 12,1 & 9,09 & 6,26 & $-5,08$ & 3,5 & 63,6 \\
LDT30 (20) & 32,0 & -- & 9,39 & 6,57 & $-5,63$ & 4,1 & 35,5 \\
LDT28 (18) & -- & -- & 9,94 & -- & $-8,65$ & -- & 46,5 \\
LDT29 (19) & -- & -- & 10,13 & -- & $-8,72$ & 9,9 & 46,5 \\
LDT208 (21) & -- & -- & 9,37 & -- & $-8,28$ & -- & 52,6 \\
\hline
\end{tabular}




\section{Conclusões e Perspectivas}




\section{CONCLUSÕES E PERSPECTIVAS}

Como visto, a DC apresenta-se como uma doença multifatorial de etiologia desconhecida, cuja eficácia do tratamento a longo prazo ainda é precária. Na última década, vários estudos na área da Química Medicinal têm utilizado a estratégia de ligantes multialvo-dirigidos no planejamento de moléculas capazes de atuarem simultaneamente em alvos moleculares convergentes ao tratamento de patologias complexas - como a Doença de Crohn - a qual foi empregada neste trabalho. Neste contexto, foram sintetizados 30 derivados-alvo planejados a partir do ácido anacárdico utilizando reações clássicas i.e. acetilação, alquilação, hidrogenação catalítica e hidrólise por meio de aquecimento convencional ou radiação micro-ondas, em rendimentos que variaram de $35 \%$ a $98 \%$, cujas estruturas foram confirmadas por métodos espectroscópicos de análise de $\mathrm{RMN}{ }^{1} \mathrm{H}$ e RMN ${ }^{13} \mathrm{C}$ e no IV.

A avaliação da atividade biológica in vitro dos compostos-alvo frente à enzima p300 revelou que os derivados ácidos LDT11 (16), LDT13 (17) e LDT30 (20) foram capazes de inibir mais de $50 \%$ da atividade enzimática na concentração de $50 \mu \mathrm{M}$, e apresentaram $\mathrm{IC}_{50}$ de 3,0 $\mu \mathrm{M}$ (16 e 17) e 10,0 $\mu \mathrm{M}$ (20). A baixa solubilidade dos demais compostos avaliados foi reportada nas condições experimentais empregadas e pode estar associada a ausência de atividade em p300. As relações entrutura-atividade (SAR) - baseadas nos dados fisico-químicos teóricos de $\log \mathrm{S}, \log \mathrm{P}$ e $\log \mathrm{D}$ - revelaram a importância da polaridade para o reconhecimento da enzima, sendo os derivados LDT11 (16), LDT13 (17) e LDT30 (20) pelos menos mil vezes menos hidrofóbicos que os compostos inativos. As possíveis interações com o sítio ativo da p300 foram relacionadas ao íon carboxilato e ALH presentes nos 2'-hidroxiderivados e seus substituintes - como respectivos grupo farmacofórico e moduladores da atividade inibitória - os quais podem interargir com o resíduo R1410 da p300 por meio de interações íon-íon, íon-dipolo e dipolo-diplo.

Os estudos preliminares do perfil frente a PPAR- $\alpha$ e PPAR-y foram finalizados para a primeira série, em que os derivados ácidos LDT11 (16), 
LDT13(17) e LDT30 (20) foram identificados como agonistas parciais para ambos receptores em relação aos agonistas plenos GW590735 e rosiglitazona. Os valores de $\mathrm{EC}_{50}$ foram determinados para os derivados 16, 17 e 20 e variaram entre 1,5 a 32,0 $\mu \mathrm{M}$. Considerando PPAR- $\gamma$, os derivados LDT11 (16) e LDT13 (17) mostraram-se equipotentes com EC En $_{50}$ em torno de 12,0 $\mu \mathrm{M}$. As análises SAR evidenciaram as mesmas relações de relevância observadas para p300 - íon carboxilato e ALH como grupos farmacofórico e moduladores para o reconhecimento molecular e ativação de ambos PPAR- $\alpha$ e PPAR-y. Os estudos ainda sugeriram que a inatividade de LDT30 frente à PPAR-y pode estar relacionada à redução da área de superfície polar para $35,5 \AA^{2}$ bem como a aspectos conformacionais influenciados pelo grupo metoxila (efeito orto) durante o reconhecimento pelo receptor. Estudos de ancoragem molecular revelaram que LDT13 (17) é reconhecido no DLL de PPAR-a por meio de interações com os resíduos de serina 280, tirosinas 314 e 464 e histidina 440 no bolsão polar no domínio de ligação do ligante (DLL), com adicional interação pi-pi stacking com a fenilalanina 273. Da mesma forma, esses estudos sugerem que LDT11 (16) é reconhecido pelo sítio ativo do receptor PPAR-y por meio de interações com os resíduos de serina 289 , tirosina 473 e histidinas 323 e 449 no bolsão polar no DLL, com interações pi-pi stacking com as fenilalanina 282 e 363 no mesmo DLL.

Os resultados preliminares revelaram que derivados LDT11 (16) e LDT13 (17) atuam como inibidores da enzima p300 e agonistas parciais duais frente PPAR- $\alpha$ e PPAR- $\gamma$, sendo considerados ligantes multialvo. O derivado LDT30 (20) foi identificado como ligante dual, capaz de inibir p300 (IC ${ }_{50}$ 10,0$15,0 \mu \mathrm{M})$ e ativar PPAR- $\alpha(32,0 \mu \mathrm{M})$ com perfis semelhantes para os alvos estudados. Além disso, este estudo fornece informações úteis para a otimização molecular na busca de ligantes com melhor perfil de atividade.

Faz-se necessária a avaliação dos derivados ativos quanto à modulação da atividade NF-KB, como importante alvo terapêutico na DC em face da atividade exacerbada na doença, para confirmação de nossos pressupostos teóricos para ligantes multialvo. Vale destacar que, ainda que inativos nos ensaios in vitro, as amidas e ésteres análogos ao 5-CSPA deverão ser avaliados em modelos experimentais in vivo para confirmação do planejamento como anti-inflamatórios. Desse modo, otimização dos rendimentos das 
reações, a avaliação de todas as séries frente à inibição NF-kB in vitro e posteriormente em modelos de colite in vivo e o planejamento de novi derivados constituem as perspectivas deste trabalho. 
Referências Bibliográficas 


\section{REFERÊNCIAS BIBLIOGRÁFICAS}

[1] Braun J, Wei B. Body Traffic: Ecology, Genetics, and Immunity inInflammatory Bowel Disease. Annu Rev Pathol Mech Dis. 2007; 2:401-429.

[2] Lakatos PL. Recent trends in the epidemiology of inflammatory bowel diseases: Up or down? World J Gastroenterol. 2006; 12(38): 6102-6108.

[3] World Gastroenterology Organisation. Inflammatory bowel disease: a global perspective. WGO Global Guidelines. 2009.

[4] Souza MHLP, Troncon LEA, Rodrigues CM, Viana CFG, Onofre PHC, Monteiro RA, Passos ADC, Martinelli ALC, Meneghelli UG. Evolução da ocorrência (1980-1999) da doença de Crohn e da retocolite ulcerativa idiopática e análise das suas características clínicas em um hospital universitário do sudeste do Brasil. Arq Gastroenterol. 2002; 39 (2): 98-105.

[5] Schoffen JPF, Prado IMM. Aspectos epidemiológicos e etiológicos da doença de Crohn. Rev Saúde e Pesquisa. 2011; 4 (1): 73-80.

[6] Santos SC. Doença de Crohn: Uma abordagem geral [monografia]. Curitiba (PR): Universidade Federal do Paraná; 2011.

[7] Kotze PG, Araújo SEA. Tratamento cirúrgico da doença de Crohn. Cury D, Moss A, organizadores. Doenças inflamatórias intestinais: reto colite ulcerativa e Doença de Crohn. 2011; 171-186.

[8] Hsiang CY, Lo HY, Huang HC, Li CC, Wu SL, Ho TY. Ginger extract and zingerone ameliorated trinitrobenzene sulphonic acid-induced colitis in mice via modulation of nuclear factor-KB activity and interleukin-1 $\beta$ signaling pathway. Food Chemistry. 2013; 12: 170-177. 
[9] Mazzeto SE, Lomonaco D. Óleo da castanha de cajú: oportunidades e desafios no contexto do desenvolvimento e sustentabilidade industrial. Quim Nova. 2009; 32 (3): 732-741.

[10] Hemshekhar M, Santhosh MS, Kemparaju K, Girish KS. Emerging roles of anacardic acid and its derivatives: a pharmacological overview. Basic \& Clinical Pharmacology \& Toxicology. 2011; 110: 122-132.

[11] Trevisan MTS, Pfundstein B, Haubner R, et al. Characterization of alkyl phenols in cashew (Anacardium occidentale) products and assay of their antioxidant capacity. Food and Chem Tox. 2006; 44: 188-197.

[12] Sung B, Pandey MK, Ahn KS, Yi T, Chaturvedi MM, Liu M, Aggarwal BB. Anacardic acid (6-nonadecyl salicylic acid), an inhibitor of histone acetyltransferase, suppresses expression of nuclear factor-kB - regulated gene products involved in cell survival, proliferation, invasion and inflammation through inhibition of the inhibitory subunit of nuclear factor-kBa kinase, leading to potentiation of apoptosis. Blood. 2008; 111(10): 4880-4891.

[13] Raposo FAQ. Doença Inflamatória Intestinal [dissertação]. Covilhã (PT): Universidade da Beira Interior, Faculdade de Ciências da Saúde; 2008.

[14] Baumgart DC, Sandborn WJ. Crohn's disease. The Lancet. 2012; 380 (9853): 1590-1605.

[15] Ribeiro ICT. Doença de Crohn: Etiologia, Patogénese e suas implicações na terapêutica [dissertação]. Covilhã (PT): Universidade da Beira Interior, Faculdade de Ciências da Saúde; 2009.

[16] Hart AL, Ng SC. Crohn's disease. Medicine. 2011; 39 (4): 229-236.

[17] Kirsner JB. The historical basis of the idiopathic inflammatory bowel diseases. Inflammatory Bowel Diseases. 1995; 1(1): 2-26. 
[18] Crohn BB, Ginzburg L, Oppenheimer GD. Regional ileitis: a pathologic and clinical entity. JAMA. 1932; 99: 1323-9.

[19] Economou M, Zambeli E, Michopoulos S. Incidence and prevalence of Crohn's disease and its etiological influences. Annals of Gastroenterology. 2009; 22(3): 158-167.

[20] Silverberg MS, Satsangi J, Ahmad T, Arnott I, Bernstein CN, Brant SR et al. Toward an integrated clinical, molecular and serological classification of inflammatory bowel disease: Report of a Working Party of the 2005 Montreal World Congress of Gastroenterology. Can J Gastroenterol. 2005;19 (A): 5A35A.

[21] Sartor RB. Mechanisms of Disease: pathogenesis of Crohn's disease and ulcerative colitis. Nature Clinical Pratice Gastroenterology \& Hepatology. 2006; 3(7): 390-407.

[22] Jewell DP. Crohn's disease. Medicine. 2007; 35 (5): 283-289.

[23] Shanahan F. Crohn's disease. The Lancet. 2002; 359: 62-69.

[24] Shih DQ, Targan SR. Imunopathogenesis of inflammatory bowel disease. World J Gastroenterol. 2008; 14(3):390-400.

[25] Cario E, Podolsky DK. Differential Alteration in Intestinal Epithelial Cell Expression of Toll-Like Receptor 3 (TLR3) and TLR4 in Inflammatory Bowel Disease. Infection and Immunity. 2000; 68(12): 7010-7017.

[26] Cheifetz AS. Management of Active Crohn Disease. JAMA. 2013; 309(20): 2150-2158. 
[27] Mendonça DCS. Supressão da resposta do HIF-1a pelo NF-kB via competição pela ligaçao com a coativador transcricional p300 [tese]. Brasília: Universidade Católica de Brasília, Ciências Genômicas e Biotecnologia. 2010.

[28] Gilmore TD. Introduction to NF-KB: players, pathways, perspectives. Oncogene. 2006; 25: 6680-6684.

[29] Hayden MS, Ghosh S. Signaling to NF-KB. Genes \& Development. 2004; 18: 2195-2224.

[30] Ivanenkov YA, Balakin KV, Lavrovsky Y. Small Molecule Inhibitors of NF$\mathrm{KB}$ and JAK/STAT Signal Transduction Pathways as Promising AntiInflammatory Therapeutics. Mini-Reviews in Medicinal Chemistry. 2011; 11: 5578.

[31] Souto JA, Conte MR, Alvarez R, Nebbioso A, Carafa V, Altucci L, Lera AR. Synthesis of Benzamides Related to Anacardic Acid and Their Histone Acetyltransferase (HAT) Inhibitory Activities. ChemMedChem. 2008; 3 (9): 1435-1442.

[32] Portela A, Esteller M. Epigenetic modifications and human disease. Nature Biotechnology. 2010; 28(10): 1057-1068.

[33] Wu J. Development of Inhibitors and Assay Methods for Histone Acetyltransferases [dissertação]. Estados Unidos: Georgia State University. 2011.

[34] Dekker FJ, Haisma HJ. Histone acetyl transferases as emerging drug targets. Drug Discovery Today. 2009; 14(19/20): 942-948.

[35] Devipriya B, Paramenwari AR, Rajalkshmi, Palvannan T, Kumaradhas P. Exploring the binding affinities of p300 enzyme activators CTPB and CTB using docking method. Indian Jour Biochem \& Bioph. 2010; 47: 364-369. 
[36] Ghizzoni M, Haisma HJ, Maarsingh H, Dekker FJ. Histone acetyltransferases are crucial regulators in NF-KB mediated inflammation. Drug Discovery Today. 2011; 0(0): 1-8.

[37] Jin Q, Yu L, Wang L, Zhang Z, Kasper LH, Lee J, Wang C et al. Distinct roles of GCN5/PCAF-mediated H3K9ac and CBP/p300-mediated H3K18/27ac in nuclear receptor transactivation. The EMBO Journal. 2011; 30(2): 249-262.

[38] Costi R, Santo RD, Artico M, Miele G, Valentini P, Novellino E, Cereseto A. Cinnamoyl Compounds as Simple Molecules tha inhibit p300 Histone Acetyltransferase. J Med Chem. 2007; 50: 1973-1977.

[39] Monteleone G, Blanco GDV, Monteleone I, Fina D, Caruso R, Gioia V, Ballerini S, Federici G et al. Post-transcriptional Regulation of Smad7 in the Gut of Patients With Inflammatory Bowel Disease. Gastroenterology. 2005; 129(5): 1420-1429.

[40] Tsaprouni LG, Ito K, Powell JJ, Adcock IM, Punchard N. Differential patterns of histone acetylation in inflammatory bowel diseases. Journal of Inflammation. 2011; 8(1): 1-12.

[41] Desreumaux P, Ghosh S. Review article: mode of action and delivery of 5aminosalicylic acid - new evidence. Aliment Pharmacol Ther. 2006; 24(1): 2-9.

[42] Kaser A, Zeissig S, Blumberg RS. Inflammatory Bowel Disease. Annu. Rev. Immunol. 2010; 28: 573-621.

[43] Monsalve FA, Pyarasani RD, Delgado-Lopez F, Carrasco RM. Peroxissome proliferator-activated receptor target for treatment of metabolic diseases. Mediators of Inflammation. 2013; 2013: 18 pages.

[44] Desreumaux P. Understanding the Mechanism of 5-ASA in Treating Colonic Inflammation. Gastroenterology \& Hepatology. 2008; 4 (5): 319-320. 
[45] Balachandran, VS, Jadhav SR, Vemula PK, John G. Recent advances in cardanol chemistry in a nutshell: from a nut to nanomaterials. Chem Soc Rev. 2013; 42(2): 427-438.

[46] Chandregowda V, Kush A, Reddy GC. Synthesis of benzamide derivatives of anacardic acid and their cytotoxic activity. European Journal of Medicinal Chemistry. 2009; 44: 2711-2719.

[47] Logrado, LPL, Santos, CO, Romeiro, LAS, et al. Synthesis and cytotoxicity screening of substituted isobenzofuranones designed from anacardic acids. Eur J Med Chem. 2010; 45:3480-89.

[48] Swamy, BN, Suma, TK, Rao, GV, et al. Synthesis of isonicotinoylhydrazones from anacardic acid and their in vitro activity against Mycobacterium smegmatis. Eur J of Med Chem. 2007; 42:420-24.

[49] Vempati RK, Alapati SR, Reddy NS, Naresh VV, Dubey PK. Synthesis of novel Quinoline Carboxylic acids from Anacardic acid. Der Pharma Chemica. 2012; 4 (1): 248-254.

[50] Kim J, Kang S, Hong S, Yum S, Kim YM, Jung Y. Structure-activity relationship of salicylic acid derivatives on inhibition of TNF- $\alpha$ dependent NF-KB activity: Implication on anti-inflammatory effect of $\mathrm{N}$-(5-chlorosalicyloyl) phenethylamine against experimental colitis. European Journal of Medicinal Chemistry. 2012; 48: 36-44.

[51] Carvalho AS, Feitosa LO, Soares M, Costa TEMM, Henriques MG, Salomão K, Castro SL, et al. Design and synthesis of new (E)-cinnamic Nacylhydrazones as potent antitrypanosomal agents. Eur Jour Med Chem. 2012; 54: $512-521$

[52] Barreiro EJ, Manssour CA. Química Medicinal: As bases moleculares da ação dos fármacos. 2ª edição. Porto Alegre: Artmed, 2008. 
[53] Smith DA, Waterbeemd H, Walker DK. Pharmacokinetics and Metabolism in Drug Design. $2^{\underline{a}}$ edição. Weinheim: Willey-VCH Verlag GmbH \& Co, 2006.

[54] Ertl P, Rohde B, Selzer P. Fast calculation of molecular polar surface area as a sum of fragment based contributions and its application to the prediction of drug transport properties. J. Med. Chem. 2000; 43: 3714-3717.

[55] Peixoto EP. Previsão da solubilidade de fármacos orgânicos em água, baseado na relação quantitativa entre estrutura molecular in silico [Dissertação]. Anápolis: Universidade Estadual de Goiás, Unidade Universitária de Ciências Exatas e Tecnológicas, Pró-reitoria de Pesquisa e Pós-graduação em Ciências Moleculares; 2010.

[56] Dancy BM, Cole PA. Protein Lysine Acetylation by p300/CBP. Chem Rev. No prelo, 2015.

[57] Ferreira TAM. Síntese e Avaliação Farmacológica de Novos Ligantes PPAR Planejados a Partir do Cardanol [Dissertação]. Brasília: Universidade de Brasília, Faculdade de Saúde, Ciências Farmacêuticas; 2014.

[58] Poda, Bhattacharyya e Uehling (Em publicação) 2015.

[59] Amato AA. Investigação da atividade farmacológica de benzilideno- e acrilideno- tiazolidinedionas e de isoflavonas nos receptores alfa, beta/delta e gama ativados por proliferadores peroxissomais [Tese]. Brasília: Universidade de Brasília, Ciências da Saúde; 2008.

[60] Michalik L, Wahli W. PPARsMediate Lipid Signaling in Inflammation and Cancer. PPAR Research. 2008; 2008: 15 pags.

[61] Shan W, Nicol CJ, Ito S, Bility MT, Kennett MJ, Ward et al. Peroxissome proliferator-activated receptor-beta/delta protects against chemically induced liver toxicity in mice. Hepatology. 2008; 47, 225-235. 
[62] McMullen PD, Bhattacharya S, Woods CG, Sun B, Yarborough K, Ross $\mathrm{SM}$, et al. A map of the PPARa transcription regulatory network for primary human hepatocytes. Chemico-Biol Inter. 2014; 209: 14-24.

[63] Ricote M, Glass CK. PPARs and molecular mechanisms of transrepression. Biochim Biophys Acta. 2007; 1771(8): 926-935.

[64] Gelman L, Zhou G, Fajas L, Raspé E, Fruchart J, Auwerx J. p300 Interacts with the $\mathrm{N}$ - and $\mathrm{C}$-terminal Part of PPARg2 in a Ligand-independent and dependent Manner, Respectively. Journ of Biol Chem.1999; 274 (12): 76817688.

[65] Zhao F, Drohomyrecky P, Dunn S. Peroxisome proliferator-activated receptor delta (PPARס) limits Th1 inflammation through effects on interferon (IFN)- $\gamma$ transcription and lymphocyte homeostasis (IRM7P. 480). Jour of Immunol. 2014; 192 (1): 126-5.

[66] Hollingshead HE, Morimura K, Adachi M, Kennett MJ, Billin AN, Wilson TM, et al. PPAR $\beta / \delta$ Protects Against Experimental Colitis Through a LigandIndependent Mechanism. Dig Dis Sci. 2007; 52: 2912-2919.

[67] Nuclear Receptor Resource. Drawings [internet]. Disponível em: http://nrresource.org/drawings/.

[68] SGC. Human E1A binding protein p300 (bromodomain) [internet]. Toronto: University of Toronto. Disponível em: http://www.thesgc.org/structures/3i3j. 
Anexos 
ANEXO 1 - ESPECTRO NO INFRAVERMELHO $\left(v \mathrm{~cm}^{-1}, \mathrm{KBr}\right)$ - LDT11 (16)

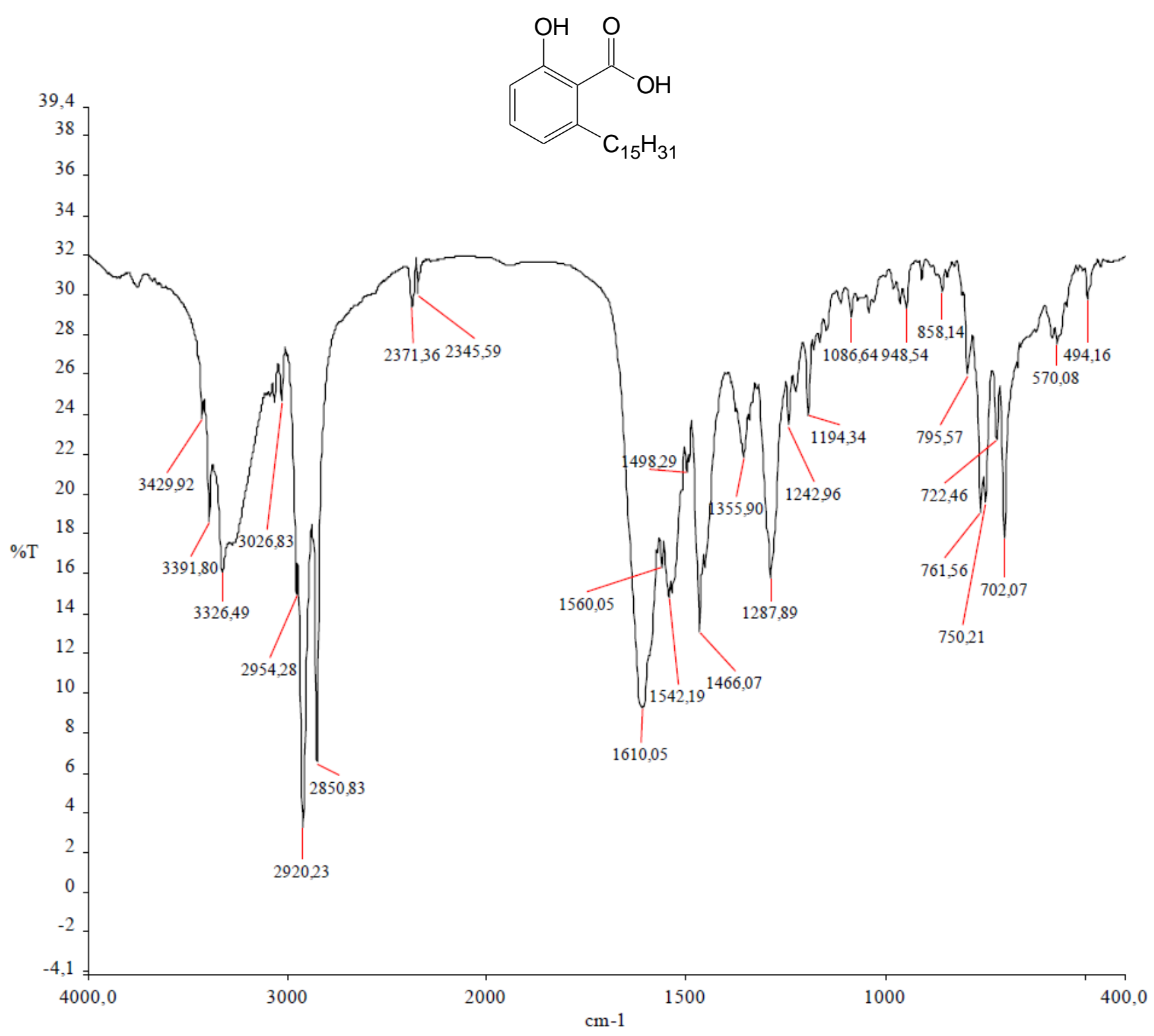


ANEXO 2 - ESPECTRO DE RMN ${ }^{1} \mathrm{H}\left(300 \mathrm{MHz}, \mathrm{CDCl}_{3}\right)$ - LDT11 (16)
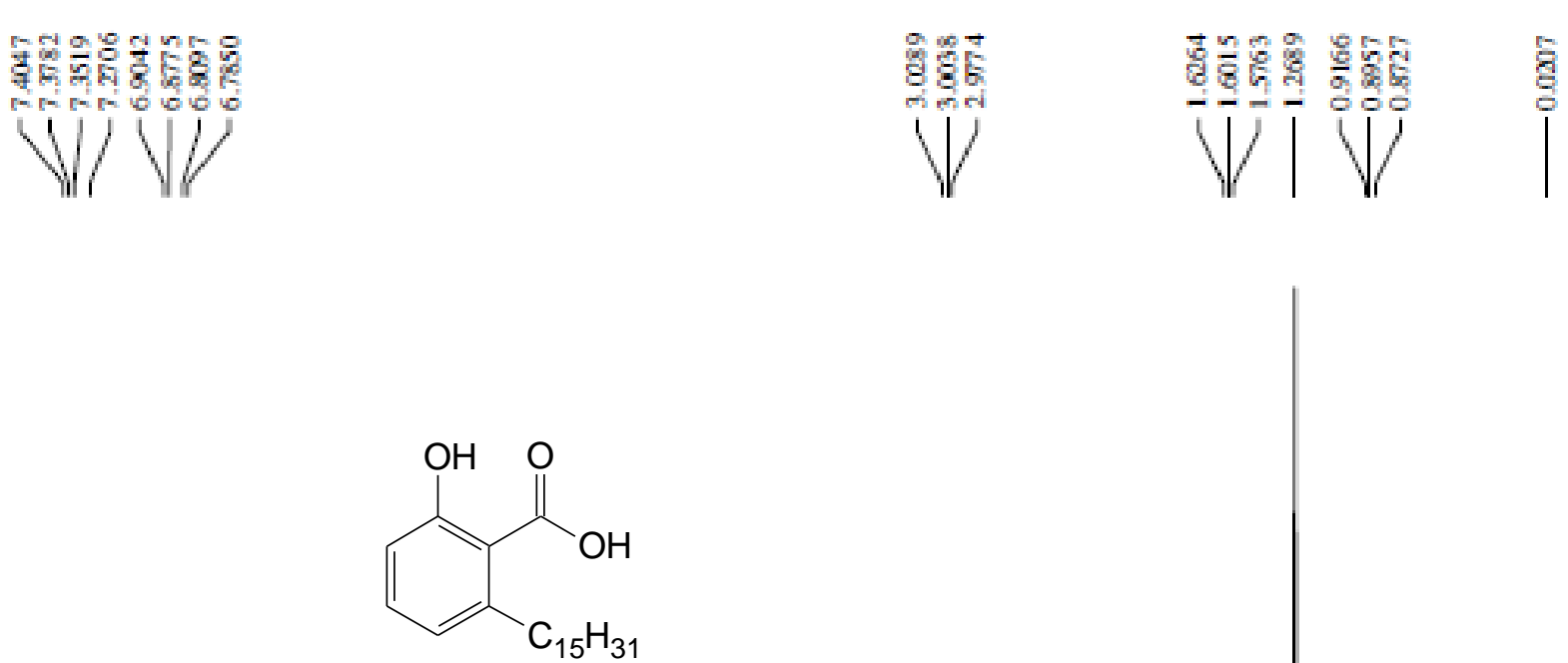
ANEXO 3 - ESPECTRO DE RMN ${ }^{13} \mathrm{C}(75 \mathrm{MHz}, \mathrm{CDCl})$ - LDT11 (16)

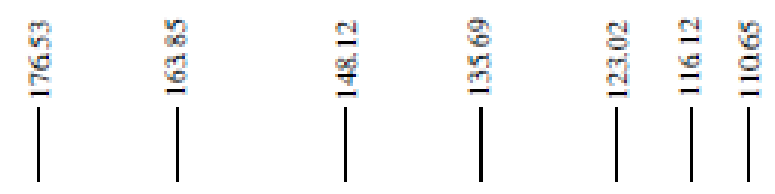
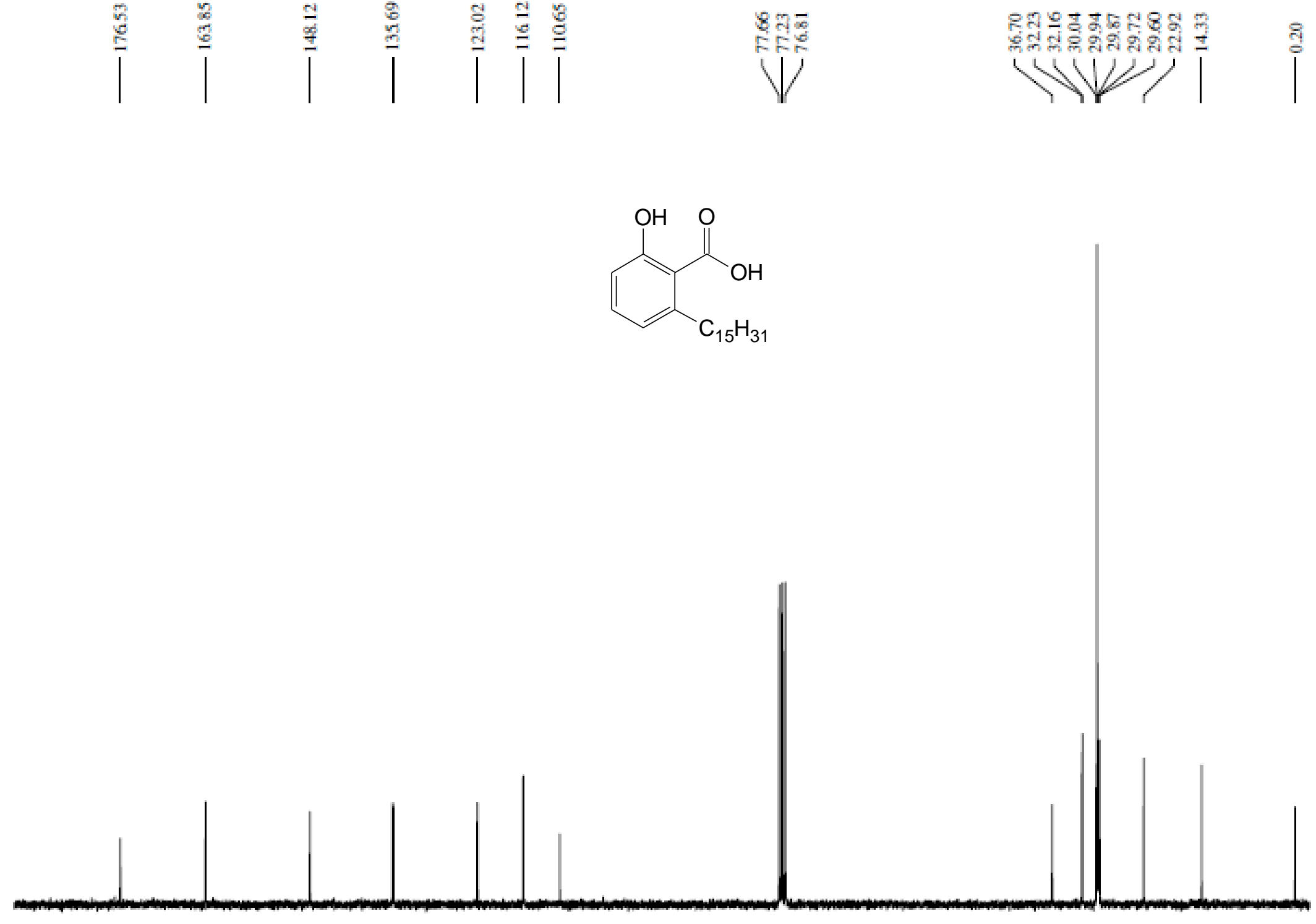
ANEXO 4 - ESPECTRO NO INFRAVERMELHO $\left(v \mathrm{~cm}^{-1}, \mathrm{KBr}\right)$ - LDT13 (17)

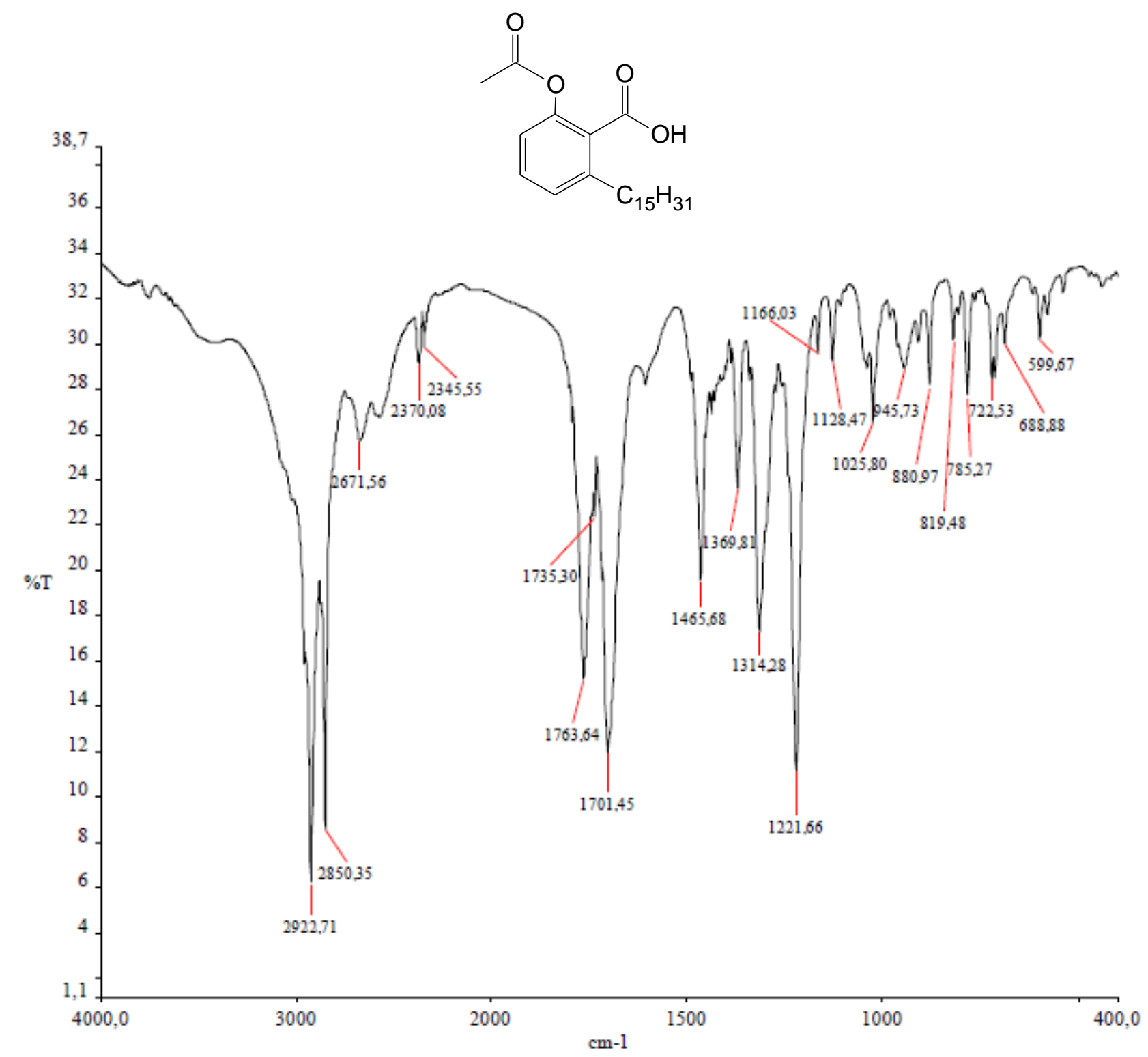


ANEXO 5 - ESPECTRO DE RMN ${ }^{1} \mathrm{H}\left(300 \mathrm{MHz}, \mathrm{CDCl}_{3}\right)$ - LDT13 (17)
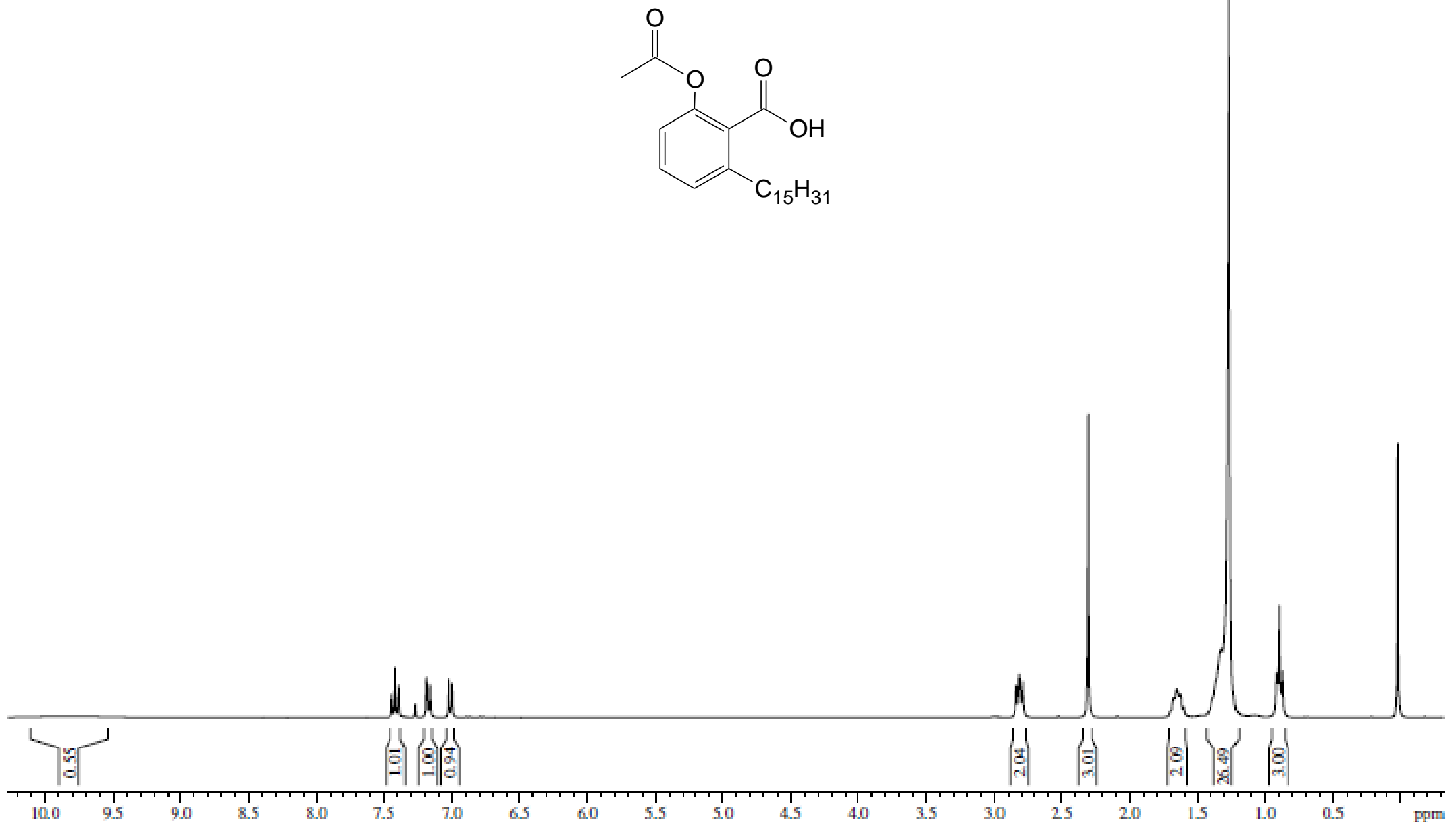
ANEXO 6 - ESPECTRO RMN ${ }^{13} \mathrm{C}\left(75 \mathrm{MHz}, \mathrm{CDCl}_{3}\right)$ - LDT13 (17)
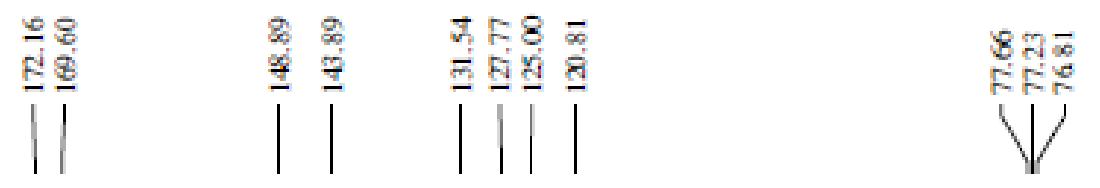

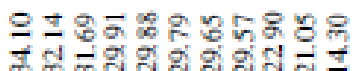

WNis)
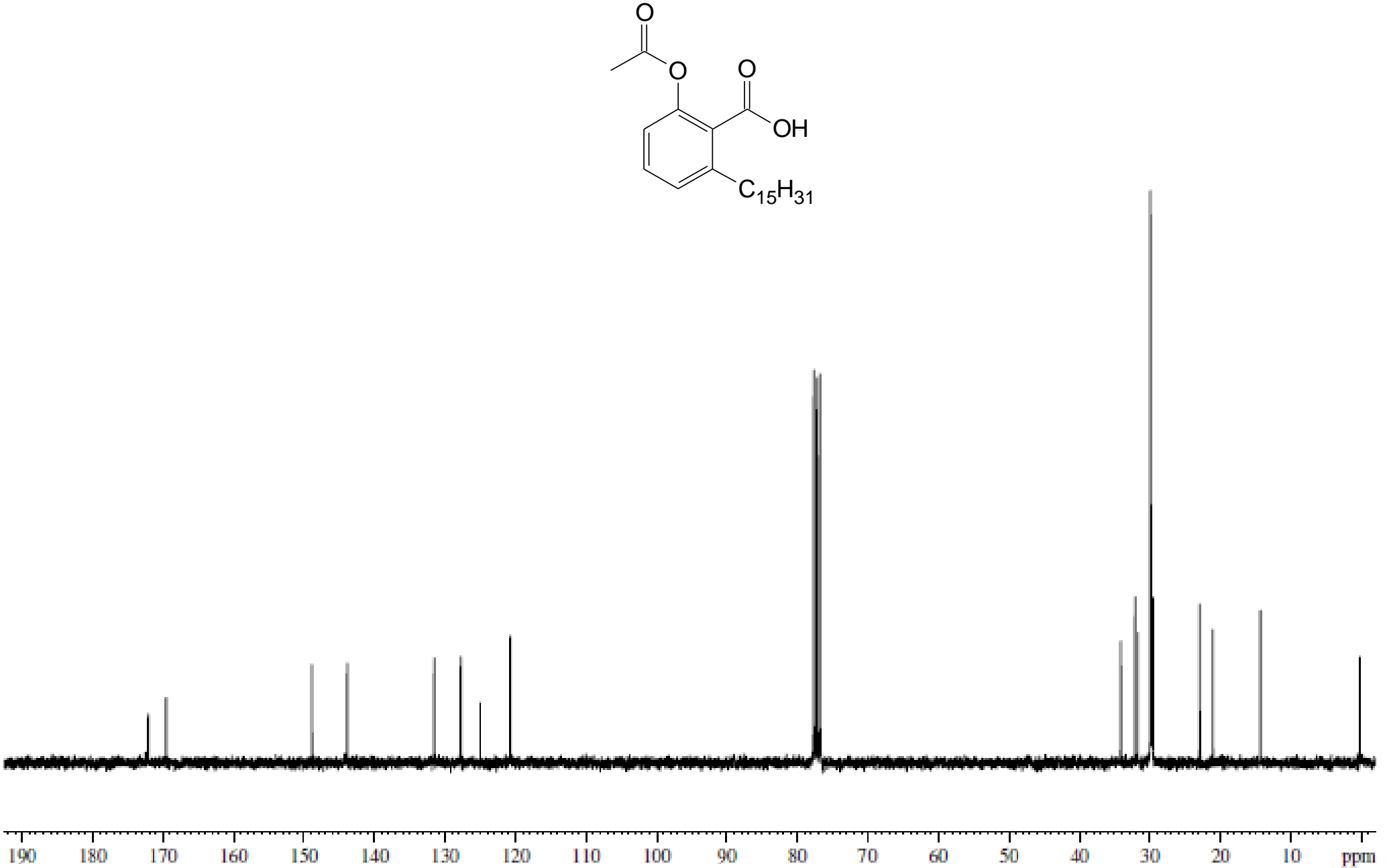
ANEXO 7 - ESPECTRO NO INFRAVERMELHO $\left(v \mathrm{~cm}^{-1}, \mathrm{KBr}\right)$ - LDT28 (18)

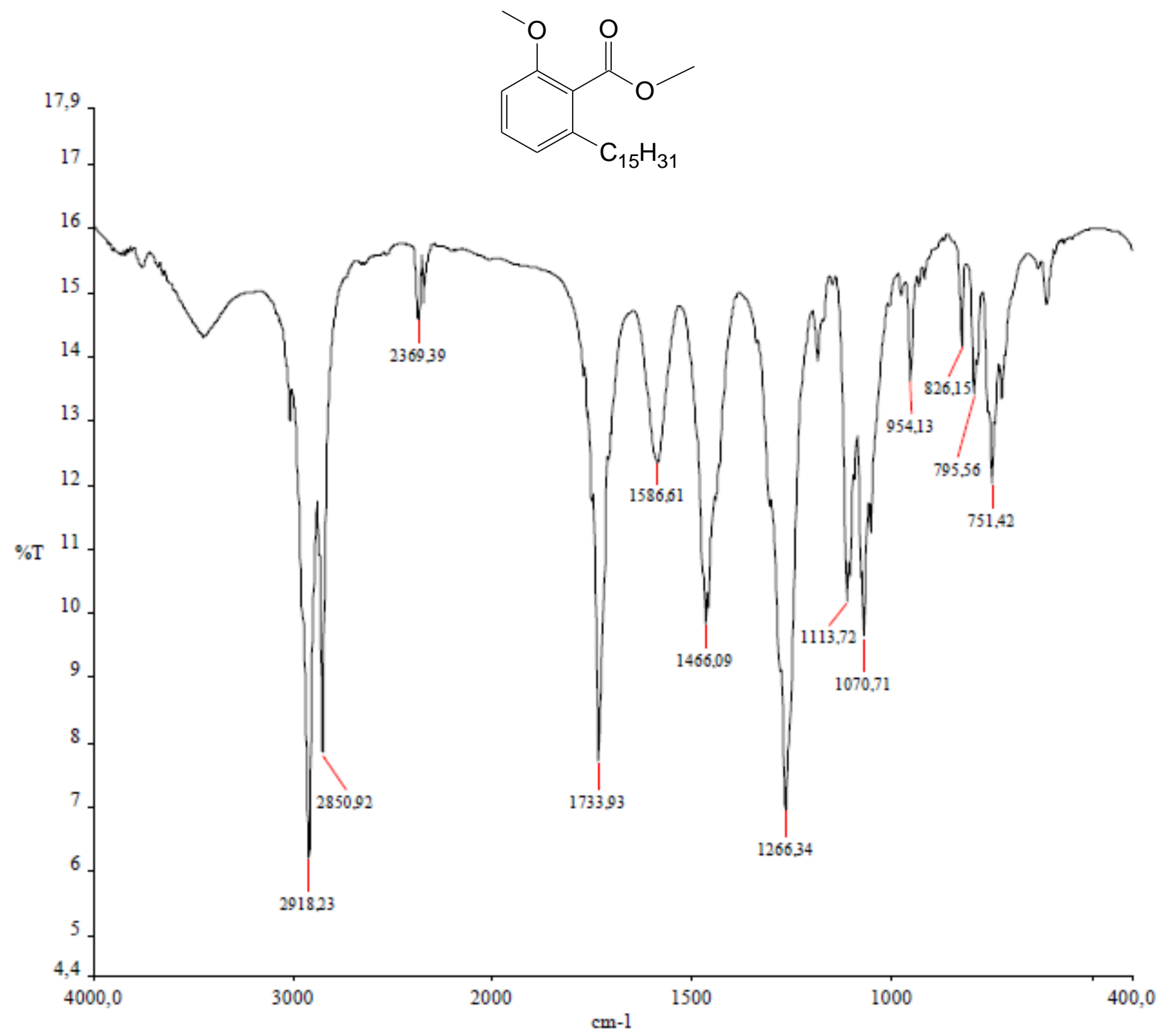


ANEXO 8 - ESPECTRO DE RMN ${ }^{1} \mathrm{H}\left(300 \mathrm{MHz}, \mathrm{CDCl}_{3}\right)$ - LDT28 (18)

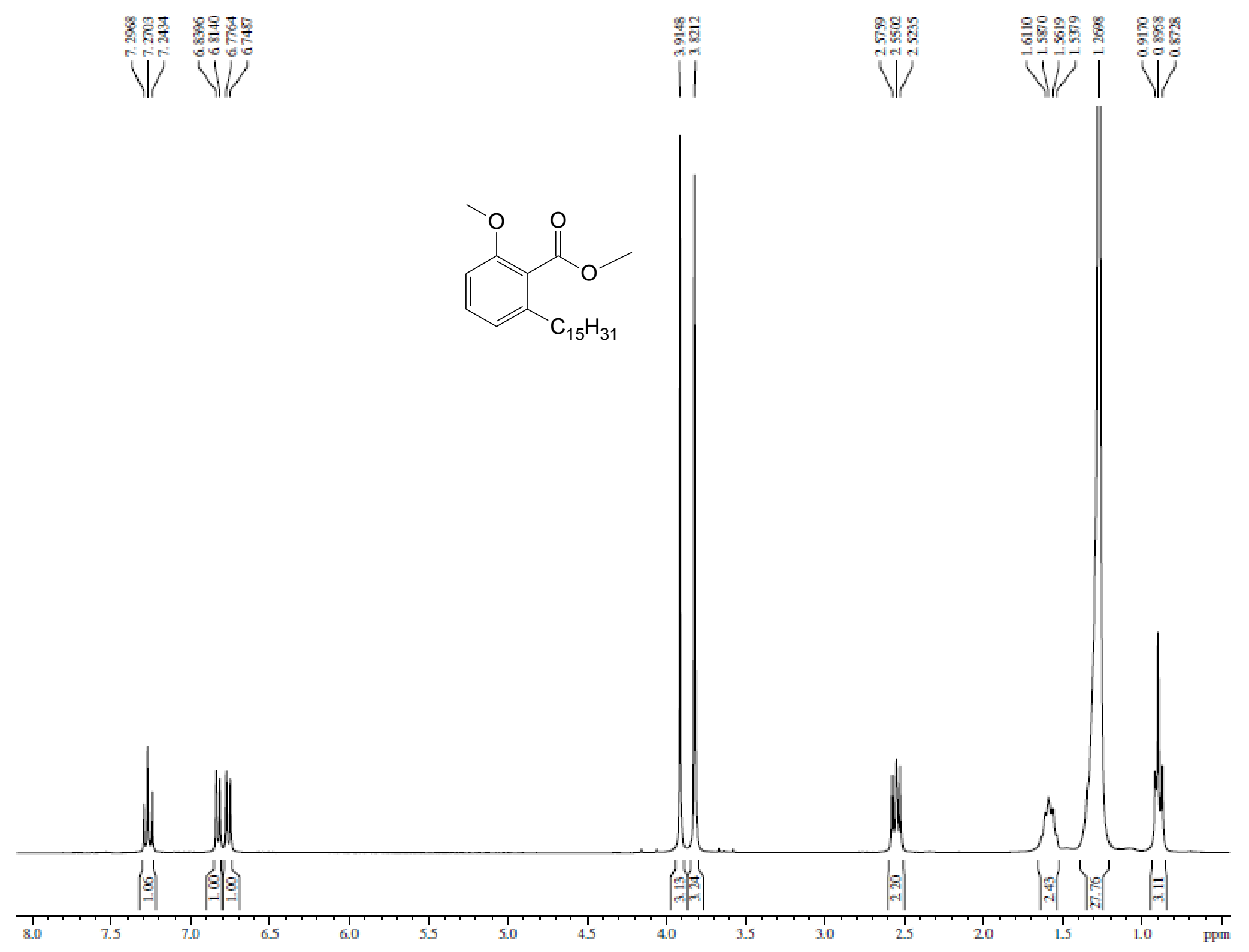


ANEXO 9 - ESPECTRO RMN ${ }^{13} \mathrm{C}\left(75 \mathrm{MHz}, \mathrm{CDCl}_{3}\right)$ - LDT28 (18)

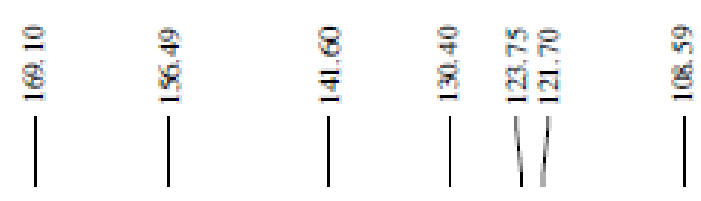

$\sqrt{8 \pi}$

$\mid$
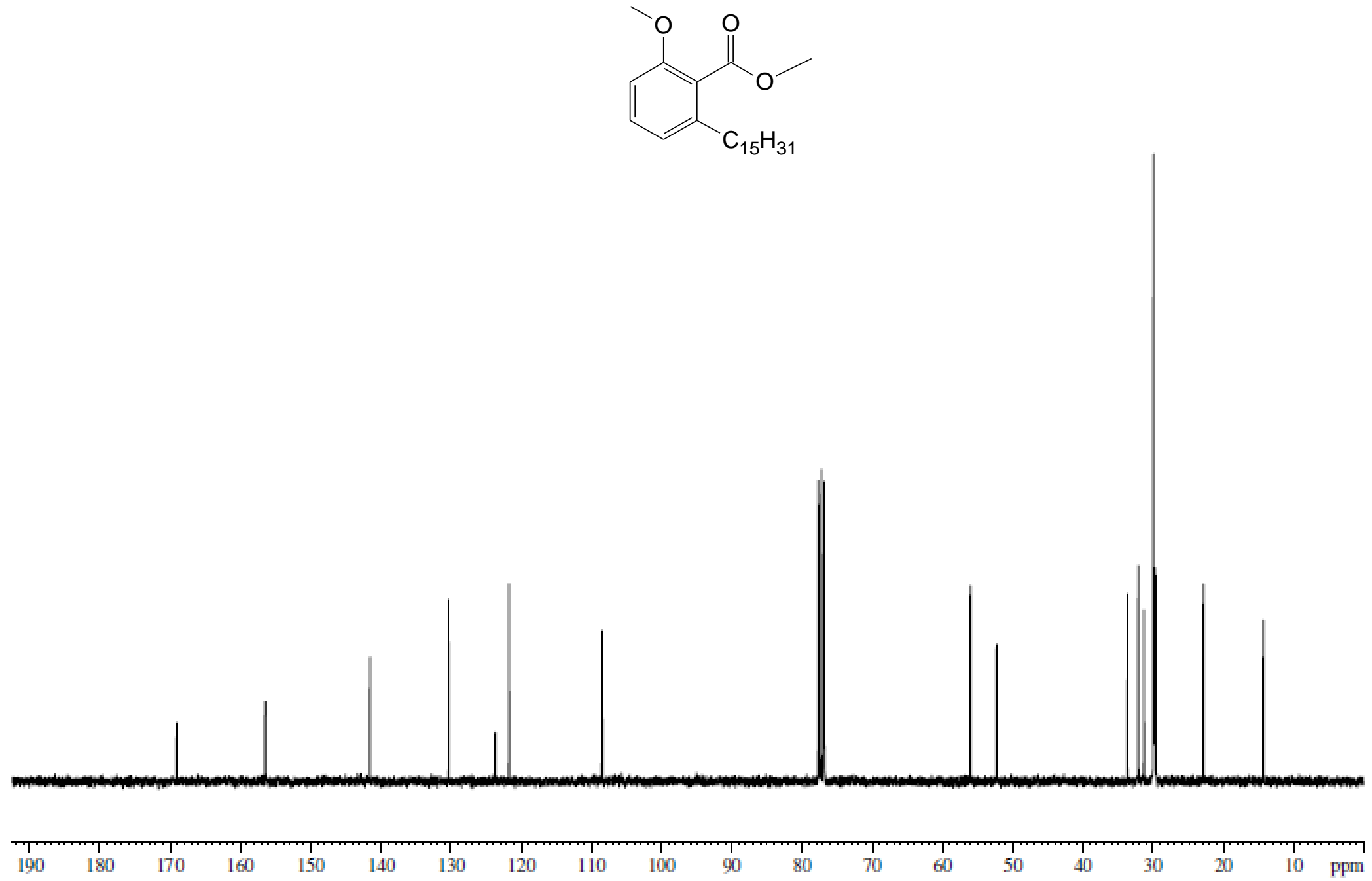
ANEXO 10 - ESPECTRO NO INFRAVERMELHO $\left(v \mathrm{~cm}^{-1}, \mathrm{KBr}\right)$ - LDT30 (20)

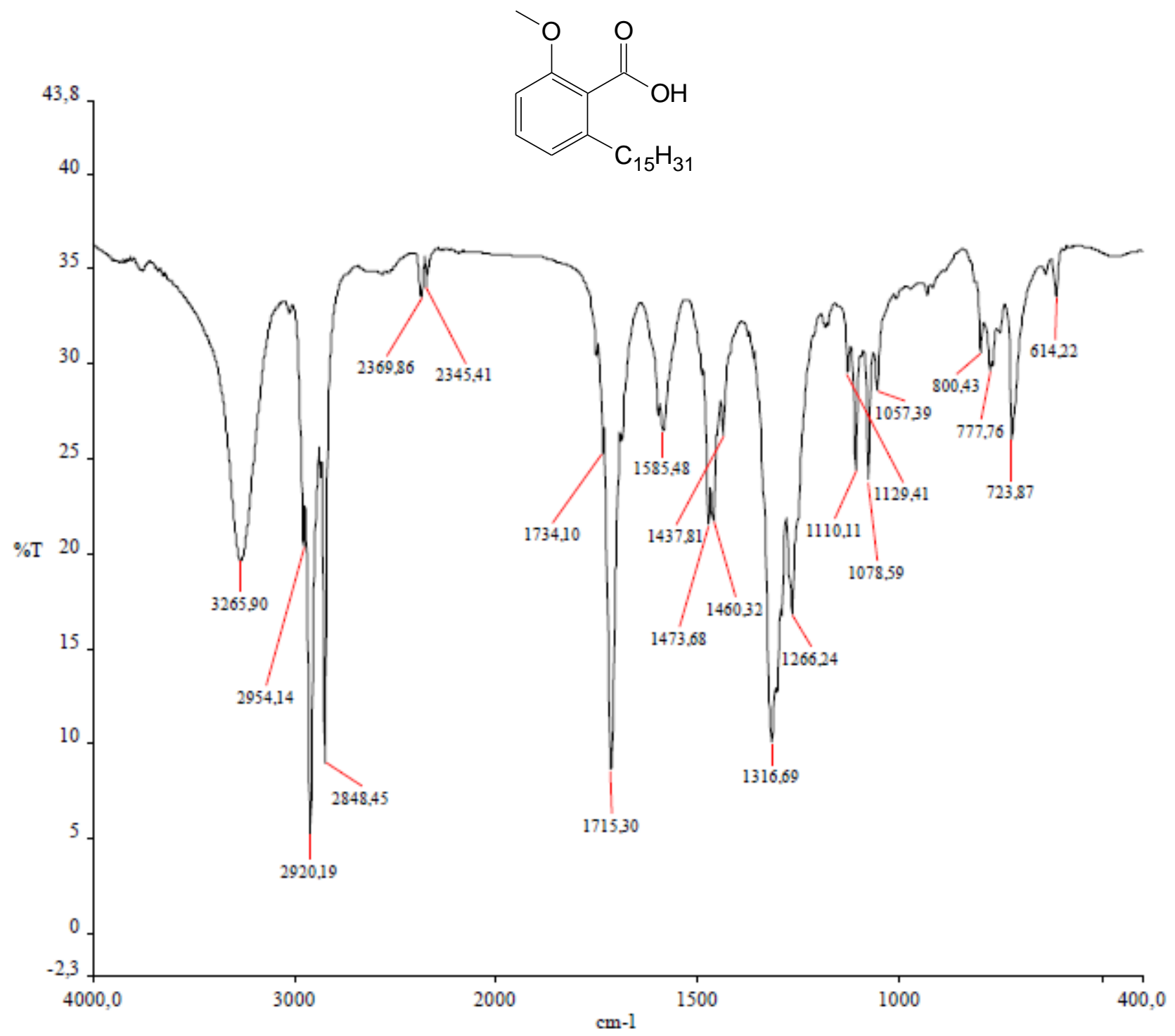


ANEXO 11 - ESPECTRO DE RMN ${ }^{1} \mathrm{H}\left(300 \mathrm{MHz}, \mathrm{CDCl}_{3}\right)$ - LDT30 (20)

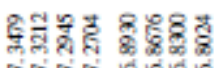

VIV U
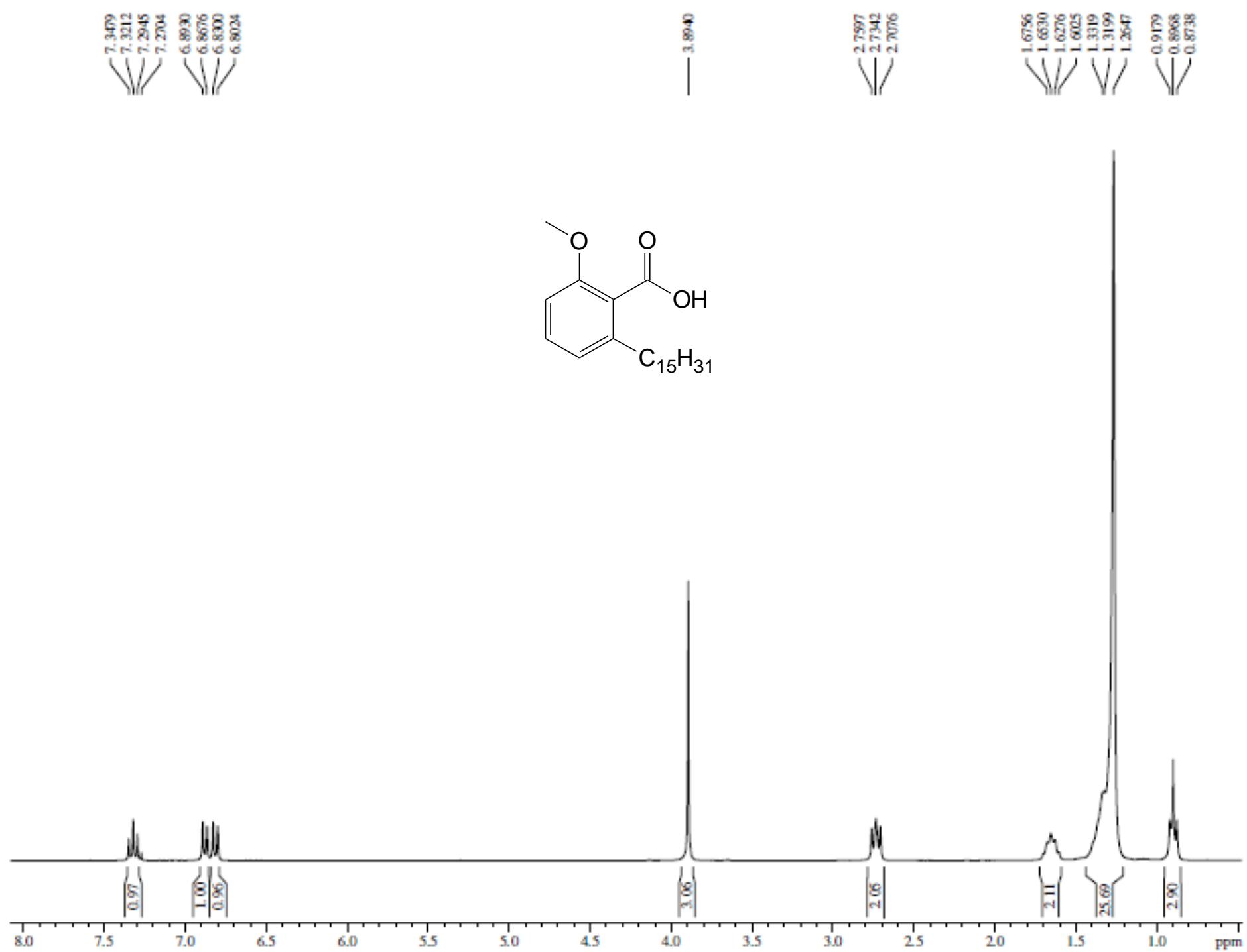
ANEXO 12 - ESPECTRO RMN ${ }^{13} \mathrm{C}\left(75 \mathrm{MHz}, \mathrm{CDCl}_{3}\right)$ - LDT30 (20)

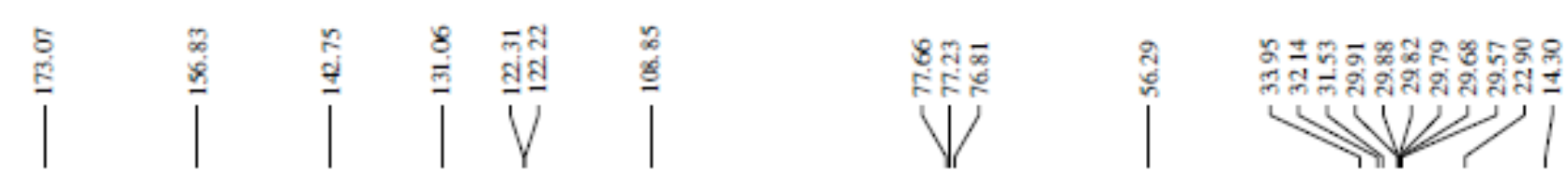
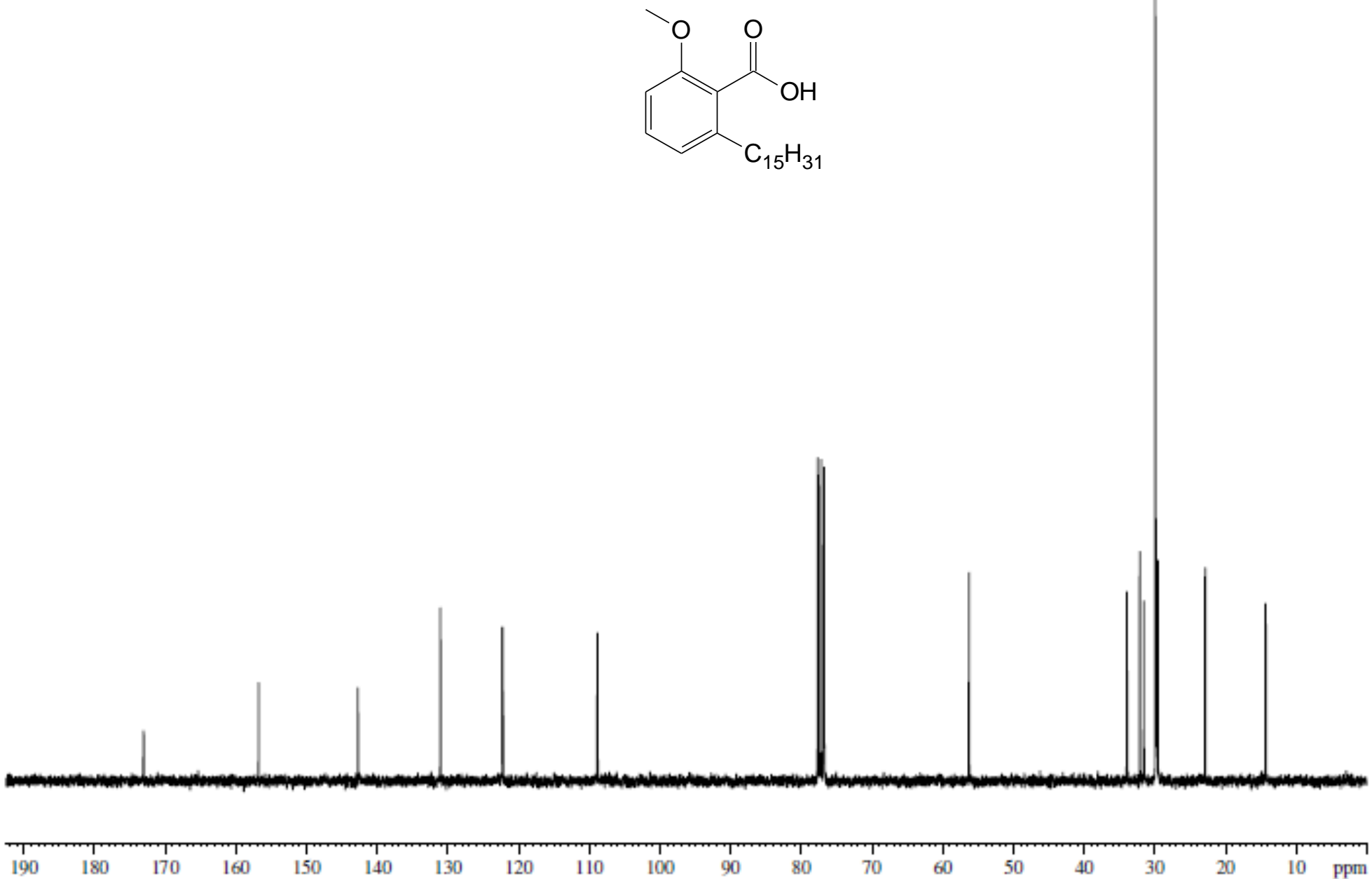
ANEXO 13 - ESPECTRO NO INFRAVERMELHO $\left(v \mathrm{~cm}^{-1}, \mathrm{KBr}\right)$ - LDT29 (19)

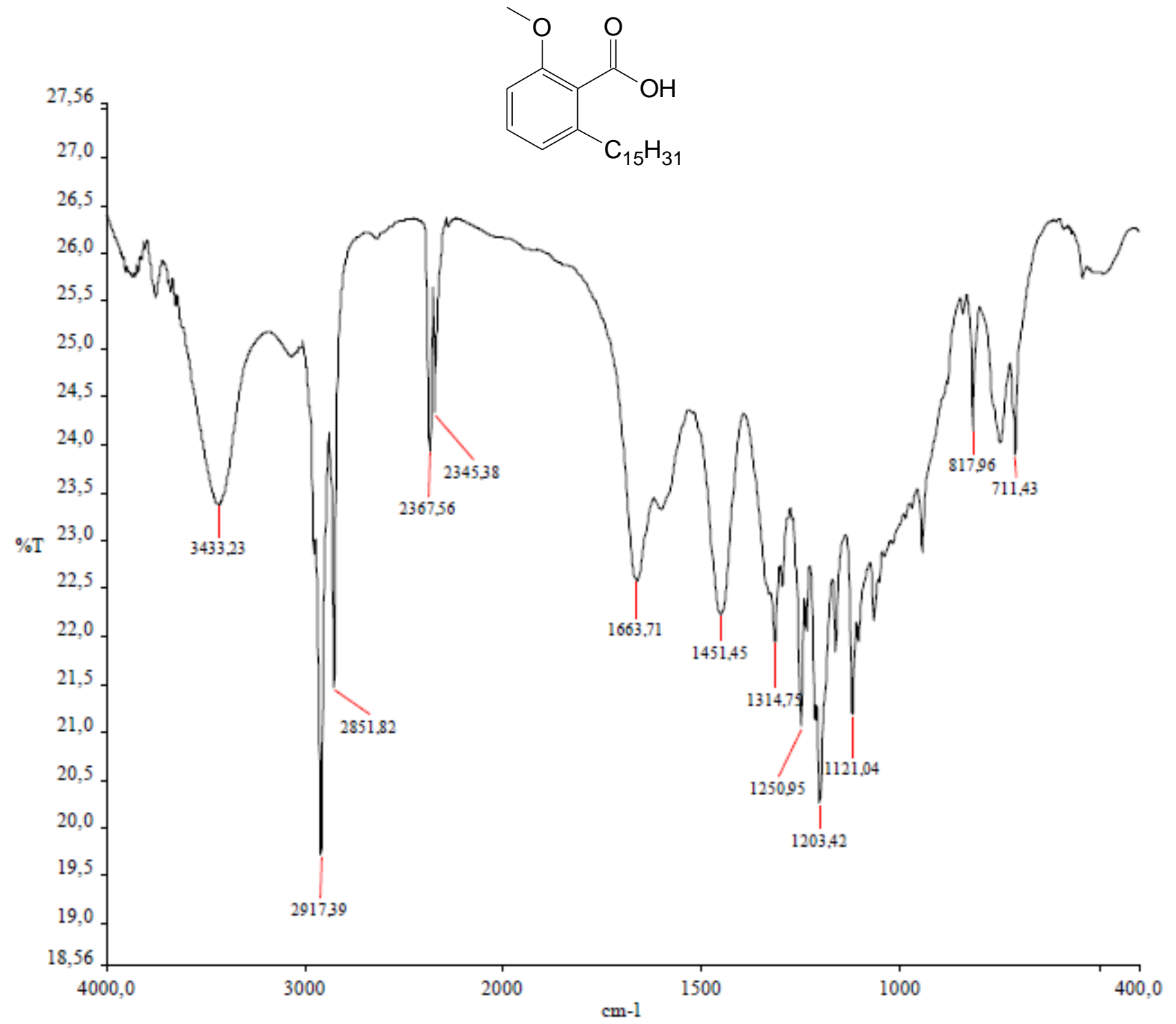


ANEXO 14 - ESPECTRO DE RMN ${ }^{1} \mathrm{H}\left(500 \mathrm{MHz}, \mathrm{CDCl}_{3}\right)$ - LDT29 (19)
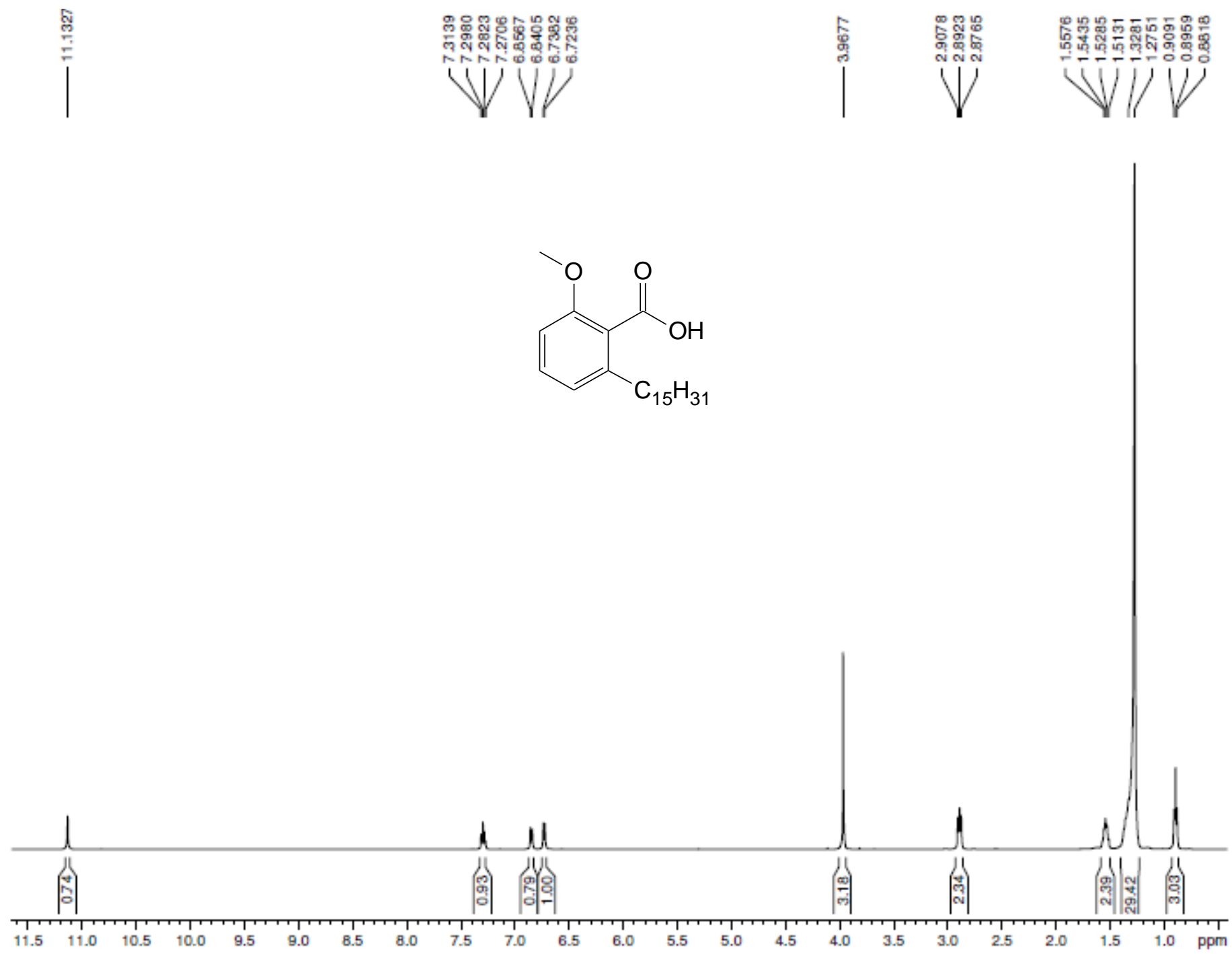
ANEXO 15 - ESPECTRO RMN ${ }^{13} \mathrm{C}\left(125 \mathrm{MHz}, \mathrm{CDCl}_{3}\right)$ - LDT29 (19)

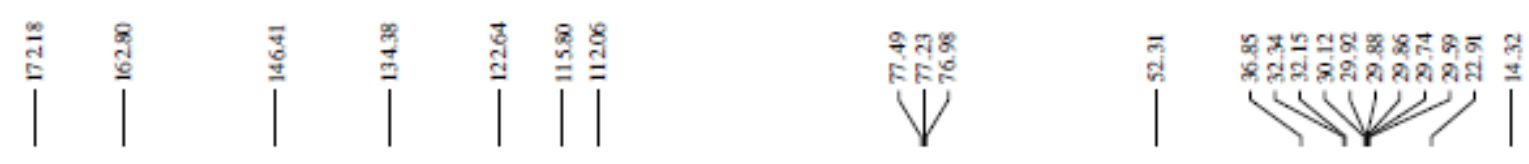
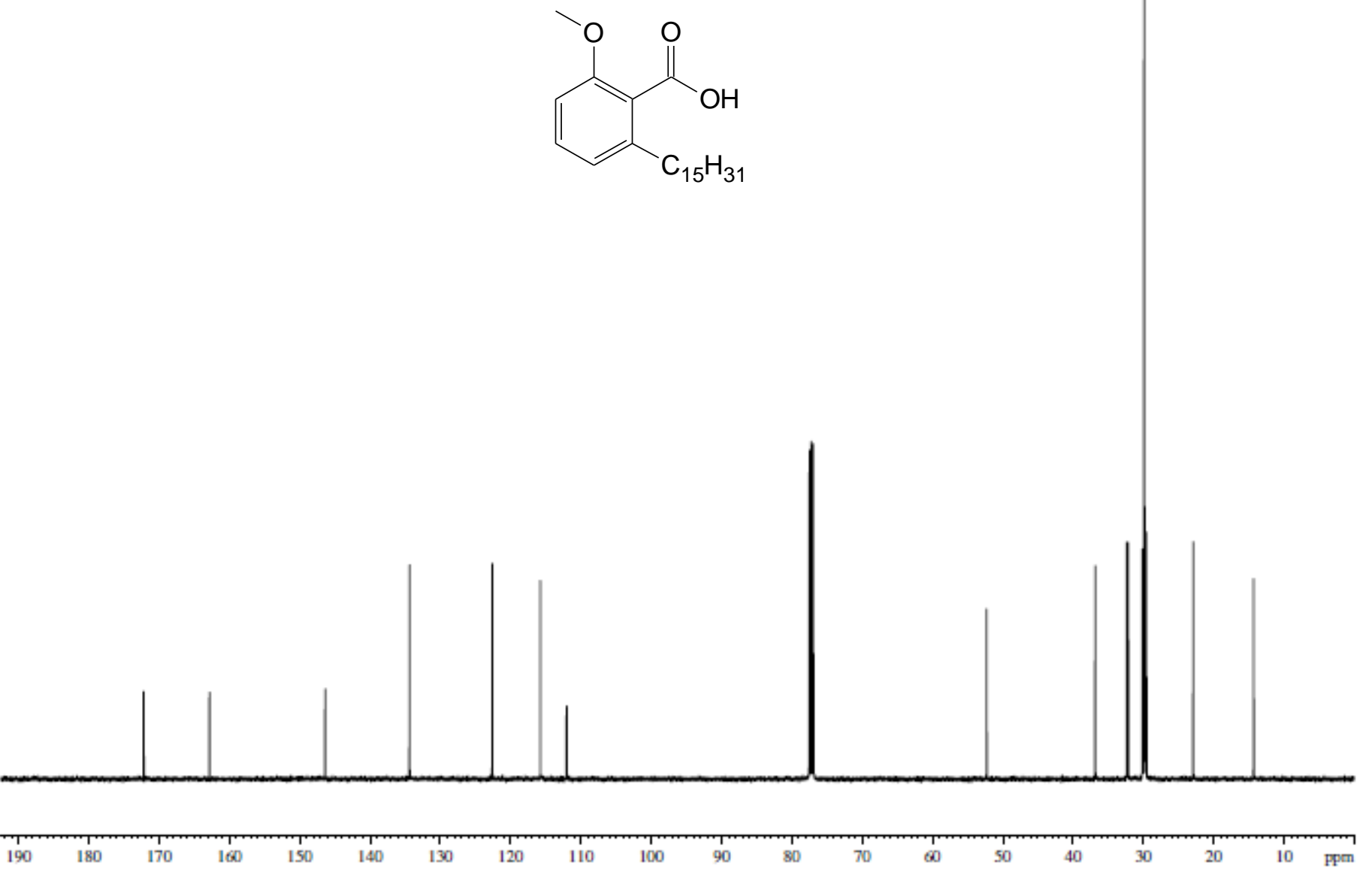
ANEXO 16 - ESPECTRO NO INFRAVERMELHO $\left(v \mathrm{~cm}^{-1}, \mathrm{KBr}\right)$ - LDT208 (21)

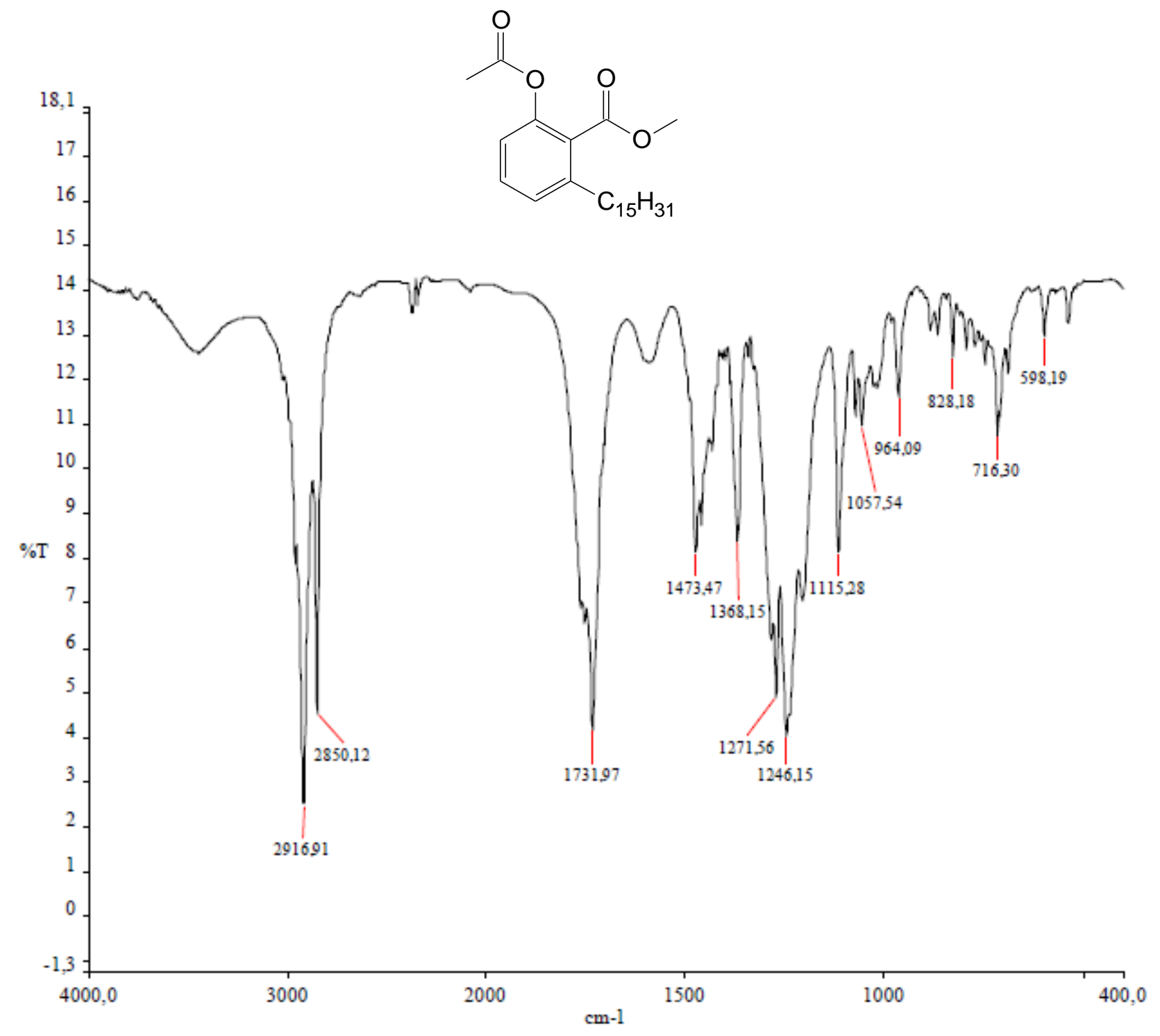


ANEXO 17 - ESPECTRO DE RMN ${ }^{1} \mathrm{H}\left(300 \mathrm{MHz}, \mathrm{CDCl}_{3}\right)$ - LDT208 (21)
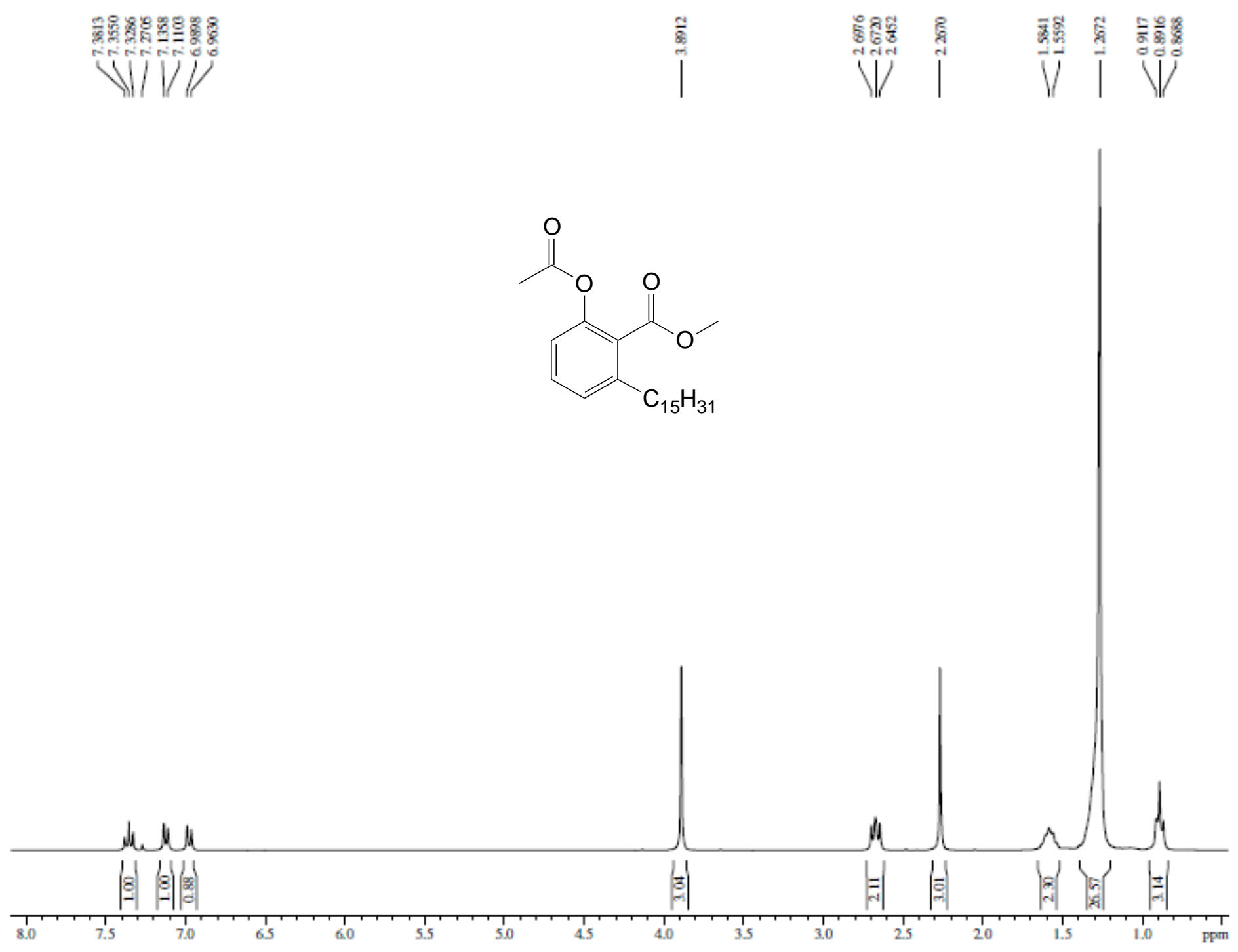
ANEXO 18 - ESPECTRO RMN ${ }^{13} \mathrm{C}\left(75 \mathrm{MHz}, \mathrm{CDCl}_{3}\right)$ - LDT208 (21)
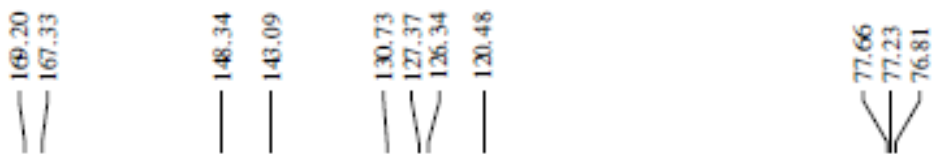

$\sqrt{1}$

त्ञ

| Nil|
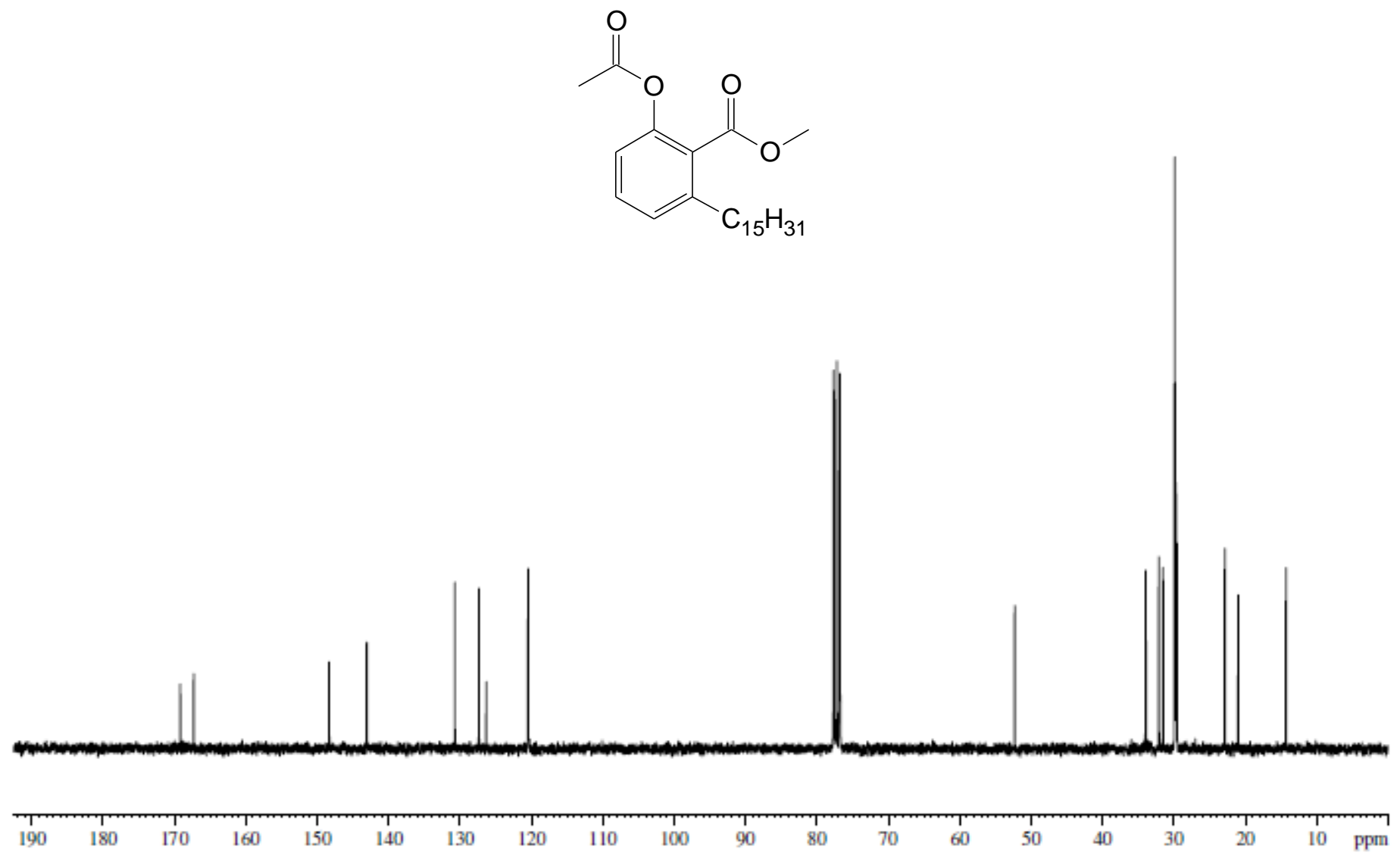
ANEXO 19 - ESPECTRO NO INFRAVERMELHO $\left(v \mathrm{~cm}^{-1}, \mathrm{KBr}\right)$ - LDT651 (22)

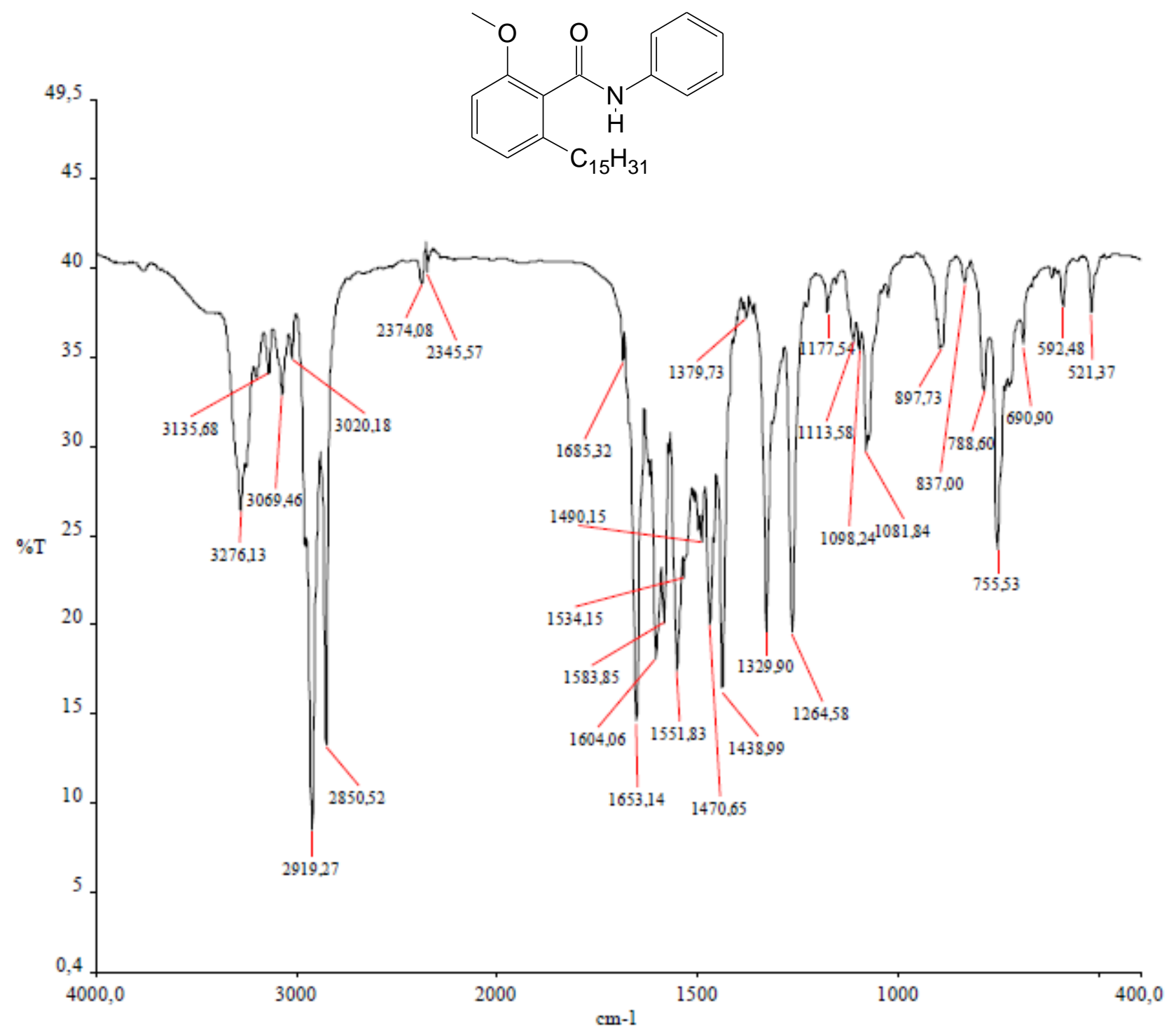


ANEXO 20 - ESPECTRO DE RMN ${ }^{1} \mathrm{H}\left(500 \mathrm{MHz}, \mathrm{CDCl}_{3}\right)$ - LDT651 (22)

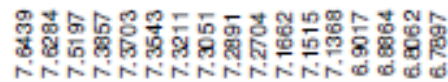

|

Vy

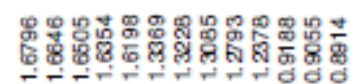

W W V

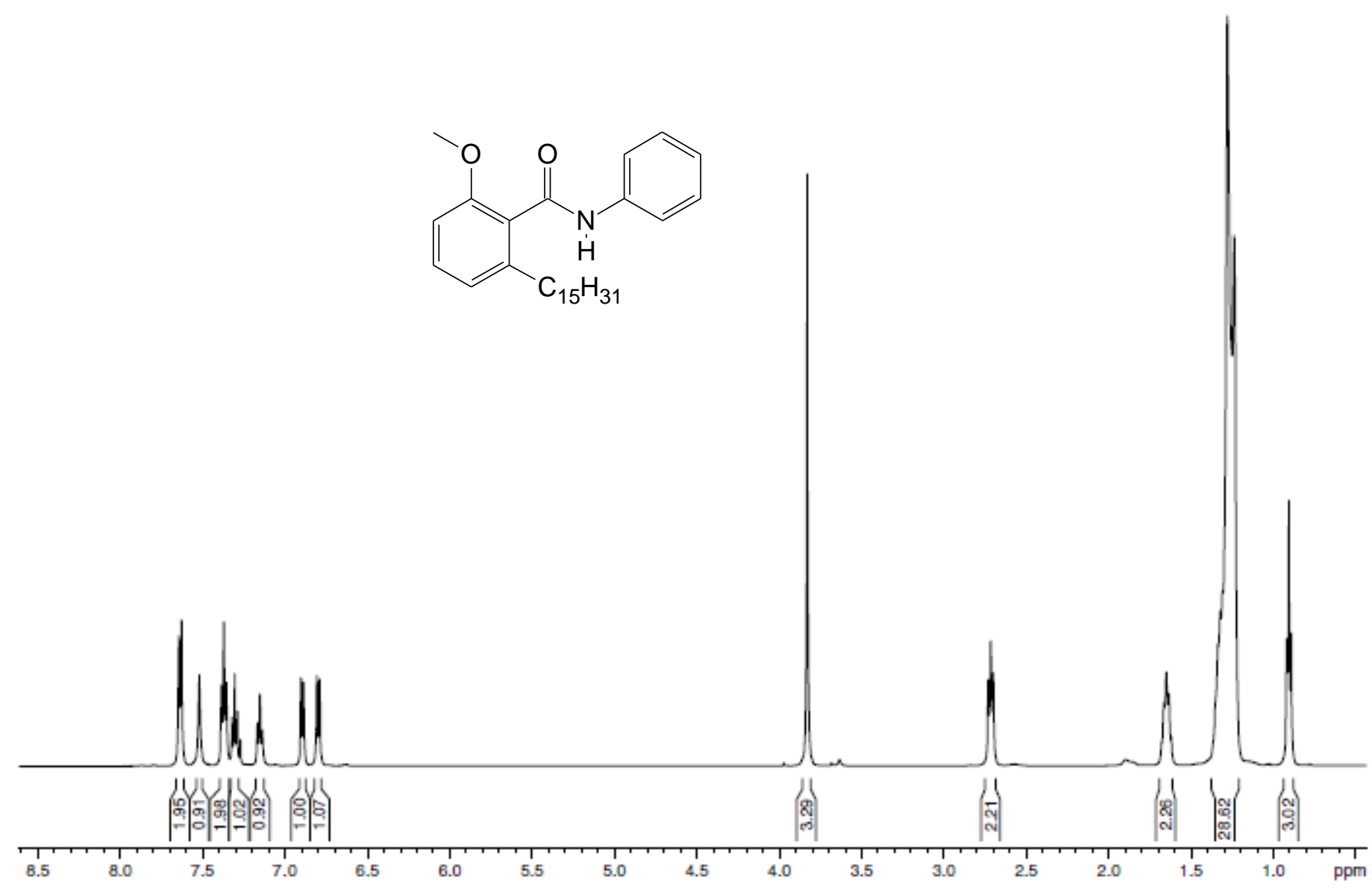


ANEXO 21 - ESPECTRO RMN ${ }^{13} \mathrm{C}\left(125 \mathrm{MHz}, \mathrm{CDCl}_{3}\right)$ - LDT651 (22)
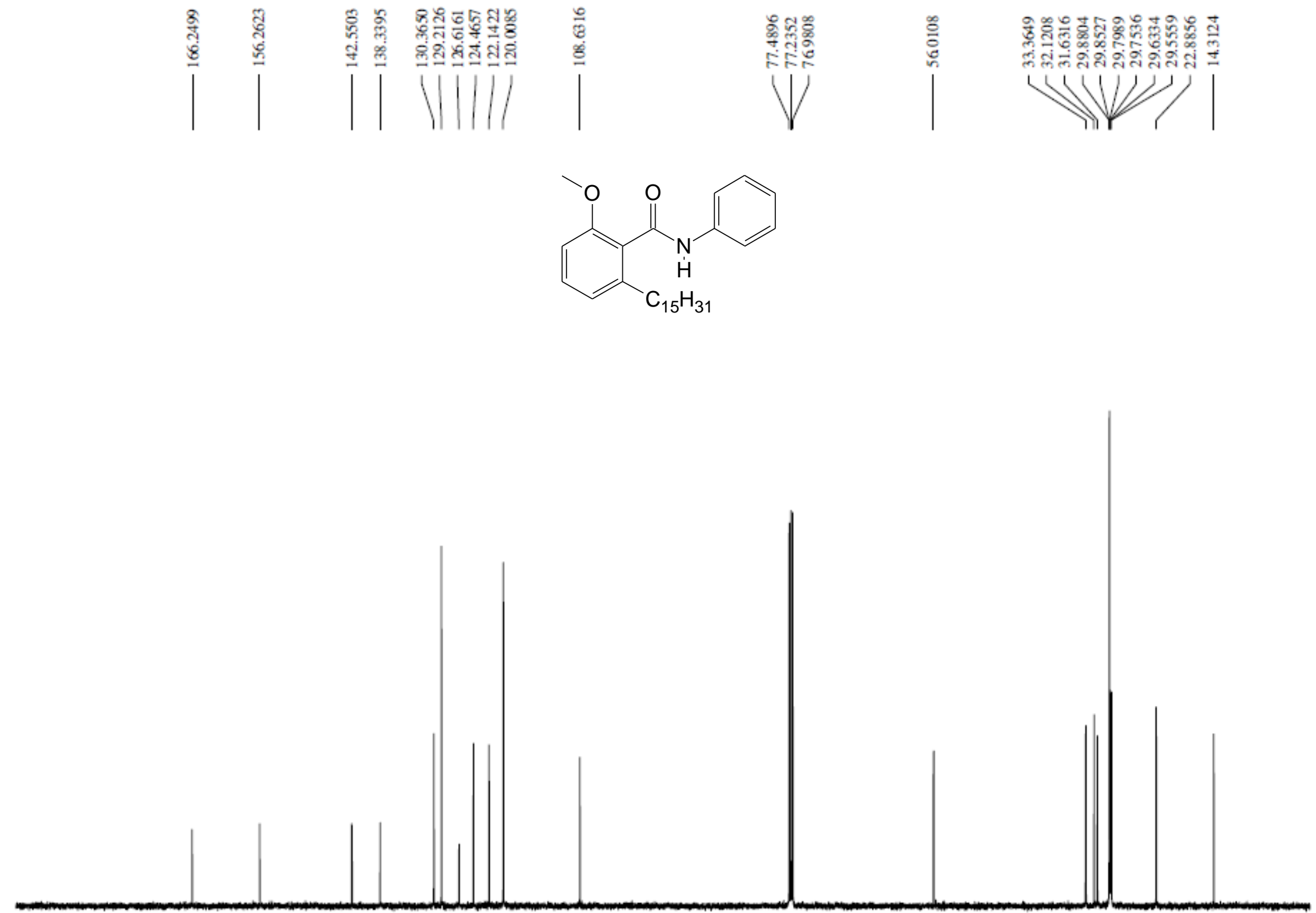
ANEXO 22 - ESPECTRO NO INFRAVERMELHO $\left(v \mathrm{~cm}^{-1}, \mathrm{KBr}\right)$ - LDT653 (23)

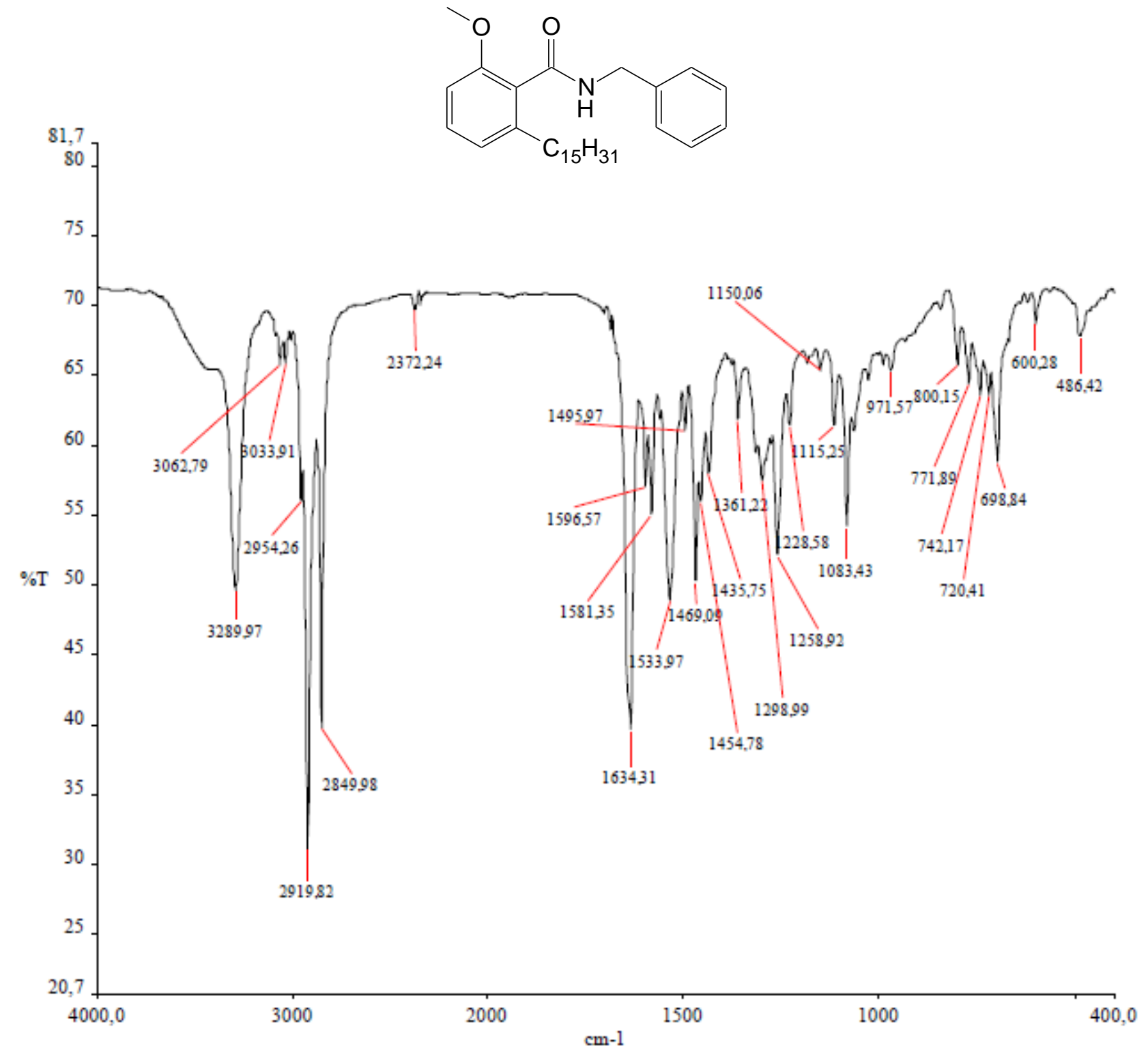


ANEXO 23 - ESPECTRO DE RMN ${ }^{1} \mathrm{H}\left(300 \mathrm{MHz}, \mathrm{CDCl}_{3}\right)$ - LDT653 (23)

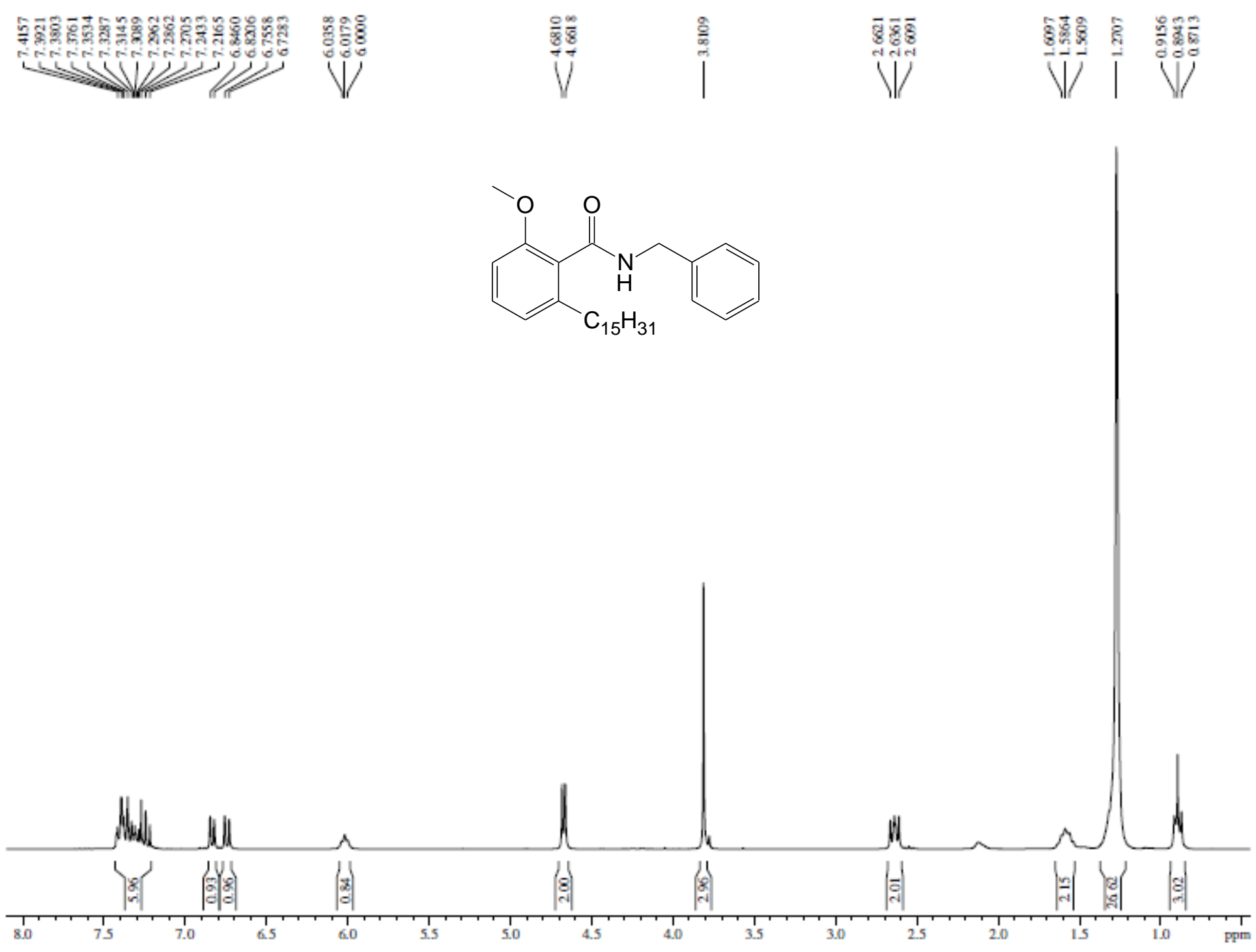


ANEXO 24 - ESPECTRO RMN ${ }^{13} \mathrm{C}\left(75 \mathrm{MHz}, \mathrm{CDCl}_{3}\right)$ - LDT653 (23)

||$\left|\frac{1}{9}\right|$
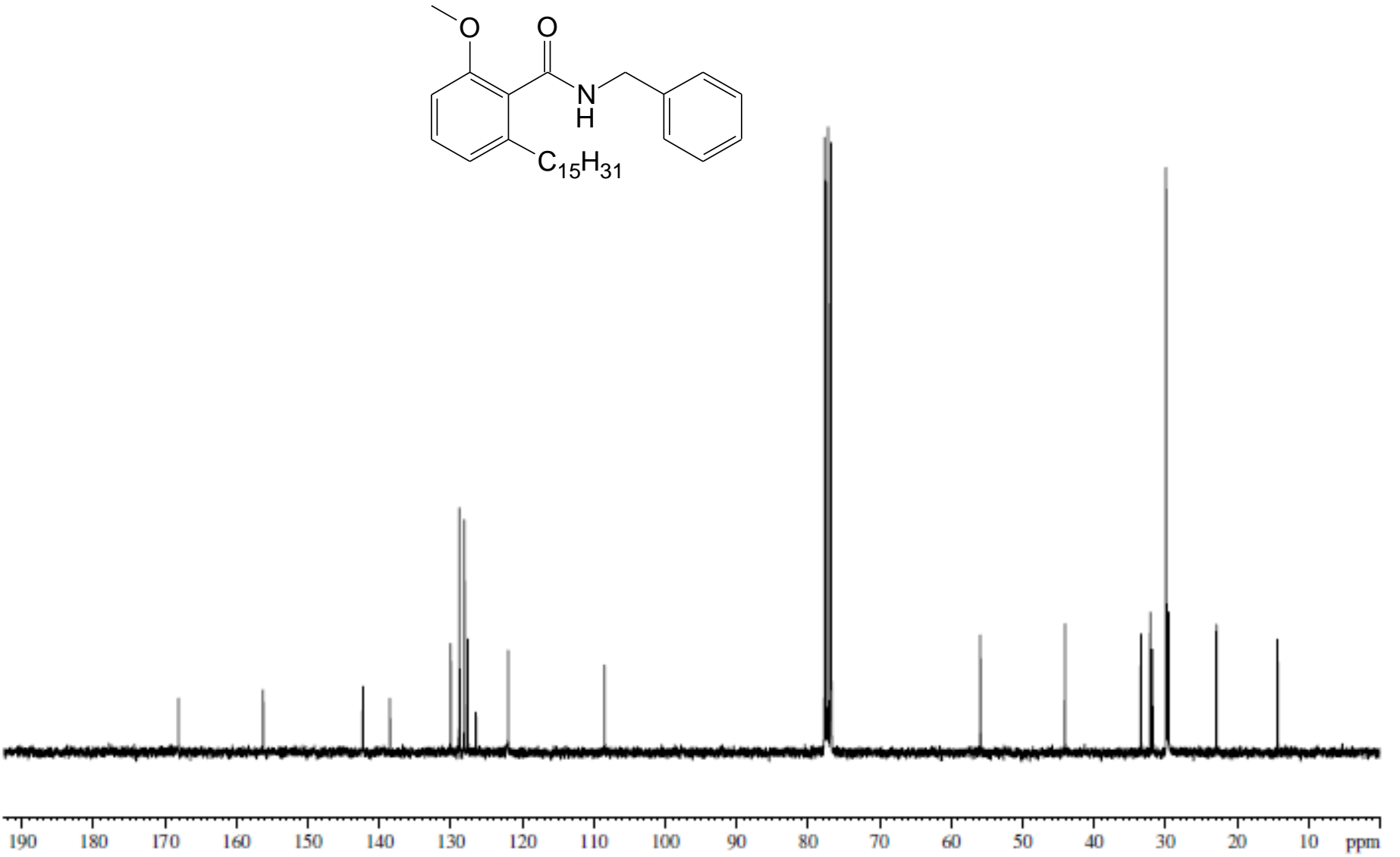
ANEXO 25 - ESPECTRO NO INFRAVERMELHO $\left(v \mathrm{~cm}^{-1}, \mathrm{KBr}\right)$ - LDT655 (24)

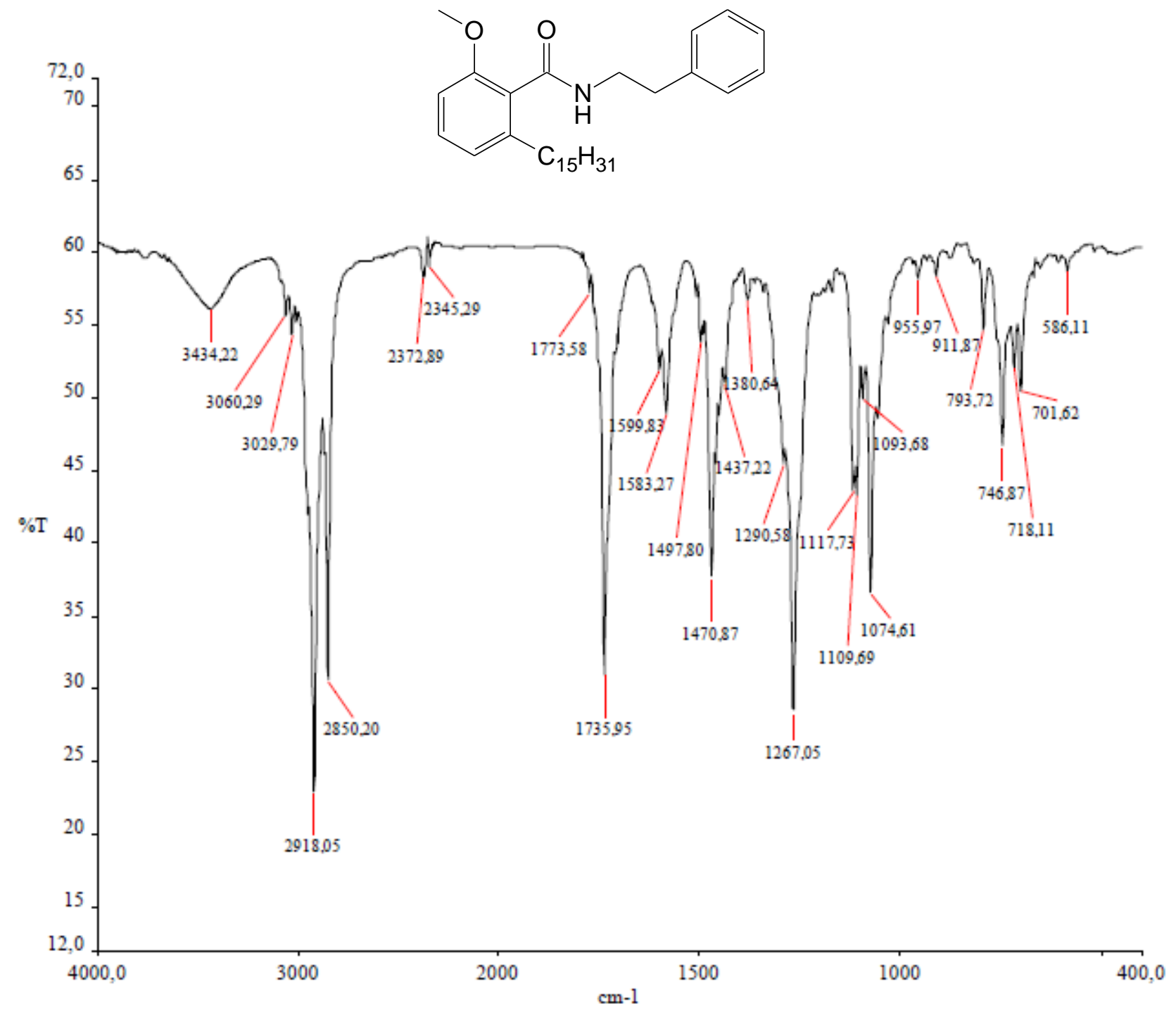


ANEXO 26 - ESPECTRO DE RMN ${ }^{1} \mathrm{H}\left(300 \mathrm{MHz}, \mathrm{CDCl}_{3}\right)$ - LDT655 (24)

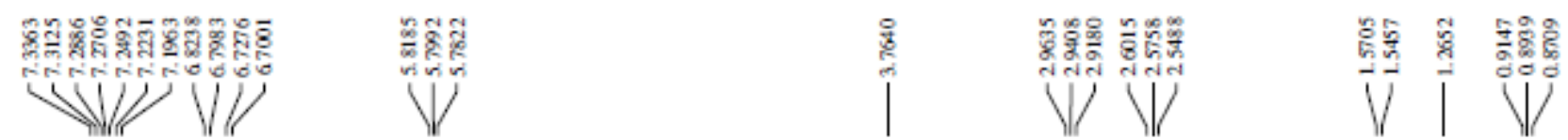
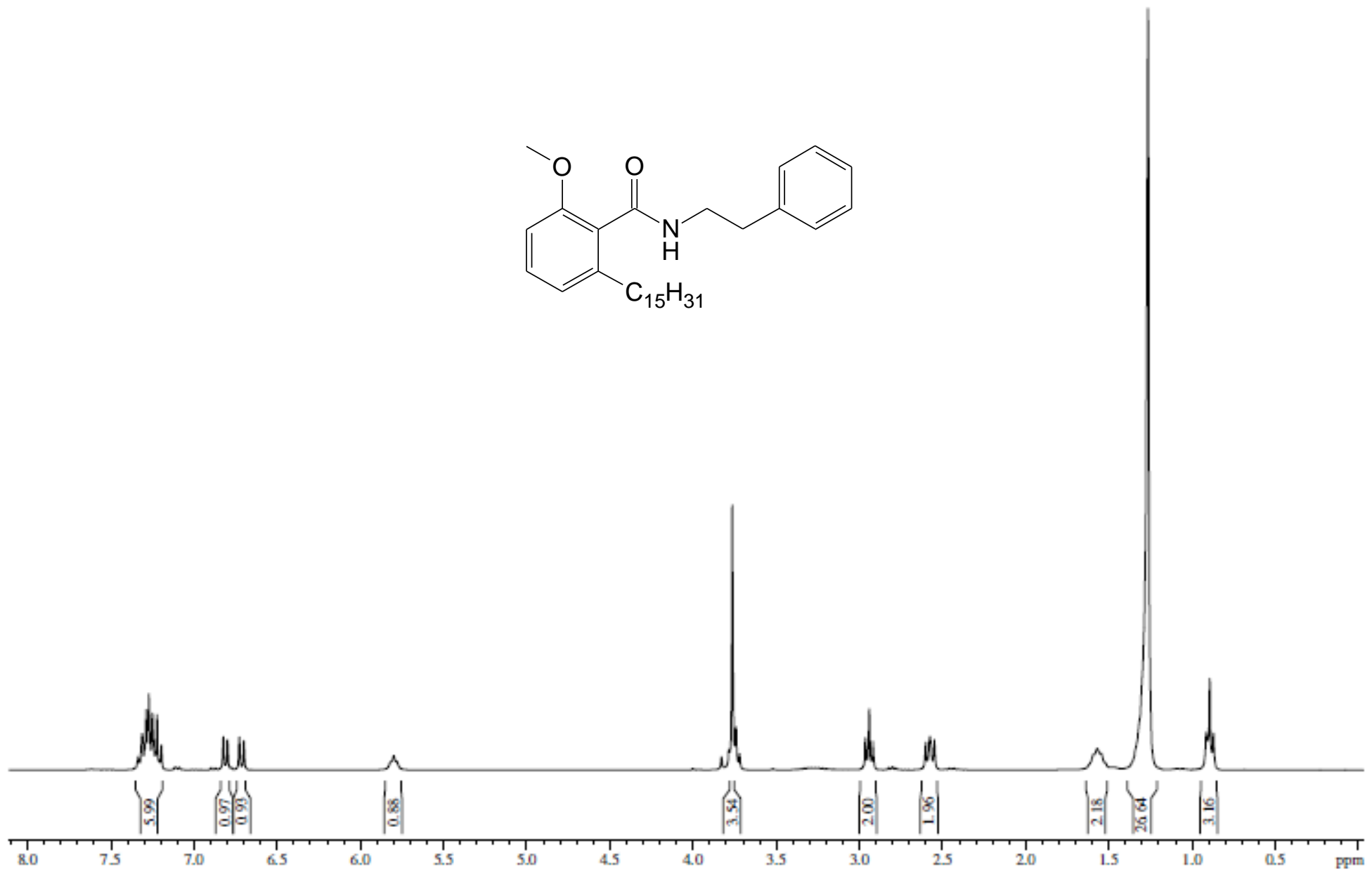
ANEXO 27 - ESPECTRO RMN ${ }^{13} \mathrm{C}\left(75 \mathrm{MHz}, \mathrm{CDCl}_{3}\right)$ - LDT655 (24)
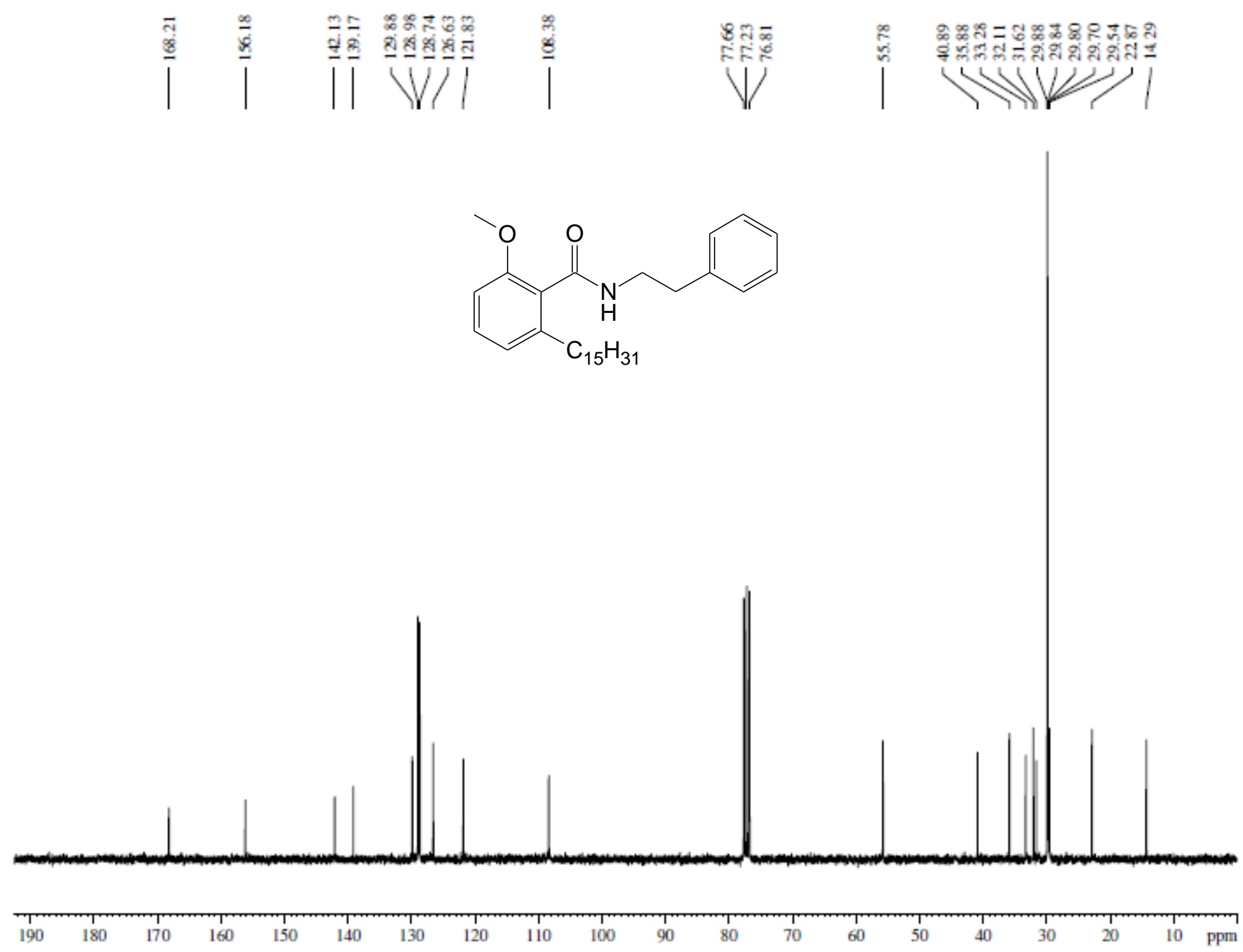
ANEXO 28 - ESPECTRO NO INFRAVERMELHO $\left(v \mathrm{~cm}^{-1}, \mathrm{KBr}\right)$ - LDT657 (25)

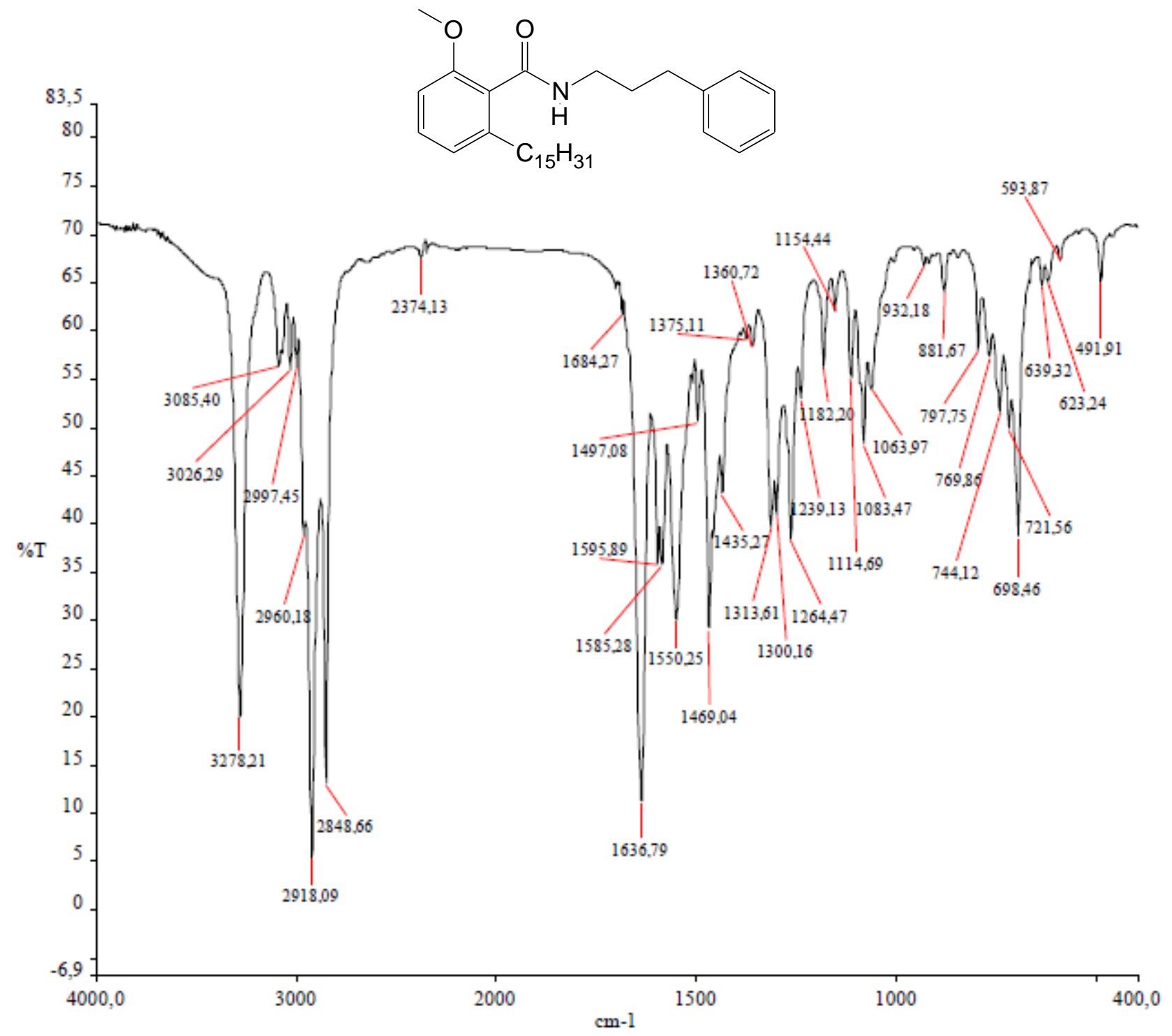


ANEXO 29 - ESPECTRO DE RMN ${ }^{1} \mathrm{H}\left(300 \mathrm{MHz}, \mathrm{CDCl}_{3}\right)$ - LDT657 (25)

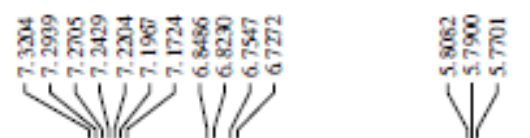

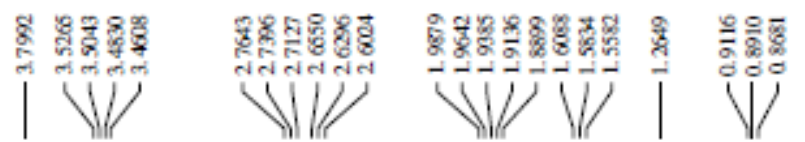
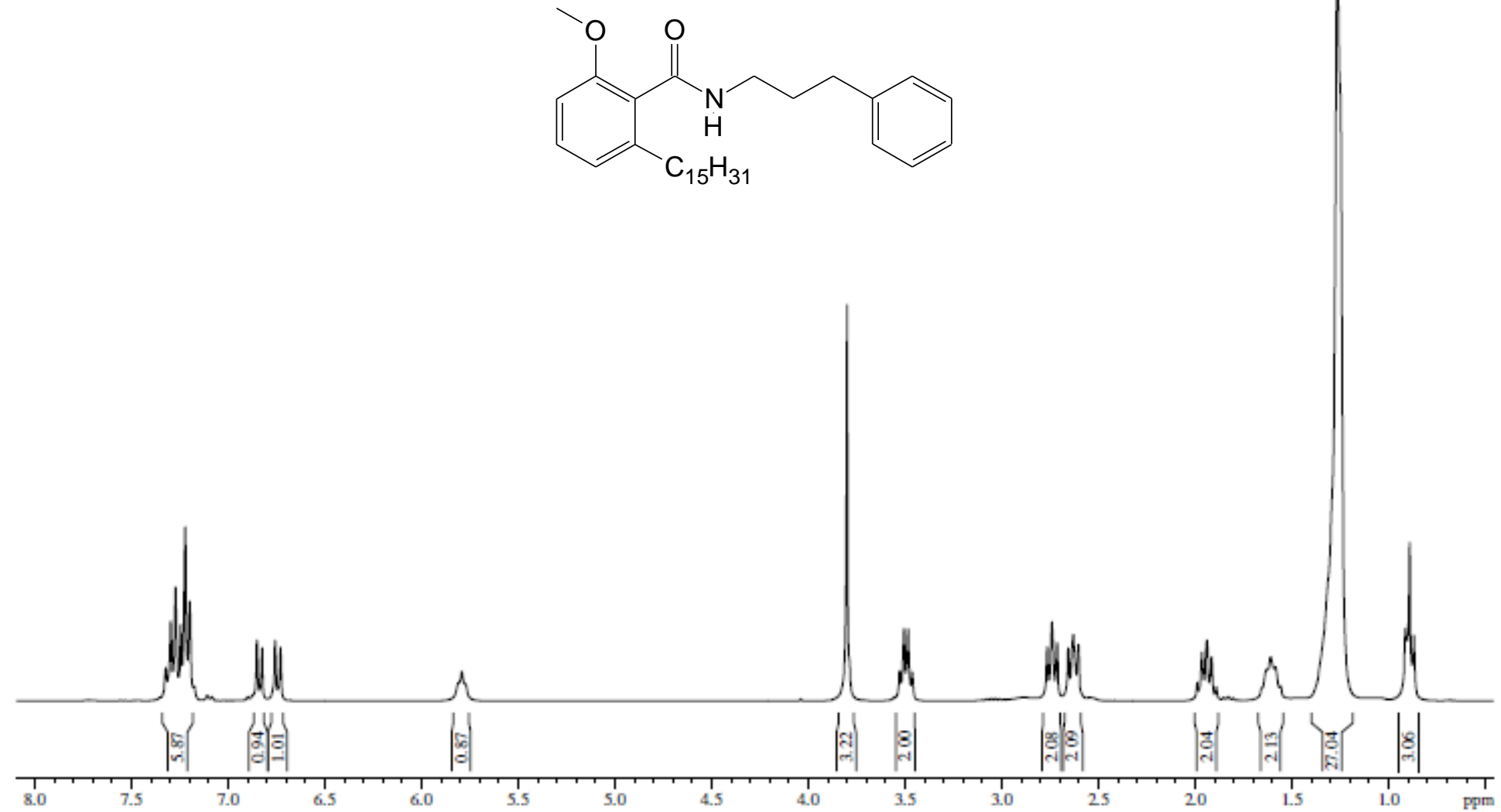
ANEXO 30 - ESPECTRO RMN ${ }^{13} \mathrm{C}\left(75 \mathrm{MHz}, \mathrm{CDCl}_{3}\right)$ - LDT657 (25)

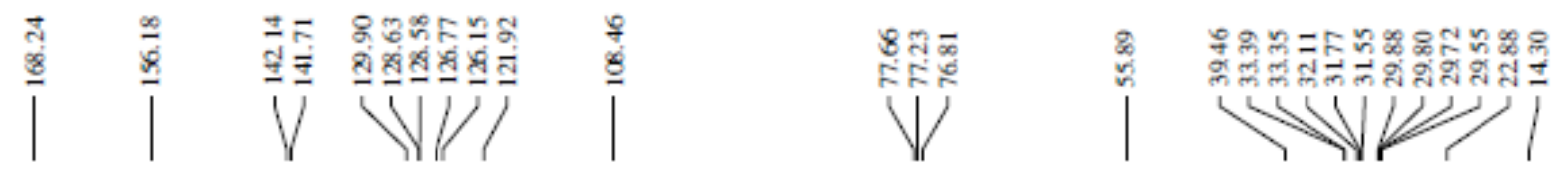
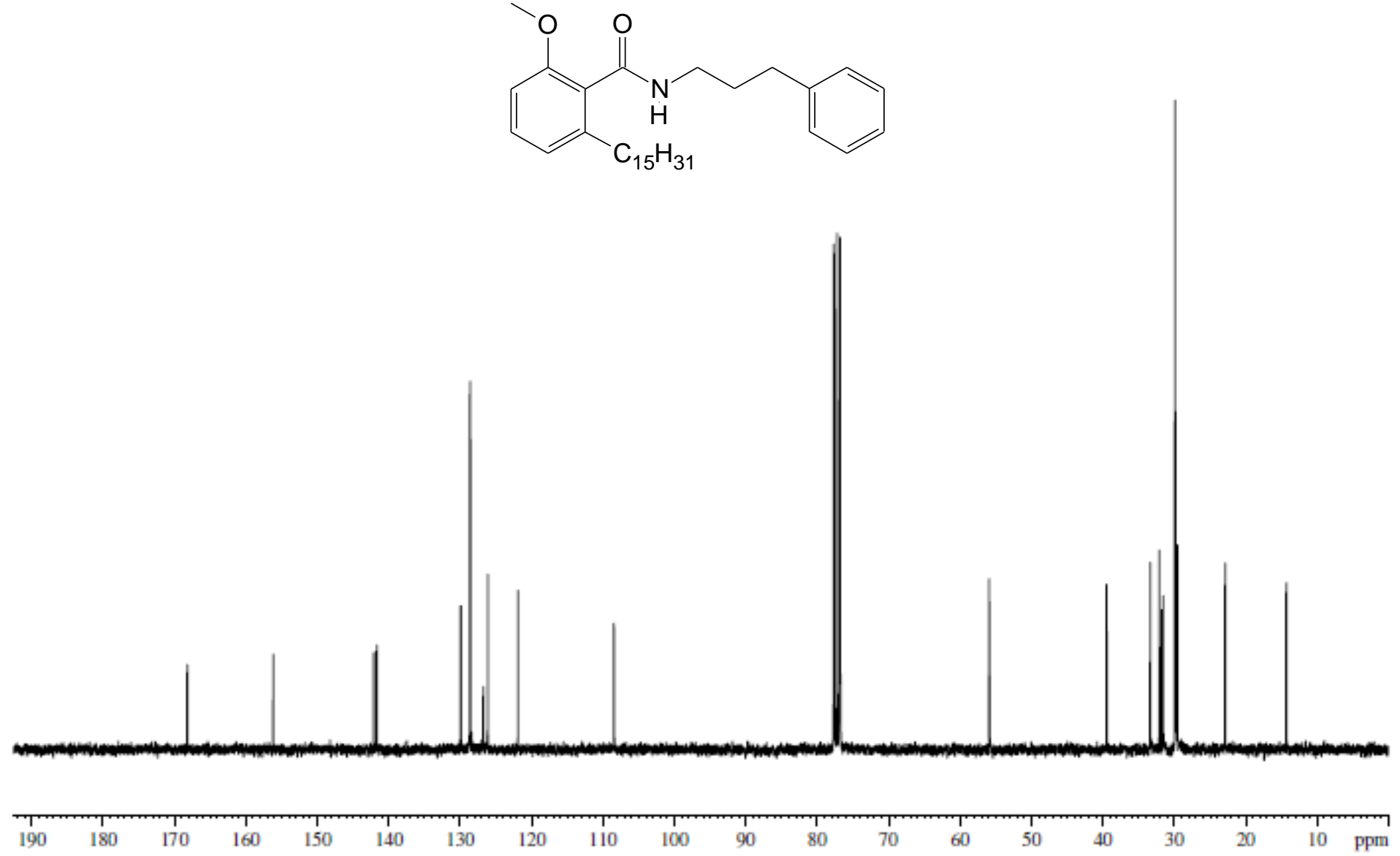
ANEXO 31 - ESPECTRO NO INFRAVERMELHO $\left(v \mathrm{~cm}^{-1}, \mathrm{KBr}\right)$ - LDT82 (30)

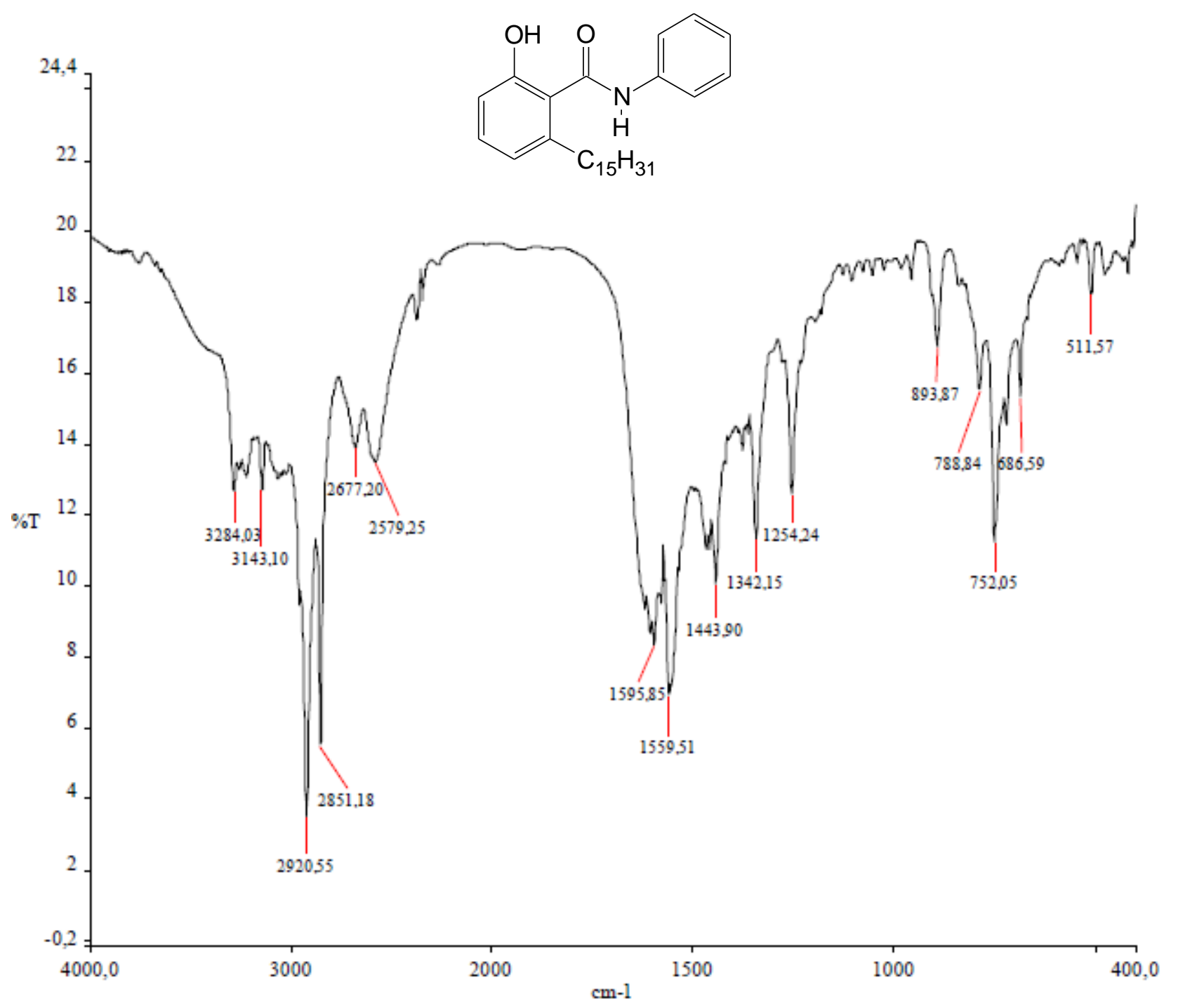


ANEXO 32 - ESPECTRO DE RMN ${ }^{1} \mathrm{H}\left(300 \mathrm{MHz}, \mathrm{CDCl}_{3}\right)$ - LDT82 (30)
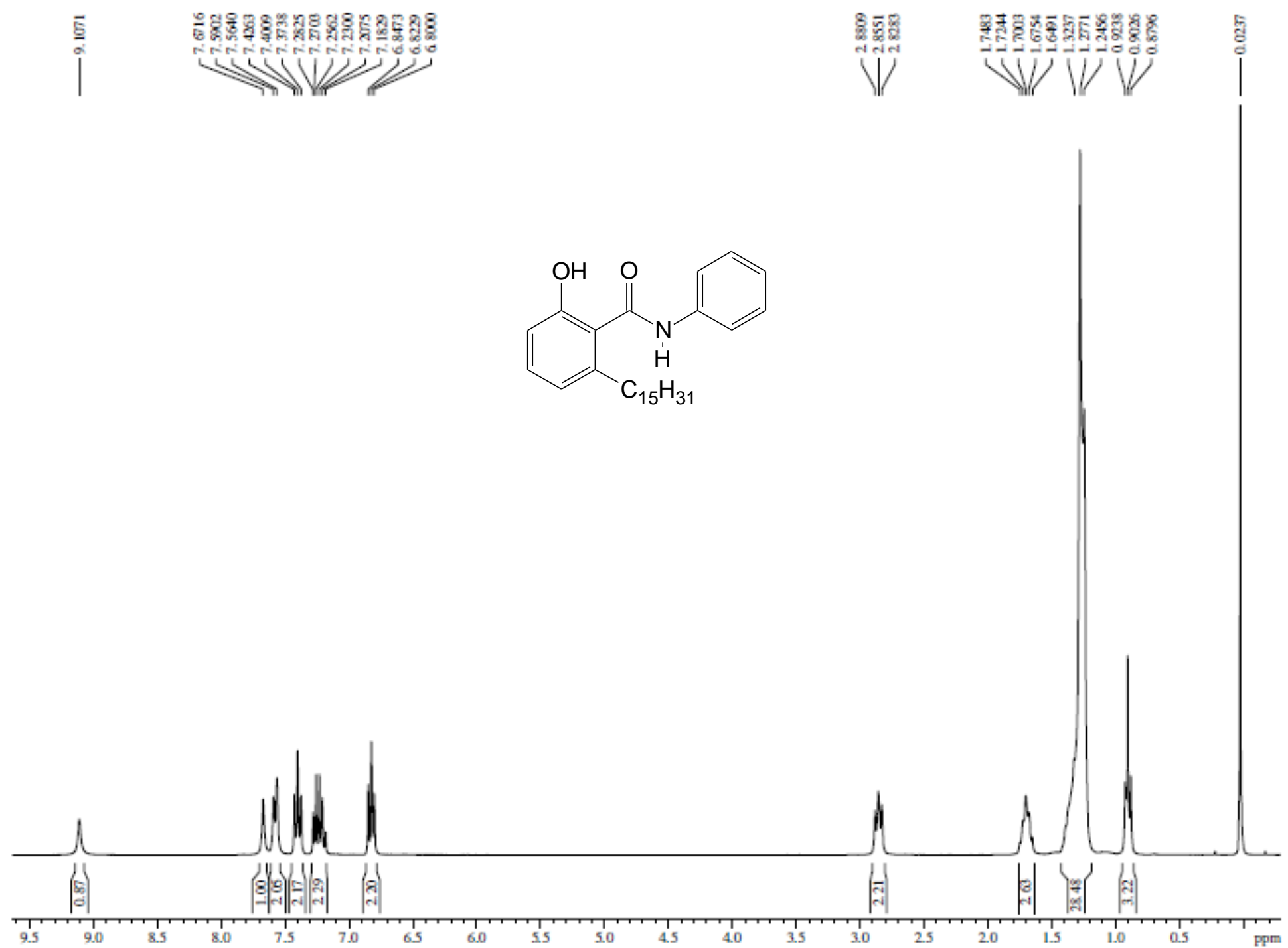
ANEXO 33 - ESPECTRO RMN ${ }^{13} \mathrm{C}\left(75 \mathrm{MHz}, \mathrm{CDCl}_{3}\right)$ - LDT82 (30)
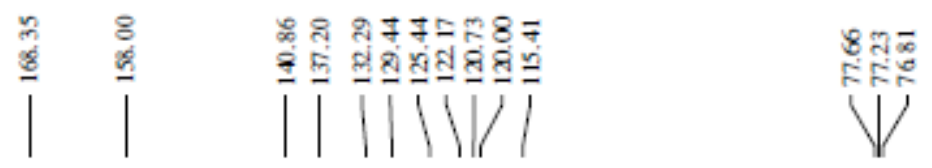

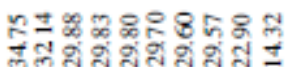

w)

\section{영}

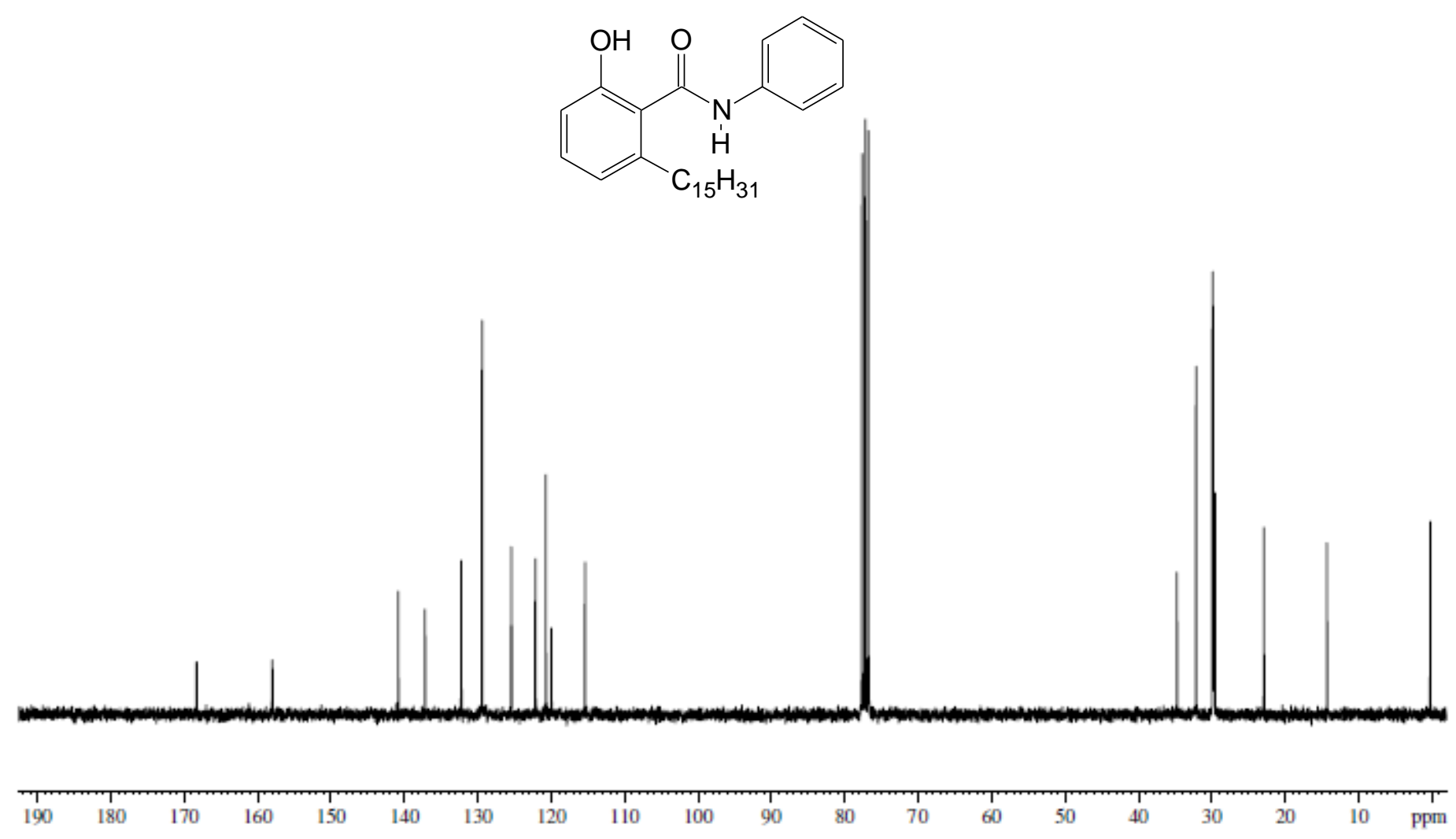


ANEXO 34 - ESPECTRO NO INFRAVERMELHO $\left(v \mathrm{~cm}^{-1}, \mathrm{KBr}\right)$ - LDT645 (31)

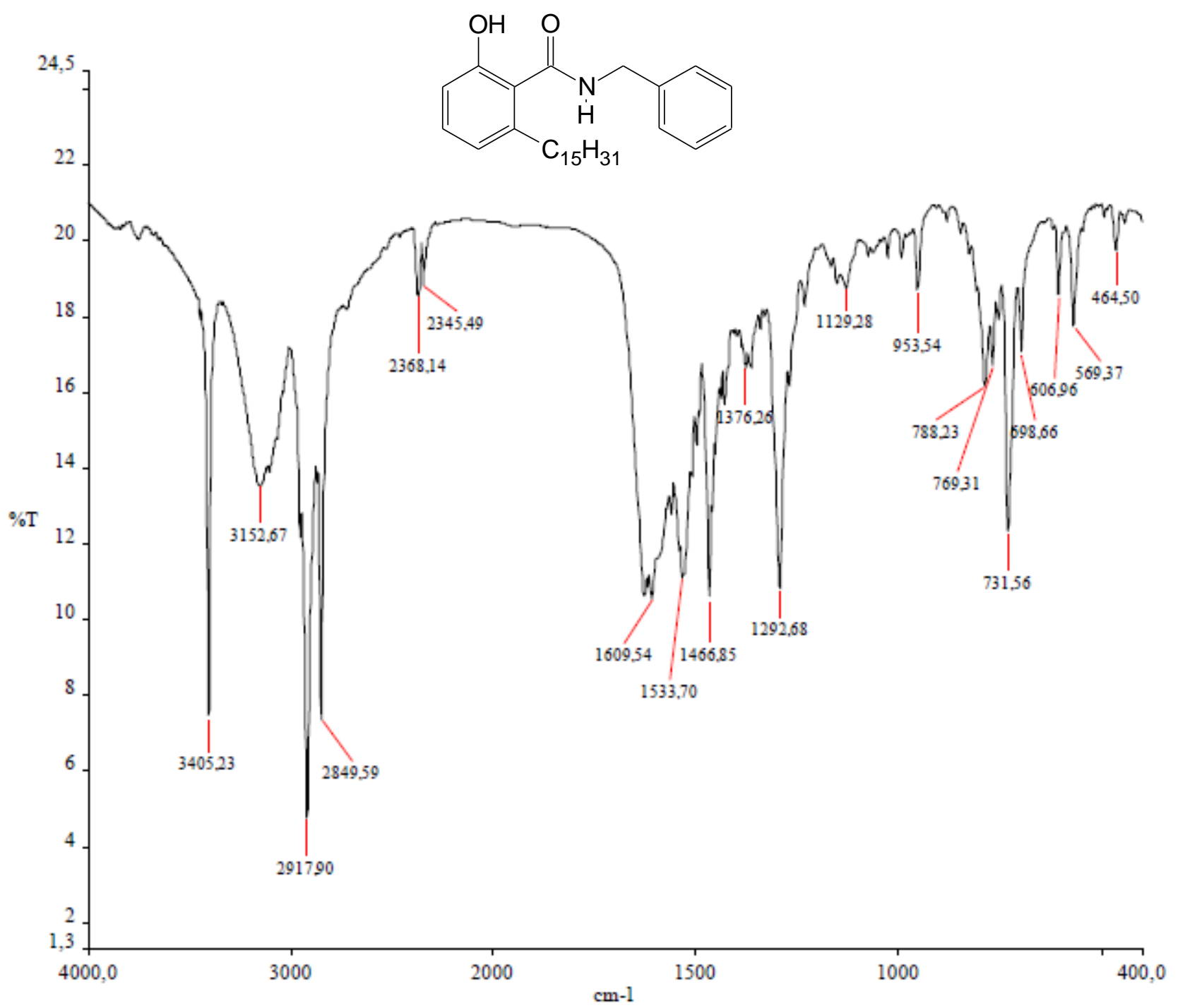


ANEXO 35 - ESPECTRO DE RMN ${ }^{1} \mathrm{H}\left(300 \mathrm{MHz}, \mathrm{CDCl}_{3}\right)$ - LDT645 (31)
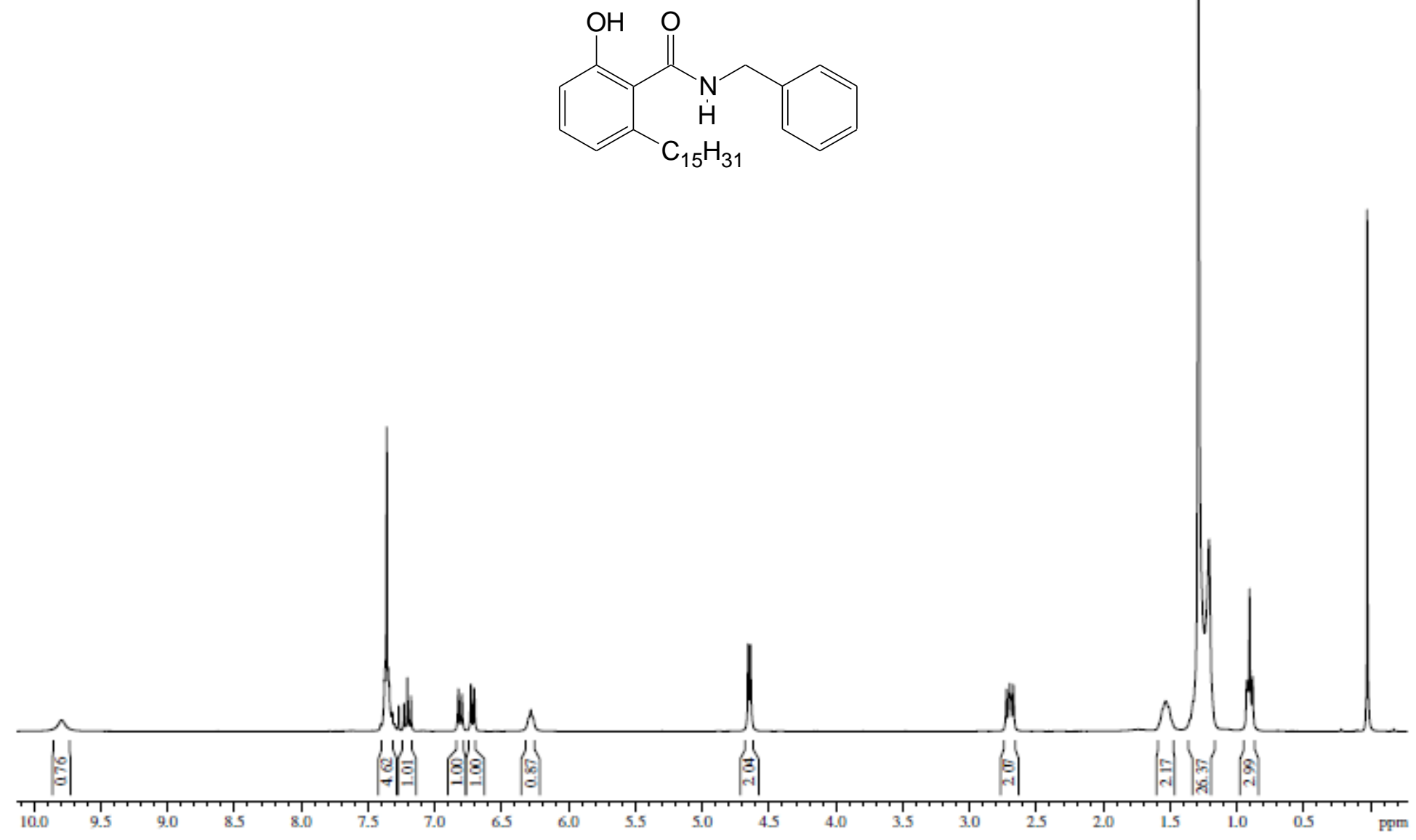
ANEXO 37 - ESPECTRO NO INFRAVERMELHO $\left(v \mathrm{~cm}^{-1}, \mathrm{KBr}\right)$ - LDT647 (32)

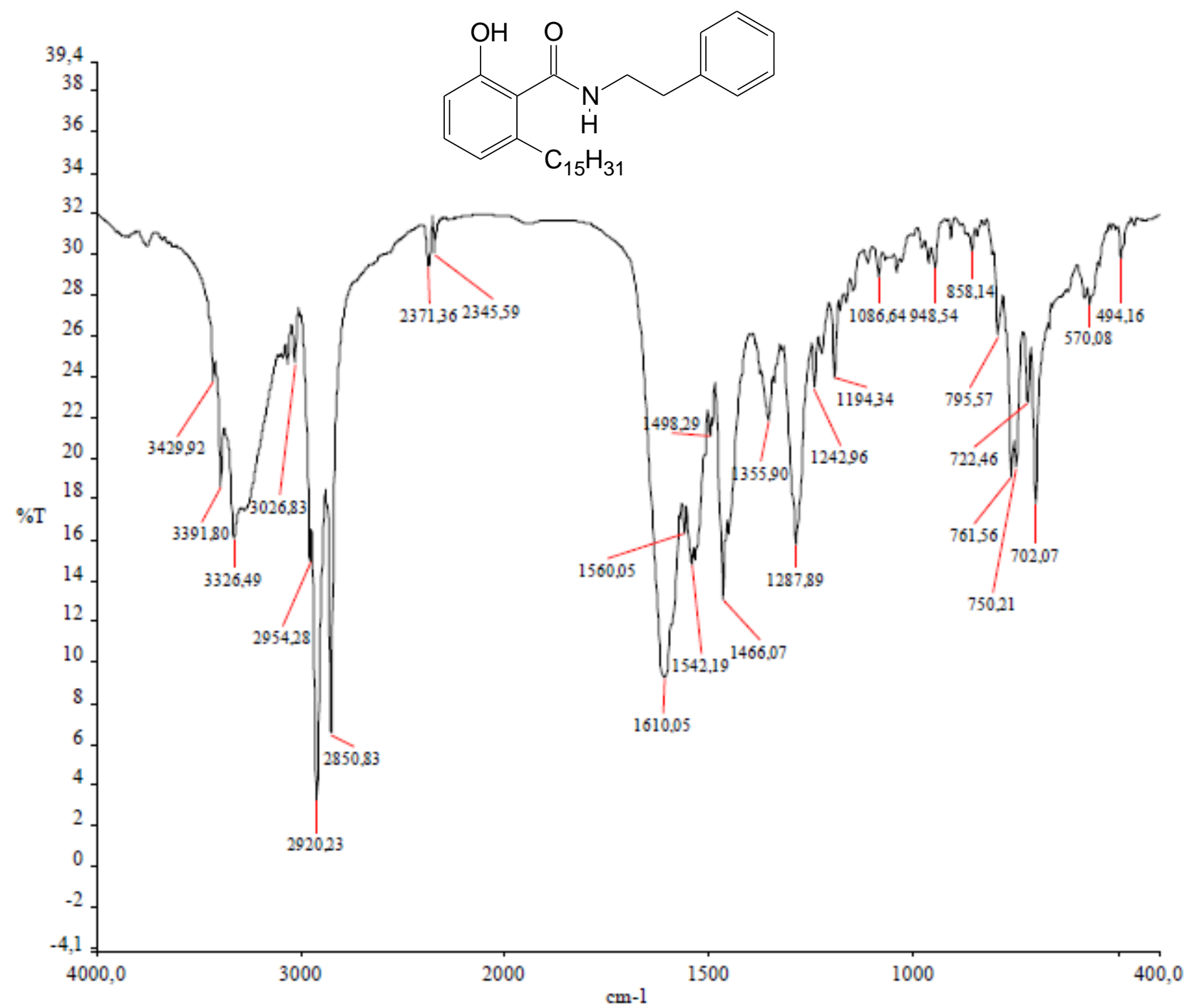


ANEXO 38 - ESPECTRO DE RMN ${ }^{1} \mathrm{H}\left(300 \mathrm{MHz}, \mathrm{CDCl}_{3}\right)$ - LDT647 (32)

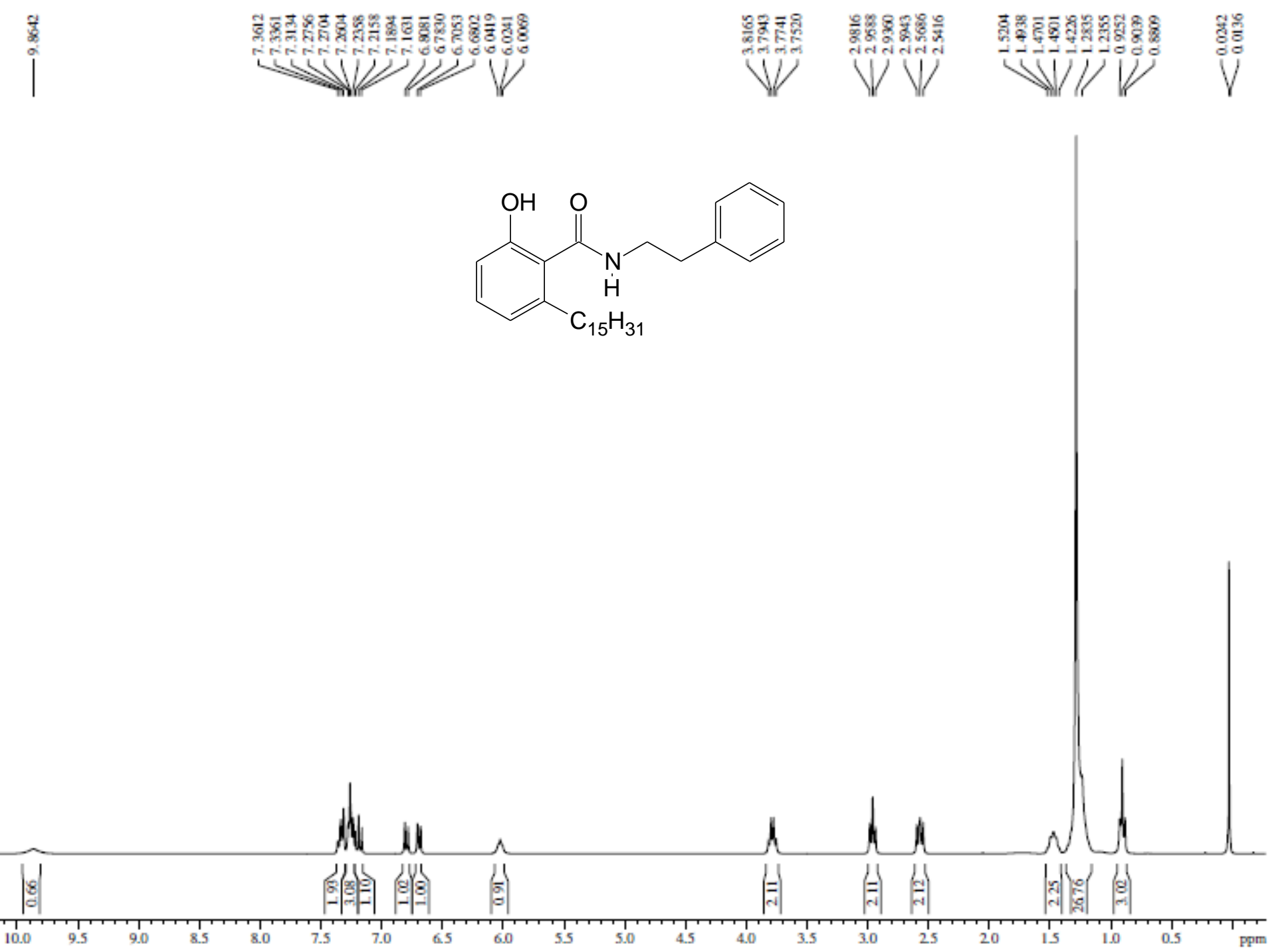


ANEXO 39 - ESPECTRO RMN ${ }^{13} \mathrm{C}\left(75 \mathrm{MHz}, \mathrm{CDCl}_{3}\right)$ - LDT647 (32)
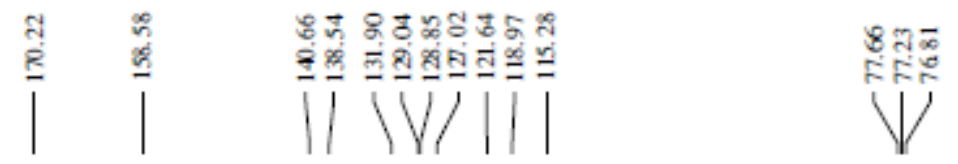

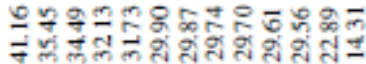

WNins
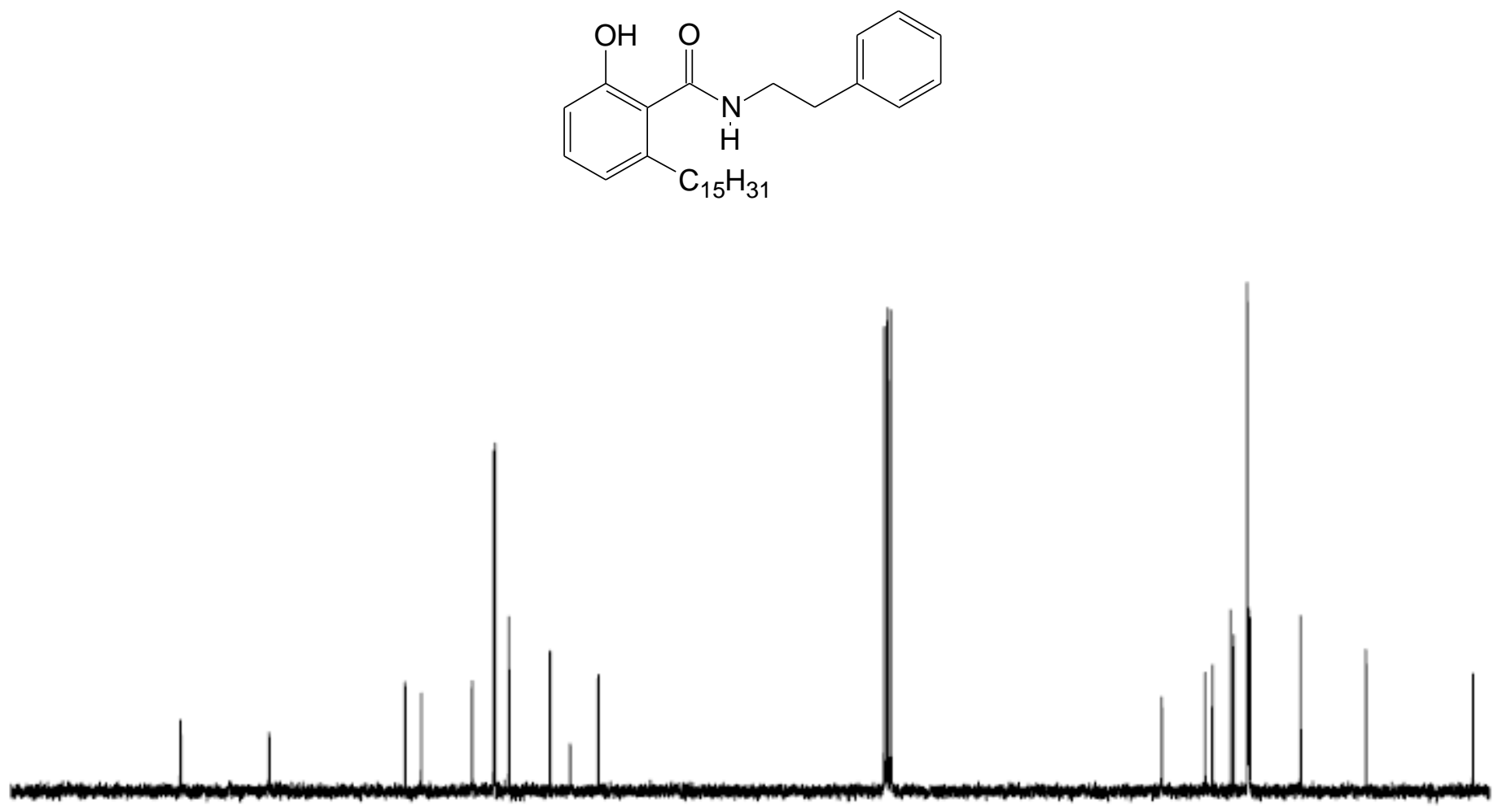
ANEXO 40 - ESPECTRO NO INFRAVERMELHO $\left(v \mathrm{~cm}^{-1}, \mathrm{KBr}\right)$ - LDT649 (33)

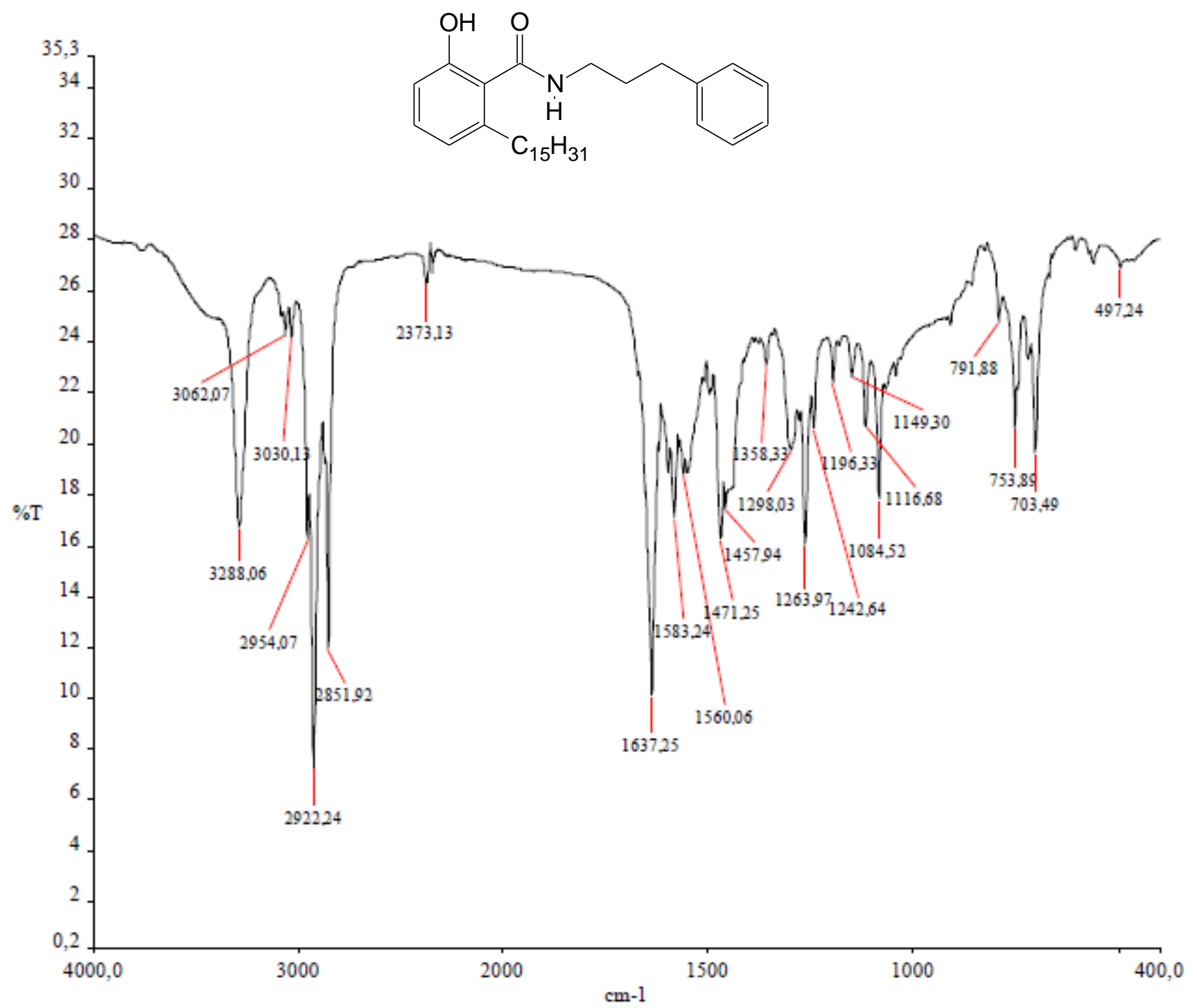


ANEXO 41 - ESPECTRO DE RMN ${ }^{1} \mathrm{H}\left(300 \mathrm{MHz}, \mathrm{CDCl}_{3}\right)$ - LDT649 (33)

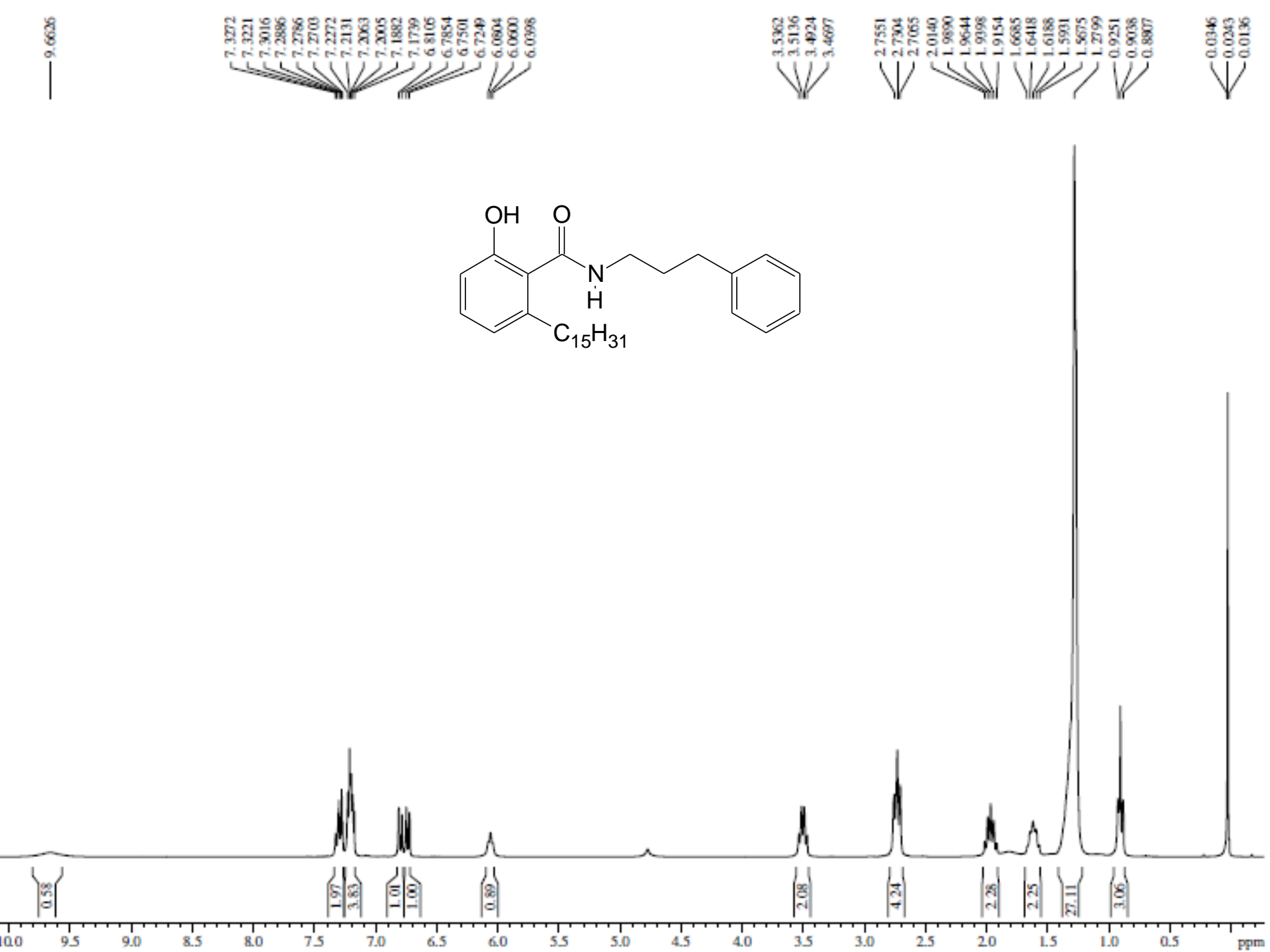


ANEXO 42 - ESPECTRO RMN ${ }^{13} \mathrm{C}\left(75 \mathrm{MHz}, \mathrm{CDCl}_{3}\right)$ - LDT649 (33)
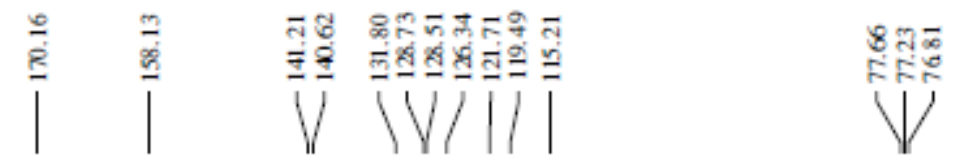

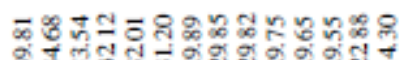

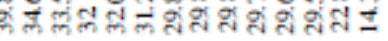
$\cdots$
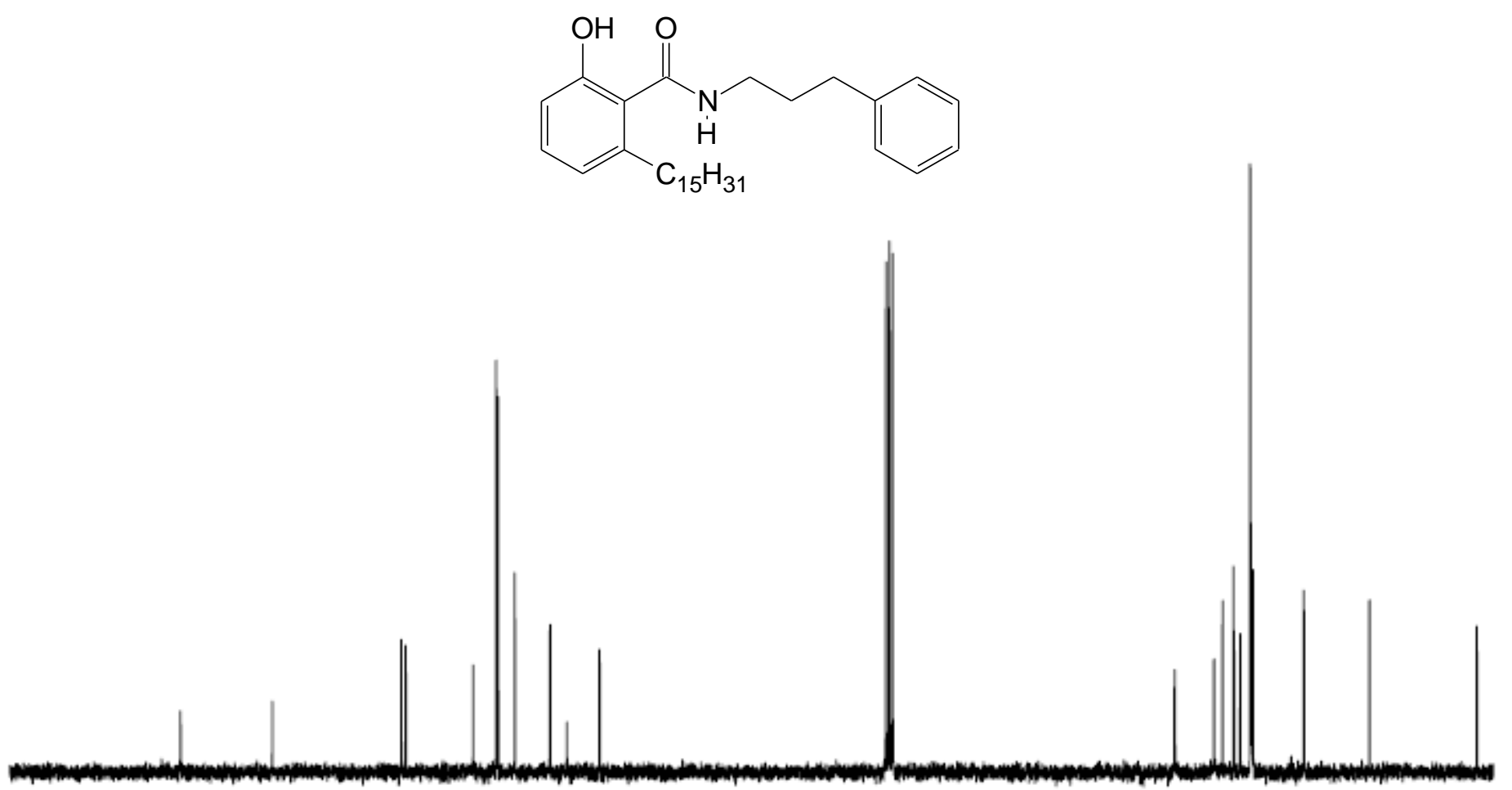
ANEXO 43 - ESPECTRO NO INFRAVERMELHO $\left(v \mathrm{~cm}^{-1}, \mathrm{KBr}\right)$ - LDT675 (38)

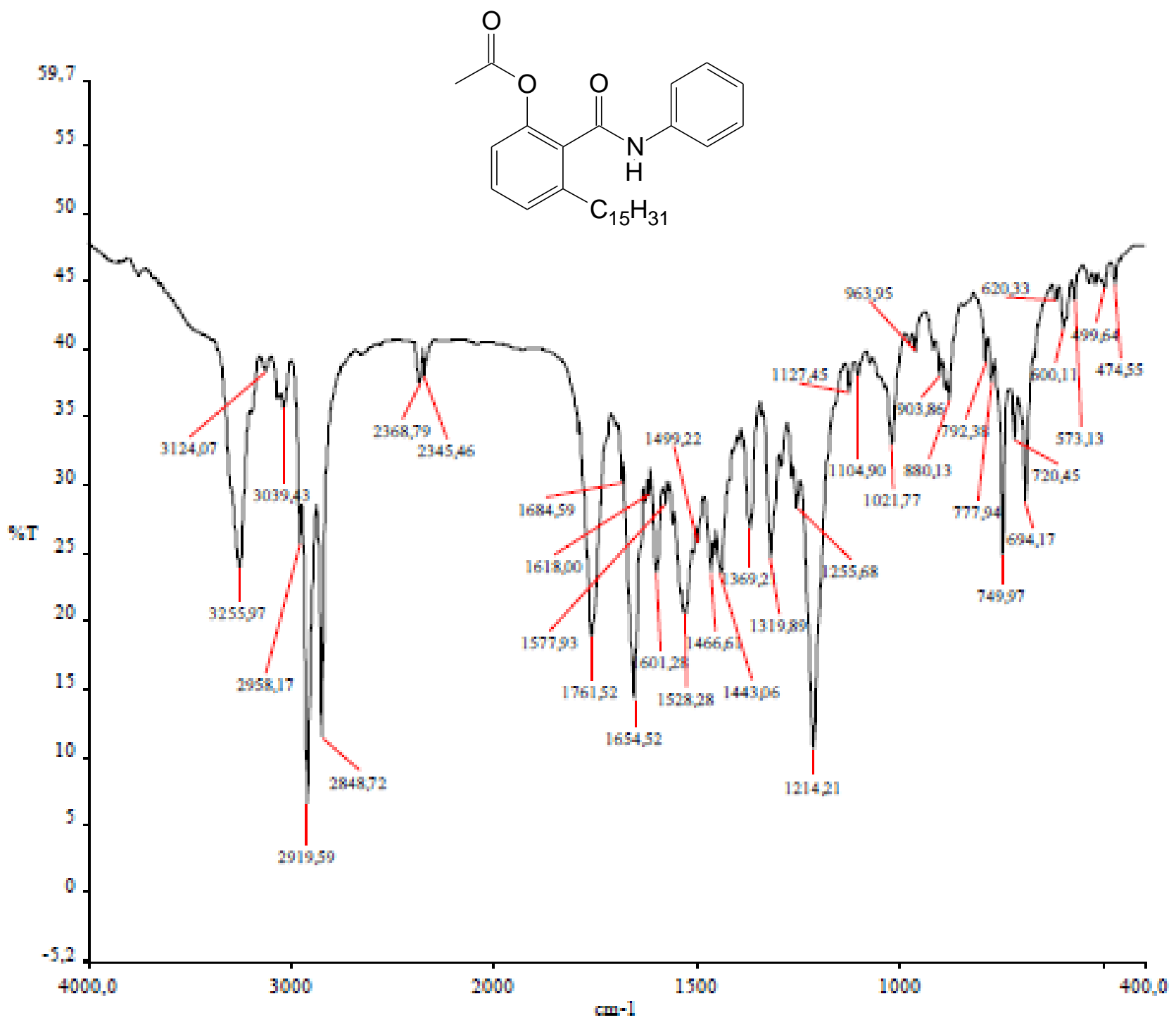


ANEXO 44 - ESPECTRO DE RMN ${ }^{1} \mathrm{H}\left(500 \mathrm{MHz}, \mathrm{CDCl}_{3}\right)$ - LDT675 (38)

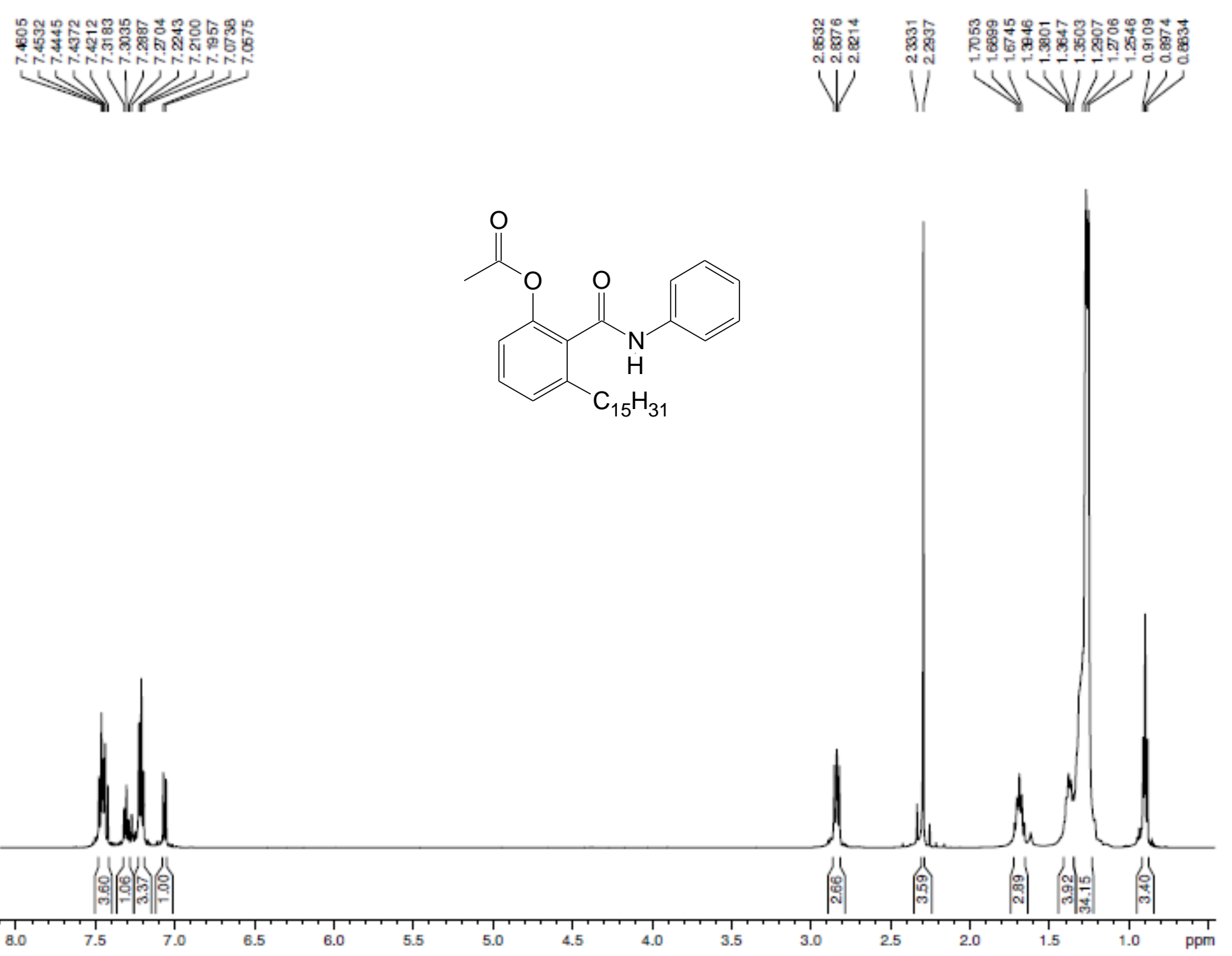


ANEXO 45 - ESPECTRO RMN ${ }^{13} \mathrm{C}\left(125 \mathrm{MHz}, \mathrm{CDCl}_{3}\right)$ - LDT675 (38)
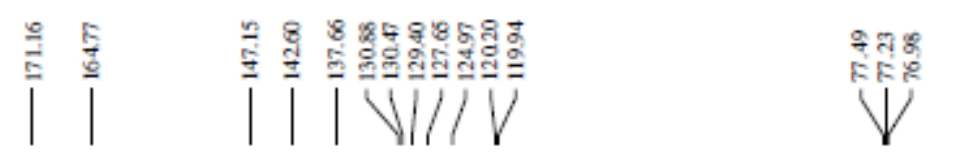

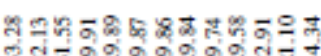

(

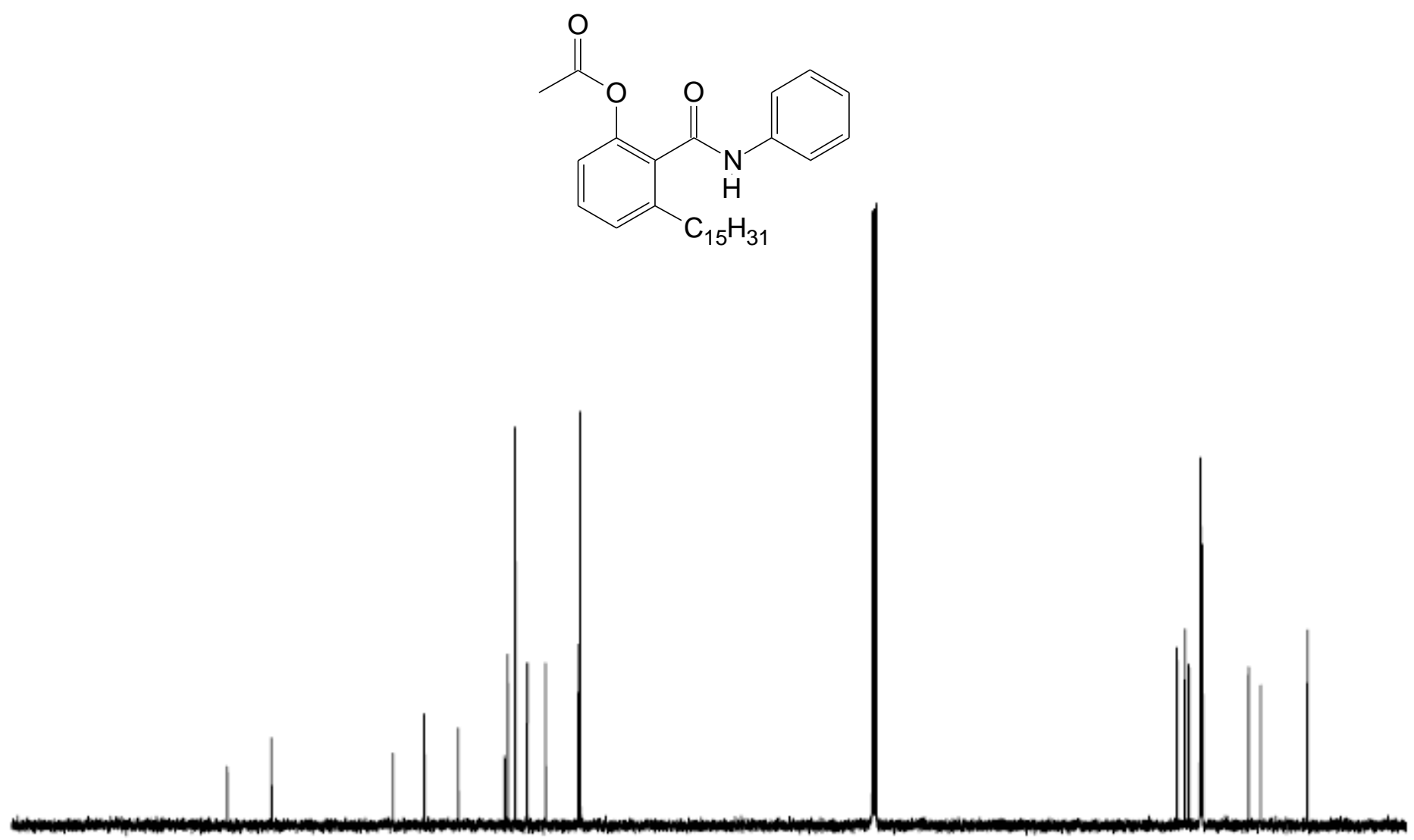

200
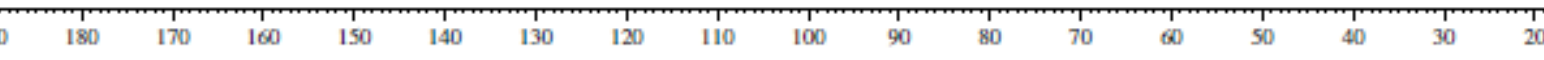
ANEXO 46 - ESPECTRO NO INFRAVERMELHO $\left(v \mathrm{~cm}^{-1}, \mathrm{KBr}\right)$ - LDT677 (39)

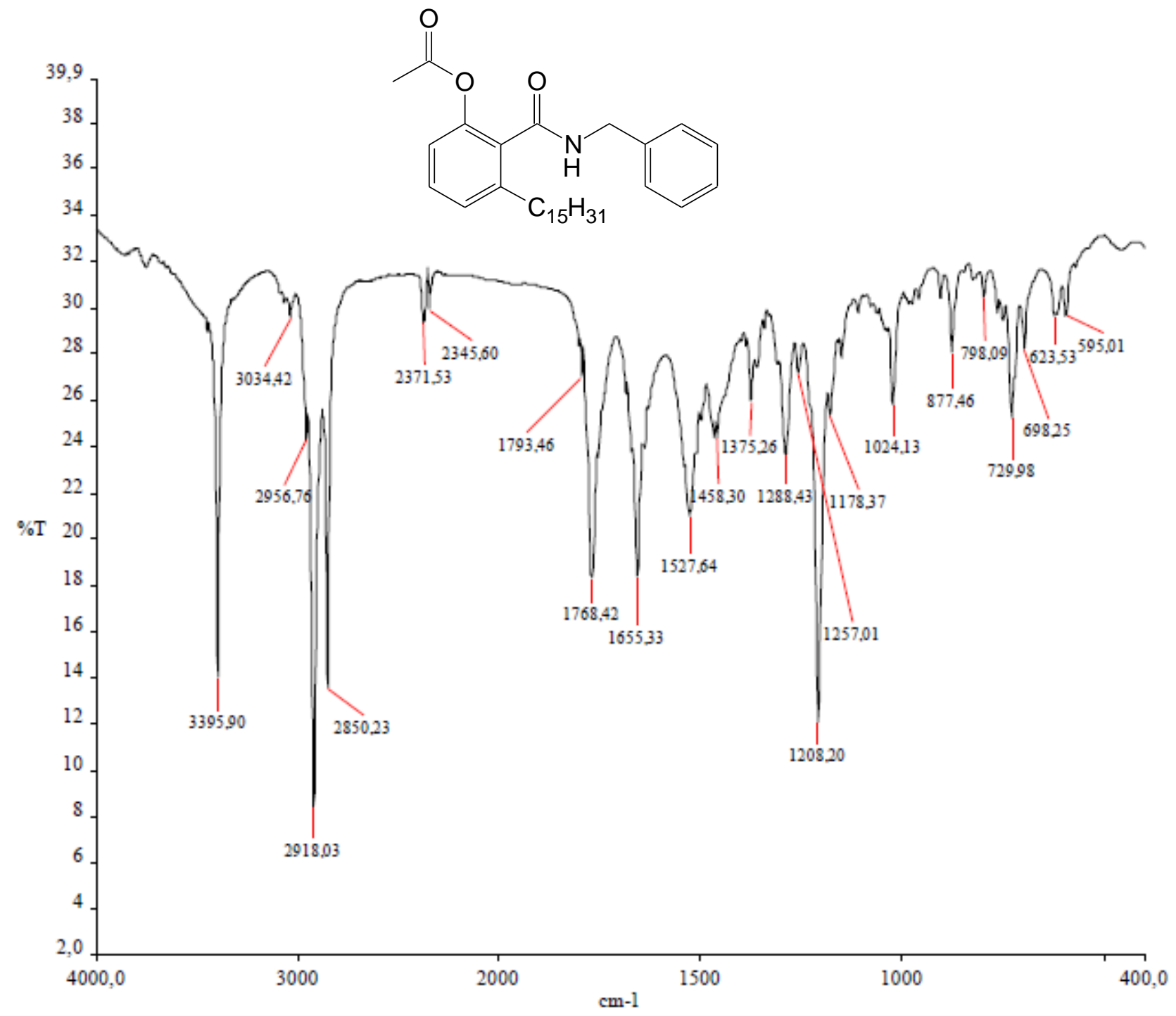


ANEXO 47 - ESPECTRO DE RMN ${ }^{1} \mathrm{H}\left(500 \mathrm{MHz}, \mathrm{CDCl}_{3}\right)$ - LDT677 (39)

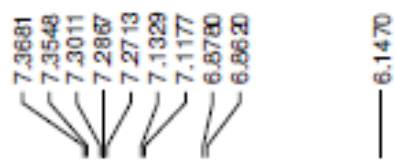

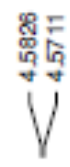

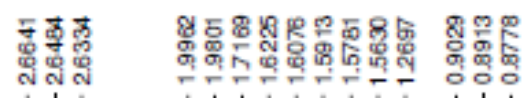

$\checkmark$

VNWT V
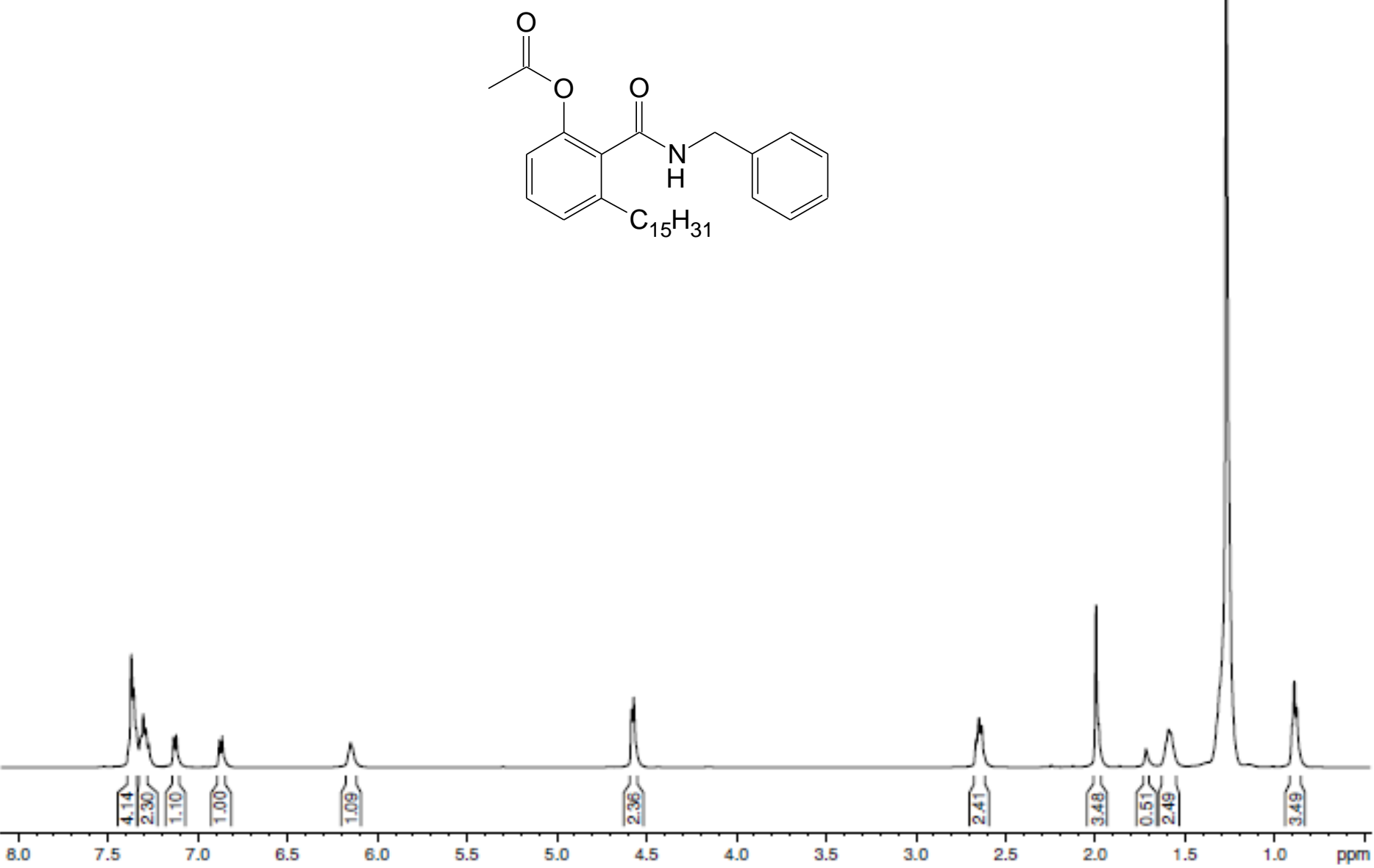
ANEXO 48 - ESPECTRO RMN ${ }^{13} \mathrm{C}\left(125 \mathrm{MHz}, \mathrm{CDCl}_{3}\right)$ - LDT677 (39)
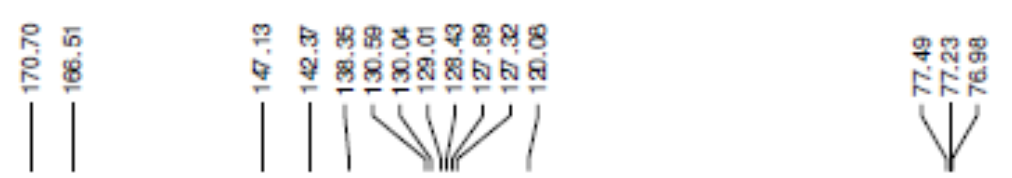

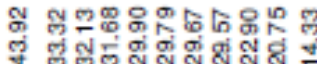

(1)।
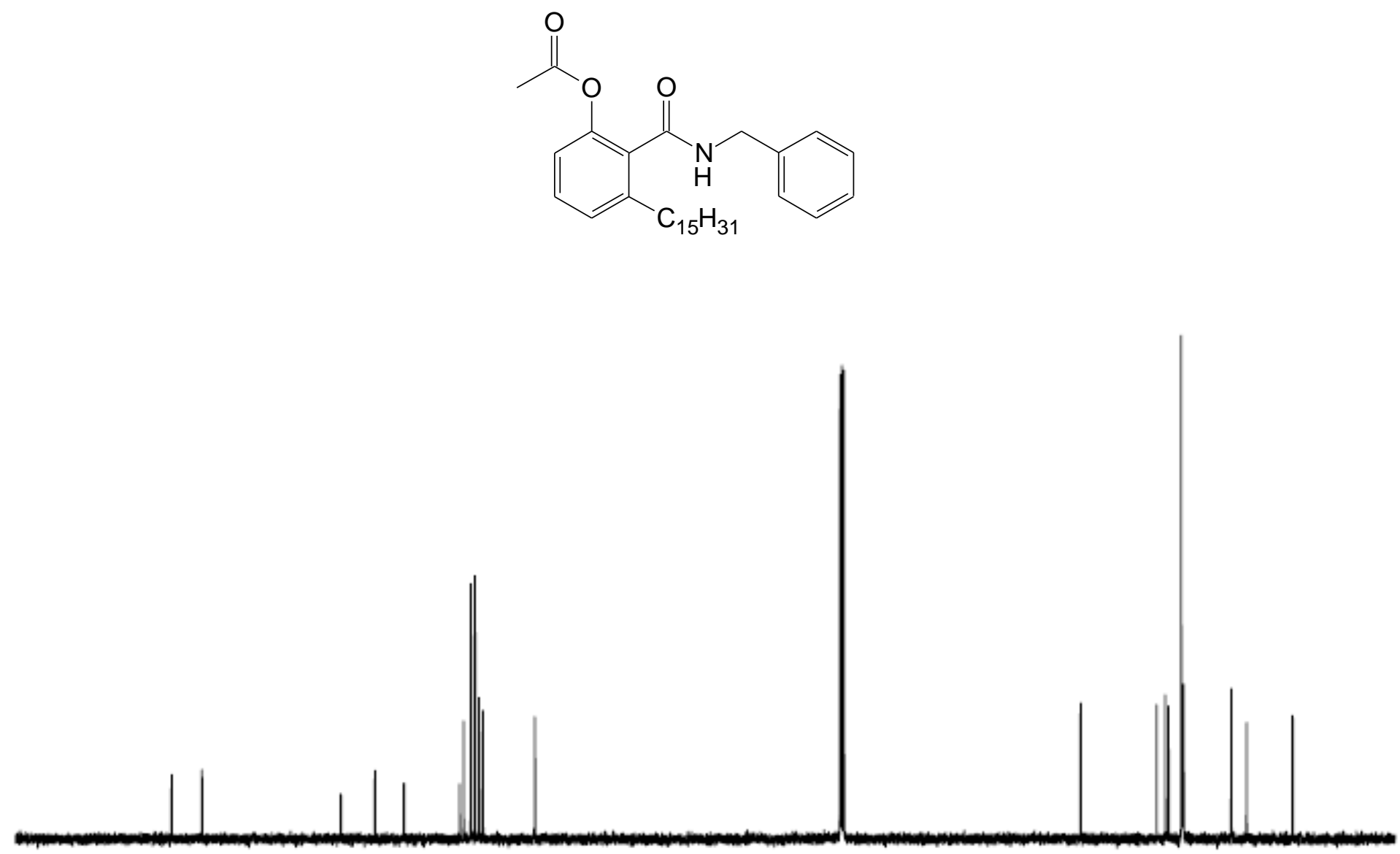

$$
190
$$


ANEXO 49 - ESPECTRO NO INFRAVERMELHO $\left(v \mathrm{~cm}^{-1}, \mathrm{KBr}\right)$ - LDT679 (40)

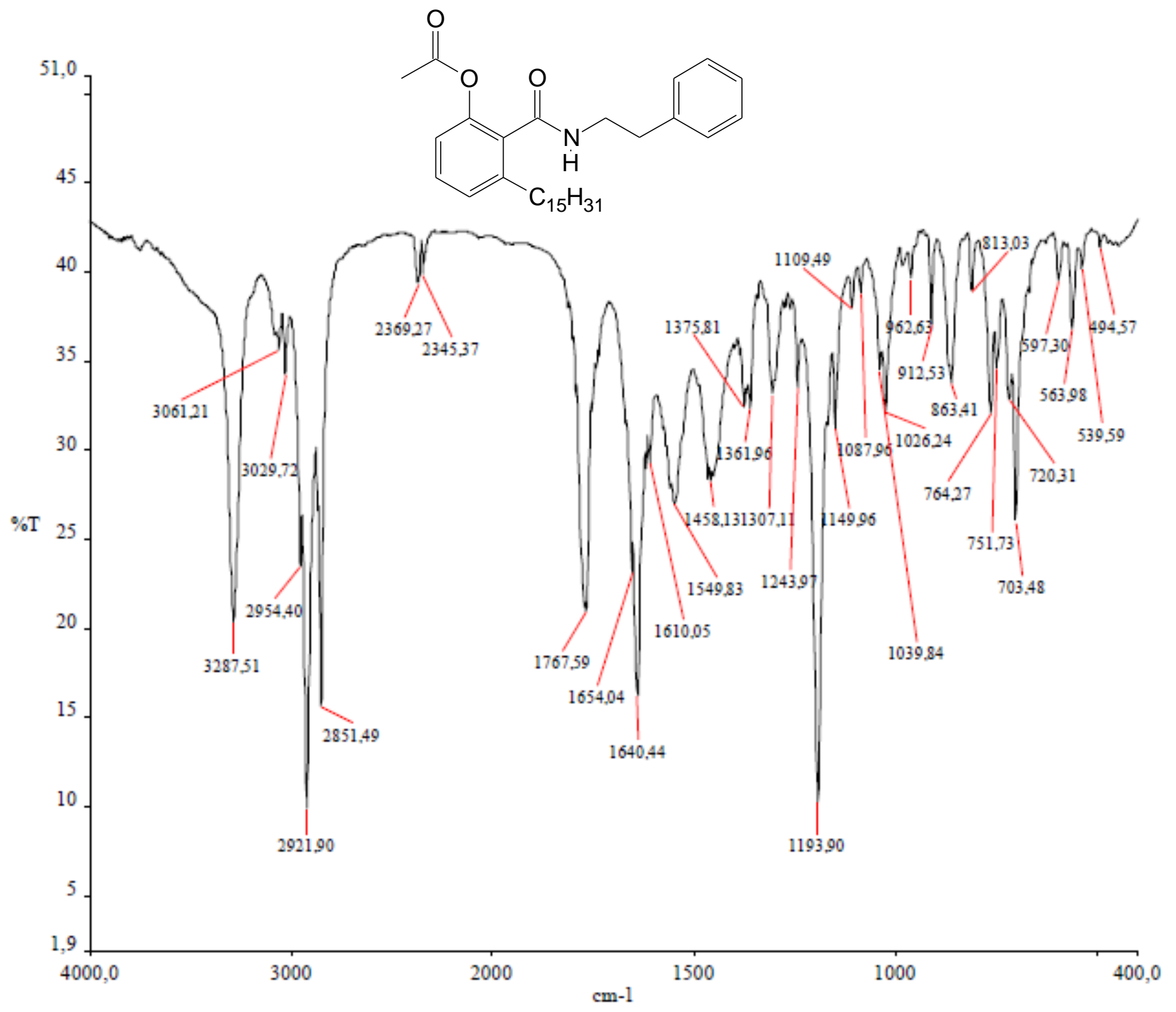


ANEXO 50 - ESPECTRO DE RMN ${ }^{1} \mathrm{H}\left(500 \mathrm{MHz}, \mathrm{CDCl}_{3}\right)$ - LDT679 (40)
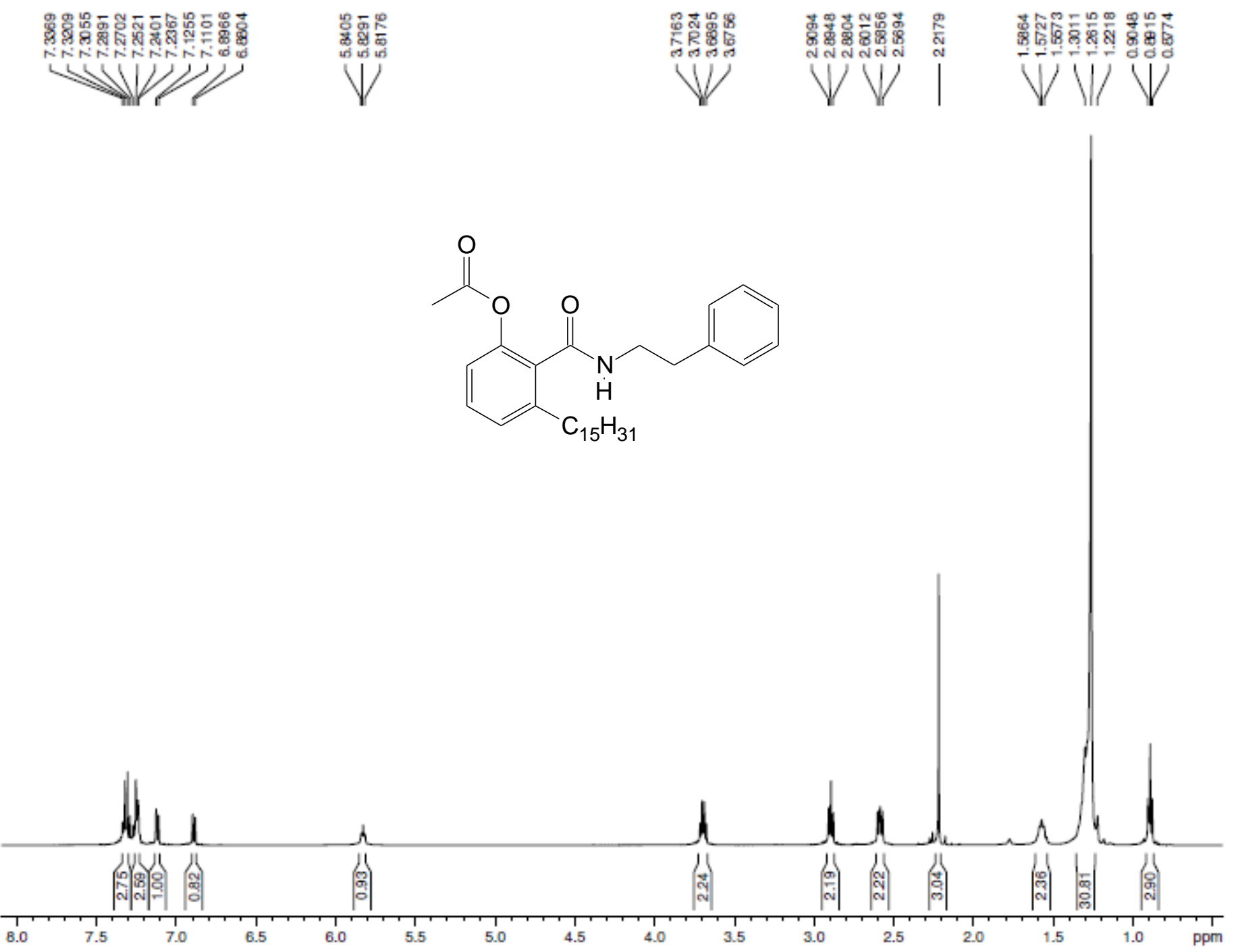
ANEXO 51 - ESPECTRO RMN ${ }^{13} \mathrm{C}\left(125 \mathrm{MHz}, \mathrm{CDCl}_{3}\right)$ - LDT679 (40)

||

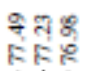

V

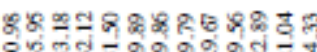

wivi)

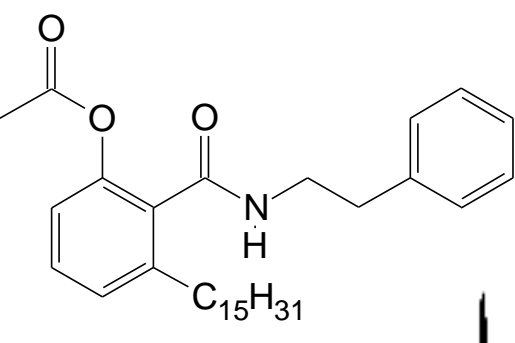

$\mathrm{C}_{15} \mathrm{H}_{31}$

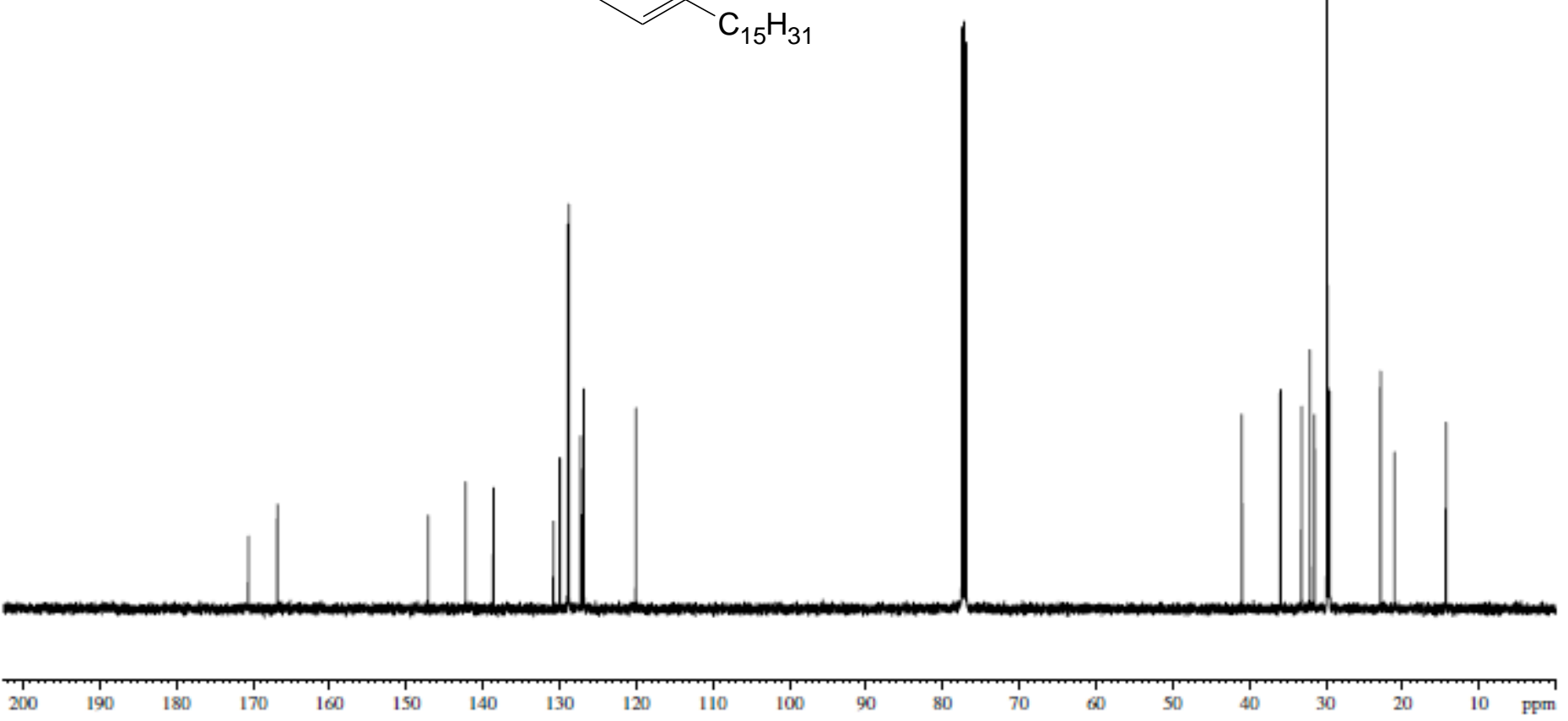


ANEXO 52 - ESPECTRO NO INFRAVERMELHO $\left(v \mathrm{~cm}^{-1}, \mathrm{KBr}\right)$ - LDT681 (41)

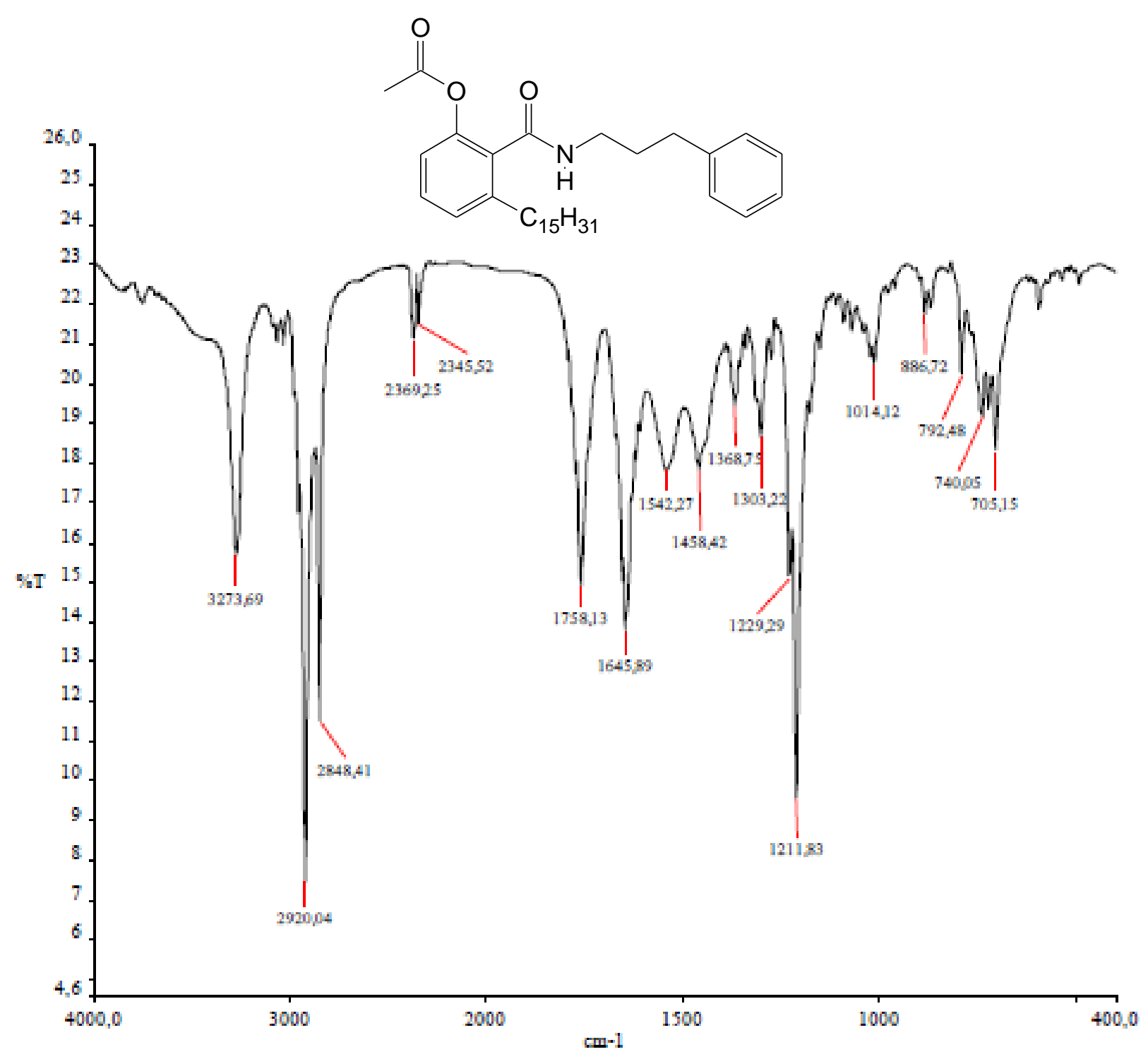


ANEXO 53 - ESPECTRO DE RMN ${ }^{1} \mathrm{H}\left(300 \mathrm{MHz}, \mathrm{CDCl}_{3}\right)$ - LDT681 (41)

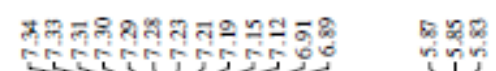

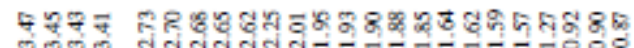
$\rightarrow \rightarrow-i$

.<smiles>CC(=O)Oc1cccc(C(F)(F)F)c1C(=O)NCCCc1ccccc1</smiles>

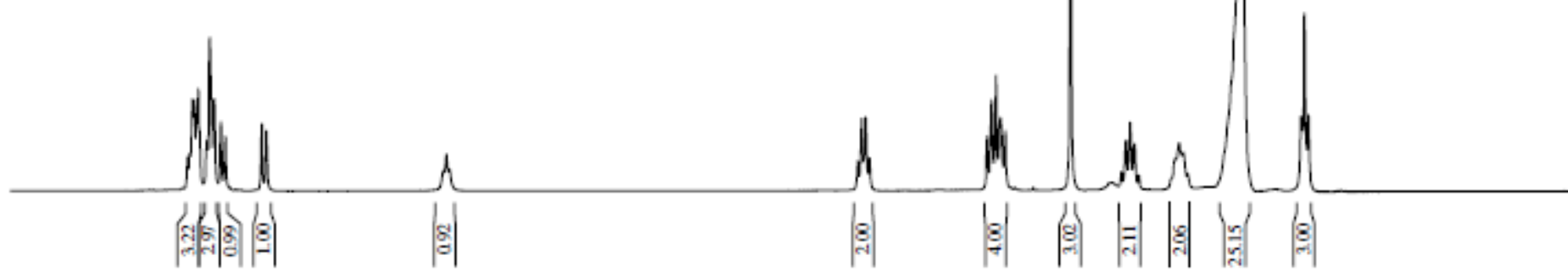


175

ANEXO 54 - ESPECTRO RMN ${ }^{13} \mathrm{C}\left(75 \mathrm{MHz}, \mathrm{CDCl}_{3}\right)$ - LDT681 (41)
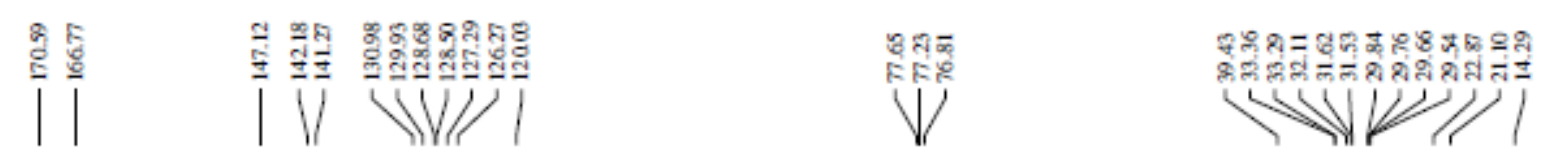<smiles>CCCCC(C)(C)c1cccc(OC(C)=O)c1C(=O)NCCCc1ccccc1</smiles>

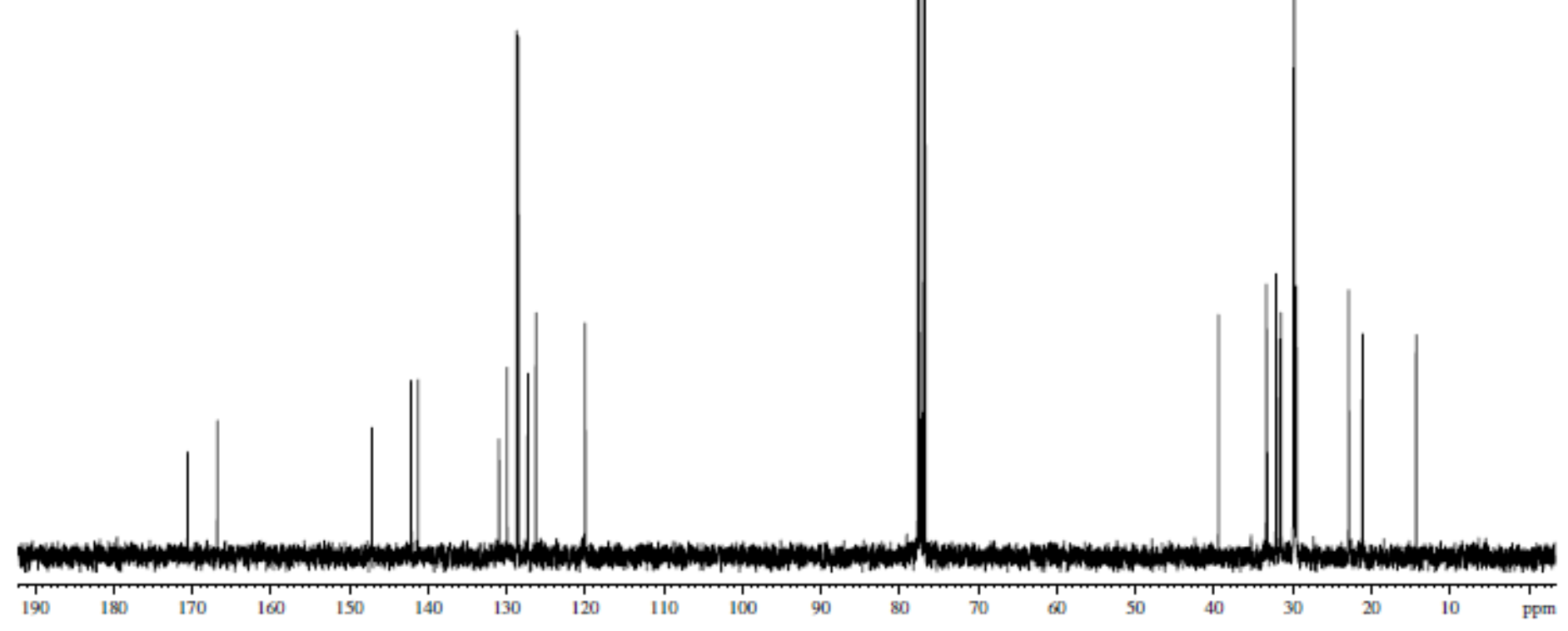


ANEXO 55 - ESPECTRO NO INFRAVERMELHO $\left(v \mathrm{~cm}^{-1}, \mathrm{KBr}\right)$ - LDT667 (26)

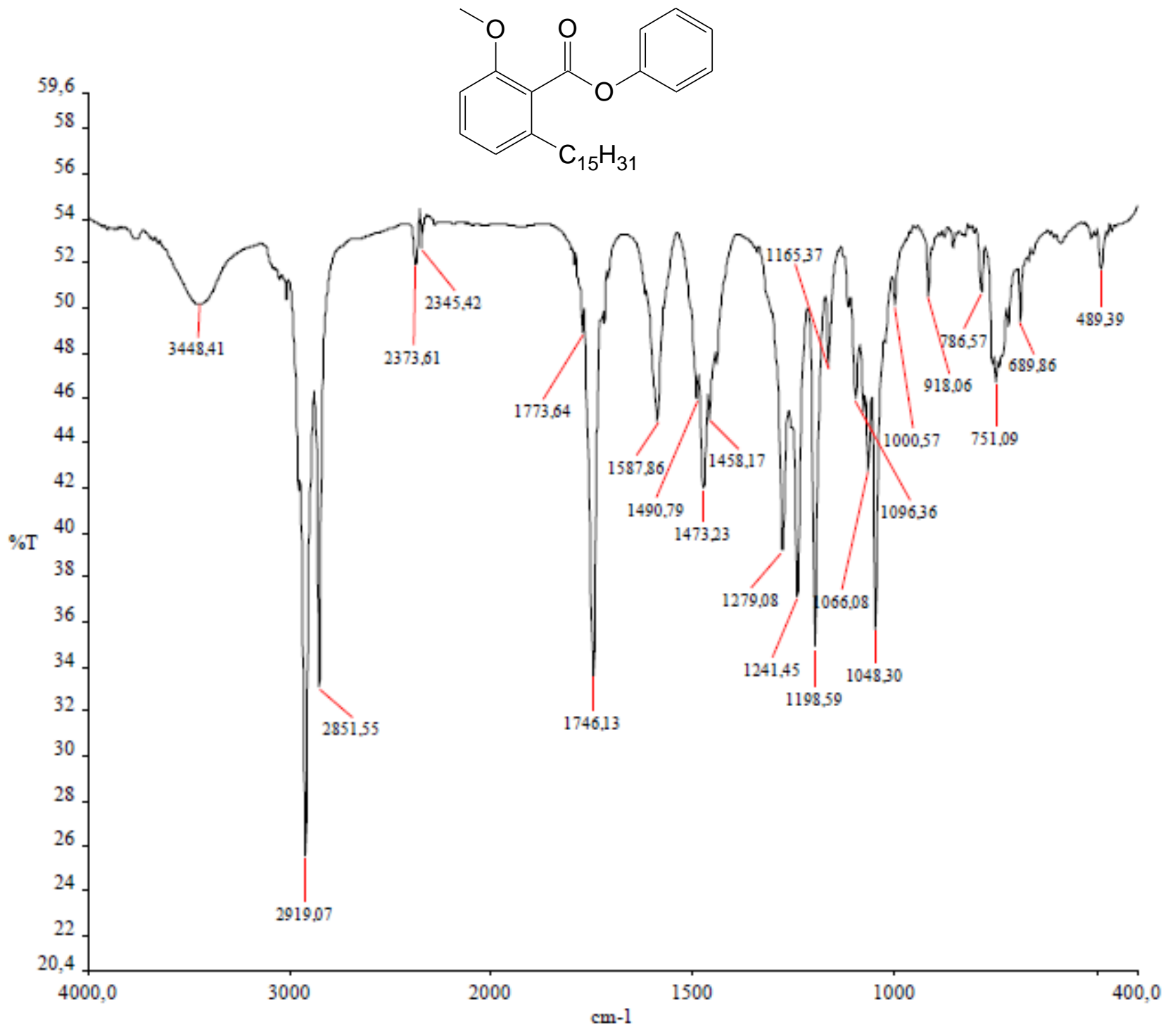


ANEXO 56 - ESPECTRO DE RMN ${ }^{1} \mathrm{H}\left(500 \mathrm{MHz}, \mathrm{CDCl}_{3}\right)$ - LDT667 (26)

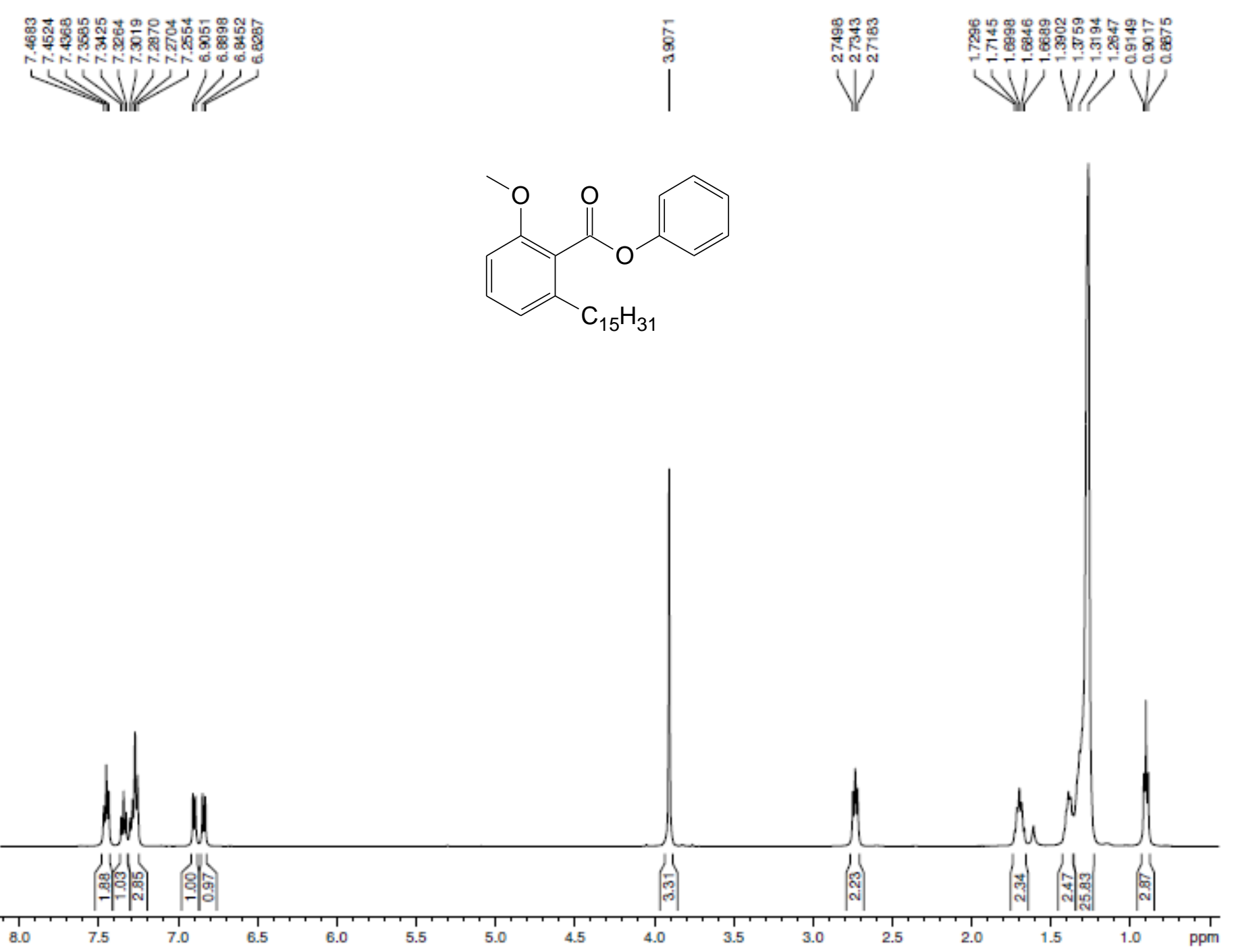


ANEXO 57 - ESPECTRO RMN ${ }^{13} \mathrm{C}\left(125 \mathrm{MHz}, \mathrm{CDCl}_{3}\right)$ - LDT667 (26)
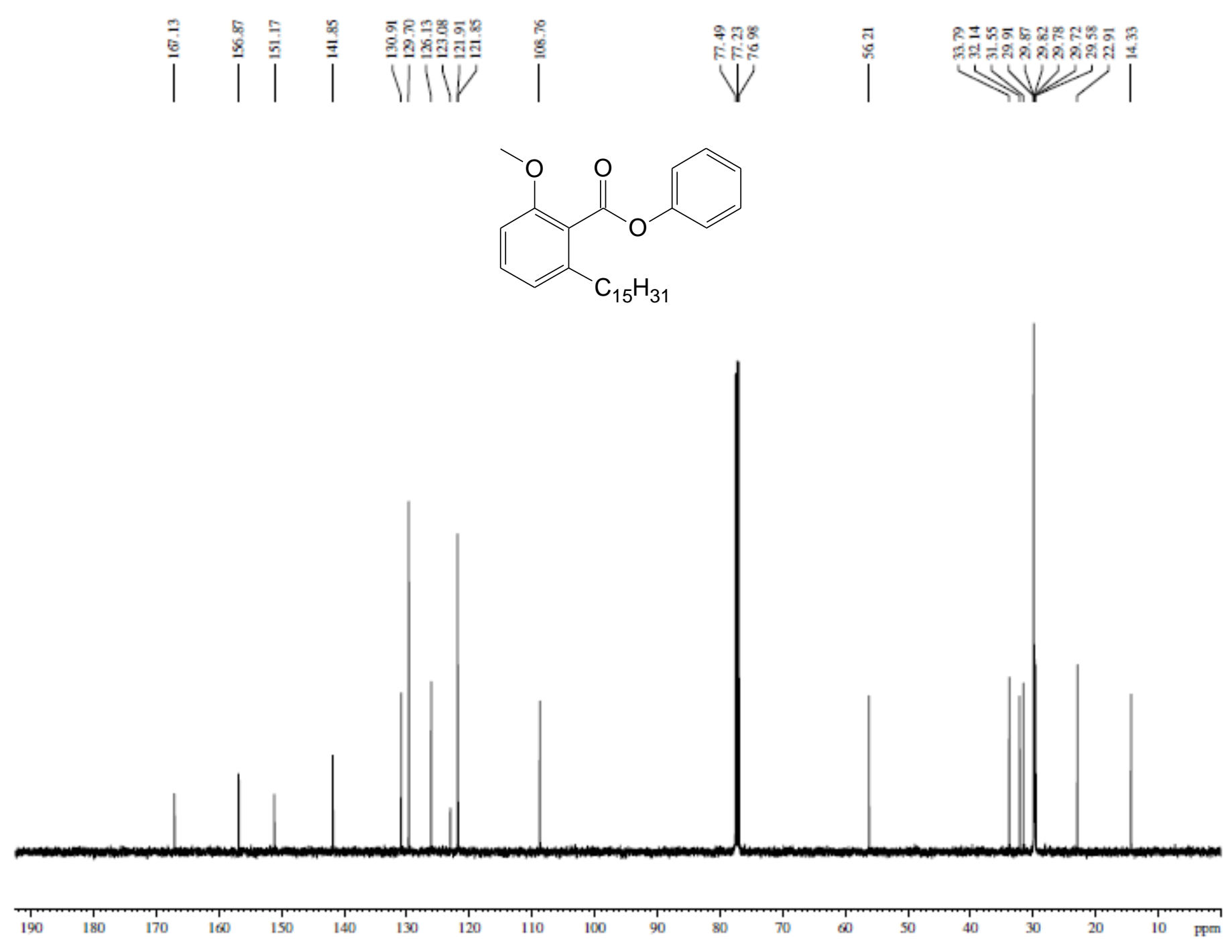
ANEXO 58 - ESPECTRO NO INFRAVERMELHO $\left(v \mathrm{~cm}^{-1}, \mathrm{KBr}\right)$ - LDT669 (27)

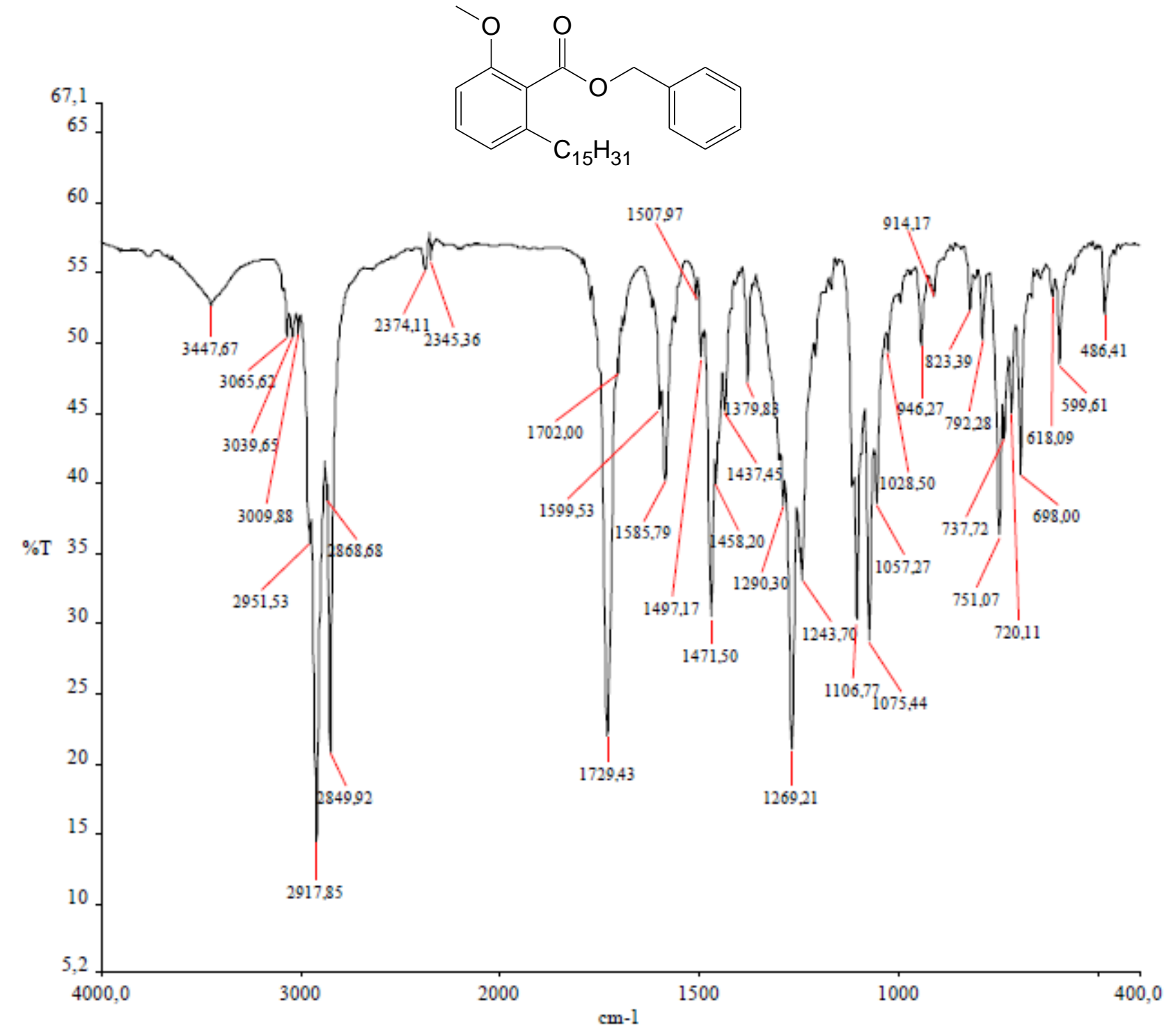


ANEXO 59 - ESPECTRO DE RMN ${ }^{1} \mathrm{H}\left(300 \mathrm{MHz}, \mathrm{CDCl}_{3}\right)$ - LDT669 (27)

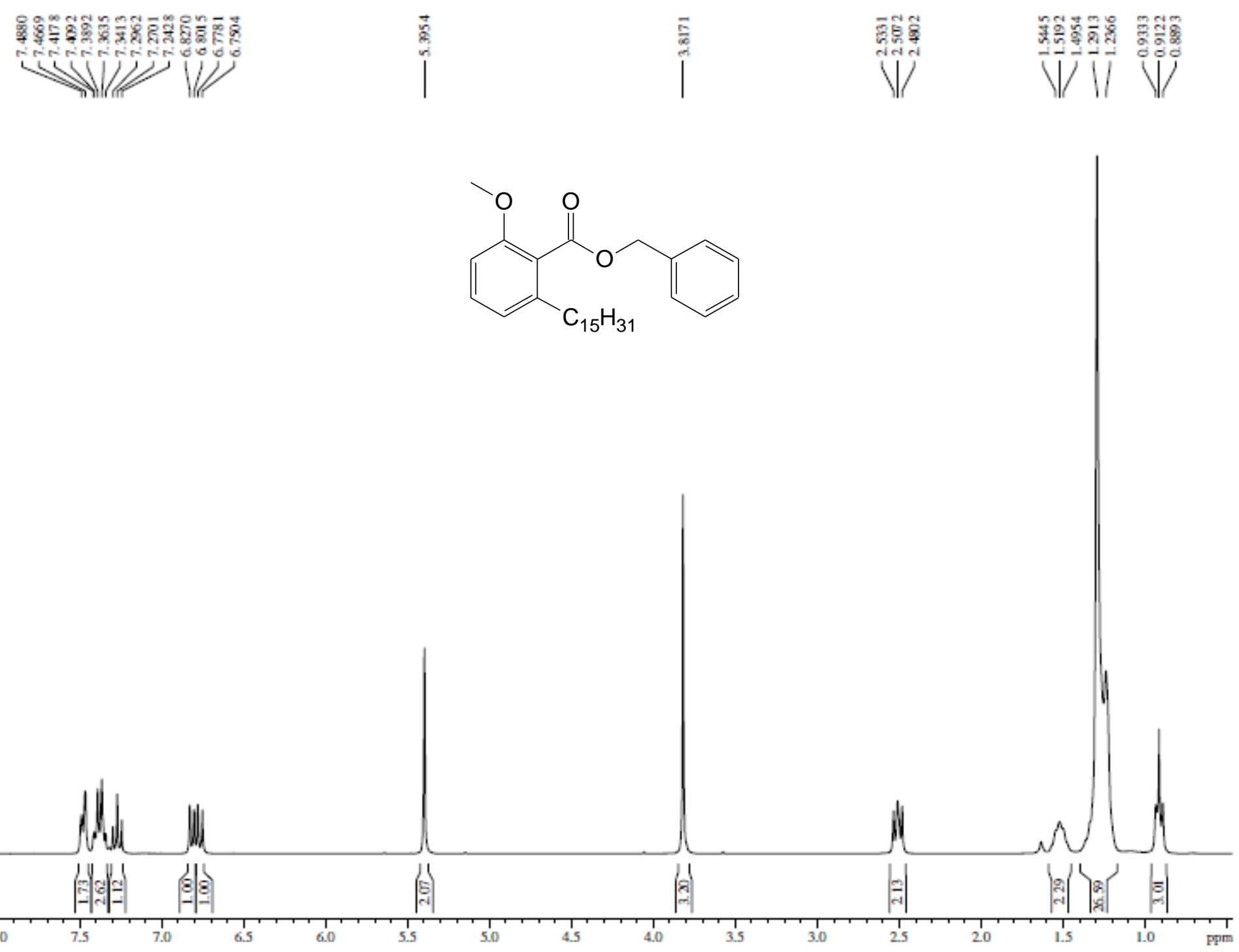


ANEXO 60 - ESPECTRO RMN ${ }^{13} \mathrm{C}\left(75 \mathrm{MHz}, \mathrm{CDCl}_{3}\right)$ - LDT669 (27)
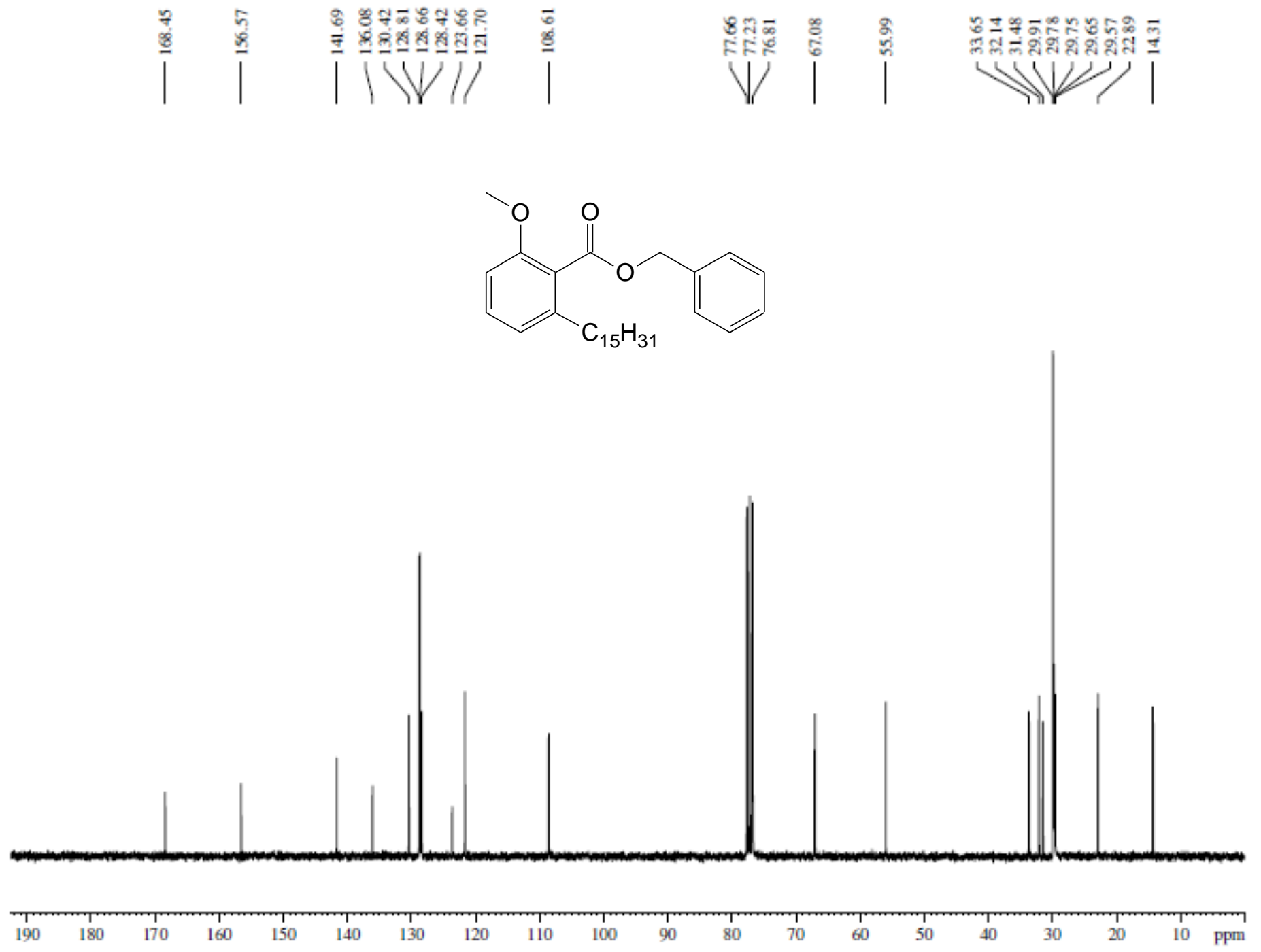
ANEXO 61 - ESPECTRO NO INFRAVERMELHO $\left(v \mathrm{~cm}^{-1}, \mathrm{KBr}\right)$ - LDT671 (28)

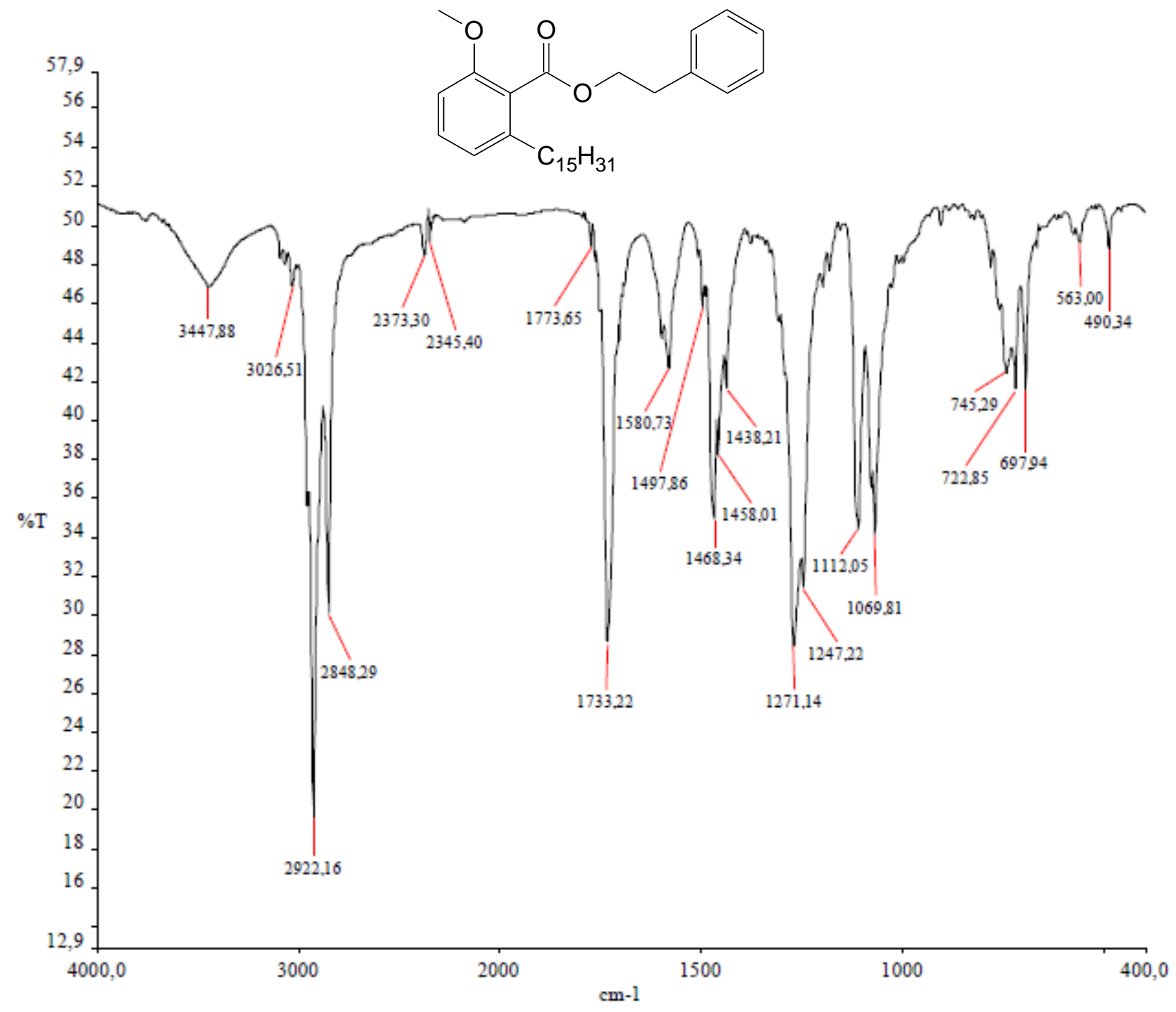


ANEXO 62 - ESPECTRO DE RMN ${ }^{1} \mathrm{H}\left(300 \mathrm{MHz}, \mathrm{CDCl}_{3}\right)$ - LDT671 (28)

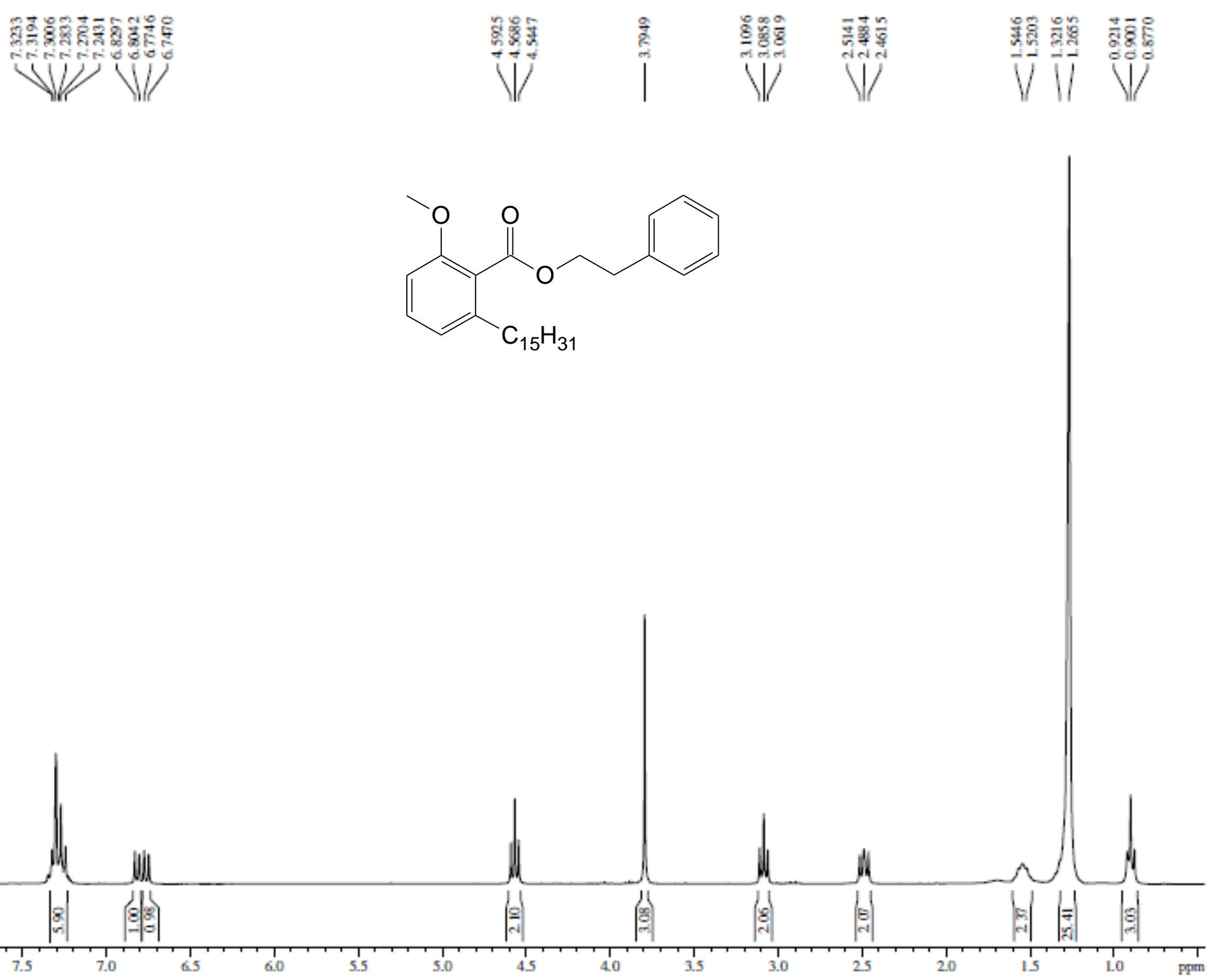


ANEXO 63 - ESPECTRO RMN ${ }^{13} \mathrm{C}\left(75 \mathrm{MHz}, \mathrm{CDCl}_{3}\right)$ - LDT671 (28)
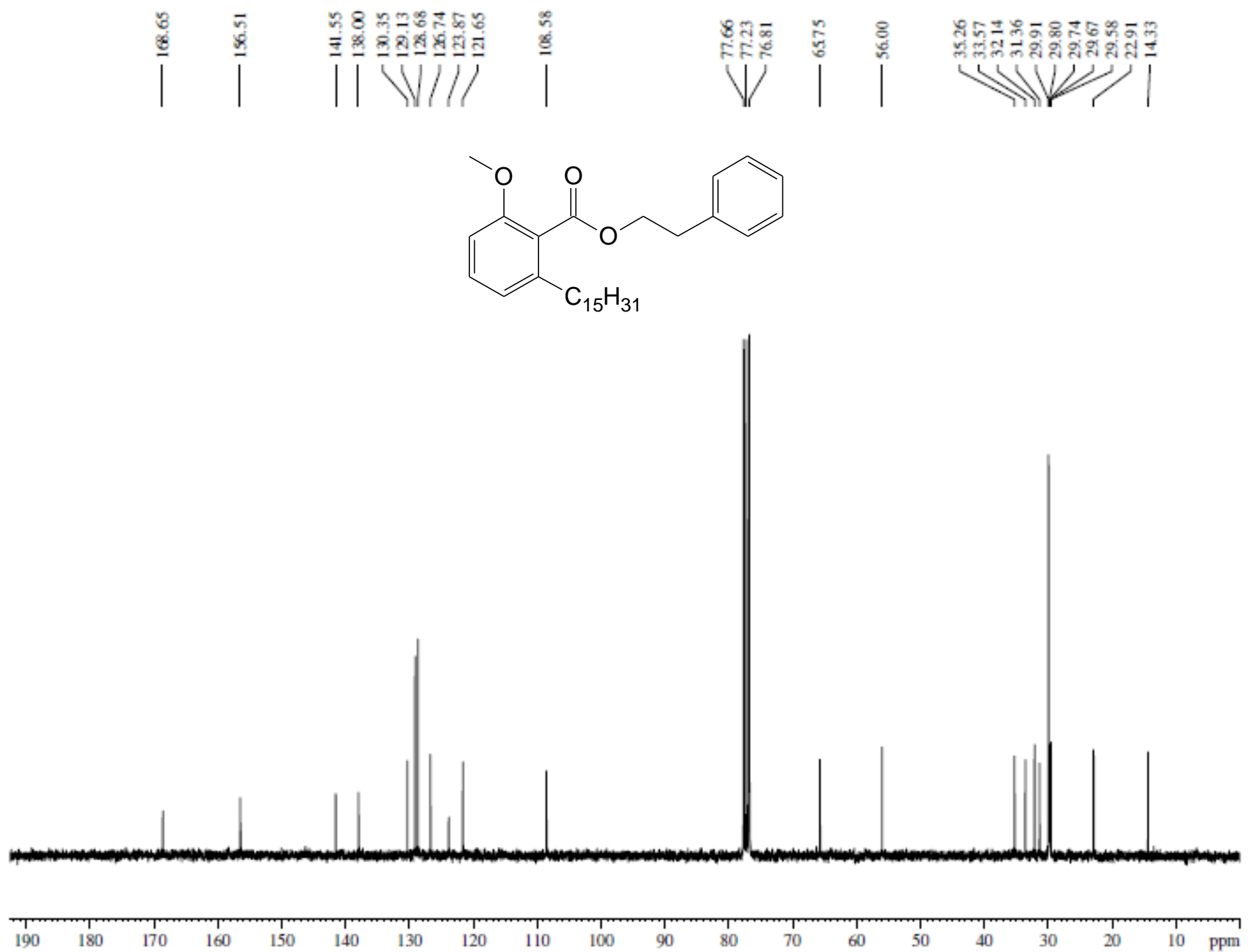
ANEXO 64 - ESPECTRO NO INFRAVERMELHO $\left(v \mathrm{~cm}^{-1}, \mathrm{KBr}\right)$ - LDT673 (29)

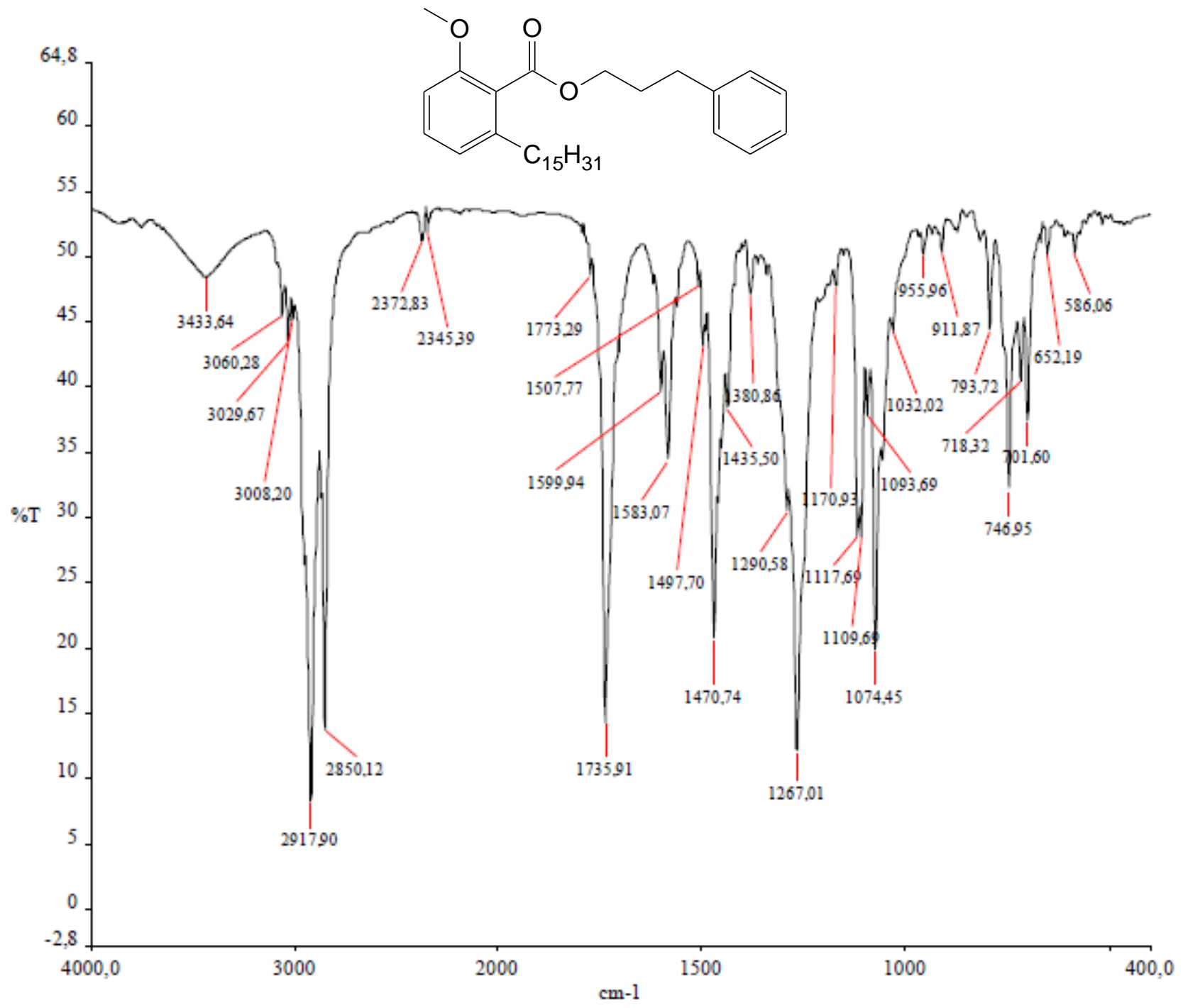


ANEXO 65 - ESPECTRO DE RMN ${ }^{1} \mathrm{H}\left(300 \mathrm{MHz}, \mathrm{CDCl}_{3}\right)$ - LDT673 (29)

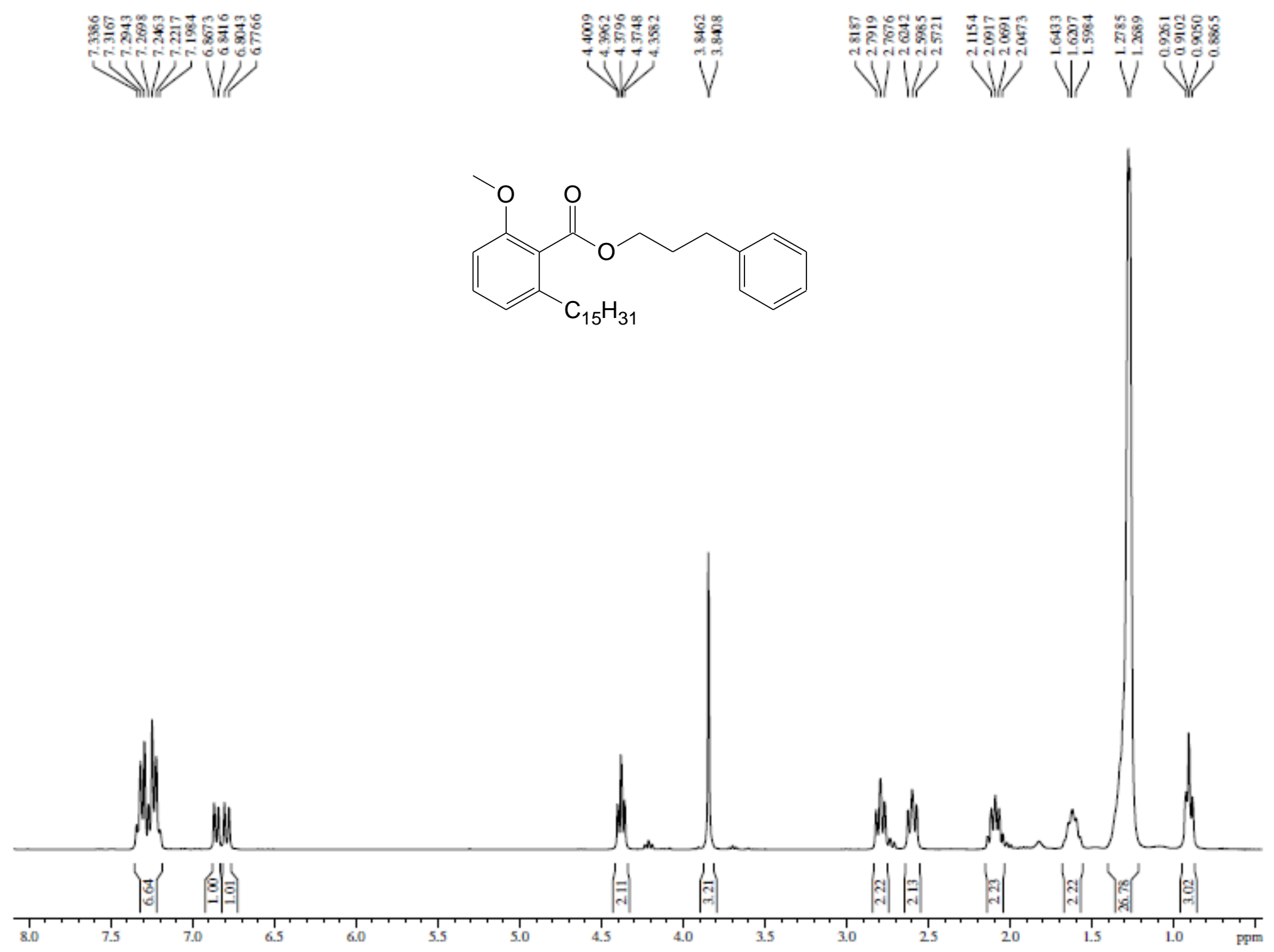


ANEXO 66 - ESPECTRO RMN ${ }^{13} \mathrm{C}\left(75 \mathrm{MHz}, \mathrm{CDCl}_{3}\right)$ - LDT673 (29)

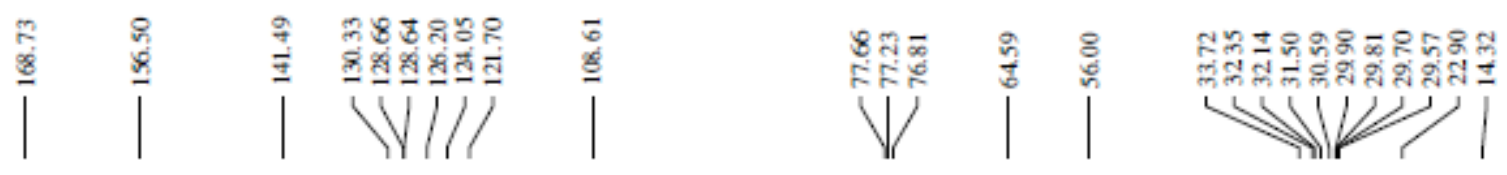
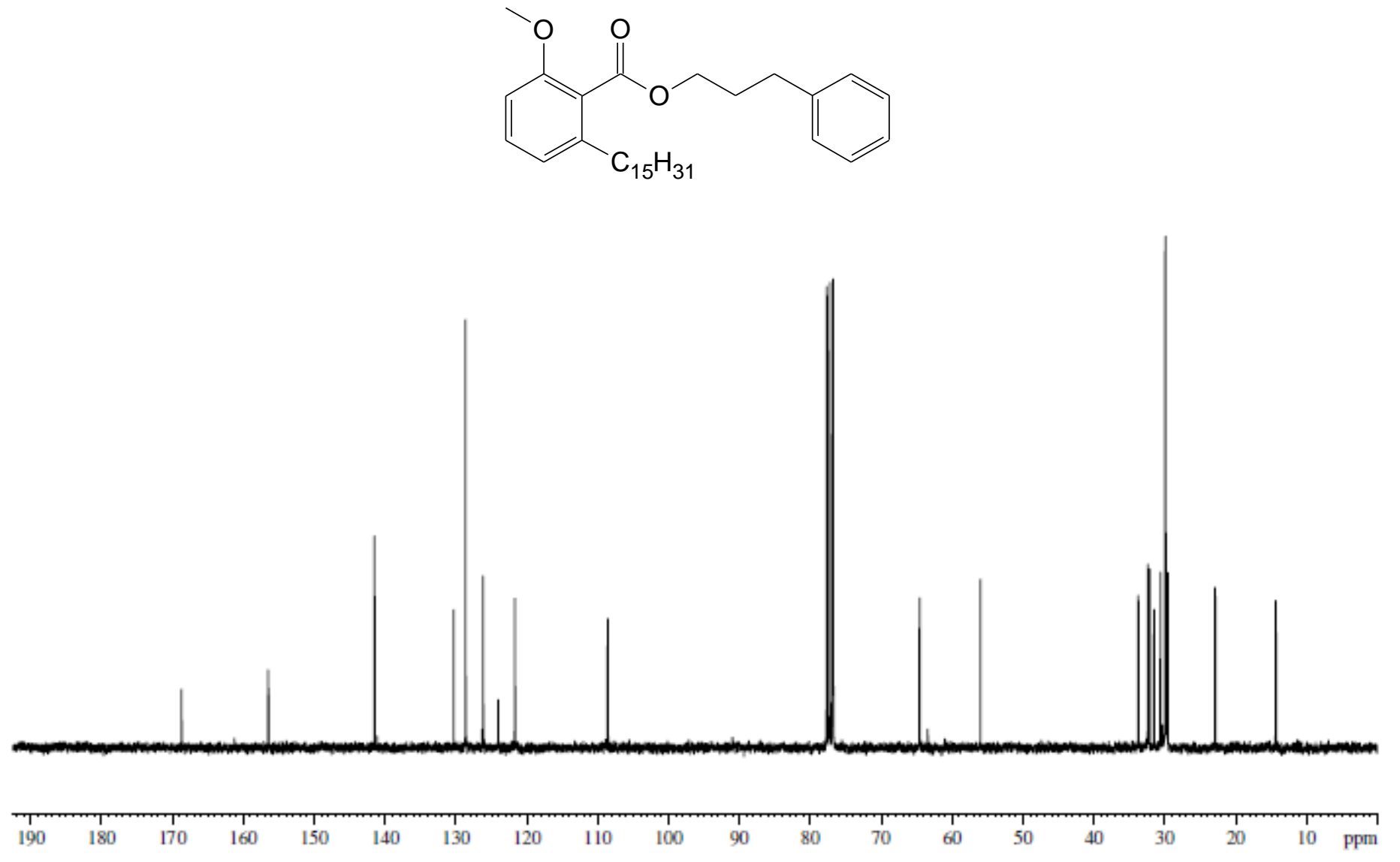
ANEXO 67 - ESPECTRO NO INFRAVERMELHO $\left(v \mathrm{~cm}^{-1}, \mathrm{KBr}\right)$ - LDT659 (34)

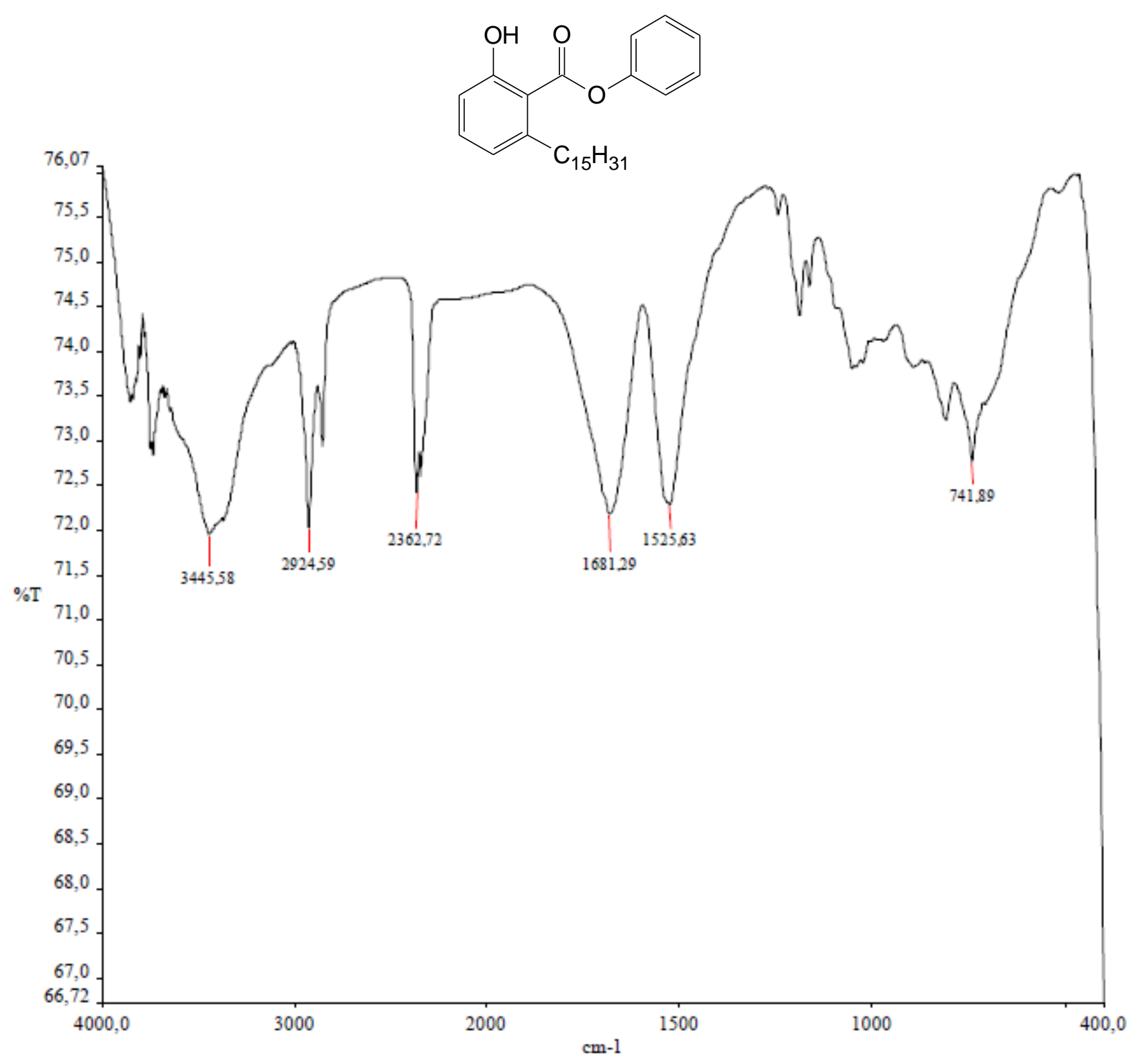


ANEXO 68 - ESPECTRO DE RMN ${ }^{1} \mathrm{H}\left(500 \mathrm{MHz}, \mathrm{CDCl}_{3}\right)$ - LDT659 (34)

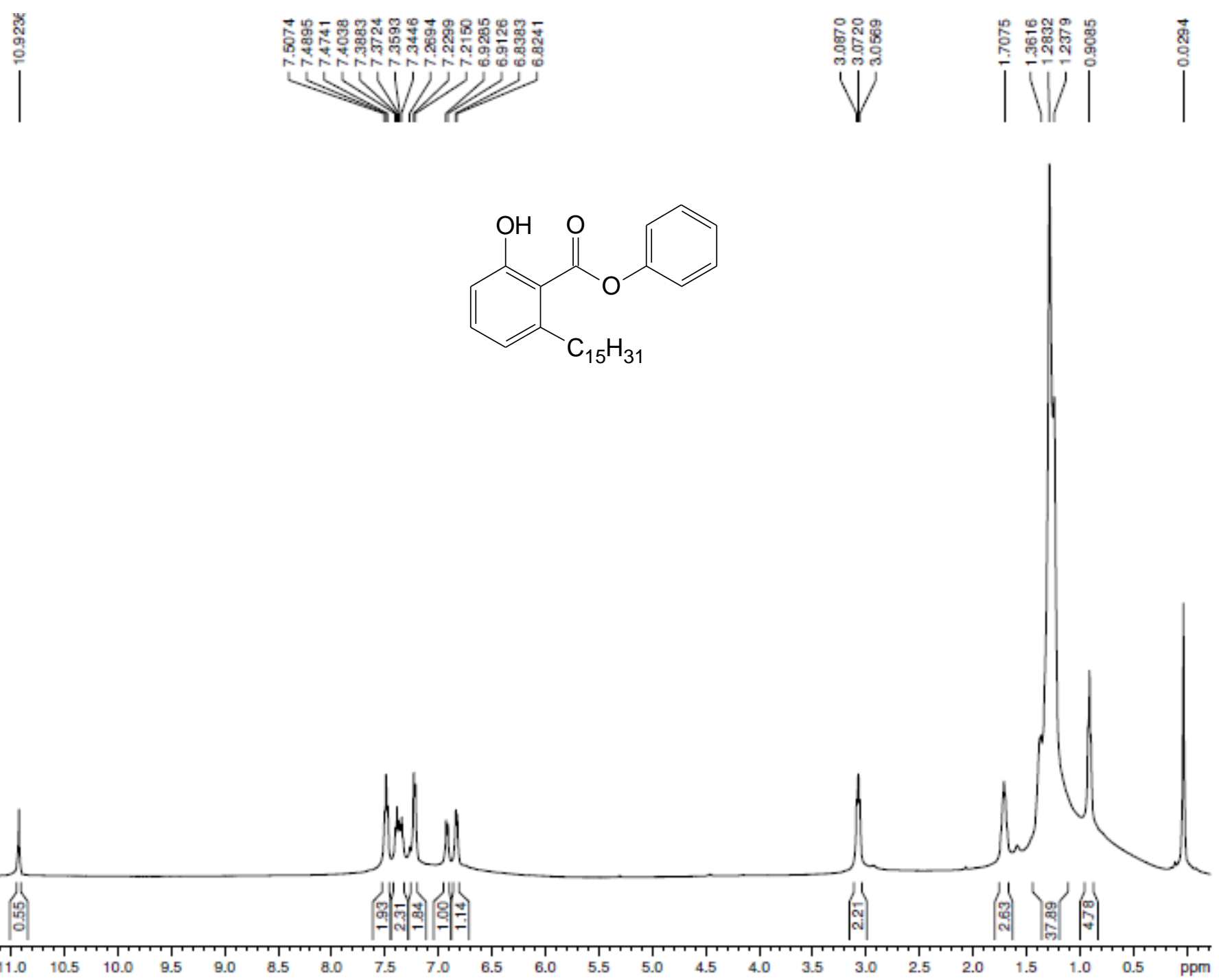


ANEXO 69 - ESPECTRO RMN ${ }^{13} \mathrm{C}\left(125 \mathrm{MHz}, \mathrm{CDCl}_{3}\right)$ - LDT659 (34)
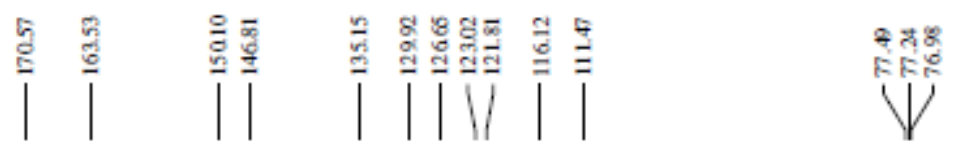

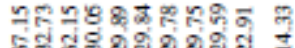

NW
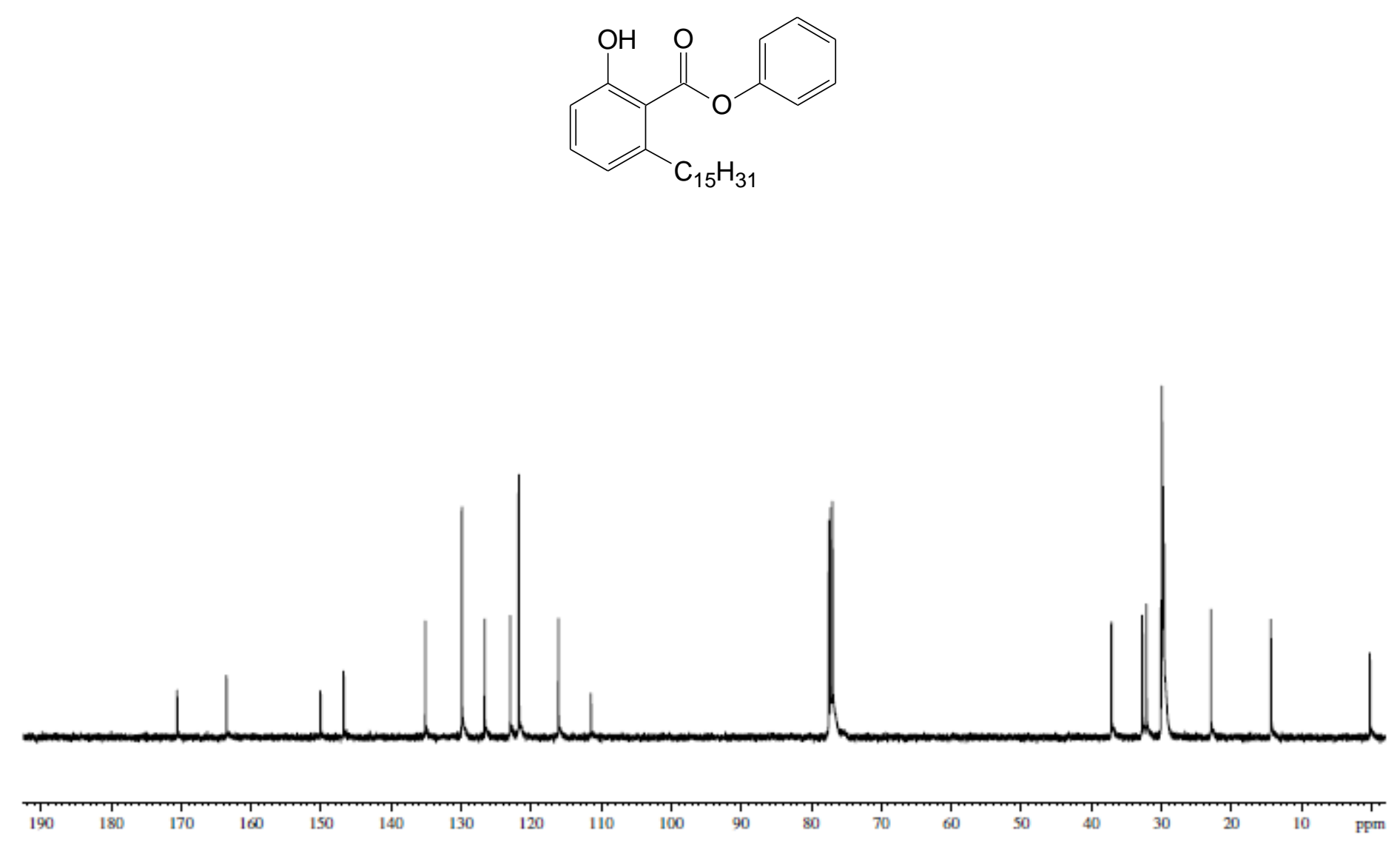
ANEXO 70 - ESPECTRO NO INFRAVERMELHO $\left(v \mathrm{~cm}^{-1}, \mathrm{KBr}\right)$ - LDT661 (35)

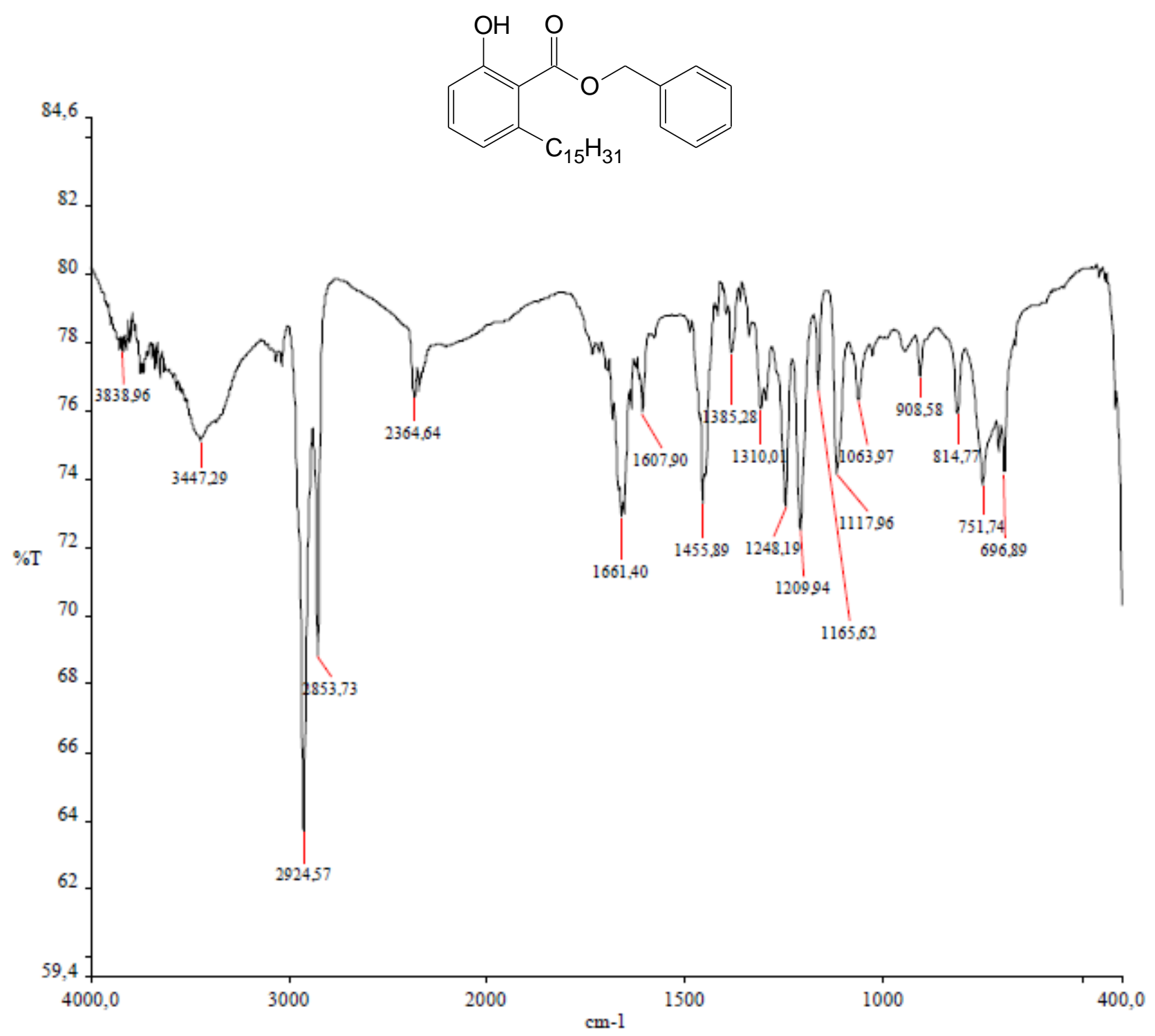


ANEXO 71 - ESPECTRO DE RMN ${ }^{1} \mathrm{H}\left(500 \mathrm{MHz}, \mathrm{CDCl}_{3}\right)$ - LDT661 (35)
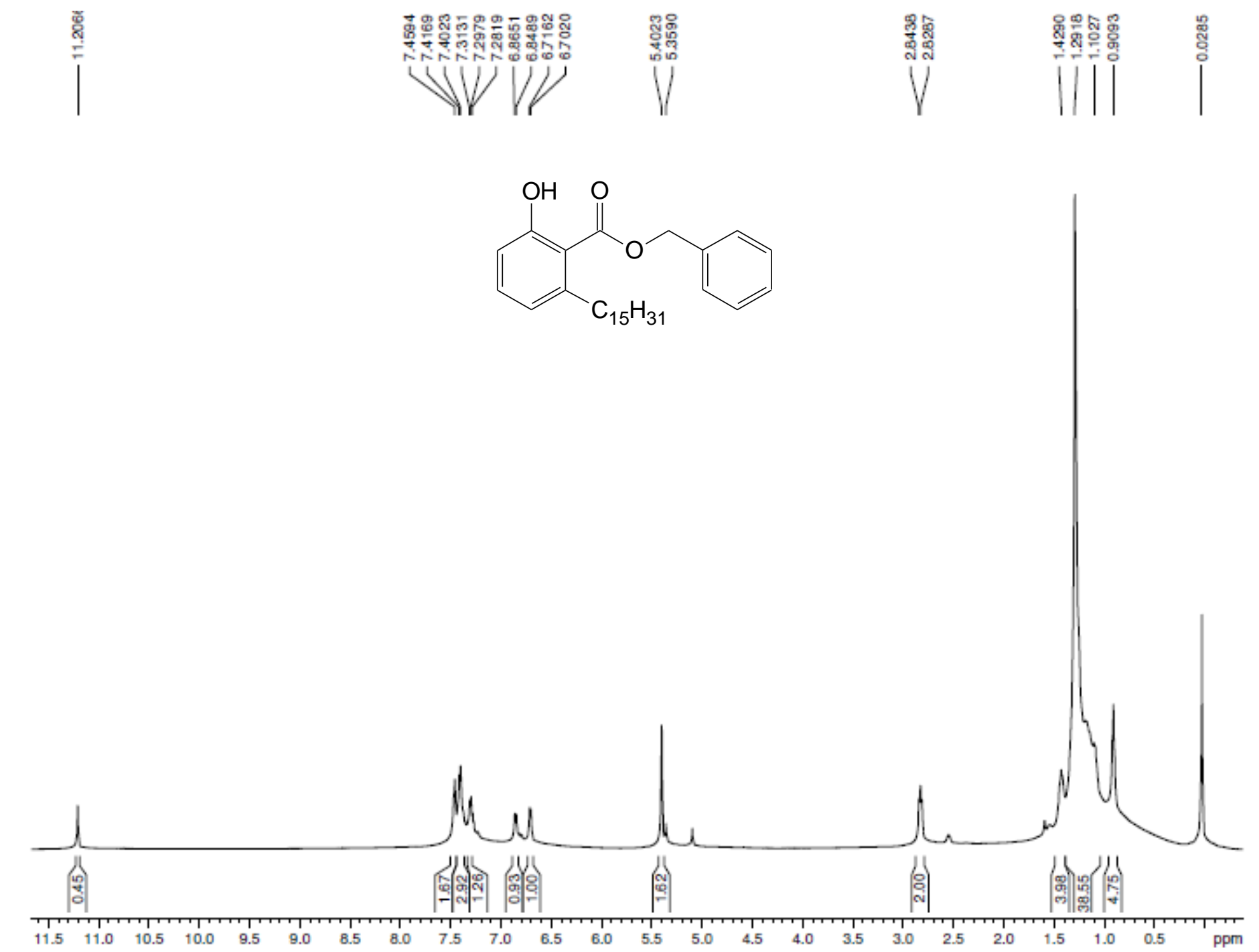
ANEXO 72 - ESPECTRO RMN ${ }^{13} \mathrm{C}\left(125 \mathrm{MHz}, \mathrm{CDCl}_{3}\right)$ - LDT661 (35)
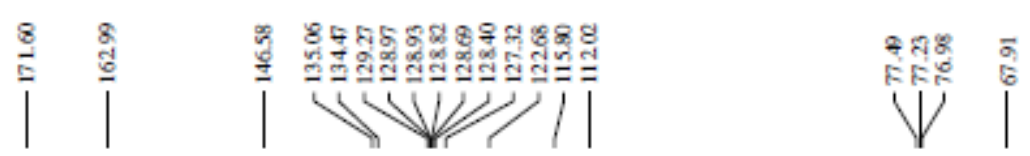

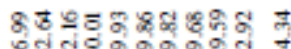
Nivis
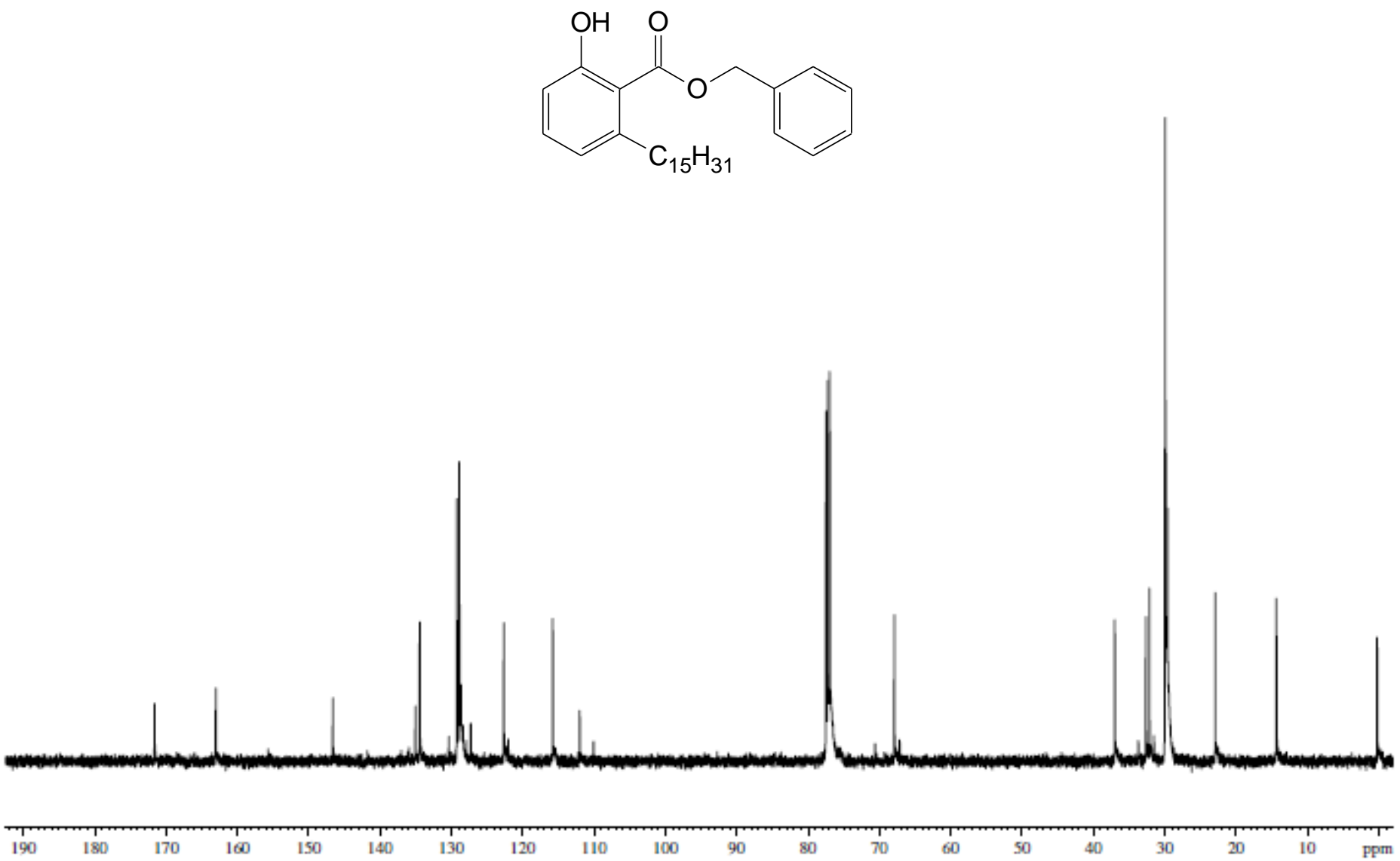
ANEXO 73 - ESPECTRO NO INFRAVERMELHO $\left(v \mathrm{~cm}^{-1}, \mathrm{KBr}\right)$ - LDT663 (36)

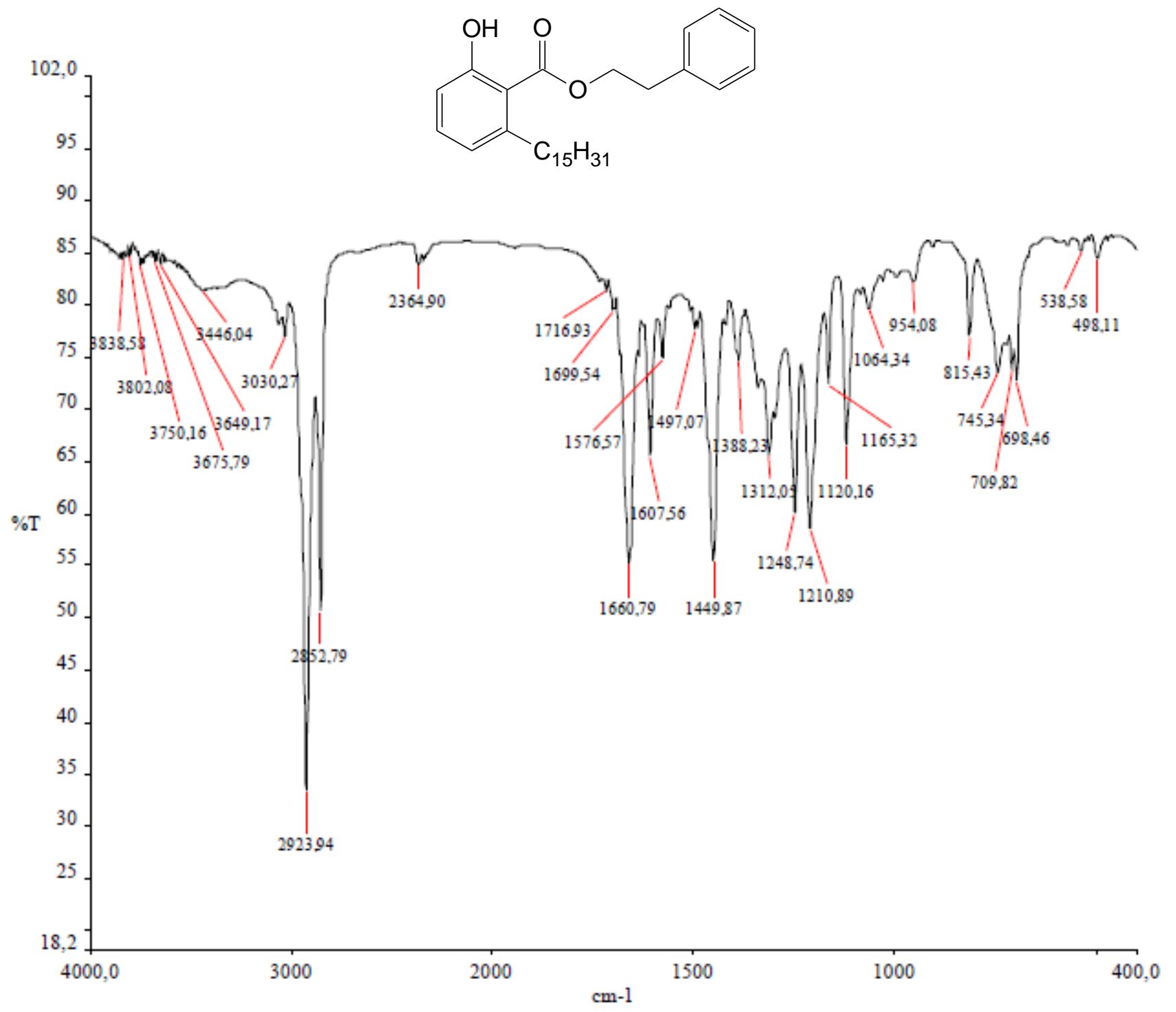


ANEXO 74 - ESPECTRO DE RMN ${ }^{1} \mathrm{H}\left(500 \mathrm{MHz}, \mathrm{CDCl}_{3}\right)$ - LDT663 (36)
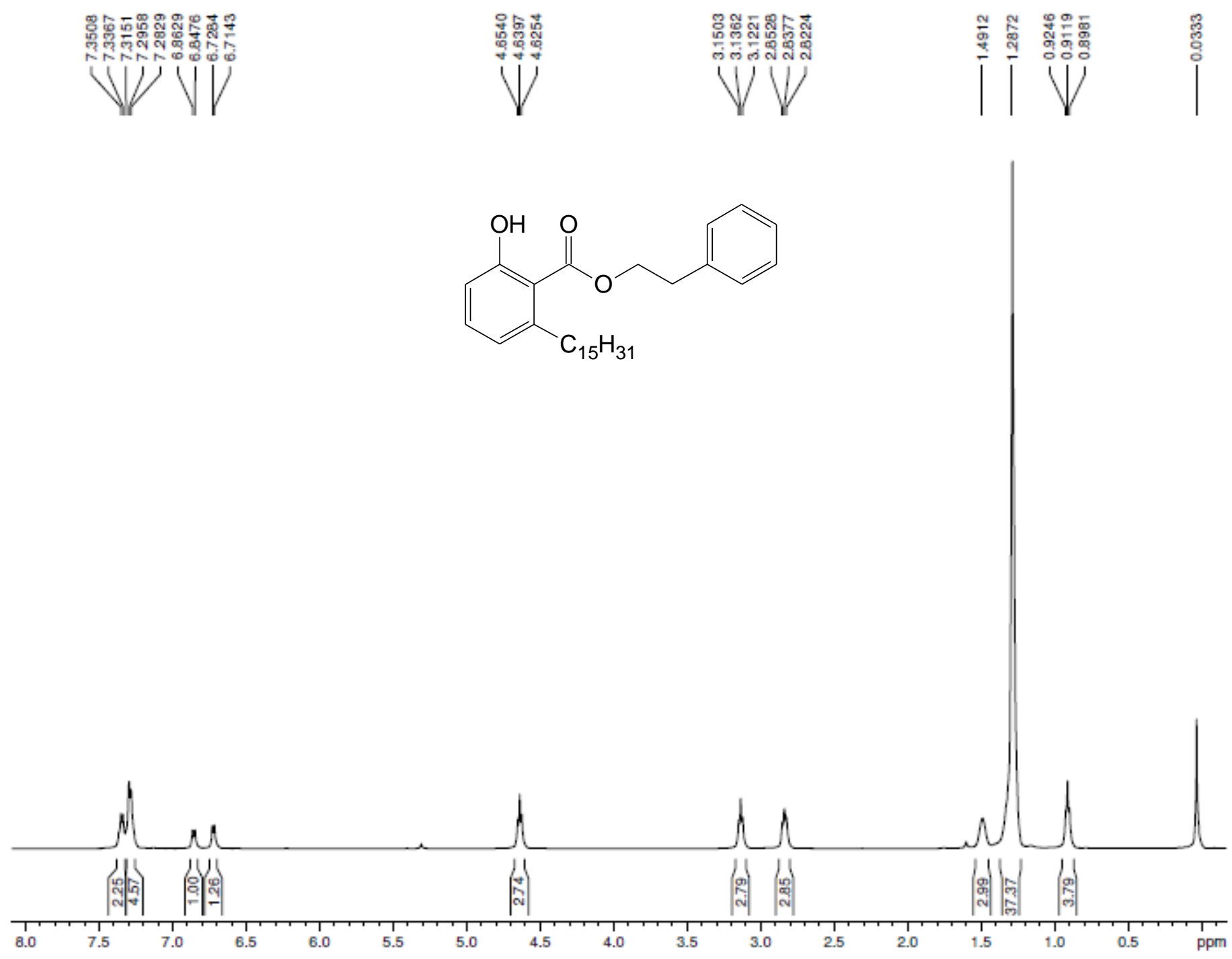
ANEXO 75 - ESPECTRO RMN ${ }^{13} \mathrm{C}\left(125 \mathrm{MHz}, \mathrm{CDCl}_{3}\right)$ - LDT663 (36)

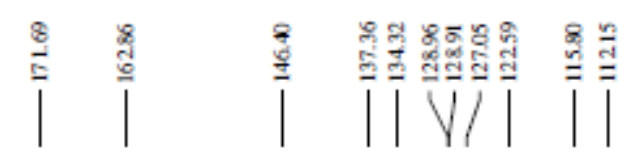

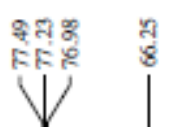

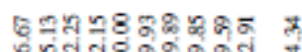

WVI |
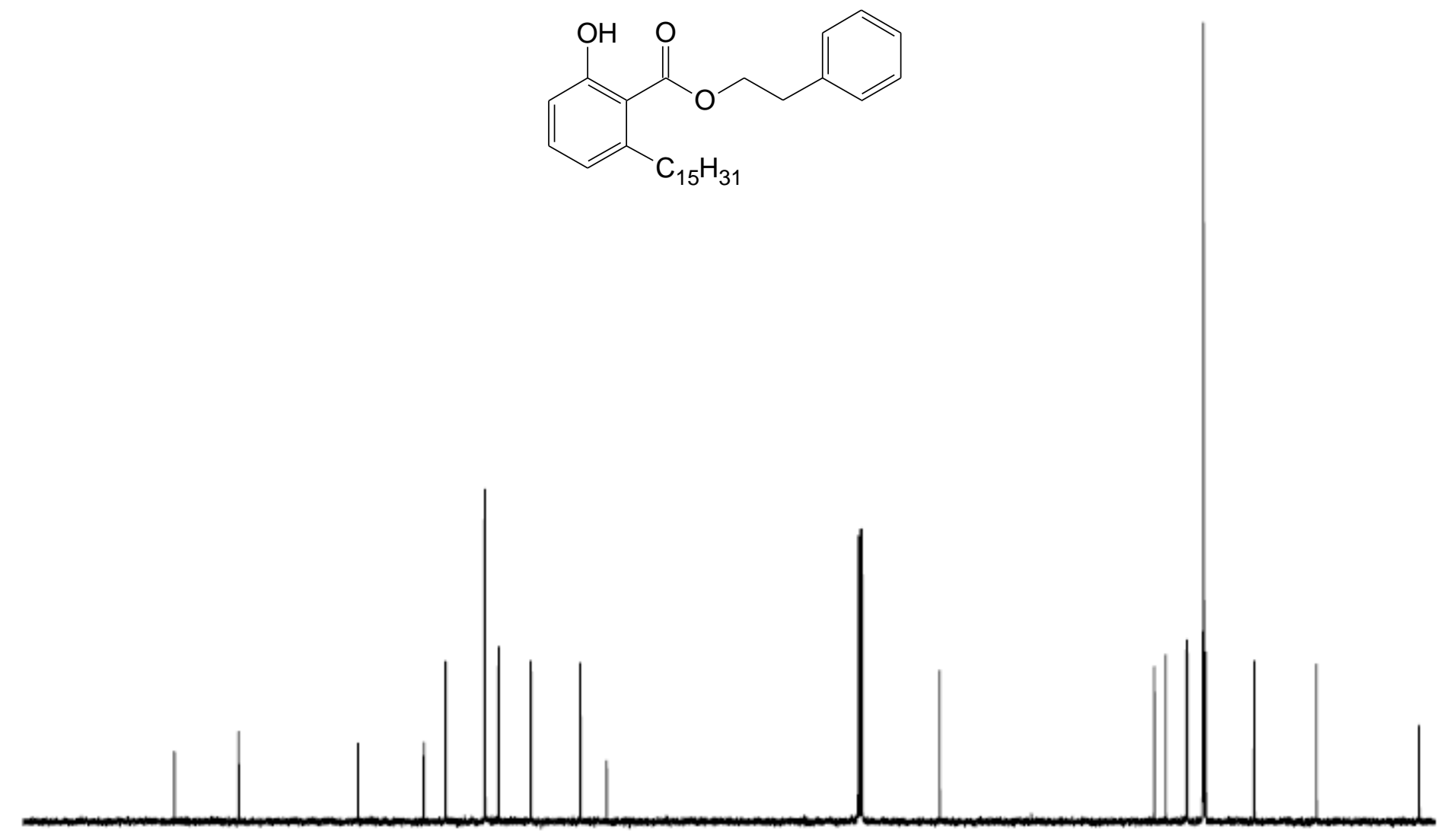
ANEXO 76 - ESPECTRO NO INFRAVERMELHO $\left(v \mathrm{~cm}^{-1}, \mathrm{KBr}\right)$ - LDT665 (37)

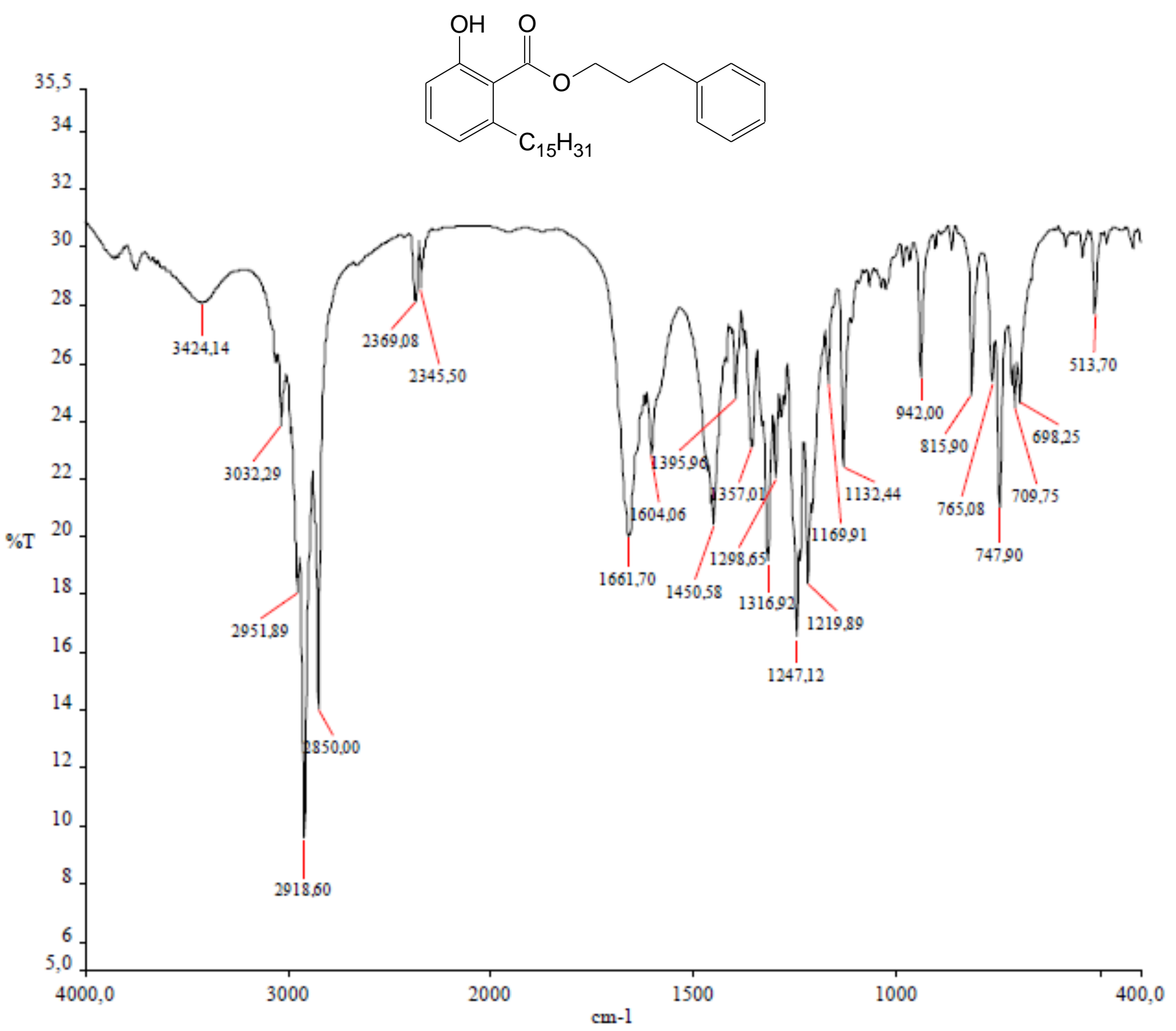


ANEXO 77 - ESPECTRO DE RMN ${ }^{1} \mathrm{H}\left(300 \mathrm{MHz}, \mathrm{CDCl}_{3}\right)$ - LDT665 (37)

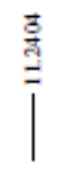

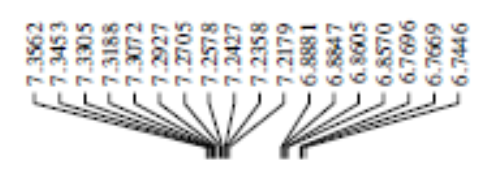

影

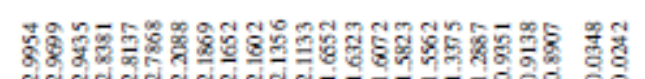
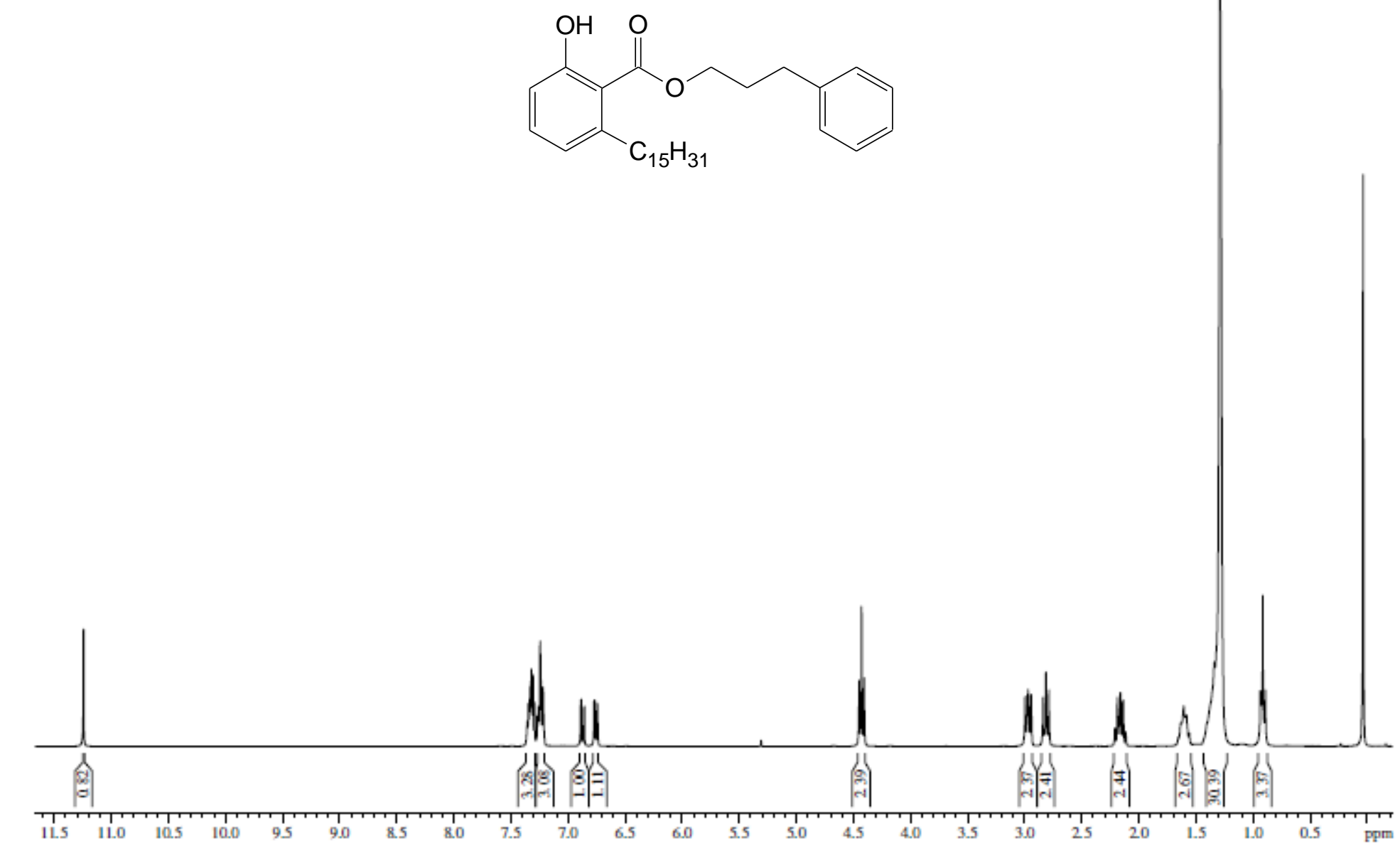
ANEXO 78 - ESPECTRO RMN ${ }^{13} \mathrm{C}\left(75 \mathrm{MHz}, \mathrm{CDCl}_{3}\right)$ - LDT665 (37)

$\left.|| \frac{1}{0}\right|^{2}$
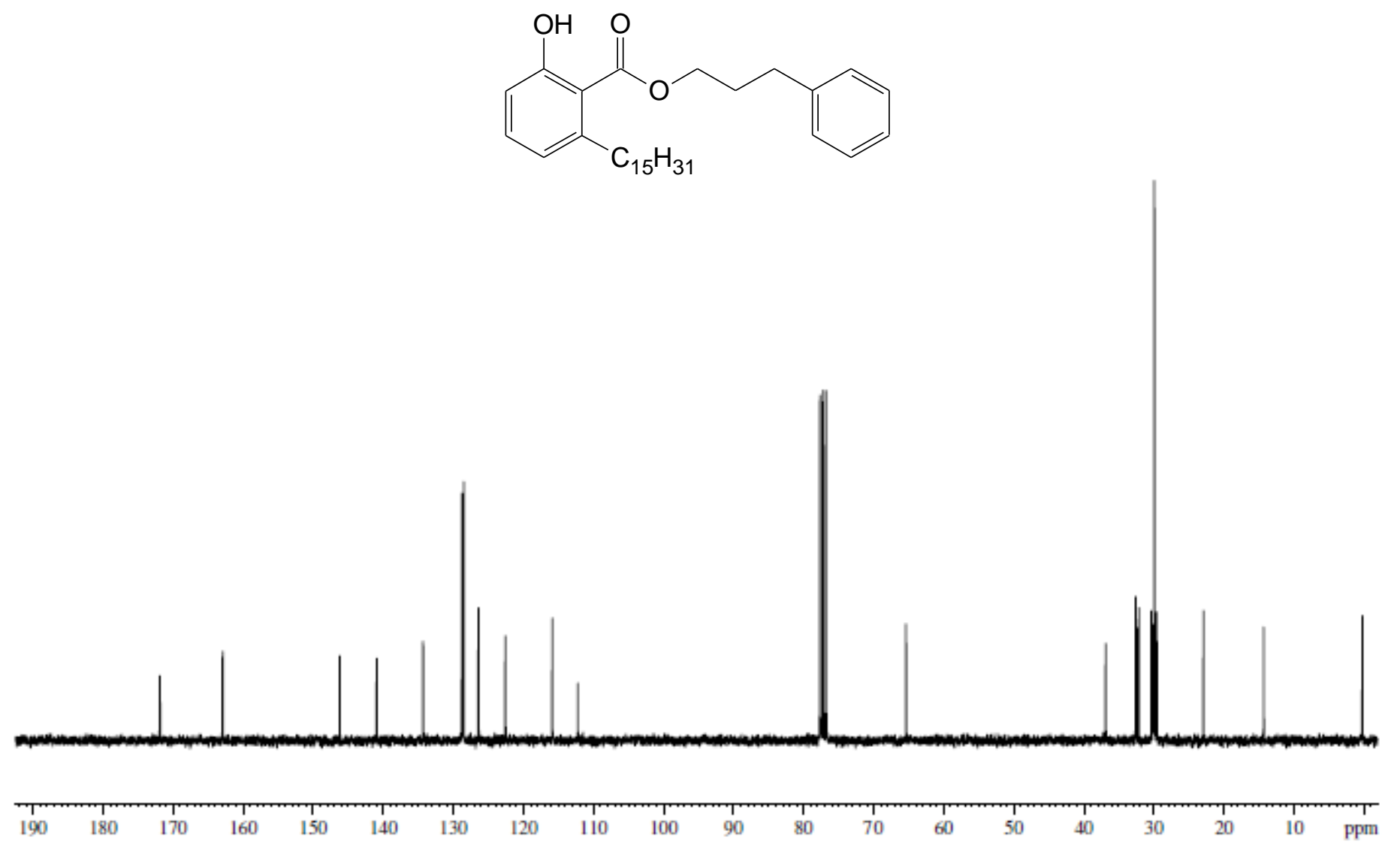
ANEXO 79 - ESPECTRO NO INFRAVERMELHO $\left(v \mathrm{~cm}^{-1}, \mathrm{KBr}\right)$ - LDT683 (42)

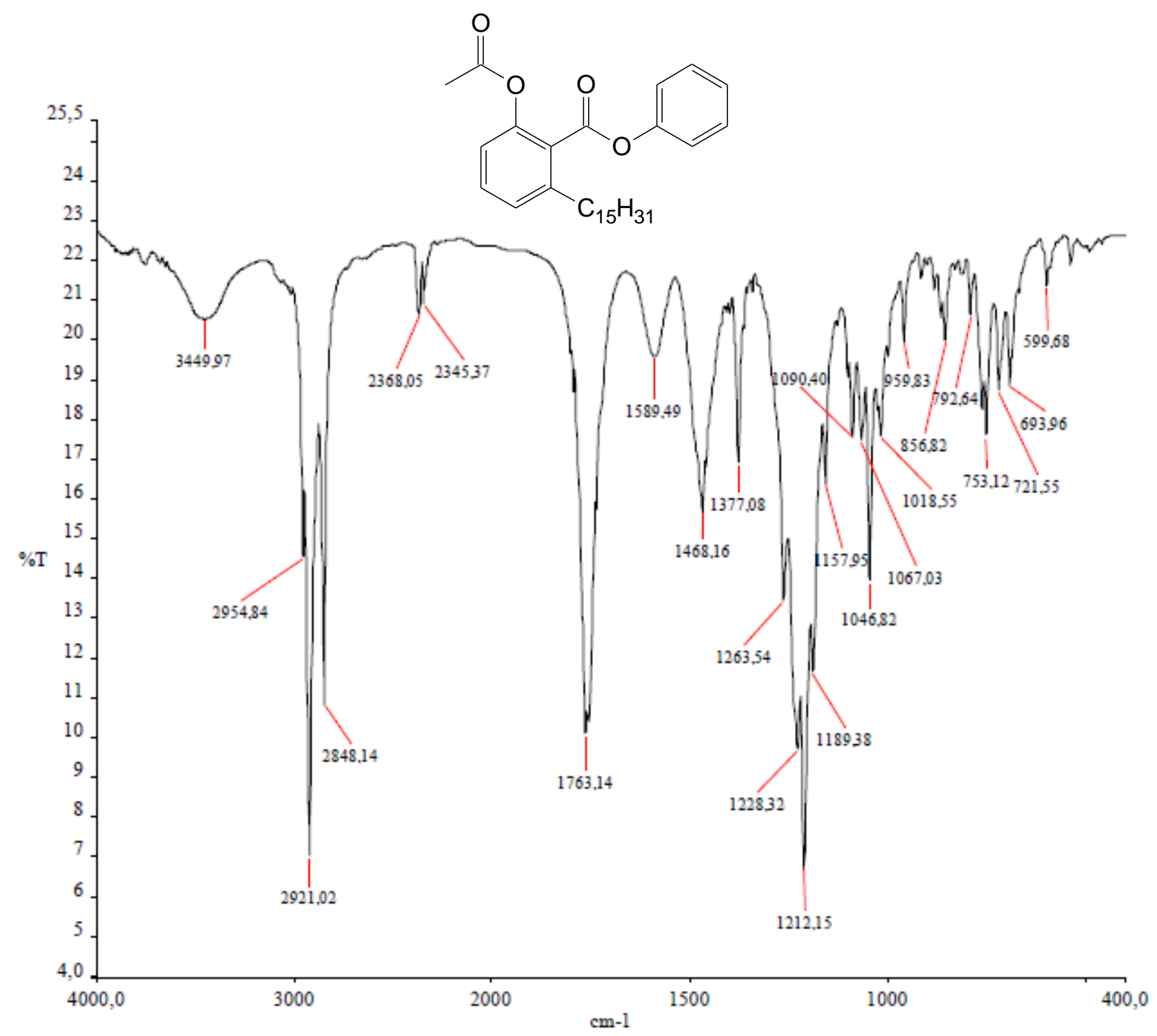


ANEXO 80 - ESPECTRO DE RMN ${ }^{1} \mathrm{H}\left(500 \mathrm{MHz}, \mathrm{CDCl}_{3}\right)$ - LDT683 (42)

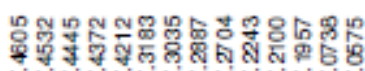

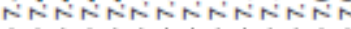

M VI

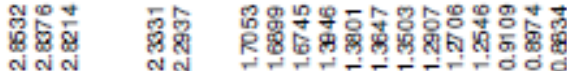

W

W W V

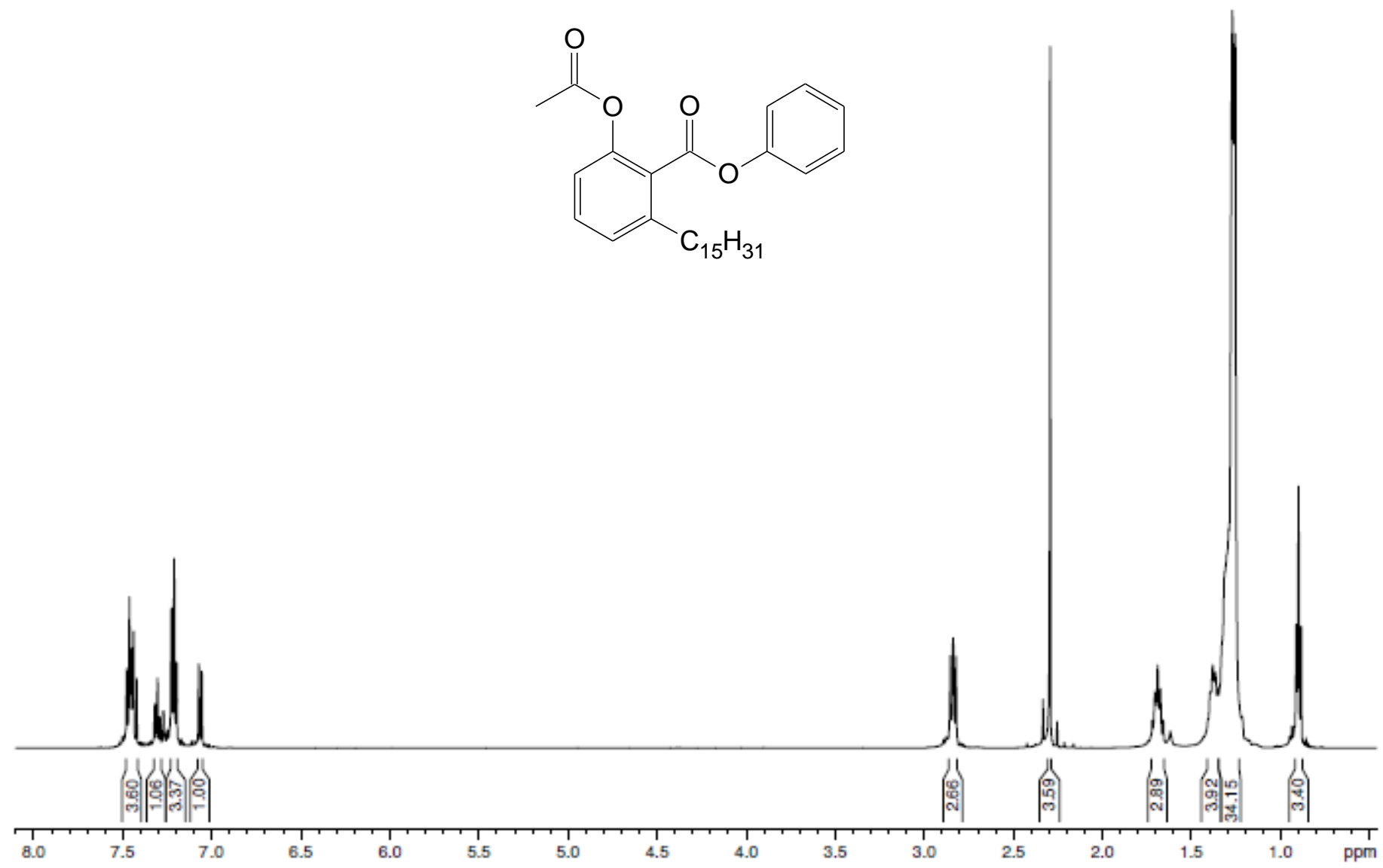


ANEXO 81 - ESPECTRO RMN ${ }^{13} \mathrm{C}\left(125 \mathrm{MHz}, \mathrm{CDCl}_{3}\right)$ - LDT683 (42)
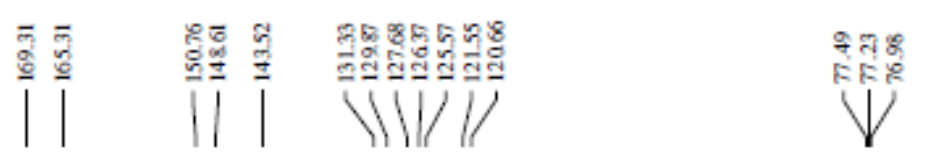

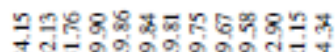

avis)
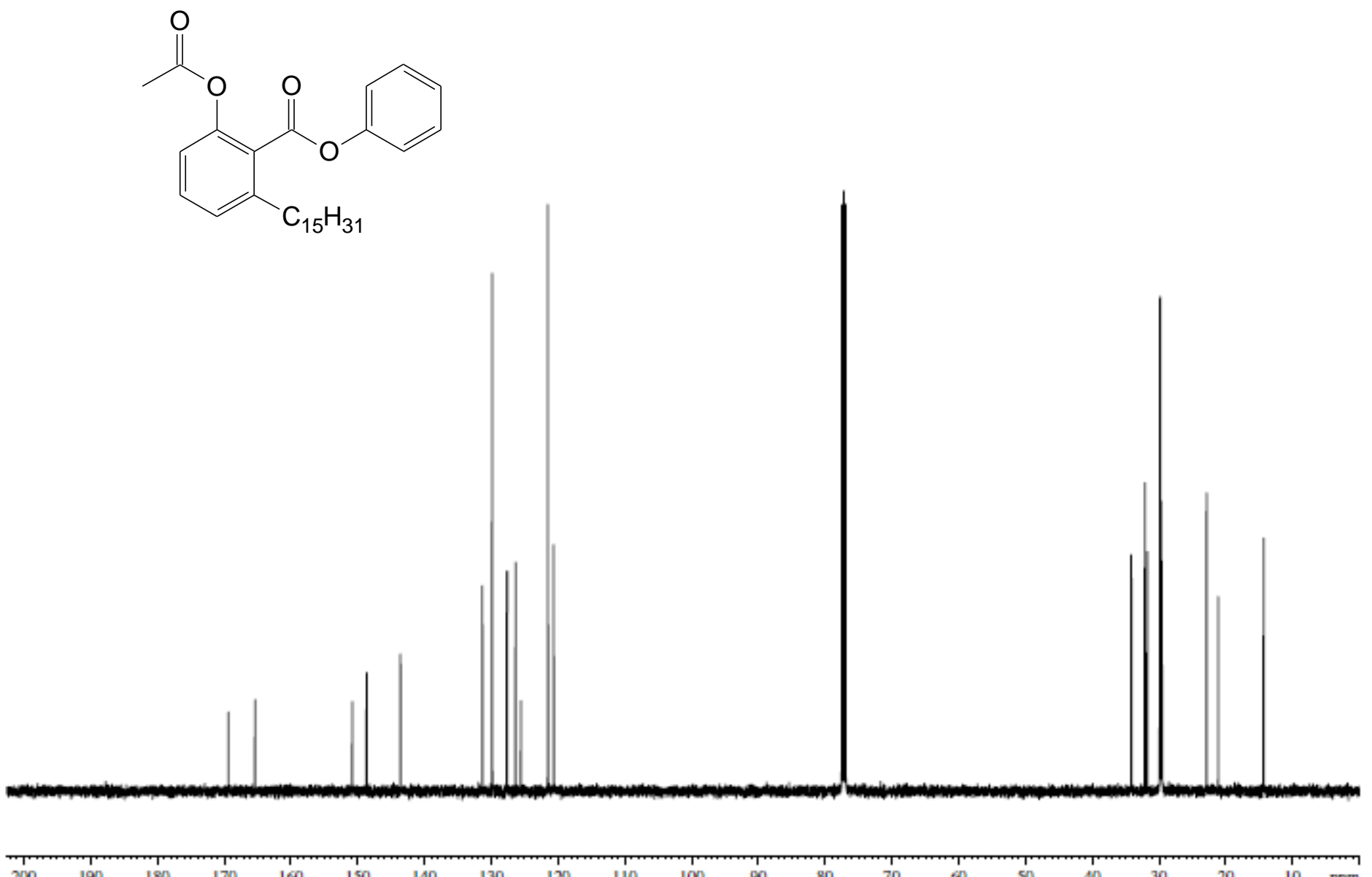
ANEXO 82 - ESPECTRO NO INFRAVERMELHO $\left(v \mathrm{~cm}^{-1}, \mathrm{KBr}\right)$ - LDT685 (43)

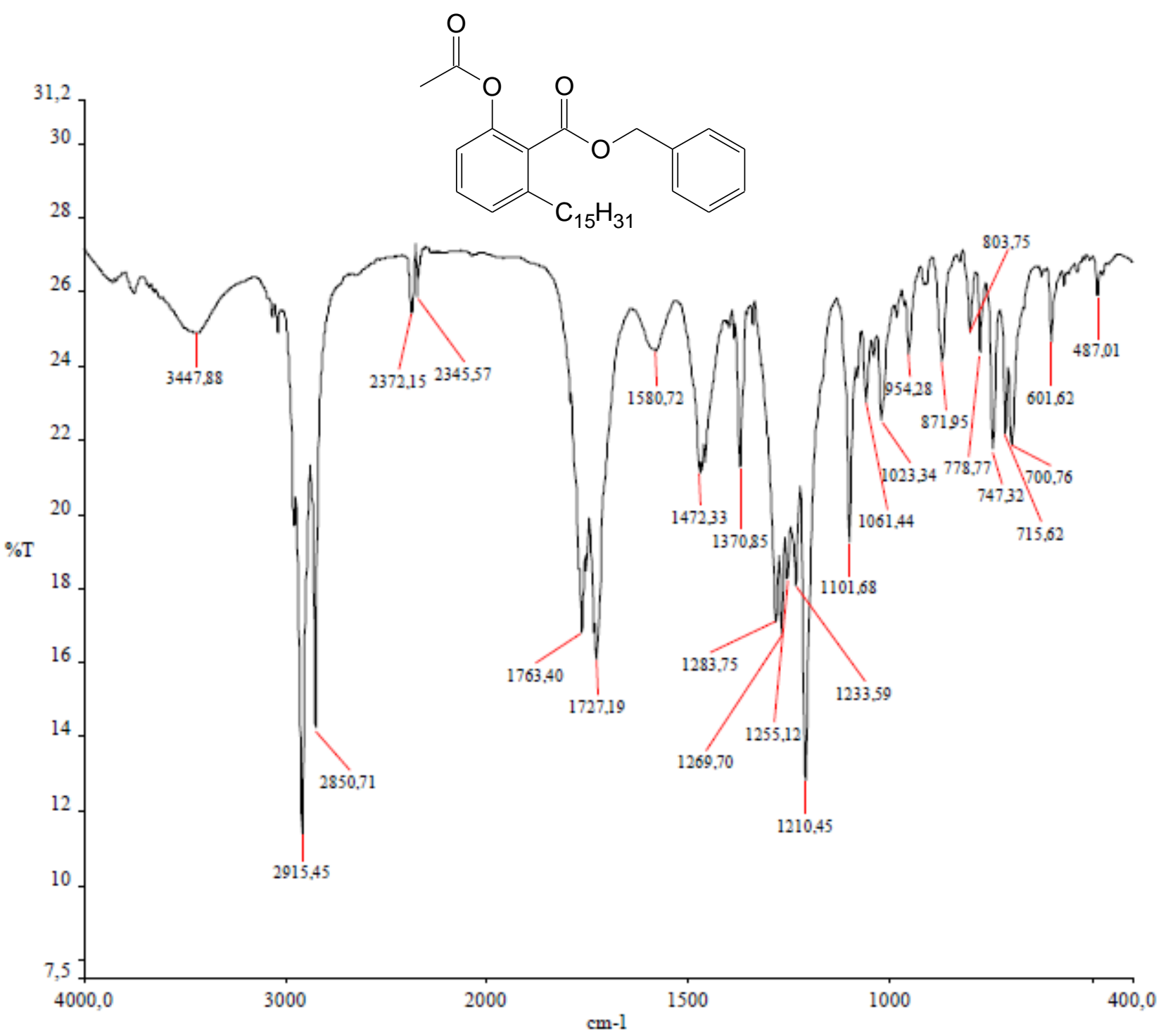


ANEXO 83 - ESPECTRO DE RMN ${ }^{1} \mathrm{H}\left(500 \mathrm{MHz}, \mathrm{CDCl}_{3}\right)$ - LDT685 (43)

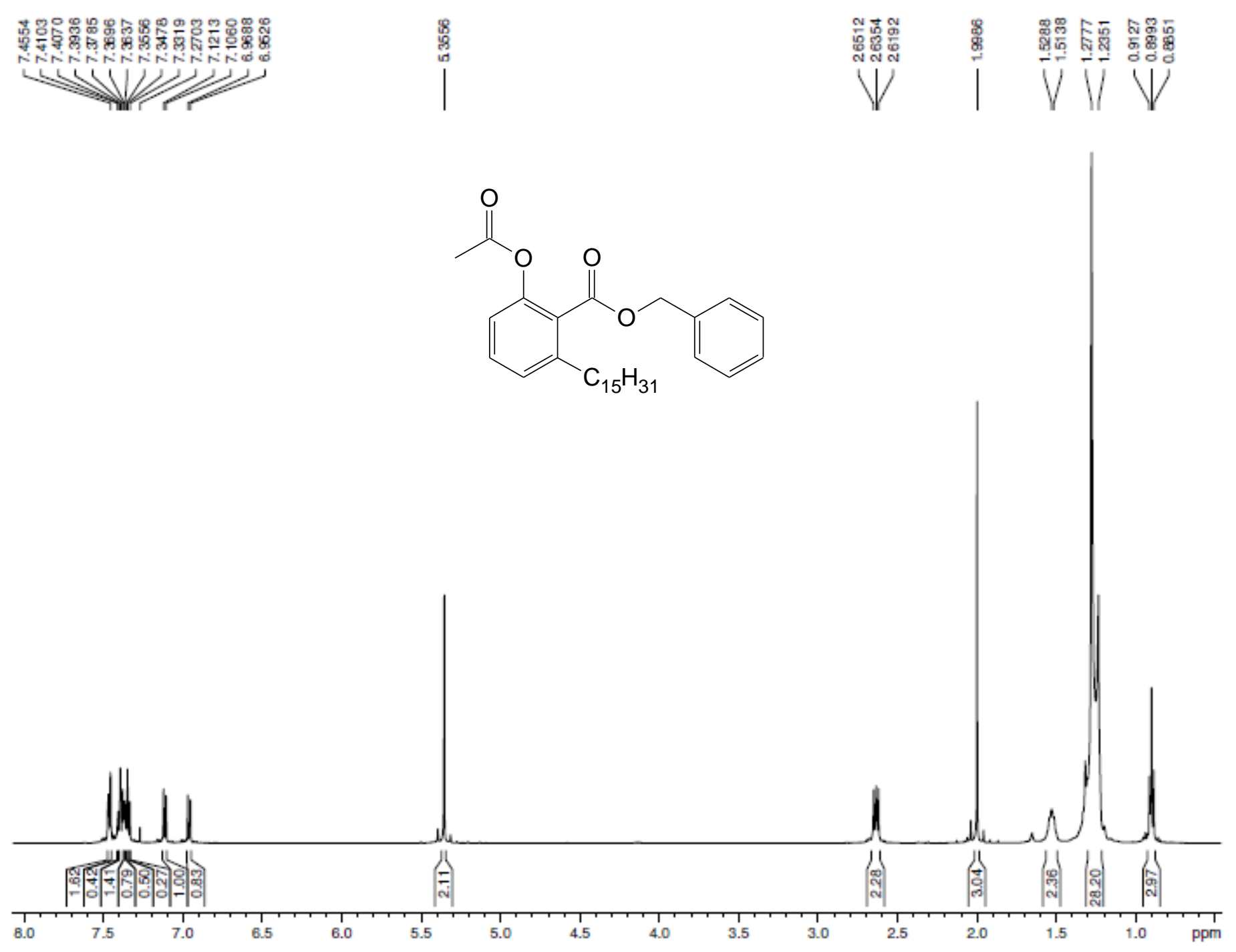


ANEXO 84 - ESPECTRO RMN ${ }^{13} \mathrm{C}\left(125 \mathrm{MHz}, \mathrm{CDCl}_{3}\right)$ - LDT685 (43)
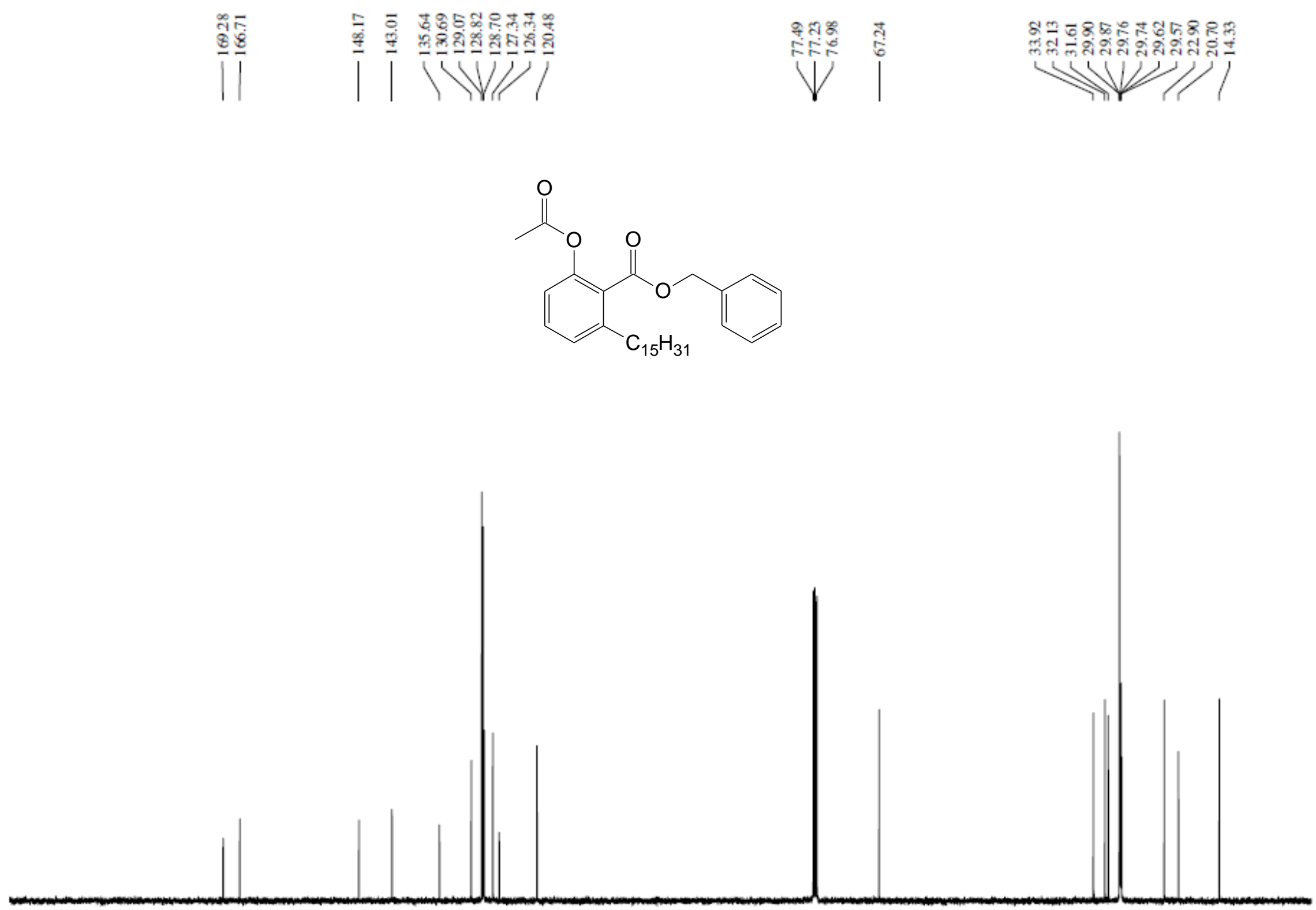
ANEXO 85 - ESPECTRO NO INFRAVERMELHO $\left(v \mathrm{~cm}^{-1}, \mathrm{KBr}\right)$ - LDT687 (44)

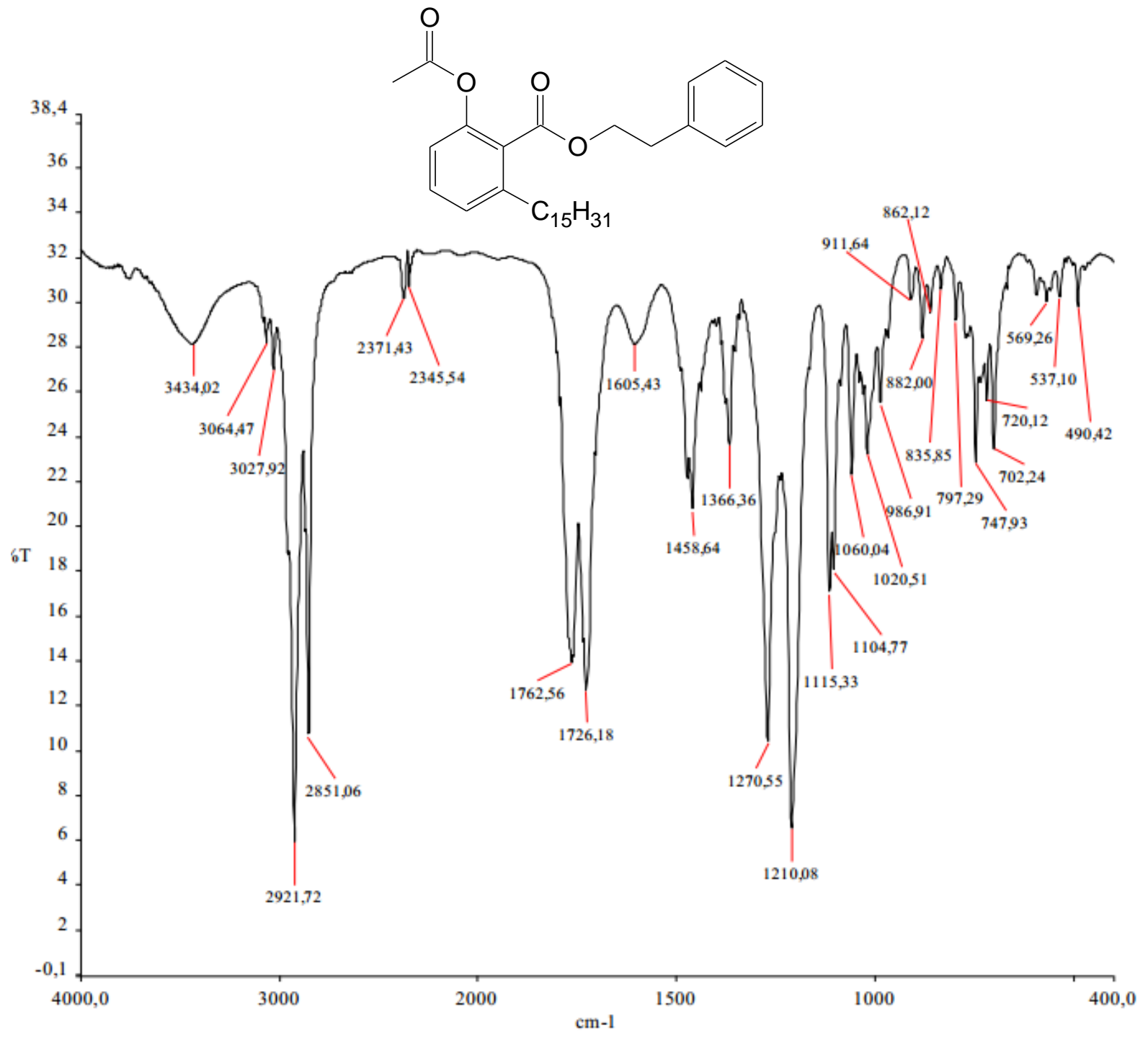


ANEXO 86 - ESPECTRO DE RMN ${ }^{1} \mathrm{H}\left(300 \mathrm{MHz}, \mathrm{CDCl}_{3}\right)$ - LDT687 (44)

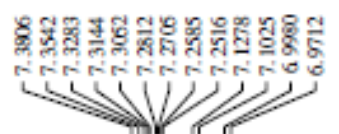

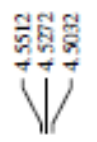

V V |
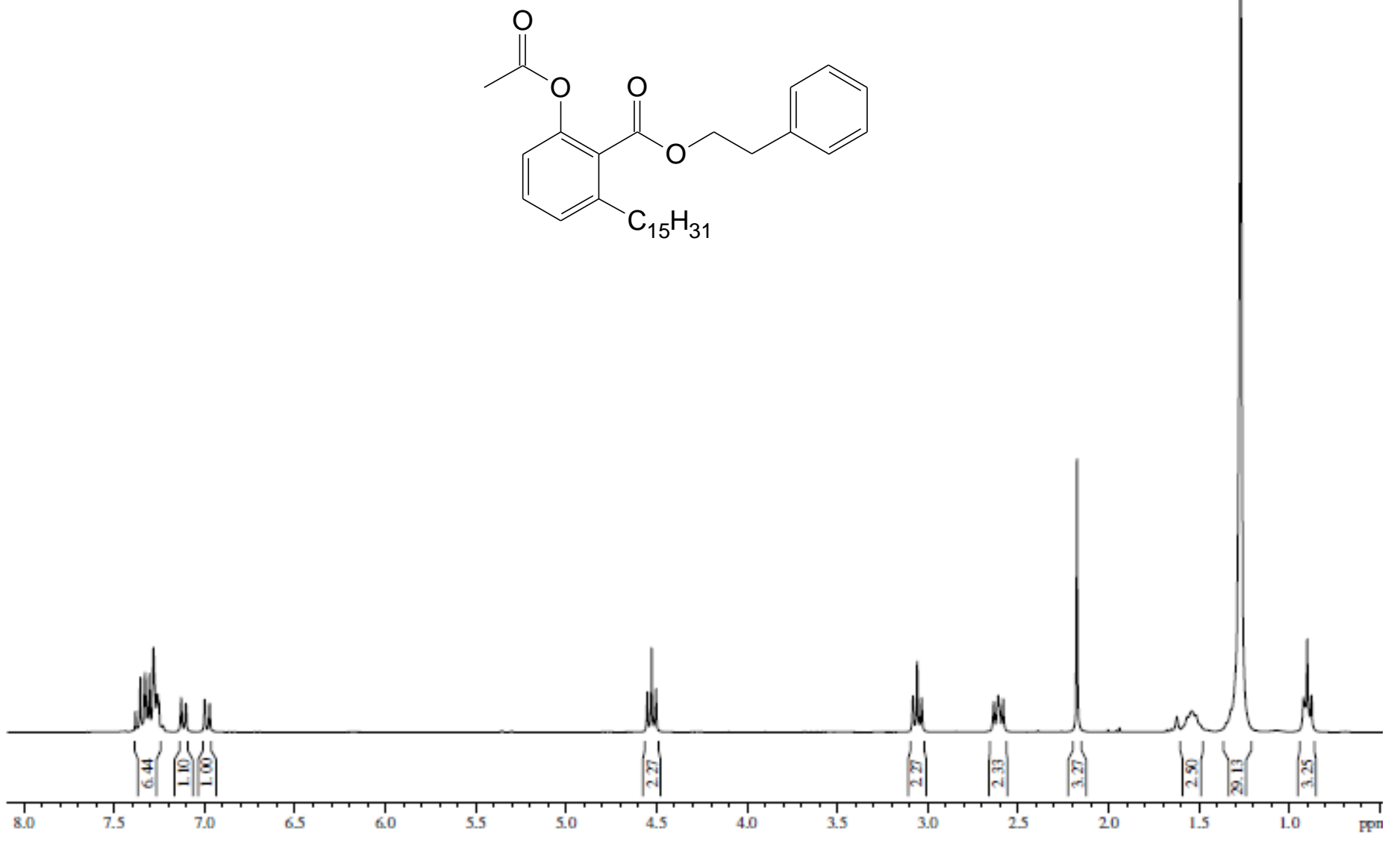
ANEXO 87 - ESPECTRO RMN ${ }^{13} \mathrm{C}\left(75 \mathrm{MHz}, \mathrm{CDCl}_{3}\right)$ - LDT687 (44)
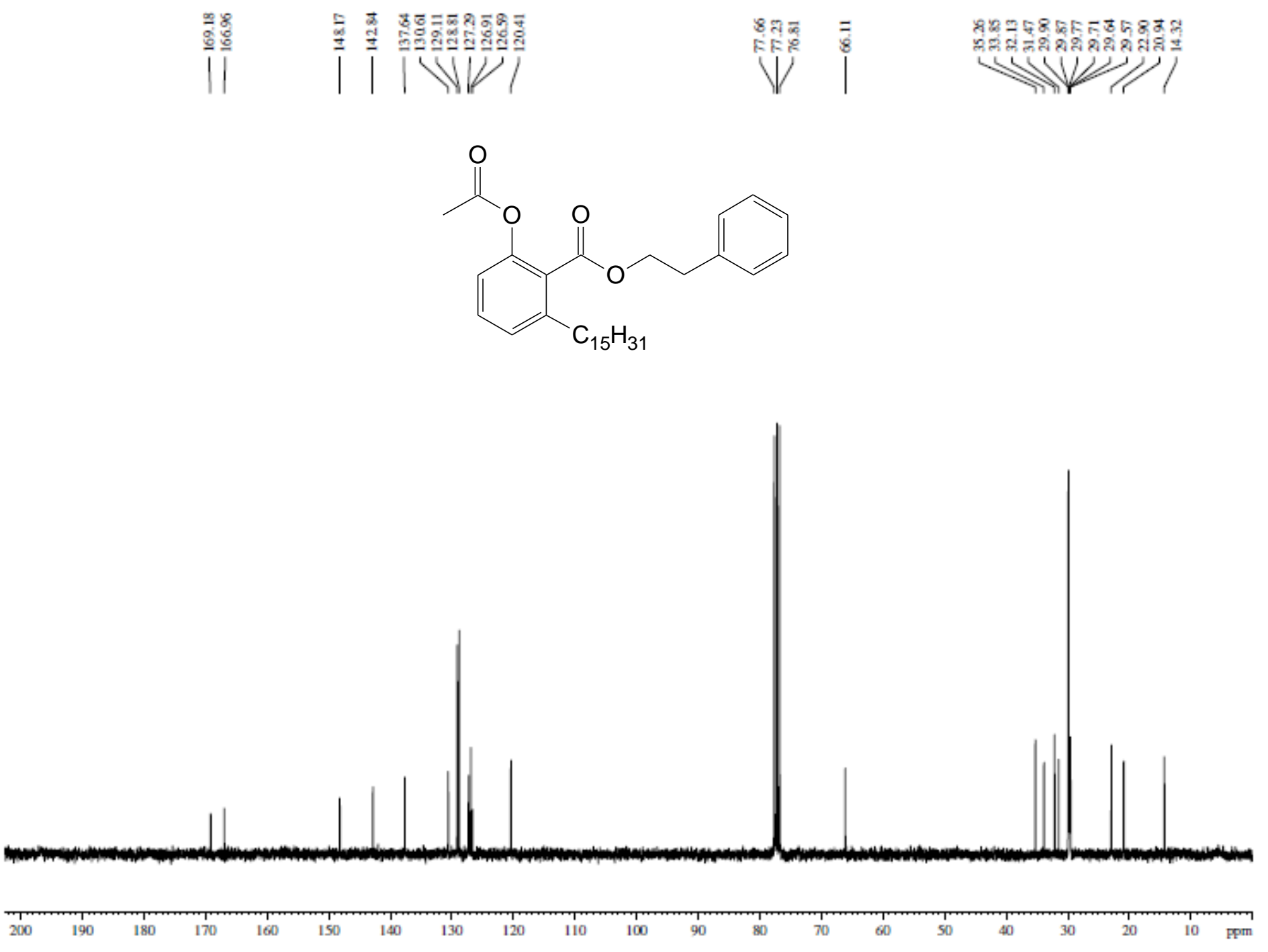
ANEXO 88 - ESPECTRO NO INFRAVERMELHO $\left(v \mathrm{~cm}^{-1}, \mathrm{KBr}\right)$ - LDT689 (45)

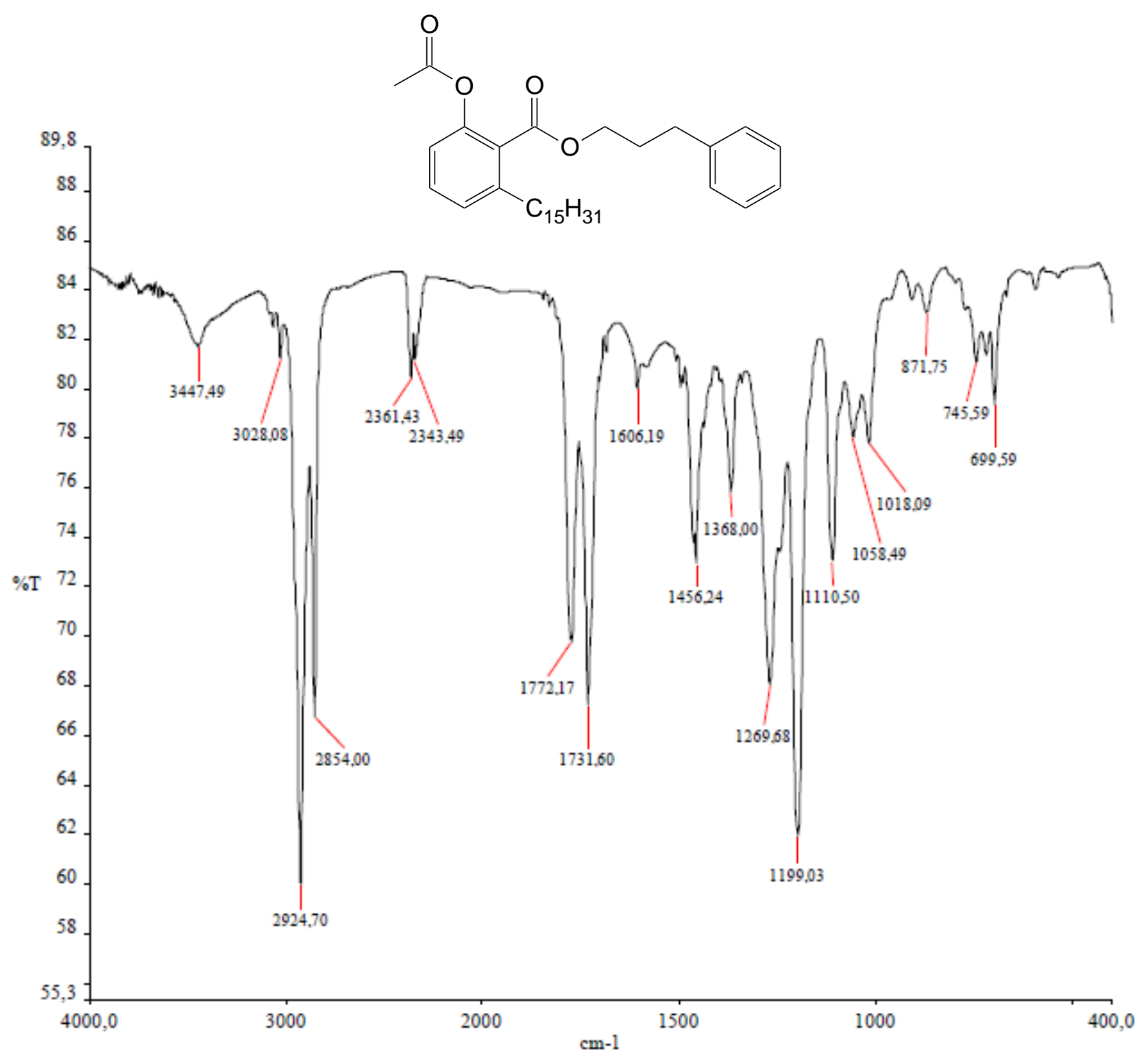


ANEXO 89 - ESPECTRO DE RMN ${ }^{1} \mathrm{H}\left(300 \mathrm{MHz}, \mathrm{CDCl}_{3}\right)$ - LDT689 (45)

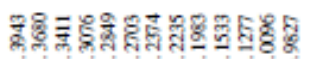

rivivifisio

V

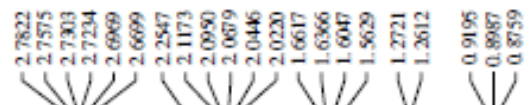

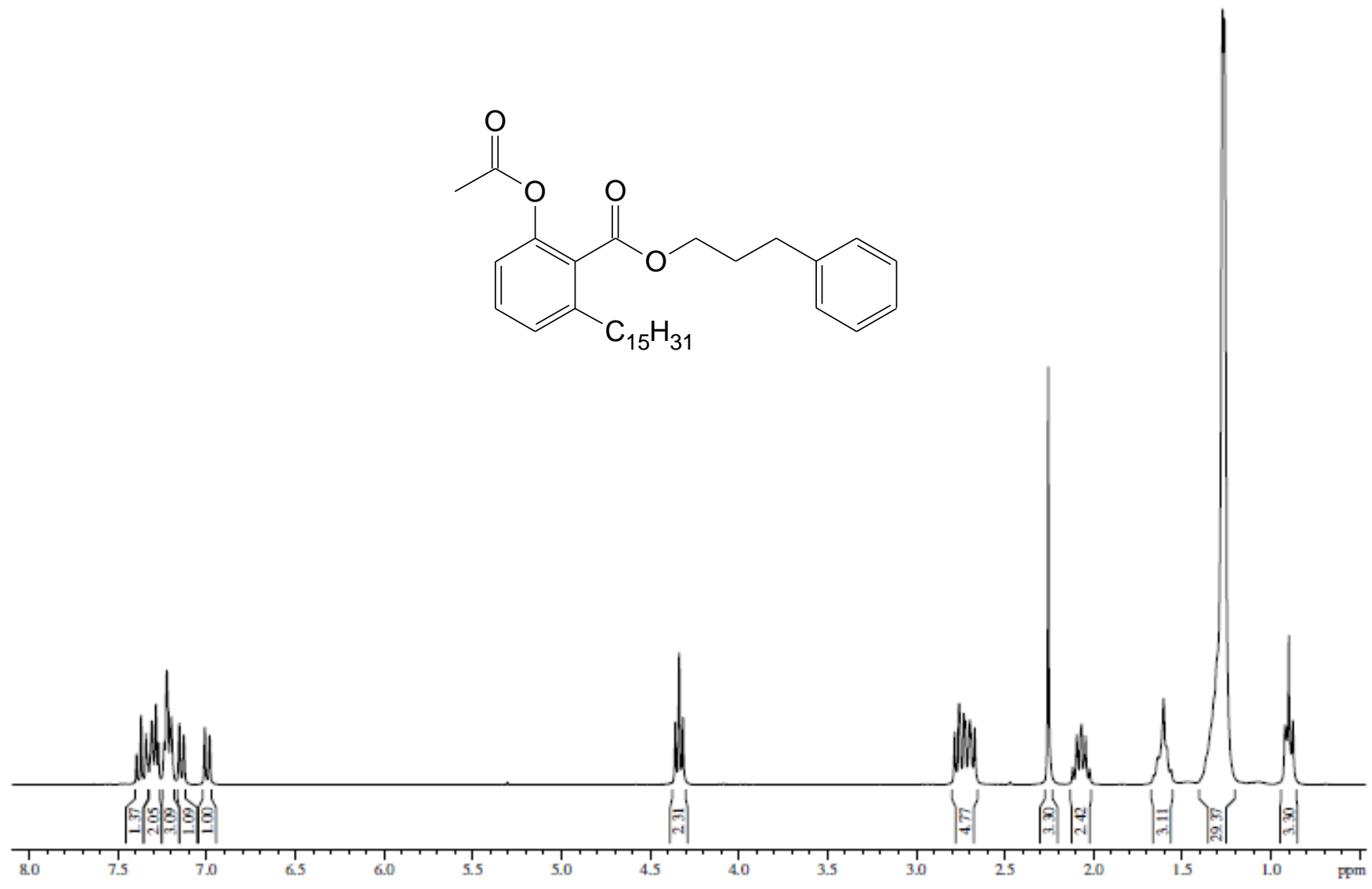


ANEXO 90 - ESPECTRO RMN ${ }^{13} \mathrm{C}\left(75 \mathrm{MHz}, \mathrm{CDCl}_{3}\right)$ - LDT689 (45)
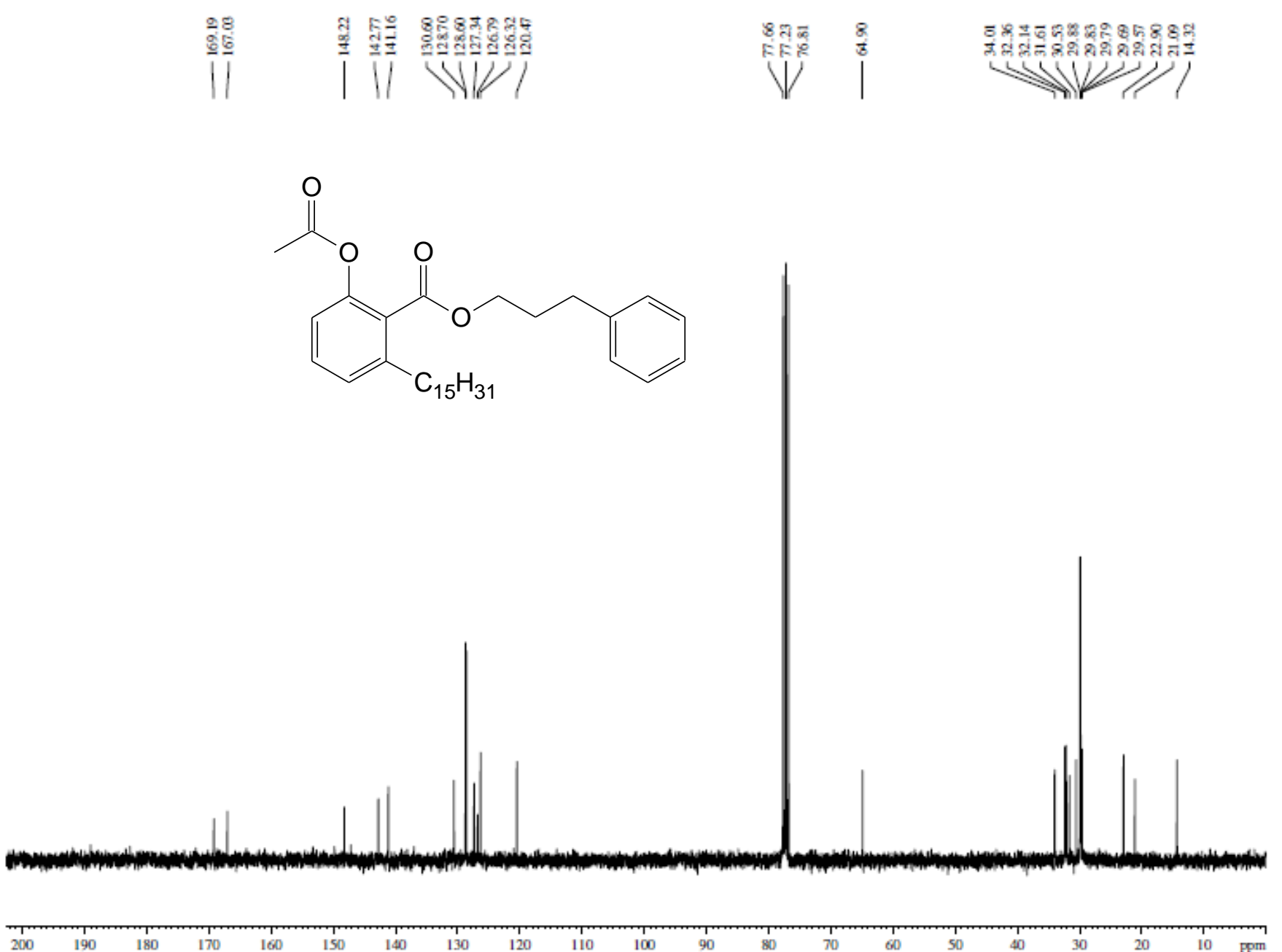